\title{
COMPARATIVE STUDY OF AUXILIARY OXIDANTS IN THE CYANIDATION OF SILVER SULFIDE
}

\author{
by \\ Hao Jiang \\ B.Eng. Central South University, China, 2010 \\ A THESIS SUBMITTED IN PARTIAL FULFILMENT OF \\ THE REQUIREMENTS FOR THE DEGREE OF \\ MASTER OF APPLIED SCIENCE \\ in
}

THE FACULTY OF GRADUATE AND POSTDOCTORAL STUDIES

(Materials Engineering)

THE UNIVERSITY OF BRITISH COLUMBIA

(Vancouver)

April 2014

(C) Hao Jiang, 2014 


\section{Abstract}

Noticeably lower extraction of silver than gold in conventional cyanidation process has been commonly observed. Acanthite $\left(\mathrm{Ag}_{2} \mathrm{~S}\right)$ is one of the typical silver minerals with low solubility in aqueous medium, which result in low overall silver extraction. This thesis discusses the performance of hydrogen peroxide $\left(\mathrm{H}_{2} \mathrm{O}_{2}\right)$, calcium peroxide $\left(\mathrm{CaO}_{2}\right)$, lead nitrate $\left(\mathrm{Pb}\left(\mathrm{NO}_{3}\right)_{2}\right)$ and LeachWELL ${ }^{\mathrm{TM}}$ as potential auxiliary oxidants to improve the conventional cyanidation process.

The dissolution of synthetic silver sulfide in cyanide solution with different oxidants was studied with stirred reactor leaching tests. The addition of $\mathrm{H}_{2} \mathrm{O}_{2}$ increased final silver extraction, and also raised cyanide and hydroxide consumption. The addition of $\mathrm{CaO}_{2}$ had few effects on silver extraction. LeachWELL ${ }^{\mathrm{TM}}$ had a better performance than $\mathrm{H}_{2} \mathrm{O}_{2}$ and $\mathrm{CaO}_{2}$ in terms of increasing silver extraction and reducing reagent cost. Furthermore, $\mathrm{Pb}\left(\mathrm{NO}_{3}\right)_{2}$ was also tested on synthetic silver sulfide leaching separately and was shown to have a similar effects as LeachWELL ${ }^{\mathrm{TM}}$ on this system.

The effect of leaching parameters in the LeachWELL ${ }^{\mathrm{TM}}$-cyanide system, such as LeachWELL $^{\mathrm{TM}}$ concentration, cyanide concentration, temperature and $\mathrm{pH}$, were also studied. It was indicated that the increase of LeachWELL ${ }^{\mathrm{TM}}$ and cyanide concentration could further accelerate leaching and the performance of LeachWELL ${ }^{\mathrm{TM}}$ in this system was not affected by pulp $\mathrm{pH}$.

The extraction of silver from synthetic silver sulfide in the LeachWELL ${ }^{\mathrm{TM}}{ }_{-}$cyanide system was influenced to different extents by the presence of non-silver sulfide minerals. In general, most of the non-silver sulfides interfered with silver extraction via consumption of LeachWELL ${ }^{\mathrm{TM}}$ and cyanide. However, galena acted as a promoter and enhanced silver extraction. 
The performance of $\mathrm{H}_{2} \mathrm{O}_{2}, \mathrm{CaO}_{2}$ and LeachWELL ${ }^{\mathrm{TM}}$ on natural acanthite sample cyanidation was also tested. Leaching of the natural lead-bearing acanthite sample with no auxiliary oxidant presented higher silver recovery than that achieved when leaching synthetic $\mathrm{Ag}_{2} \mathrm{~S}$. The addition of $\mathrm{H}_{2} \mathrm{O}_{2}$ or $\mathrm{CaO}_{2}$ further accelerated leaching while the addition of LeachWELL ${ }^{\mathrm{TM}}$ had no significant effect. It could be concluded that with enough lead in the leaching system the presence of sufficient oxidant could further enhance cyanidation of acanthite. 


\section{Preface}

This dissertation is original, unpublished, independent work by the author, Hao Jiang. 


\section{Table of Contents}
Abstract ii

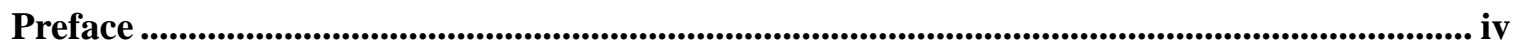

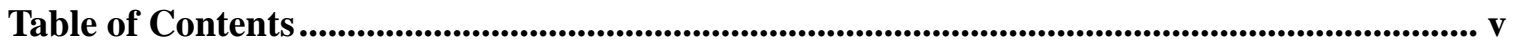

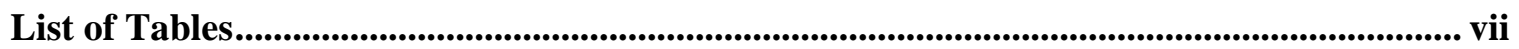

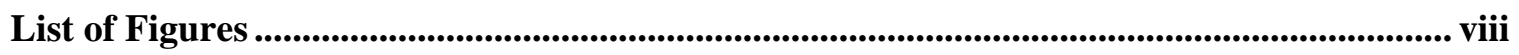

Nomenclature ................................................................................................................................. xii

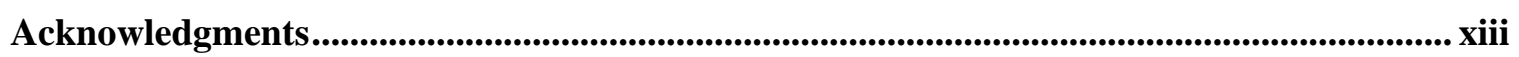

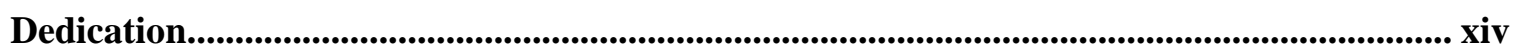

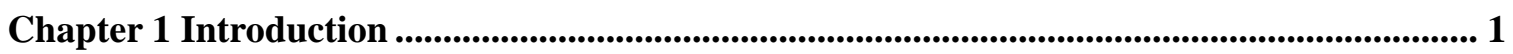

Chapter 2 Background and Literature Review ........................................................................ 3

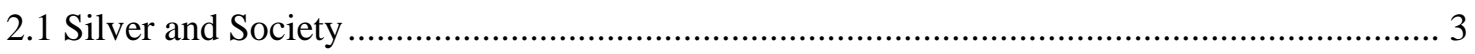

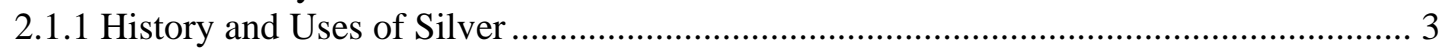

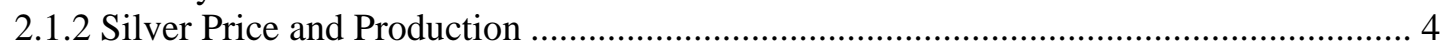

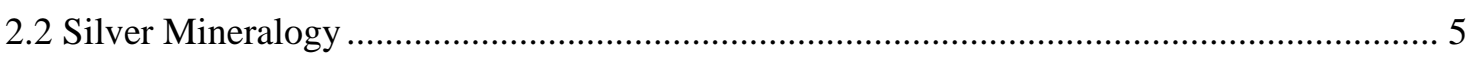

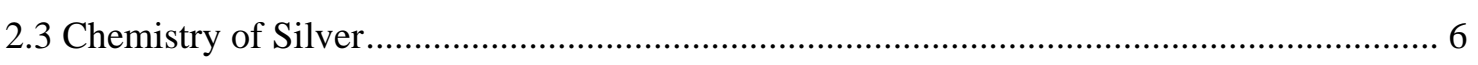

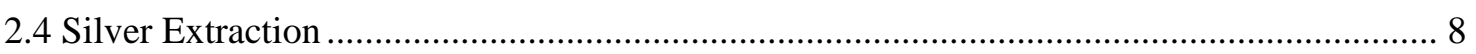

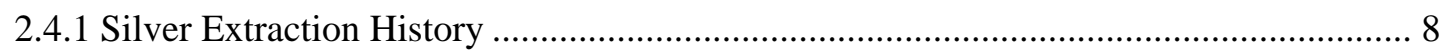

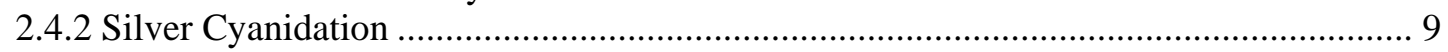

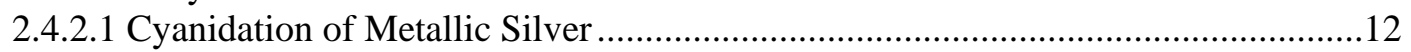

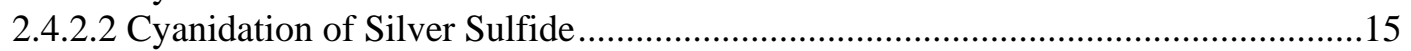

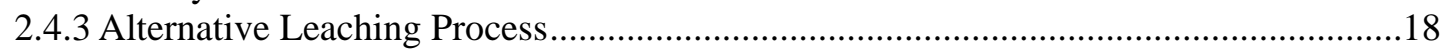

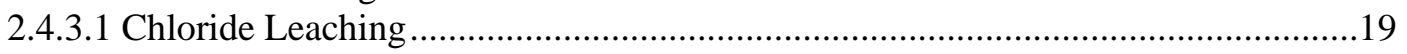

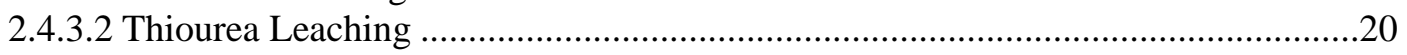

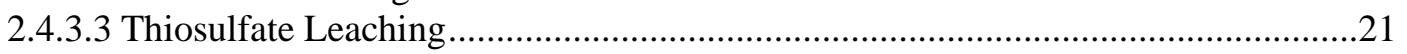

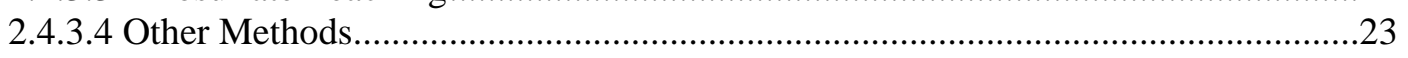

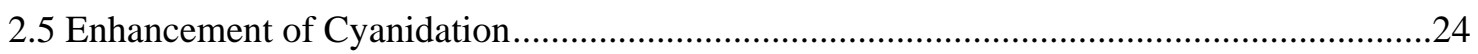

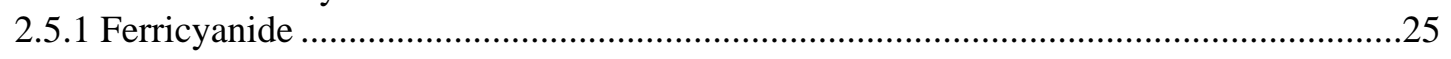

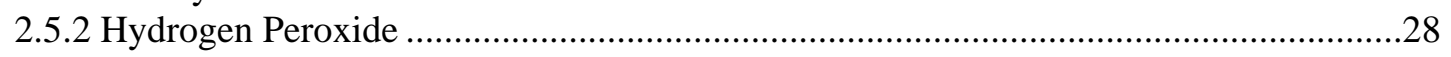

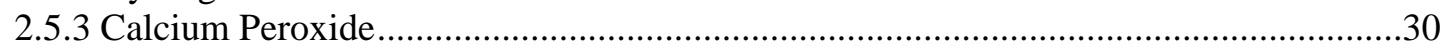

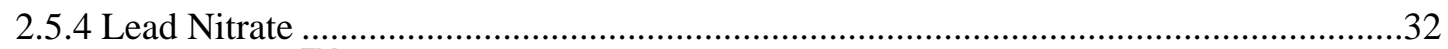

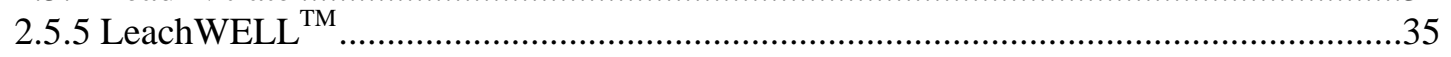

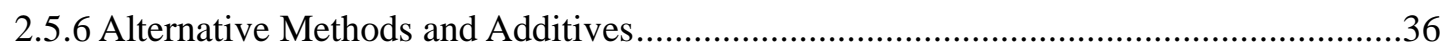

Chapter 3 Cyanidation of Synthetic Silver Sulfide with Auxiliary Oxidants...........................38

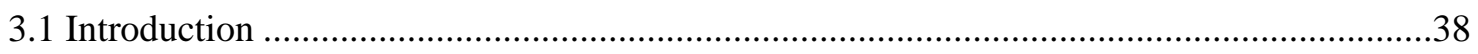

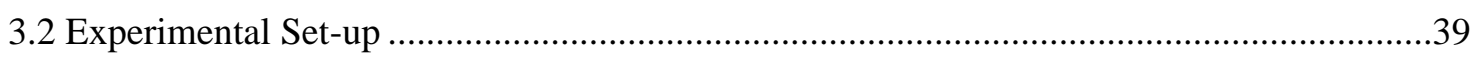




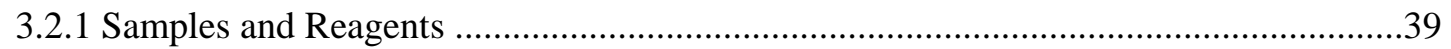

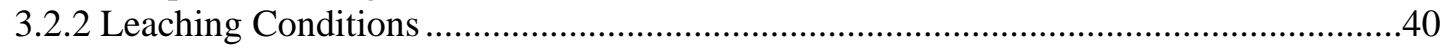

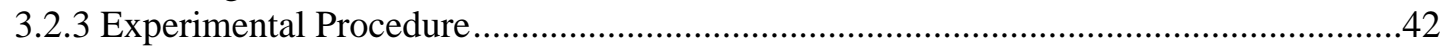

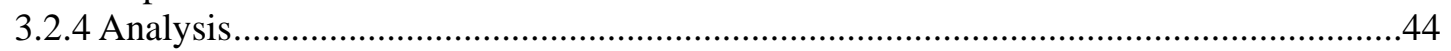

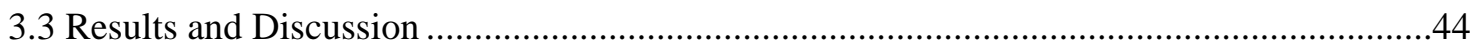

3.3.1 Synthetic Silver Sulfide Leaching in Aerated Cyanide Solution ...................................44

3.3.2 Silver Sulfide Cyanidation with Auxiliary Oxidants .....................................................4

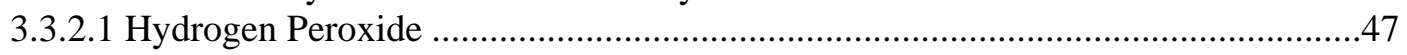

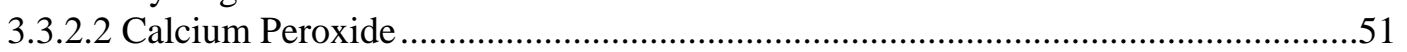

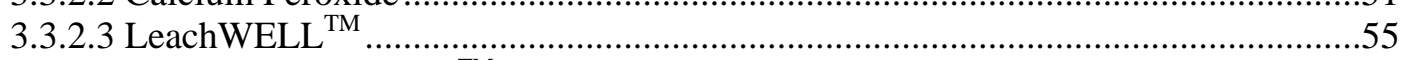

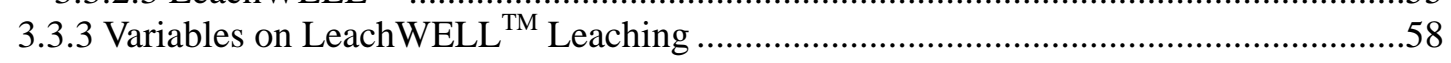

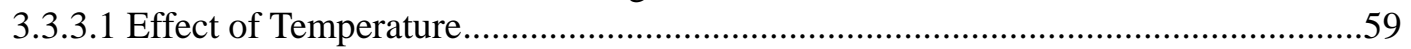

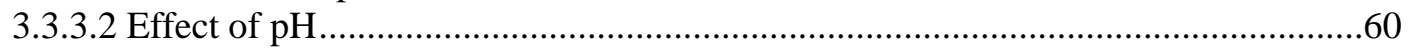

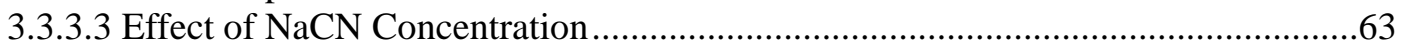

3.3.4 Investigation of the LeachWELL ${ }^{\mathrm{TM}}$-Cyanide System ...............................................66

3.3.4.1 Consumption of $\mathrm{NaCN}$ and $\mathrm{NaOH}$ by LeachWELL ${ }^{\mathrm{TM}}$.......................................66

3.3.4.2 Synthetic Silver Sulfide Leaching with Lead Nitrate............................................68

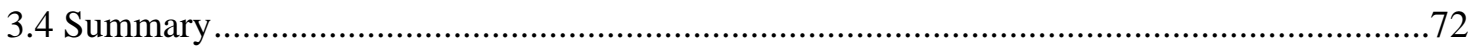

\section{Chapter 4 Cyanidation of Mixed Minerals and Natural Acanthite ............................................74}

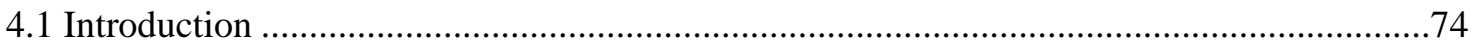

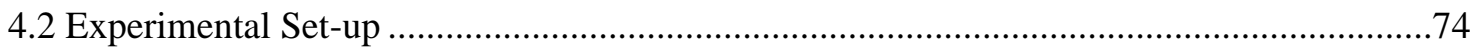

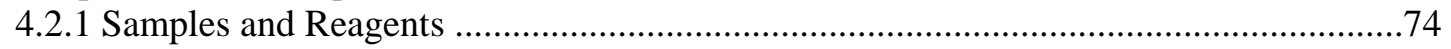

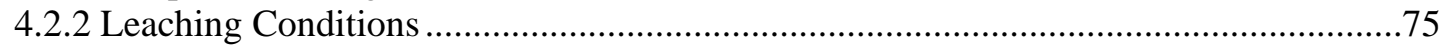

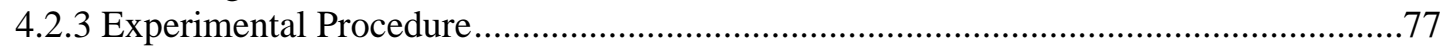

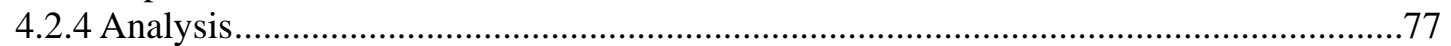

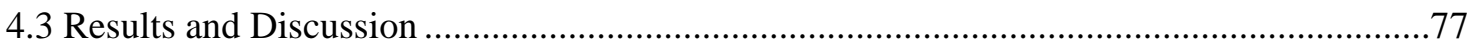

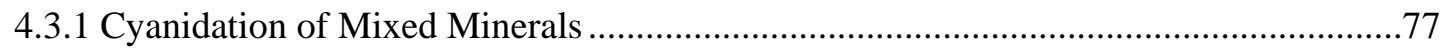

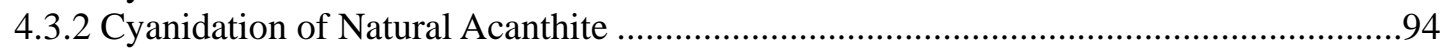

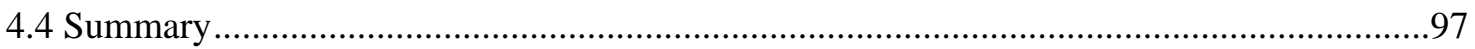

Chapter 5 Conclusions and Recommendations .............................................................99

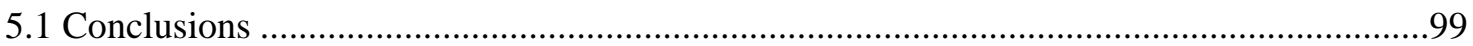

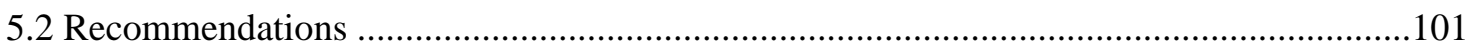

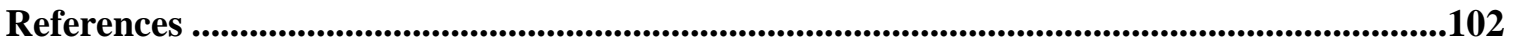

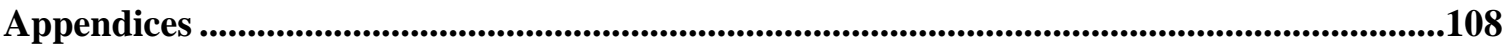

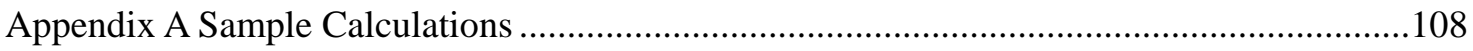

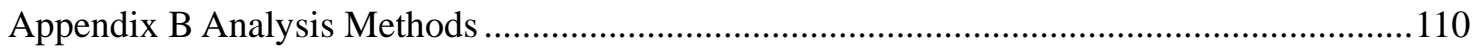

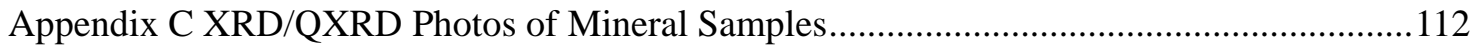




\section{List of Tables}

Table 2-1 Top 10 Silver producing countries in 2012 (millions of ounces) (WSS, 2013).............. 4

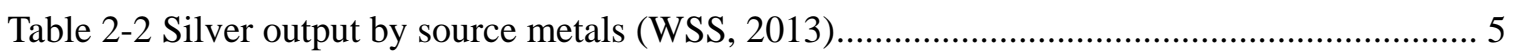

Table 2-3 Silver recovery from silver minerals by cyanide leaching (Fleming, 2007a)................15

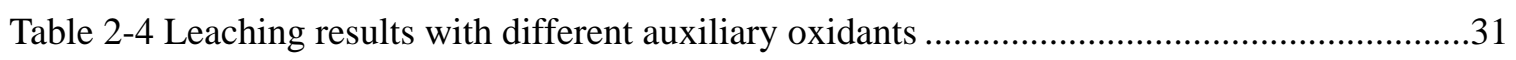

Table 3-1 Leaching conditions of baseline experiment ...........................................................

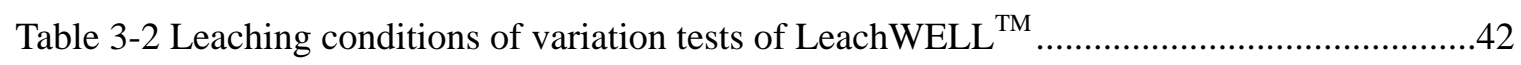

Table 3-3 Auxiliary parameters of baseline experiments ..........................................................46

Table 3-4 Cyanide utilization efficiency in LeachWELL ${ }^{\mathrm{TM}}$ leaching .........................................65

Table 4-1 Fire Assay and ICP analysis results of natural acanthite sample ..................................75

Table 4-2 Leaching conditions of sulfide minerals mixtures cyanidation ...................................76

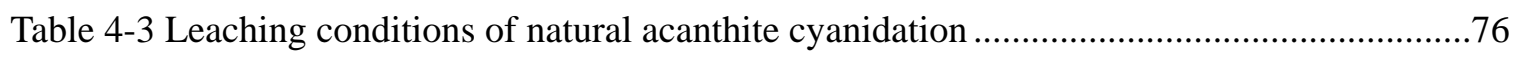

Table 4-4 Accumulated $\mathrm{NaCN}$ and $\mathrm{NaOH}$ consumption in 60hours in different leaching systems 


\section{List of Figures}

Figure 2-1 Eh-pH diagram for $\mathrm{Ag}-\mathrm{H}_{2} \mathrm{O}$ system at $20^{\circ} \mathrm{C},[\mathrm{Ag}]=10^{-3} \mathrm{M}$ (by $\mathrm{HSC}$ ) ..................... 7

Figure 2-2 Flowsheet for a typical CIP plant treating a free-milling gold ore (Fleming, 2007c)...11

Figure 2-3 Eh-pH diagram for $\mathrm{Ag}-\mathrm{CN}-\mathrm{H}_{2} \mathrm{O}$ system at $20^{\circ} \mathrm{C},[\mathrm{Ag}]=10^{-3} \mathrm{M},\left[\mathrm{CN}^{-}\right]=10^{-2} \mathrm{M}$ (by

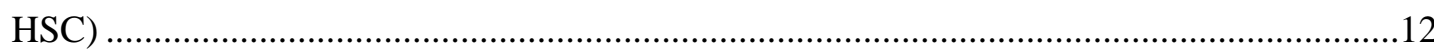

Figure 2-4 General sequence of oxygen reduction (Hiskey and Sanchez, 1990) ..........................14

Figure 2-5 Eh-pH diagram for Ag-S-CN-H${ }_{2} \mathrm{O}$ system at $20{ }^{\circ} \mathrm{C},[\mathrm{Ag}]=1 \mathrm{M},[\mathrm{S}]=1 \mathrm{M},\left[\mathrm{CN}^{-}\right]=1 \mathrm{M}$

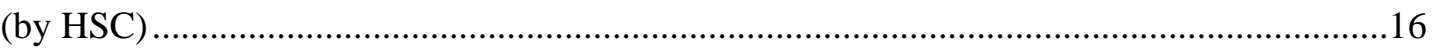

Figure 2-6 Simplified flowsheet for the application of ferricyanide in gold/silver cyanidation (Xie

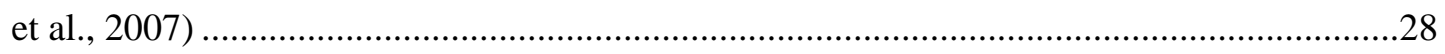

Figure 2-7 Schematic diagram of primary cell reaction ...........................................................33

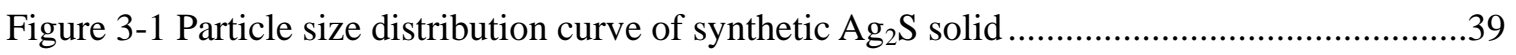

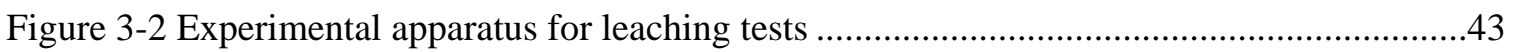

Figure 3-3 Ag extraction vs leaching time in baseline experiments .........................................45

Figure 3-4 Pulp potential vs leaching time in baseline experiments .........................................46

Figure 3-5 Ag extraction vs leaching time with different $\mathrm{H}_{2} \mathrm{O}_{2}$ concentrations ...........................48

Figure 3-6 $\mathrm{NaCN}$ consumption vs leaching time with different $\mathrm{H}_{2} \mathrm{O}_{2}$ concentrations ..................49

Figure 3-7 $\mathrm{NaOH}$ consumption vs leaching time with different $\mathrm{H}_{2} \mathrm{O}_{2}$ concentrations ..................49

Figure 3-8 Ag extraction vs leaching time with different $\mathrm{CaO}_{2}$ concentrations ..........................52

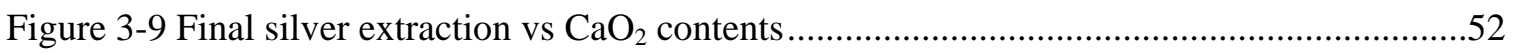

Figure 3-10 NaCN consumption vs leaching time with different $\mathrm{CaO}_{2}$ concentrations .................54

Figure 3-11 $\mathrm{NaOH}$ consumption vs leaching time with different $\mathrm{CaO}_{2}$ concentrations.................55

Figure 3-12 Ag extraction vs leaching time with different LechWELL ${ }^{\mathrm{TM}}$ concentrations.............56 
Figure 3-13 Accumulated $\mathrm{NaCN}$ consumption in 60 hours with different oxidants

Figure 3-14 Accumulated $\mathrm{NaOH}$ consumption in 60 hours with different oxidants .58

Figure 3-15 Ag extraction vs leaching time at different temperatures in LeachWELL $^{\mathrm{TM}}$-cyanide system

Figure 3-16 Accumulated $\mathrm{NaCN}$ consumption in 60 hours at different temperatures in

LeachWELL ${ }^{\mathrm{TM}}$-cyanide system......

Figure 3-17 Ag extraction vs leaching time at different $\mathrm{pH}$ in LeachWELL $^{\mathrm{TM}}$-cyanide system....61

Figure 3-18 NaCN consumption vs leaching time at different $\mathrm{pH}$ in LeachWELL ${ }^{\mathrm{TM}}$-cyanide

system

Figure 3-19 $\mathrm{NaOH}$ consumption vs leaching time at different $\mathrm{pH}$ in LeachWELL ${ }^{\mathrm{TM}}$-cyanide

system

Figure 3-20 Ag extraction vs leaching time at different $\mathrm{NaCN}$ concentration in

LeachWELL ${ }^{\mathrm{TM}}$-cyanide system

Figure 3-21 NaCN consumption vs leaching time at different $\mathrm{NaCN}$ concentration in

LeachWELL ${ }^{\mathrm{TM}}$-cyanide system

Figure 3-22 $\mathrm{NaCN}$ consumption vs leaching time without $\mathrm{Ag}_{2} \mathrm{~S}$ in LeachWELL ${ }^{\mathrm{TM}}$-cyanide system

Figure 3-23 $\mathrm{NaOH}$ consumption vs leaching time without $\mathrm{Ag}_{2} \mathrm{~S}$ in LeachWELL ${ }^{\mathrm{TM}}$-cyanide

system

Figure 3-24 Ag extraction vs leaching time with LeachWELL ${ }^{\mathrm{TM}} / \mathrm{Pb}\left(\mathrm{NO}_{3}\right)_{2}$

Figure 3-25 Accumulated $\mathrm{NaCN}$ consumption in 60 hours with LeachWELL ${ }^{\mathrm{TM}} / \mathrm{Pb}\left(\mathrm{NO}_{3}\right)_{2} \ldots \ldots \ldots . .71$

Figure 3-26 Accumulated $\mathrm{NaOH}$ consumption in 60 hours with LeachWELL ${ }^{\mathrm{TM}} / \mathrm{Pb}\left(\mathrm{NO}_{3}\right)_{2} \ldots \ldots . . .71$

Figure 4-1 Ag extraction vs leaching time with different pyrite addition in

LeachWELL ${ }^{\mathrm{TM}}$-cyanide system

Figure 4-2 Accumulated $\mathrm{NaCN}$ consumption in 60 hours with different pyrite addition in

LeachWELL ${ }^{\mathrm{TM}}$-cyanide system .79 
Figure 4-3 Ag extraction vs leaching time with different pyrrhotite addition in

LeachWELL ${ }^{\mathrm{TM}}$-cyanide system

Figure 4-4 Accumulated $\mathrm{NaCN}$ consumption in 60 hours with different pyrrhotite addition in

LeachWELL ${ }^{\mathrm{TM}}$-cyanide system

Figure 4-5 Ag extraction vs leaching time with different chalcopyrite addition in

LeachWELL ${ }^{\mathrm{TM}}$-cyanide system

Figure 4-6 Cu concentration vs leaching time with different chalcopyrite addition in

LeachWELL ${ }^{\mathrm{TM}}$-cyanide system

Figure 4-7 Fe concentration vs leaching time with different chalcopyrite addition in

LeachWELL ${ }^{\mathrm{TM}}$-cyanide system

Figure 4-8 Accumulated NaCN consumption in 60 hours with different chalcopyrite addition in

LeachWELL ${ }^{\mathrm{TM}}$-cyanide system

Figure 4-9 Ag extraction vs leaching time with different covellite addition in

LeachWELL ${ }^{\mathrm{TM}}$-cyanide system......

Figure 4-10 Cu concentration vs leaching time with different covellite addition in

LeachWELL ${ }^{\mathrm{TM}}$-cyanide system......

Figure 4-11 Accumulated $\mathrm{NaCN}$ consumption in 60 hours with different covellite addition in

LeachWELL ${ }^{\mathrm{TM}}$-cyanide system

Figure 4-12 Ag extraction vs leaching time with different chalcocite addition in

LeachWELL ${ }^{\mathrm{TM}}$-cyanide system

Figure 4-13 Cu concentration vs leaching time with different chalcocite addition in

LeachWELL ${ }^{\mathrm{TM}}$-cyanide system

Figure 4-14 Accumulated NaCN consumption in 60 hours with different chalcocite addition in

LeachWELL ${ }^{\mathrm{TM}}$-cyanide system

Figure 4-15 Ag extraction vs leaching time with different sphalerite mineral addition in

LeachWELL ${ }^{\mathrm{TM}}$-cyanide system 
Figure 4-16 Zn concentration vs leaching time with different sphalerite mineral addition in LeachWELL ${ }^{\mathrm{TM}}$-cyanide system

Figure 4-17 Accumulated $\mathrm{NaCN}$ consumption in 60 hours with different sphalerite mineral addition in LeachWELL ${ }^{\mathrm{TM}}$-cyanide system 92

Figure 4-18 Ag extraction vs leaching time with different galena mineral addition in LeachWELL ${ }^{\mathrm{TM}}$-cyanide system .93

Figure 4-19 Ag extraction from different minerals vs leaching time 94

Figure 4-20 Ag extraction from natural acanthite sample vs leaching time with different oxidants

Figure 4-21 Ag extraction from different minerals vs leaching time with different LeachWELL ${ }^{\mathrm{TM}}$

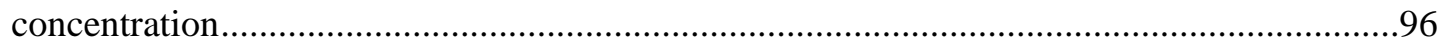




\section{Nomenclature}

\begin{tabular}{|c|c|c|}
\hline$\Delta \mathrm{G}^{\circ}$ & standard Gibbs free energy, & $\mathrm{kJ} / \mathrm{mol}$ \\
\hline $\mathrm{E}^{\circ}$ & standard potential, & V \\
\hline Eh & potential, & V \\
\hline SHE & standard hydrogen electrode & \\
\hline $\mathrm{pH}$ & $\begin{array}{l}\text { negative logarithm to base } \\
\text { of the activity of hydrogen } \\
\text { ion }\end{array}$ & \\
\hline $\mathrm{K}_{\mathrm{sp}}$ & solubility constant & \\
\hline K & equilibrium constant & \\
\hline pK & $-\log K$ & \\
\hline M & Molarity, & $\mathrm{mol} / \mathrm{L}$ \\
\hline ppm & $\begin{array}{l}\text { molarity concentration, } \\
\text { (denotes the total } \\
\text { concentration of dissolved } \\
\text { species in this paper) } \\
\text { part per million }\end{array}$ & $\mathrm{mol} / \mathrm{L}$ \\
\hline Moz & million ounce & \\
\hline 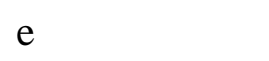 & Electron & \\
\hline $\mathrm{n}$ & $\begin{array}{l}\text { number of electrons } \\
\text { transferred }\end{array}$ & \\
\hline RPM & rotations per minutes & \\
\hline $\mathrm{T}$ & Temperature, & ${ }^{\circ} \mathrm{C}$ or $\mathrm{K}$ \\
\hline SAG milling & $\begin{array}{l}\text { Semi-Autogenous Grinding } \\
\text { milling }\end{array}$ & \\
\hline $\begin{array}{l}\text { AARL carbon } \\
\text { elution }\end{array}$ & $\begin{array}{l}\text { Anglo American Research } \\
\text { Laboratories carbon elution }\end{array}$ & \\
\hline
\end{tabular}




\section{Acknowledgments}

I owe particular thanks to my supervisor, Dr. David Dreisinger, for the guidance provided throughout my degree and the many helpful discussions which form the basis of this thesis. Your talent and passion for hydrometallurgy is inspiring. All your kind help and support, which means a lot to me, during the special time is greatly appreciated.

The help of Dr. Feng Xie in this project is greatly appreciated. Thank you to Dr. Bé Wassink for patiently assisting me with my analytical techniques and answering my numerous chemistry questions.

I offer my enduring gratitude to the faculty, staff and my fellow students at the UBC. Your concerning and support inspired me to continue my work in this field

In addition, thank you to Dr. Dreisinger, the Department of Materials Engineering at UBC, and Pan American Silver Corporation for providing the financial assistance necessary to undertake this thesis.

Special thanks are owed to my parents, Zhaode Jiang and Yipin Chen, who have supported me throughout my years of education, both morally and financially. You are always there, offering generous love and support, when I need you. This would not have been possible without you. 


\section{Dedication}

Dedicated to my parents, the shelter and beacon of my life. 


\section{Chapter 1 Introduction}

In most cases silver is often recovered along with the process of gold extraction due to the similarities between gold and silver. Nowadays, the most popular operation to extract gold/silver is cyanidation process which involves gold/silver dissolution in aerated cyanide solution to form metal-cyanide complexes. The standard Elsner equation reveals the stoichiometry of the reactions as following (Marsden and House, 2006);

$$
\begin{array}{ll}
4 \mathrm{Au}+8 \mathrm{CN}^{-}+\mathrm{O}_{2}+2 \mathrm{H}_{2} \mathrm{O}=4 \mathrm{Au}(\mathrm{CN})_{2}{ }^{-}+4 \mathrm{OH}^{-} & \text {Reaction 1-1 } \\
4 \mathrm{Ag}+8 \mathrm{CN}^{-}+\mathrm{O}_{2}+2 \mathrm{H}_{2} \mathrm{O}=4 \mathrm{Ag}(\mathrm{CN})_{2}{ }^{-}+4 \mathrm{OH}^{-} & \text {Reaction 1-2 }
\end{array}
$$

There are a number of options for recovery of gold and silver from the cyanide leachate. The preferred alternative for the gold system is to load the gold-cyanide complex on activated carbon and then elute the carbon with a hot, caustic cyanide solution. The eluent from the carbon is then electrowon to produce metallic gold for refining. Activated carbon can also be used to recover the silver-cyanide complex. However, the loading is weaker and therefore carbon is less efficient for silver in comparison to gold. For silver, the leach solution can be recovered by solid-liquid separation and then subjected to zinc dust cementation to recover a crude silver precipitate for refining.

Even though cyanide leaching is widely applied to gold/silver ores and concentrates, the recovery of silver is often lower than that of gold, especially in heap leaching. These processes are predominately designed based on gold mineralogy with the aim to obtain reasonable gold recovery since gold is more valuable. Hence it is believed that the difference in mineralogy of silver and gold is a significant reason for the noticeably lower extraction of silver than gold. Compared to gold, which almost always occurs in metallic form (Marsden and House, 2006), silver mineralogy is more complicated. Minerals such as silver sulfides $\left(\mathrm{Ag}_{2} \mathrm{~S}\right)$, argentojarosites $\left(\mathrm{AgFe}_{3}\left[\mathrm{SO}_{4}\right]_{2}(\mathrm{OH})_{6}\right)$ and silver-containing manganese minerals are believed to yield lower silver extraction in conventional cyanide 
leaching process. This thesis investigates appropriate auxiliary oxidants to the cyanidation process with the goal of specifically improving silver extraction from silver sulfide.

In this thesis, the effect of different auxiliary oxidants on the silver sulfide cyanidation process is investigated. Current silver extraction methods, optimization of cyanide leaching process and other relevant background information are reviewed in Chapter 2. The study of synthetic silver sulfide cyanidation in the presence of different auxiliary oxidants is described in Chapter 3. The application of LeachWELL ${ }^{\mathrm{TM}}$ to cyanidation of mixed minerals and natural silver sulfide ore is presented in Chapter 4. Finally conclusions and recommendations are presented in Chapter 5. 


\section{Chapter 2 Background and Literature Review}

\subsection{Silver and Society}

\subsubsection{History and Uses of Silver}

Silver metal has been discovered and used for millennia. Discovered around 2500 B.C., in the following period most silver was mined and cupelled from lead ores (Patterson, 1972). It was first used as currency in 700 B.C. and played a role as a trading metal in nearly every ancient and modern culture until the $19^{\text {th }}$ century. However, gold later took silvers dominant place in the coinage and currency industry (WWS, 2013). Nowadays, it is not an exchange currency, but it is still considered by many to be a good option for investment.

Silver is a dense metal and commercially it is a precious metal. The use of silver can be divided into three areas: traditional use, industrial use and emerging use. Even though silver is one of the least expensive precious metals, it still has a significant role in jewelry and decoration due to its scarcity, luster and ease of workability. For example, sterling silver, which contains $92.5 \%$ silver and $7.5 \%$ copper, has been a popular alloy for silver earrings and bracelets for centuries (WWS, 2013). Despite its traditional use, silver can be seen in many modern areas. Because of its excellent conductivity for heat and electricity, silver is an excellent choice for conductor applications and is used in many electrical circuits as a component of contacts, switches and fuses. Silver is further applied to membrane switches and conductive adhesives. Additionally, high purity silver is essential in the film photography industry although this traditional application is largely supplanted by the use of digital photography. Generally speaking, silver halide crystals' light sensitivity is the fundamental principle behind the use of the photographic film process. The light interacts with the structure of silver halide, rendering it selectively 
reducible to metallic silver. Silver can also be used as a coating material for compact disks and digital video disks. Other industrial demands for silver include solar cells, mirrors, glass coatings and batteries (WWS, 2013).

\subsubsection{Silver Price and Production}

Total silver fabrication demand was $876.6 \mathrm{Moz}$ in $2011,1.5 \%$ lower than 2010, but this value was still reported to be the second highest consumption on record since 2000. World silver supply increased by $1.4 \%$, achieving a new record level of $761.6 \mathrm{Moz}$ (23,689 t) in 2011. Silver's annual average price leapt in 2011 to $\$ 35.12$ dollars (U.S.) maintaining an upward trend (WWS, 2013).

Table 2-1 Top 10 Silver producing countries in 2012 (millions of ounces) (WSS, 2013)

\begin{tabular}{|c|c|c|}
\hline Ranking & Country & Production / millions of ounces \\
\hline 1. & Mexico & 162.2 \\
\hline 2. & China & 117.0 \\
\hline 3. & Peru & 111.3 \\
\hline 4. & Australia & 56.9 \\
\hline 5. & Russia & 45.0 \\
\hline 6. & Poland & 41.2 \\
\hline 7. & Bolivia & 39.7 \\
\hline 8. & Chile & 37.0 \\
\hline 9. & United States & 32.6 \\
\hline 10. & Argentina & 24.1 \\
\hline
\end{tabular}

Geographically, five of the ten largest silver producing countries are in the Americas, including the two biggest - Mexico and Peru (WSS, 2013). 
It should be noted that most silver is produced as a by-product in the extraction processes for other metals. Lead/zinc operations are the biggest contributor to silver production. World silver output by source metals is listed in Table 2-2. It indicates that in the past two years almost $60 \%$ of silver production came as a by-product in lead, zinc and copper extraction while the gold industry also contributed more than $10 \%$ of silver production (WWS, 2013).

Table 2-2 Silver output by source metals (WSS, 2013)

\begin{tabular}{c|cccc}
\hline & $\mathbf{2 0 1 1}, \mathbf{M o z}$ & \% of total & $\mathbf{2 0 1 2}, \mathbf{M o z}$ & \% of total \\
\hline Primary & 219.8 & $29 \%$ & 221.6 & $28 \%$ \\
Gold & 98.2 & $13 \%$ & 101.8 & $13 \%$ \\
Lead/Zinc & 278.2 & $37 \%$ & 303.7 & $39 \%$ \\
Copper & 157.5 & $21 \%$ & 156.2 & $20 \%$ \\
Other & 3.5 & $0 \%$ & 3.8 & $0 \%$ \\
\hline Total & 757.0 & & 787.0 & \\
\hline
\end{tabular}

\subsection{Silver Mineralogy}

Gasparrini (1984) classified 200 minerals bearing silver in major, minor and variable amounts. Common silver ores usually have 5 or 6 and in some instances as many as 10 distinct silver minerals (Gasparrini, 1984). Silver can form covalent bonds with sulfur and tellurium as well as selenium. Additionally, silver also combines with arsenic, antimony, lead, bismuth, tin, mercury and indium in many cases as a minor element in sulfides, sulfonates and native element minerals (Greenwood, 1997; Wyslouzil and Salter, 1990).

Boyle (1968) summarized silver deposits and mineral assemblages. According to his report, silver concentrations often exist in hypogene veins, lodes and stock works. Because of supergene oxidation process, a large number of silver minerals exist in the near-surface parts of some of these veins. Additionally, silver can be commonly found in 
gold placers, veins and lodes (Boyle, 1968). Even though more than 200 minerals contain silver, only 10 to 12 of them are economically important in industry. Native silver (Ag), electrum $(\mathrm{Ag}-\mathrm{Au})$, acanthite $\left(\mathrm{Ag}_{2} \mathrm{~S}\right)$, and pyrargyrite $\left(\mathrm{Ag}_{3} \mathrm{SbS}_{3}\right)$ are the most common silver-bearing minerals. Silver appears to be most commonly associated with lead and copper minerals such as galena $(\mathrm{PbS})$, covellite $(\mathrm{CuS})$ and chalcopyrite $\left(\mathrm{CuFeS}_{2}\right)$. The associations of these minerals with silver minerals vary with different ores and are mostly dependent on the general textual features of the ore, which often affect silver recovery to some extent (Zeng et al., 2000; Gasparrini and Lowell, 1983).

Silver sulfide $\left(\mathrm{Ag}_{2} \mathrm{~S}\right)$ is a covalently bonded mineral whose solid crystal structure varies with temperature. When temperature is higher than $586^{\circ} \mathrm{C}$, silver sulfide is in face centered cubic structure. With the decrease of temperature, argentite will be formed with a cubic structure. If the temperature keeps decreasing, argentite will transform to a monoclinic crystal structure silver sulfide, acanthite, immediately upon cooling below $173^{\circ} \mathrm{C}$ (Anthony et al., 1994-2010; Greenwood, 1997). As acanthite is the only stable form of silver sulfide at most operation temperatures in hydrometallurgy, silver sulfide and acanthite both refer to the monoclinic crystal structure silver sulfide in the literature and for the duration of this thesis.

\subsection{Chemistry of Silver}

The atomic mass of silver averages 107.868 and its atomic number is 47 . Univalent silver is a common form of silver ion because it has a single 5 s electron. However, when complexed with fluoride and pyridine, silver can form complex compounds, presenting +2 and +3 valences. The combination of silver with sulfur, nitrogen or halogen atoms are more favorable than with oxygen. Like gold, silver is very stable in the absence of oxidizing regents. When there is $\mathrm{H}_{2} \mathrm{~S}$ in the atmosphere, silver will react and the surface color will darken, forming $\mathrm{Ag}_{2} \mathrm{~S}$ on the surface (Wyslouzil and Salter, 1990; Greenwood, 1997). 


$$
4 \mathrm{Ag}+2 \mathrm{H}_{2} \mathrm{~S}+\mathrm{O}_{2}=2 \mathrm{Ag}_{2} \mathrm{~S}+2 \mathrm{H}_{2} \mathrm{O}
$$

Reaction 2-1

From Figure 2-1 it can be observed that the reduction potential of $\mathrm{Ag}^{+} / \mathrm{Ag}$ is high. Metallic silver is stable in the absence of oxidants, while in aqueous solution $\mathrm{Ag}^{+}$is the common form. The univalent oxidation state of silver is stable and bivalent and trivalent states are powerful oxidizing agents that can react with water to form oxygen. The univalent silver ion forms many slightly soluble compounds and slightly ionized complex ions (Xue and Osseo-Asare, 1985). Dilute hydrochloric, sulphuric acids and strong alkalis cannot dissolve metallic silver. However, nitric acid can dissolve silver completely, yielding the univalent silver ion and a solution of silver nitrate $\left(\mathrm{AgNO}_{3}\right)$. Concentrated sulphuric acid can react with silver with the presence of sulfur dioxide. In alkaline and oxidizing medium, silver can react with cyanide to form soluble anionic complexes, $\operatorname{Ag}(\mathrm{CN})_{\mathrm{n}}{ }^{1-\mathrm{n}}$, which is the basis of the cyanidation process. Silver also reacts with thiosulfate in the oxidizing alkaline system to form $\mathrm{Ag}\left(\mathrm{S}_{2} \mathrm{O}_{3}\right)_{2}{ }^{3-}$. On the other hand, silver ion can be reduced by formic acid, ferrous and less noble metals such as zinc, which is the principle of the Merrill-Crowe process to recover silver from solution (Hiskey and Atluri, 1988).

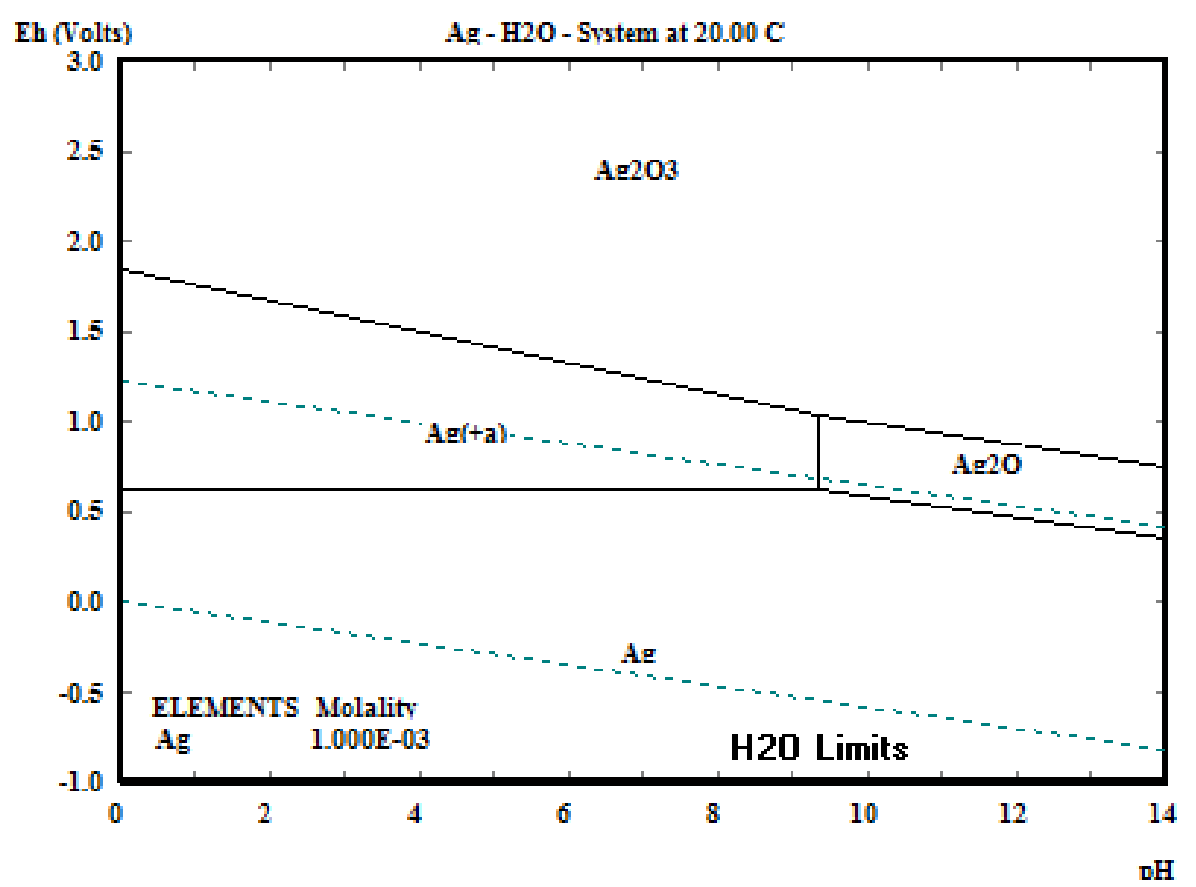

Figure 2-1 Eh-pH diagram for $\mathrm{Ag}-\mathrm{H}_{2} \mathrm{O}$ system at $20^{\circ} \mathrm{C},[\mathrm{Ag}]=10^{-3} \mathrm{M}(\mathrm{by} \mathrm{HSC})$ 


\subsection{Silver Extraction}

More than two-thirds of the world silver resources come from the associated copper, lead and zinc deposits, while the remaining are produced from the vein deposits in which silver and gold are main metallic components (WWS, 2013).

As a common by-product of copper, lead, zinc and gold mining, silver is often produced with additional operation besides the conventional process designed for the host minerals. Since most of the silver minerals float well with sulfide collectors, physical methods such as floatation to collect gold and silver may be involved (Wyslouzil and Salter, 1990).

\subsubsection{Silver Extraction History}

Silver is, in most cases, recovered along with the process of gold extraction which is predominately designed to obtain reasonable gold recovery. Before hydrometallurgy was introduced into the extraction of gold process, the practice in the $19^{\text {th }}$ century involved high-grade gold/silver ores sent directly to a pyrometallurgical process. For example, direct smelting with lead-rich fluxes was practiced. Another popular method to extract gold/silver was amalgamation. This process recovered precious metals from ores by combining them with mercury and then vaporization of mercury from the silver/gold-mercury amalgams. Sponge precious alloys were smelted with fluxes and gold/silver bullions were produced (Marsden and House, 2006). Gravity processes and floatation are often applied as the first step to recover coarse gold or silver rather than being used as a single recovery method (Hiskey and Atluri, 1988).

As was introduced to the production of precious metals, hydrometallurgical process developed with the aim to increase gold and silver dissolution rate and recovery. The similarities between gold and silver usually result in these two metals being co-extracted 
in the same process. In the context of gold/silver extraction, leaching is dissolving the gold/silver-bearing minerals into the aqueous solution which requires a complexant and sometimes an oxidant to accomplish the leaching. The pregnant leaching solution will be purified by one of a number of methods and sent for gold/silver refining (Marsden and House, 2006).

\subsubsection{Silver Cyanidation}

Nowadays, cyanide is commonly used to leach gold and silver because of its high efficiency, good selectivity and low cost. Patented by MacArthur in 1888, cyanide leaching has been the most important method to extract gold and silver from their ores for the recent 100 years (Marsden and House, 2006). The leaching process involves gold and silver oxidation by dissolved oxygen and the formation of metal-cyanide complexes. The overall stoichiometry has been shown by the well-known Elsner equations in the previous chapter (Reaction 1-1 and Reaction1-2).

The cyanidation process has to be conducted in an alkaline environment since there is a protonation-deprotonation reaction in the solution to form toxic and volatile $\mathrm{HCN}$ (Reaction 2-2).

$$
\mathrm{HCN}=\mathrm{H}^{+}+\mathrm{CN}^{-} \quad \text { pKa }\left(25^{\circ} \mathrm{C}\right)=9.31 \quad \text { Reaction } 2-2
$$

At approximately $\mathrm{pH} 9.3$, half of the total cyanide exists as hydrogen cyanide (HCN) and half as free cyanide ions $\left(\mathrm{CN}^{-}\right)$. At $\mathrm{pH} 10.2,>90 \%$ of the total cyanide is present as free cyanide $\left(\mathrm{CN}^{-}\right)$, while at $\mathrm{pH} 8.4,>90 \%$ of the total cyanide exists as hydrogen cyanide $(\mathrm{HCN})$. Hydrogen cyanide (liquid) has a relatively high vapor pressure $\left(100 \mathrm{kPa}\right.$ at $\left.26^{\circ} \mathrm{C}\right)$. Therefore, with high concentration of $\mathrm{HCN}$ in the solution, hydrogen cyanide consequently volatizes readily at the liquid surface under ambient conditions, causing a loss of cyanide from the solution. Thus, the $\mathrm{pH}$ of the leaching system is important to the reduction of the cyanide volatilization (Marsden and House, 2006). 
Both hydrogen cyanide and free cyanide can be oxidized to cyanate in the presence of oxygen and under suitable oxidizing conditions. These oxidations are undesirable because they reduce the free cyanide concentration and may depress leaching. However, the oxidation of cyanide is extremely slow in aerated cyanide solution in the absence of strong oxidizing agents (Marsden and House, 2006).

The leach solution containing metal-cyanide complexes is collected via a solid-liquid separation and washing process and then sent to zinc dust cementation (Merrill-Crowe process) or is recovered from solution or slurry by a carbon adsorption operation. In the Merrill-Crowe process, zinc powder is added into the solution and zinc displaces gold/silver in the solution and displaces gold and silver as precipitates.

$$
\begin{array}{ll}
2 \mathrm{Au}(\mathrm{CN})_{2}{ }^{-}+\mathrm{Zn}=\mathrm{Zn}(\mathrm{CN})_{4}{ }^{2-}+2 \mathrm{Au} & \text { Reaction 2-3 } \\
2 \mathrm{Ag}(\mathrm{CN})_{2}{ }^{-}+\mathrm{Zn}=\mathrm{Zn}(\mathrm{CN})_{4}{ }^{2-}+2 \mathrm{Ag} & \text { Reaction 2-4 }
\end{array}
$$

In the carbon adsorption processes, the solution with metal-cyanide complexes is sent to activated carbon columns. Due to the high selectivity and efficiency of activated carbon, the metal-cyanide complexes are adsorbed to the activated carbon. After adsorption, the carbon particles are eluted and the eluant solution is collected for further recovery. The eluant is purified and sent to electrowinning. There are three basic carbon-adsorption processes adopted by industry, Carbon-in-Pulp (CIP), Carbon-in-Leach (CIL) and Carbon-in-Columns (CIC). CIP and CIL adsorb gold/silver directly from pulps or slurries containing up to $50 \%$ or $60 \%$ solids, while the CIC process is usually used to treat solution from heap leach operations (Marsden and House, 2006). 


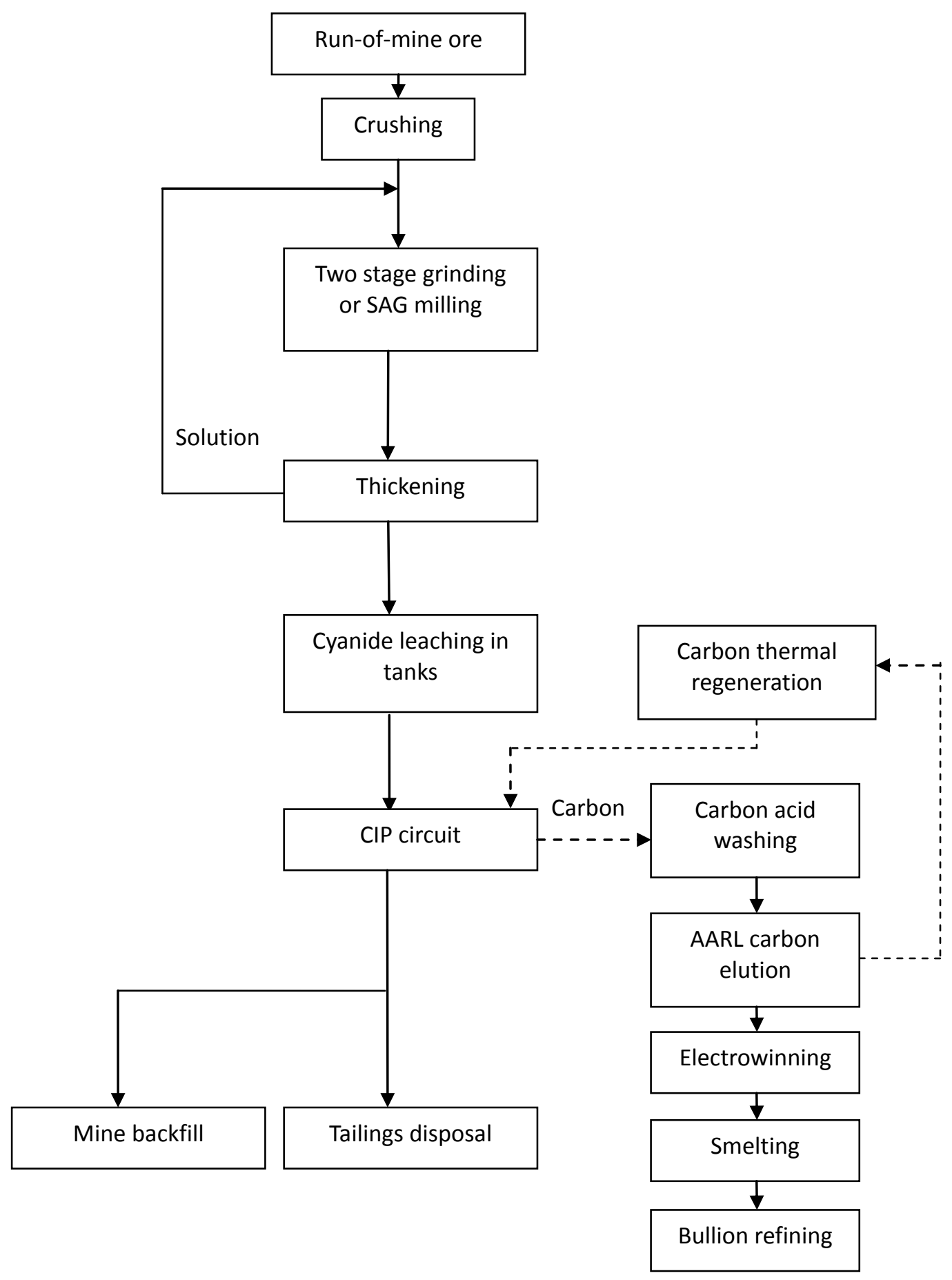

Figure 2-2 Flowsheet for a typical CIP plant treating a free-milling gold ore (Fleming, 2007c) 


\subsubsection{Cyanidation of Metallic Silver}

In a research regarding heterogeneous equilibria in the $\mathrm{Au}-\mathrm{CN}-\mathrm{H}_{2} \mathrm{O}$ and $\mathrm{Ag}-\mathrm{CN}-\mathrm{H}_{2} \mathrm{O}$ systems conducted by Xue and Osseo-Asare (1985), they proved that silver and gold have similar behaviors in cyanide media and both of them exhibit wide solubility domains with di-cyanide complexes predominating. The complexes of gold/silver with cyanide are very stable in the presence of oxygen. Solid $\mathrm{AgCN}$ forms only when the dissolved silver concentration is high while the free cyanide concentration is low in low-pH solution. The $\mathrm{Ag}(\mathrm{CN})_{3}{ }^{2-}$ and $\mathrm{Ag}(\mathrm{CN})_{4}{ }^{3-}$ species form only in concentrated cyanide solution. This can be observed from the Eh-pH diagram of silver-cyanide-water system.

Even though gold and silver behave almost the same in aqueous solution, slight differences can be found via activity-activity diagrams comparison. Gold is more stable than silver in acid cyanide-free solution while in cyanide solution silver shows lower activity (Xue and Osseo-Asare, 1985).

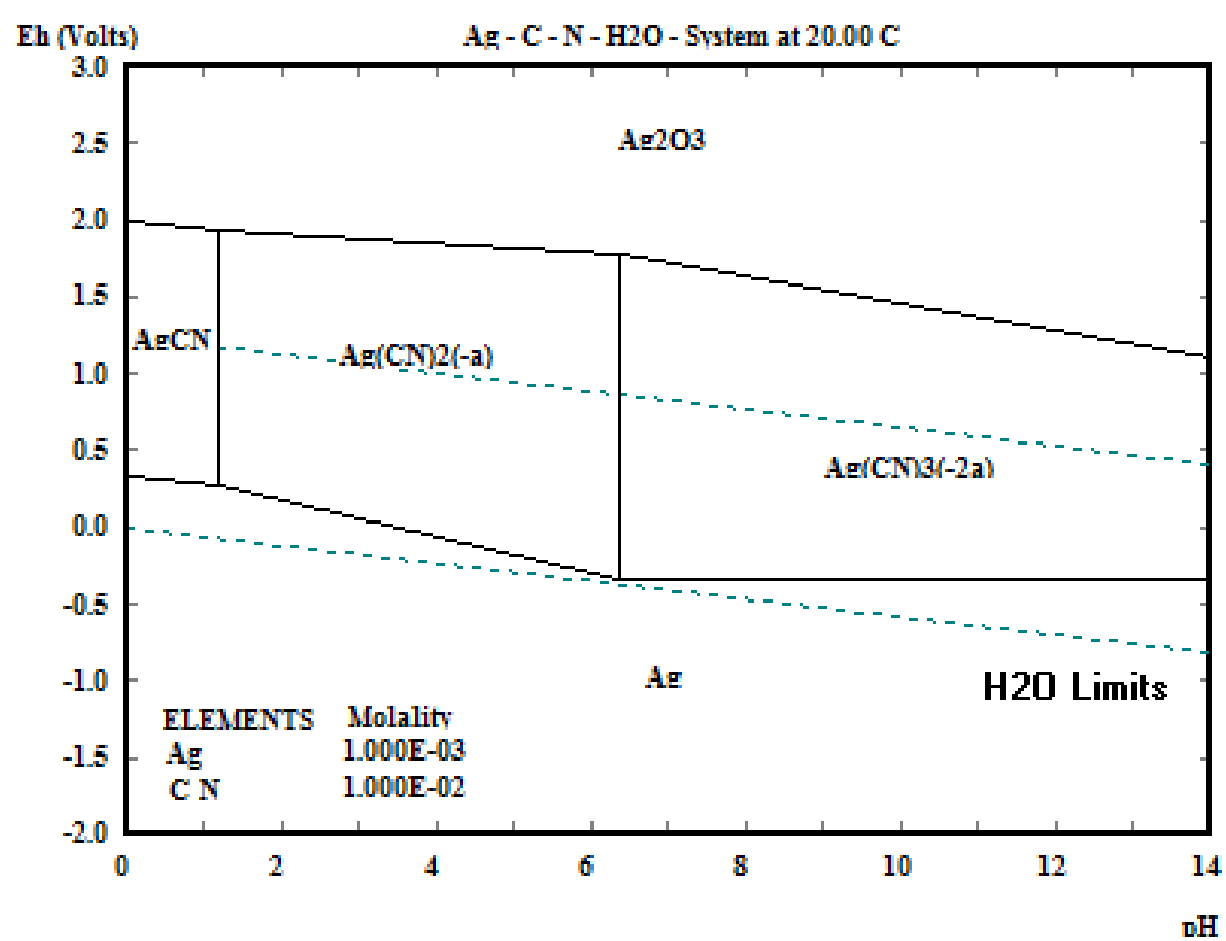

Figure 2-3 Eh-pH diagram for Ag-CN-H $\mathrm{H}_{2} \mathrm{O}$ system at $20^{\circ} \mathrm{C},[\mathrm{Ag}]=10^{-3} \mathrm{M},\left[\mathrm{CN}^{-}\right]=10^{-2} \mathrm{M}(\mathrm{by} \mathrm{HSC})$ 
$\mathrm{Li}$ and Wadsworth (1993) studied the anodic electrochemical behavior of the silver dissolution process in oxygen-free cyanide solution. The Butler-Volmer and Levich equations were used to calculate the dissolution rate. They claimed that the overall reaction between silver and cyanide solution could be separated into two steps: an electrochemical reaction (Reaction 2-5) followed by a chemical reaction (Reaction 2-6). The rate limiting factor was considered as the combination of charge transfer and the diffusion of cyanide. Senanayake (2006) investigated the limiting rate of silver dissolution in high cyanide concentration system with oxygen $\left(2.5 \times 10^{-5} \mathrm{~mol} \mathrm{~m}^{-2} \mathrm{~s}^{-1}\right.$ at about $21 \mathrm{kPa}$ oxygen pressure) and the result matched well with the Li's model.

$$
\begin{array}{cc}
\mathrm{Ag}+\mathrm{CN}^{-}=\mathrm{AgCN}+\mathrm{e} & \text { Reaction 2-5 } \\
\mathrm{AgCN}+\mathrm{CN}^{-}=\mathrm{Ag}(\mathrm{CN})_{2}^{-} & \text {Reaction 2-6 }
\end{array}
$$

The kinetics and mechanism of the dissolution of metallic silver in aerated cyanide solution have been investigated. Hiskey and Sanchez (1990) used silver rotating-disk experiments to study the electrochemical mechanism of the metallic silver dissolution in aerated cyanide solution. According to their findings, the anodic oxidation of silver followed a mixed kinetic model involving both mass transfer and charge transfer. The charge transfer rate constant matched well with the charge transfer rate constant in gold rotating-disk leaching. Based on these findings, they claimed that during the dissolution of native metals into aerated cyanide solution both gold and silver exhibited the same behavior.

The oxygen reduction reaction on the silver surface was studied by varying the oxygen partial pressure. It was reported that the kinetic model of oxygen reduction involved a mixed diffusion plus charge transfer process (Hiskey and Sanchez, 1990). Lower dissolution rate of silver than gold could be attributed to different electron path, oxygen adsorption mechanism and smaller oxygen reduction transfer coefficient. Figure 2-4 indicates the general sequence of oxygen reduction. Two different pathways of oxygen 
reduction are listed as Reaction 2-7 2-9. The 2-electron sequential path produced $\mathrm{H}_{2} \mathrm{O}_{2}$ as an intermediate product and then reduced to $\mathrm{OH}^{-}$(Hiskey and Sanchez, 1990; Kappes, 2007; Fleming, 2007a; Sun et al., 1996).

Direct 4 electron path:

$$
\mathrm{O}_{2}+2 \mathrm{H}_{2} \mathrm{O}+4 \mathrm{e}=4 \mathrm{OH}^{-}
$$

Reaction 2-7

2 electron sequential path:

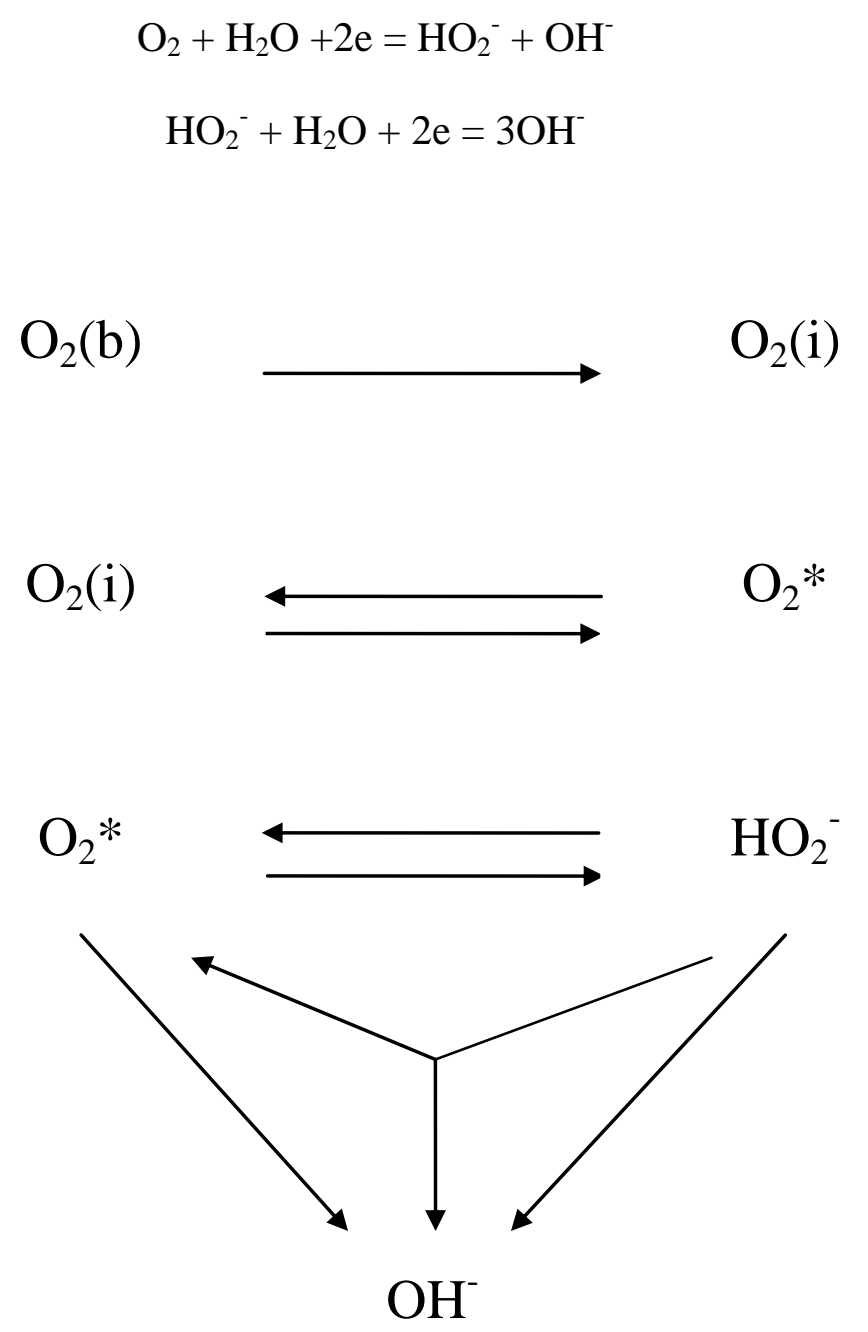

Reaction 2-8

Reaction 2-9

Figure 2-4 General sequence of oxygen reduction (Hiskey and Sanchez, 1990)

$\mathrm{O}_{2}(b)$ : oxygen concentration in bulk solution; $\mathrm{O}_{2}(i)$ : oxygen concentration on the interface;

$\mathrm{O}_{2}^{*}$ : adsorbed oxygen concentration

Even though silver frequently occurs with gold in economically significant quantities and the silver behavior in cyanide solution is similar to gold, optimum cyanidation conditions 
for gold recovery seldom results in maximum silver recovery (Marsden and House, 2006). Silver may be present in the ores in many different forms, some of which are not cyanide-leachable. Silver sulfides and most of the other silver compounds leach slowly compared to gold. The expected recovery of silver from various silver minerals by cyanide leaching is shown in Table 2-3.

Table 2-3 Silver recovery from silver minerals by cyanide leaching (Fleming, 2007a)

\begin{tabular}{ccc}
\hline Mineral & Composition & Range of Ag Recovery \\
\hline Cerargyrite & $\mathrm{AgCl}$ & $97.0 \%$ \\
Iodyrite & $\mathrm{AgI}$ & $99.3 \%$ \\
Argentite (Acanthite) & $\mathrm{Ag}_{2} \mathrm{~S}$ & $87-93 \%$ \\
Proustite & $\mathrm{Ag}_{3} \mathrm{AsS}_{3}$ & $42.5 \%$ \\
Pyrargyrite & $\mathrm{Ag}_{3} \mathrm{SbS}_{3}$ & $67.0 \%$ \\
Tetrahedrite & $4 \mathrm{Cu}_{2} \mathrm{~S}_{2} \mathrm{Sb}_{2} \mathrm{~S}_{3}$ & $25 \%$ \\
\hline
\end{tabular}

\subsubsection{Cyanidation of Silver Sulfide}

The Eh-pH diagram of the $\mathrm{Ag}-\mathrm{S}-\mathrm{CN}-\mathrm{H}_{2} \mathrm{O}$ system is shown in Figure 2-5. This diagram indicates that cyanidation of silver sulfide should be easily accomplished at elevated $\mathrm{pH}$ in the presence of dissolved cyanide and oxygen. However, the experience of leaching silver sulfide containing ores often gives inferior results. For instance, when a silver sulfide-bearing gold ore is leached in cyanide solution, silver dissolution is often less than $30 \%$ compared with the $90 \%$ gold extraction (Xie, 2006). 


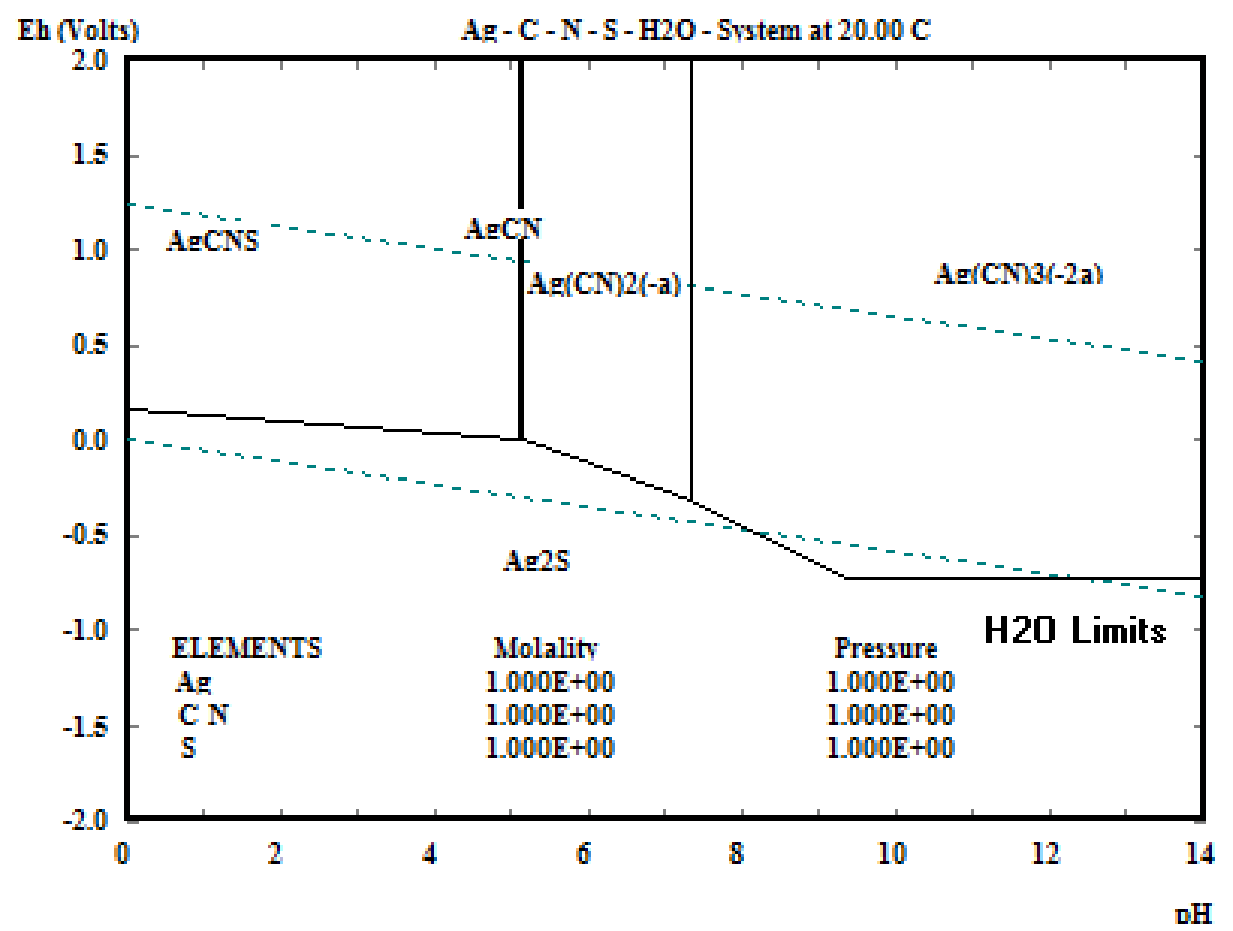

Figure 2-5 Eh-pH diagram for Ag-S-CN-H $-\mathrm{H}_{2} \mathrm{O}$ system at $20^{\circ} \mathrm{C},[\mathrm{Ag}]=1 \mathrm{M},[\mathrm{S}]=1 \mathrm{M},\left[\mathrm{CN}^{-}\right]=1 \mathrm{M}(\mathrm{by}$ HSC)

The dissolution of acanthite in cyanide solution can be described by the following reaction:

$$
\mathrm{Ag}_{2} \mathrm{~S}+\mathrm{nCN}^{-}=\mathrm{Ag}(\mathrm{CN})_{\mathrm{n}}{ }^{1-\mathrm{n}}+\mathrm{S}^{2-} \quad \mathrm{n}=1,2,3 \text { or } 4 \quad \text { Reaction 2-10 }
$$

Furthermore, the reactions among sulfur species and cyanide in oxidizing system may generate several possible products. For the sulfur species, polysulfide $\left(\mathrm{S}_{\mathrm{x}}{ }^{2-}\right)$, elemental sulfur $(\mathrm{S})$, thiosulfate $\left(\mathrm{S}_{2} \mathrm{O}_{3}{ }^{2-}\right)$ and sulfate $\left(\mathrm{SO}_{4}{ }^{2-}\right)$ are all potential products. Free cyanide in the solution can be oxidized to cyanate $\left(\mathrm{CNO}^{-}\right)$and thiocyanate $\left(\mathrm{SCN}^{-}\right)$(Davis, 1962; Luthy and Bruce, 1979).

Combined with the following equilibriums;

$$
\begin{array}{lrr}
\mathrm{Ag}_{2} \mathrm{~S}=2 \mathrm{Ag}^{+}+\mathrm{S}^{2-} & \log \mathrm{K}_{\mathrm{sp}}=-50.1 & \text { Reaction 2-11 } \\
\mathrm{Ag}^{+}+2 \mathrm{CN}^{-}=\mathrm{Ag}(\mathrm{CN})_{2}{ }^{-} & \log \mathrm{K}=20.2 & \text { Reaction 2-12 }
\end{array}
$$


It can be observed that the thermodynamic limitations of the silver extraction process are the solubility of silver sulfide in cyanide solution and the rate and extent of sulfide oxidation (Xie, 2006).

The stoichiometric relation of the leaching reaction during silver sulfide cyanidation was investigated by Luna-Sanchez and Lapidus (2000) and they also established a model to simulate the silver sulfide dissolution with different cyanide and oxygen concentrations. In their first experimental step, pure oxygen and $0.01 \mathrm{M} \mathrm{NaCN}$ solution were applied to dissolve pure silver sulfide. Thiosulfate ion was the only identified sulfur species in the leaching solution. The dominant silver complex was $\mathrm{Ag}(\mathrm{CN})_{2}{ }^{-}$and no $\mathrm{H}_{2} \mathrm{O}_{2}$ was found in the solution, implying that the oxygen underwent complete reduction to form hydroxyl ion. The oxidation reaction was established as Reaction 2-13.

$$
\mathrm{Ag}_{2} \mathrm{~S}+4 \mathrm{CN}^{-}+\mathrm{O}_{2}+1 / 2 \mathrm{H}_{2} \mathrm{O}=2 \mathrm{Ag}(\mathrm{CN})_{2}{ }^{-}+1 / 2 \mathrm{~S}_{2} \mathrm{O}_{3}{ }^{2-}+\mathrm{OH}^{-} \quad \text { Reaction 2-13 }
$$

In their variation tests, under the condition of constant temperature and ambient pressure $\left(20^{\circ} \mathrm{C}\right.$ and $\left.1 \mathrm{~atm}\right)$, the silver extraction rate increased when the cyanide concentrations varied from $0.001 \mathrm{M}$ to $0.3 \mathrm{M}$. This was different from the case of pure silver where a maximum stable extraction value was reached at a relatively low cyanide concentration, indicating that pure diffusion control in this process was doubtful. They established a kinetic model at low pulp density and claimed that silver sulfide cyanidation was kinetically controlled by a second order reaction relative to the local oxygen and sulfide ion concentrations. When the content of silver sulfide was high, there was a saturation phenomenon that retarded the silver extraction. The stagnation of the reaction could be avoided by increasing the temperature.

Luna-Sanchez et al. (2003) presented another report about the comparative study on cyanidation of different silver sulfide minerals using electrochemical technique. Both 
analytical reagent silver sulfide and a concentrate containing $86.27 \%$ silver sulfide were leached. The dissolution mechanism of the carbon paste electrode, which was made of the electro-active species-silver sulfide concentrates, was determined with the cyclic voltammetry method. As a result, pure silver sulfide cyanidation presented a clear diffusional phenomenon while the cyanidation of the concentrate exhibited a mixed control kinetic process. The cause of this difference was supposed to be the appearance of iron sulfide in the concentrate. This explanation was further proved by investigation on the electrochemical properties of pyrite concentrate leaching.

The effect of iron sulfide on silver extraction brings a new problem - the influence of non-silver metal sulfide minerals on acanthite cyanidation. Most metal sulfides decompose in aerated alkaline cyanide solution to different extents, forming metal ions, metal oxides or metal cyanide complexes (Marsden and House, 2006). Since silver usually co-exist with other sulfide minerals such as pyrite $\left(\mathrm{FeS}_{2}\right)$, chalcopyrite $\left(\mathrm{CuFeS}_{2}\right)$ and sphalerite (ZnS), the influence of these sulfide minerals on the cyanidation of silver are important. Zhang et al. (1997) claimed that the rate of silver cyanidation was limited by the dissolution of copper and iron sulfide mineral. The main reason was supposed to be the preferred dissolution of copper and iron sulfide minerals over silver sulfide, which made copper and iron sulfide minerals a cyanicide and an oxygen consuming species. Xie (2006) claimed that the presence of non-silver sulfide minerals were speculated to suppress the solubility of silver sulfide as they would liberate some sulfide ions into the solution and consume some or most of the available oxidants in the system. He tested the performance of non-silver sulfide minerals in silver sulfide leaching and found that silver extraction decreased with an increase of dissolved sulfur species under the leaching conditions.

\subsubsection{Alternative Leaching Process}

For the purpose of enhancing gold/silver dissolution and seeking non-toxic leachants, numerous studies have been done on alternative lixiviants and complex media to leach 
gold/silver. Reported alternative complexing agents include chloride, thiourea, thiosulfate and other complex media.

\subsubsection{Chloride Leaching}

Before the cyanidation process was commercialized, a chlorination process was discovered and put into practice in the gold/silver recovery process in 1774. It was once popular in the USA, South America and Australia by the end of the 1860s, but was soon replaced after the cyanidation process was introduced at the end of 19th century (Marsden and House, 2006).

Chloride leaching of acanthite has been investigated and reported by Scheiner et al. (1976). The use of a sulfurous acid-sodium chloride leaching system extracted almost $80 \%$ of the silver in the ore. This was further investigated by Dutrizac (1994) with a system including ferric and chloride. Furthermore, it was claimed that if there was a large amount of chloride in the solution, silver in acanthite could also be extracted at elevated temperatures without ferric (Almeida and Amarante, 1995).

The main reaction in the process is the combination of $\mathrm{Cl}^{-}$with $\mathrm{Ag}^{+}$. It is common knowledge that $\mathrm{AgCl}$ is insoluble in aqueous solution, however, if there is a large amount of extra $\mathrm{Cl}^{-}$in the system, Reaction 2-14 can occur and the silver can be dissolved into solution (Dutrizac, 1994).

$$
\mathrm{AgCl}+3 \mathrm{Cl}^{-}=\mathrm{AgCl}_{4}{ }^{3-} \quad \text { Reaction 2-14 }
$$

Synthetic $\mathrm{Ag}_{2} \mathrm{~S}$ rotating-disk tests in $\mathrm{FeCl}_{3}-\mathrm{HCl}$ and $\mathrm{Fe}_{2}\left(\mathrm{SO}_{4}\right)_{3}-\mathrm{H}_{2} \mathrm{SO}_{4}$ media were performed by Dutrizac (1994) for a kinetic study of silver sulfide leaching in ferric ion media. The $\mathrm{Fe}_{2}\left(\mathrm{SO}_{4}\right)_{3}-\mathrm{H}_{2} \mathrm{SO}_{4}$ media showed insignificant ability to extract silver from silver sulfide. However, rapid dissolution of silver sulfide was found in $\mathrm{FeCl}_{3}-\mathrm{HCl}$ 
solution. From the SEM picture of the silver sulfide disk after leaching, a clear thickening elemental sulfur layer could be observed, which was an solid evidence for the occurrence of Reaction 2-15. The leaching results of silver sulfide in concentrated $\mathrm{HCl}$ and $\mathrm{NaCl}$ solution supported the contention that the parabolic kinetics observed in the $\mathrm{FeCl}_{3}-\mathrm{HCl}$ system were caused by the porous layer of elemental sulfur.

$$
\mathrm{Ag}_{2} \mathrm{~S}+2 \mathrm{FeCl}_{3}=2 \mathrm{FeCl}_{2}+2 \mathrm{AgCl}+\mathrm{S} \quad \text { Reaction 2-15 }
$$

Dutrizac (1994) claimed that the whole leaching rate was controlled by the outward diffusion of various silver-chloride complexes through the solution trapped in the pores of the elemental sulfur layer. The dissolution obeyed the parabolic rate law, which was caused by the constantly thickening sulfur layer and was proved essentially independent of liquid boundary layer thickness.

\subsubsection{Thiourea Leaching}

Balaz et al. (1996) indicated that the reaction between thiourea and silver ion was favorable in acidic solution and put forward the reaction as Reaction 2-16:

$$
\mathrm{Ag}^{+}+3 \mathrm{CS}\left(\mathrm{NH}_{2}\right)_{2}=\mathrm{Ag}\left[\mathrm{CS}\left(\mathrm{NH}_{2}\right)_{2}\right]_{3}{ }^{+} \quad \text { Reaction 2-16 }
$$

Another idea was that metallic silver leaching with thiourea as lixiviant was feasible with the presence of ferric ion. Pesic and Seal (1990) proved this theory with a rotating-disk test. They insisted that the presence of ferric sulfate was the key factor in metallic silver leaching with thiourea. The rate and extent of leaching by this process was highly dependent on the ferric ion concentration. With a small amount of ferric sulfate in the system, insoluble silver-thiourea solid was formed as a passivation layer and stopped further leaching. However, with more addition of ferric sulfate the passivation layer re-dissolved and the leaching continued. 


\subsubsection{Thiosulfate Leaching}

Thiosulfate has recently emerged as a promising lixiviant for gold/silver extraction because of its low price and non toxicity. The proposed stoichiometry for metallic silver reacting with thiosulfate is given by Reaction 2-17 or 2-18 depending on the $\mathrm{pH}$ of the system (Ficeriová et al., 2005; Zipperian et al., 1988).

$$
\begin{array}{cc}
4 \mathrm{Ag}+8 \mathrm{~S}_{2} \mathrm{O}_{3}{ }^{2-}+4 \mathrm{H}^{+}+\mathrm{O}_{2}=4 \mathrm{Ag}\left(\mathrm{S}_{2} \mathrm{O}_{3}\right)_{2}{ }^{3-}+2 \mathrm{H}_{2} \mathrm{O} & \text { Reaction 2-17 } \\
4 \mathrm{Ag}+8 \mathrm{~S}_{2} \mathrm{O}_{3}{ }^{2-}+2 \mathrm{H}_{2} \mathrm{O}+\mathrm{O}_{2}=4 \mathrm{Ag}\left(\mathrm{S}_{2} \mathrm{O}_{3}\right)_{2}{ }^{3-}+4 \mathrm{OH}^{-} & \text {Reaction 2-18 }
\end{array}
$$

The cupric-ammonia catalyzed thiosulfate system was the most commonly studied system because of its ability to leach both silver and silver sulfide (Briones and Lapidus, 1998). When leaching metallic silver and gold, cupric ion oxidized the precious metals while thiosulfate formed complexes with them. Ammonia was also added to stabilize the cupric ion in the alkaline solution, avoiding copper precipitation as copper hydroxide. The role of cupric ion in the oxidation of metallic gold is shown in the following reaction (Feng and Deventer, 2007):

$$
\mathrm{Au}+5 \mathrm{~S}_{2} \mathrm{O}_{3}{ }^{2-}+\mathrm{Cu}\left(\mathrm{NH}_{3}\right)_{4}{ }^{2+}=\mathrm{Au}\left(\mathrm{S}_{2} \mathrm{O}_{3}\right)_{2}{ }^{3-}+\mathrm{Cu}\left(\mathrm{S}_{2} \mathrm{O}_{3}\right)_{3}{ }^{5-}+4 \mathrm{NH}_{3} \quad \text { Reaction 2-19 }
$$

Jeffrey (2001) studied metallic gold/silver leaching in thiosulfate-cupric-ammonia system with a rotating electrochemical quartz crystal microbalance (REQCM), which could measure the mass change of the solid in the system. Dissolution of silver in this system was found to occur rapidly. The limitation of the reaction was claimed to be the diffusion of cupric ion to the gold/silver surface. Increasing thiosulfate concentration was reported to be beneficial to the leaching kinetics of silver (Jeffrey, 2001). However, one factor hindering wide application in industry was the high consumption of cupric ion and thiosulfate, making the cost of this process higher than cyanide leaching (Aylmore and Muir, 2001). 
As mentioned, silver sulfide leaching in thiosulfate system is also feasible. The leaching of silver sulfide occurs under the same conditions as the leaching of metallic silver. Cupric ion was recognized to act as a catalyst in the process and ammonia was added to stabilize the system. However, Briones and Lapidus (1998) claimed that the thiosulfate leaching mechanisms of metallic silver and acanthite were different. The study by Briones and Lapidus (1998) elucidated that the acanthite leaching could be divided into two steps. In the first step, cupric ion reacted with thiosulfate to form the tetrathionate ion and a cuprous thiosulfate or ammonia complex (Reaction 2-20). The next step was silver liberation by substitution in the solid phase (Reaction 2-21). During the acanthite leaching process, the ratio of ammonia to thiosulfate was important and increasing copper and thiosulfate concentration was beneficial to accelerate the leaching.

$$
\begin{array}{ll}
5\left(\mathrm{NH}_{4}\right)_{2} \mathrm{~S}_{2} \mathrm{O}_{3}+2 \mathrm{CuSO}_{4}=\mathrm{Cu}_{2} \mathrm{~S}_{2} \mathrm{O}_{3} \cdot 2\left(\mathrm{NH}_{4}\right)_{2} \mathrm{~S}_{2} \mathrm{O}_{3}+\left(\mathrm{NH}_{4}\right)_{2} \mathrm{SO}_{4}+\left(\mathrm{NH}_{4}\right)_{2} \mathrm{~S}_{4} \mathrm{O}_{6} \\
& \text { Reaction 2-20 } \\
\mathrm{Cu}_{2} \mathrm{~S}_{2} \mathrm{O}_{3} \cdot 2\left(\mathrm{NH}_{4}\right)_{2} \mathrm{~S}_{2} \mathrm{O}_{3}+\mathrm{Ag}_{2} \mathrm{~S}=\mathrm{Cu}_{2} \mathrm{~S}+\mathrm{Ag}_{2} \mathrm{~S}_{2} \mathrm{O}_{3} \cdot 2\left(\mathrm{NH}_{4}\right)_{2} \mathrm{~S}_{2} \mathrm{O}_{3} & \text { Reaction 2-21 }
\end{array}
$$

Cui et al. (2011) investigated the leaching of acanthite in thiosulfate-cupric system. The difference between this system and Briones's system was the absence of ammonia in the solution. Cui et al. (2011) found that the basis of this process was the substitution of silver by cuprous ion, which was the same as the system with ammonia. However, after comparison between acanthite leaching in thiosulfate-cupric systems with or without ammonia, it was found that the presence of ammonia decelerated silver extraction. Furthermore, their tests indicated that in this process, oxygen was not necessary and solution $\mathrm{pH}$ did not influence the results.

To better study the application of thiosulfate system on silver sulfide leaching, Dr. Dreisinger and his group investigated different additives with thiosulfate as silver lixiviant. Thiosulfate systems such as ferric-ethylenediaminetetraacetic acid (EDTA), cupric-ammonia, ferric-oxalate and ferric-citrate were tested on both synthetic silver sulfide and natural ore from Yanacocha. Deutsch (2012) proved that the thiosulfate-cupric-ammonia leaching of silver sulfide was under mixed 
chemical/diffusion control in rotating-disk tests. Compared to ferric-oxalate and ferric-citrate, ferric-EDTA was the most effective oxidant in the leaching of Yanacocha ore, likely because it prevented the formation of a passive film on the surface of the solid.

\subsubsection{Other Methods}

Besides the above systems, there are some other procedures that have been investigated by researchers to extract silver from silver sulfide.

It was once reported (Scheiner et al., 1976; Dutrizac, 1994) that U.S. Bureau of Mines processed a complex silver ore from the Candelaria Mining District, Nevada, containing acanthite, silver-bearing jarosite and silver-bearing manganese oxides. Hypochlorite-brine media was applied in leaching and the result proved that $\mathrm{Ag}_{2} \mathrm{~S}$ was converted into $\mathrm{AgCl}$ by hypochlorite ion (Reaction 2-22) and further dissolved by brine (Reaction 2-14).

$$
\mathrm{Ag}_{2} \mathrm{~S}+4 \mathrm{ClO}^{-}=2 \mathrm{AgCl}+\mathrm{SO}_{4}{ }^{2-}+2 \mathrm{Cl}^{-} \quad \text { Reaction 2-22 }
$$

Ayata and Yildiran (2001) studied the possibility of using thiosulfate and sulfite to dissolve acanthite. The process was based on the reaction between silver sulfide, thiosulfate and sulfite as the following equation:

$$
\mathrm{Ag}_{2} \mathrm{~S}+4 \mathrm{~S}_{2} \mathrm{O}_{3}{ }^{2-}+2 \mathrm{SO}_{3}{ }^{2-}+6 \mathrm{H}^{+}=2 \mathrm{Ag}\left(\mathrm{S}_{2} \mathrm{O}_{3}\right)_{2}{ }^{3-}+3 \mathrm{~S}+3 \mathrm{H}_{2} \mathrm{O} \quad \text { Reaction 2-23 }
$$

They added silver sulfide mineral into a solution containing $0.8 \mathrm{M} \mathrm{Na} \mathrm{N}_{2} \mathrm{~S}_{2} \mathrm{O}_{3}$ and $0.1 \mathrm{M}$ $\mathrm{Na}_{2} \mathrm{SO}_{3}$. The solution $\mathrm{pH}$ was maintained at 4 with $\mathrm{H}_{3} \mathrm{PO}_{4}$ and the temperature was between $50^{\circ} \mathrm{C} \sim 60^{\circ} \mathrm{C}$. After 4-6 hours stirring, $100 \%$ silver extraction was achieved.

Dissolution of silver sulfide in halide solution containing $\mathrm{Fe}^{3+}$ was studied by Benari and Hefter (1992). They set up two systems that both contained $1 \mathrm{M} \mathrm{FeCl} 3$.The only 
difference between these two systems was the presence of dimethylsulphoxide (DMSO). The main reaction was believed to be the same as Reaction 2-14. It was found that without DMSO added, $80 \%$ of the silver sulfide was extracted. The explanation for the incomplete leaching was the formation of an elemental sulfur layer and $\mathrm{AgCl}$ layer that coated the solid surface. With the addition of DMSO, the extraction rate was slow, but nearly $100 \%$ silver extraction was achieved, presumably because of the solubilization of passivation layer by DMSO.

The leaching of silver sulfide precipitate in the photography process was also studied by Holloway et al. (2004). In their system, nitric acid was applied and performed well based on Reaction 2-24.

$$
3 \mathrm{Ag}_{2} \mathrm{~S}+8 \mathrm{HNO}_{3}=3 \mathrm{Ag}_{2} \mathrm{SO}_{4}+8 \mathrm{NO}+4 \mathrm{H}_{2} \mathrm{O} \quad \text { Reaction 2-24 }
$$

With the variation of temperature, pressure, acid concentration and solid concentration, the best extraction rate was achieved at $150^{\circ} \mathrm{C}, 1100 \mathrm{Kpa}$, with $9.6 \%$ solids and twice the stoichiometric amount of nitric acid.

\subsection{Enhancement of Cyanidation}

In the conventional gold/silver cyanidation process, especially in heap leaching operations, low recovery and leaching velocity are very common. One suspected reason for this is the existence of some slow leaching minerals such as acanthite $\left(\operatorname{Ag}_{2} \mathrm{~S}\right)$ and some refractory minerals such as argentojarosites $\left(\mathrm{AgFe}_{3}\left[\mathrm{SO}_{4}\right]_{2}(\mathrm{OH})_{6}\right)$. Also, another limitation may be the low activity and availability of oxygen in cyanide solution. In order to accelerate the leaching and improve the efficiency of the cyanidation process, research has been done to enhance cyanidation. For example, the use of sufficient $\mathrm{H}_{2} \mathrm{O}_{2}$ addition in the silver leaching process could achieve almost 100 hundred percent extraction under standard conditions (Woods et al., 1974). High gold/silver recovery could also be achieved if leached under a high partial pressure of oxygen. Less time would be needed 
compared to the normal cyanidation (Pietsch et al., 1984). When dealing with ores with high content of manganese oxides, use of $\mathrm{SO}_{2}$ could reduce $\mathrm{Mn}^{4+}$ in the ore to the acid-soluble $\mathrm{Mn}^{2+}$ state and presumably liberate silver that is locked in the manganese matrix (Chase, 1981; Fleming, 2007a).

\subsubsection{Ferricyanide}

The novel application of ferricyanide to gold and silver cyanidation has been investigated by Xie et al. (2008). It was reported that the use of iron (III) as an additive to cyanidation could increase the gold leaching rate due to high oxidation capability of ferricyanide. The conversion from ferricyanide to ferrocyanide is expressed as Reaction 2-25.

$$
\mathrm{Fe}(\mathrm{CN})_{6}{ }^{3-}+\mathrm{e}=\mathrm{Fe}(\mathrm{CN})_{6}{ }^{4-} \quad \mathrm{E}^{0}=0.36 \mathrm{~V}(\mathrm{SHE}) \quad \text { Reaction 2-25 }
$$

Compared with Reaction 2-26

$$
\mathrm{O}_{2}+2 \mathrm{H}_{2} \mathrm{O}+4 \mathrm{e}=4 \mathrm{OH}^{-} \quad \mathrm{E}^{0}=0.40 \mathrm{~V}(\mathrm{SHE}) \quad \text { Reaction 2-26 }
$$

Even though the reduction potential of $\mathrm{Fe}(\mathrm{CN})_{6}{ }^{3-} / \mathrm{Fe}(\mathrm{CN})_{6}{ }^{4-}$ is lower than $\mathrm{O}_{2} / \mathrm{OH}^{-}$, the higher solubility of ferricyanide in cyanide solution can increase the oxidation rate and thus the leaching rate of gold. The stability of $\mathrm{Fe}(\mathrm{CN})_{6}{ }^{3-}$ and $\mathrm{Fe}(\mathrm{CN})_{6}{ }^{4-}$ are also very high in cyanide solution. All of the above merits make ferricyanide a promising auxiliary oxidant that can enhance the cyanidation of gold and silver (Xie, 2006).

Xie (2006) tested the performance of ferricyanide on the dissolution of gold disk and found that with the addition of ferricyanide, the dissolution of gold was accelerated. With only $0.05 \mathrm{~g} / \mathrm{L} \mathrm{NaCN}$ in aerated solution, the dissolution velocity of gold was tested as 5 $\mu \mathrm{mol} / \mathrm{m}^{2} / \mathrm{s}(0.19 \mu \mathrm{m} / \mathrm{h})$. With addition of $0.5 \mathrm{~g} / \mathrm{L} \mathrm{Fe}(\mathrm{CN})_{6}{ }^{3-}$ as $\mathrm{Fe}^{3+}$, the rate rose to 19 $\mu \mathrm{mol} / \mathrm{m}^{2} / \mathrm{s}(0.74 \mu \mathrm{m} / \mathrm{h})$, indicating that ferricyanide was an effective oxidant to enhance gold cyanidation. With the analysis of the solution after leaching, the reaction was obtained as Reaction 2-27. 


$$
\mathrm{Au}+\mathrm{Fe}(\mathrm{CN})_{6}^{3-}+2 \mathrm{CN}^{-}=\mathrm{Au}(\mathrm{CN})_{2}^{-}+\mathrm{Fe}(\mathrm{CN})_{6}^{4-} \quad \text { Reaction 2-27 }
$$

The reaction between metallic silver and ferricyanide was then deduced (Reaction 2-28).

$$
\mathrm{Ag}+\mathrm{Fe}(\mathrm{CN})_{6}{ }^{3-}+2 \mathrm{CN}^{-}=\mathrm{Ag}(\mathrm{CN})_{2}^{-}+\mathrm{Fe}(\mathrm{CN})_{6}{ }^{4-} \quad \text { Reaction 2-28 }
$$

The performance of ferricyanide on cyanidation of gold/silver bearing ore was also studied. The result indicated that ferricyanide was effective in both gold and silver ore leaching. The leaching time was shortened and the final recovery was raised.

To improve the leaching of silver sulfide, Xie et al. (2007) did further research investigating the application of ferricyanide to acanthite cyanidation. It was obvious that ferricyanide resulted in a great improvement to the extraction of silver according to their results. Firstly, stoichiometry tests were performed and the analysis results revealed that most of the sulfur in the mineral was oxidized to thiocyanate by ferric (Reaction 2-29). Part of thiocyanate was further oxidized to thiosulfate by oxygen in the solution (Reaction 2-30).

$$
\begin{array}{cc}
\mathrm{Ag}_{2} \mathrm{~S}+2 \mathrm{Fe}(\mathrm{CN})_{6}{ }^{3-}+5 \mathrm{CN}^{-}=2 \mathrm{Ag}(\mathrm{CN})_{2}{ }^{-}+2 \mathrm{Fe}(\mathrm{CN})_{6}{ }^{4-}+\mathrm{SCN}^{-} & \text {Reaction 2-29 } \\
2 \mathrm{SCN}^{-}+\mathrm{O}_{2}+2 \mathrm{OH}^{-}=\mathrm{S}_{2} \mathrm{O}_{3}{ }^{2-}+2 \mathrm{CN}^{-}+\mathrm{H}_{2} \mathrm{O} & \text { Reaction 2-30 }
\end{array}
$$

The kinetics of the ferric-cyanide leaching process was studied by the rotating-disk method. The concentration of $\mathrm{NaCN}$ was $0.5 \mathrm{~g} / \mathrm{L}$ and the dissolution rate of silver sulfide was raised from $13 \mu \mathrm{mol} / \mathrm{m}^{2} / \mathrm{s}(0.48 \mu \mathrm{m} / \mathrm{h})$ with only the aerated solution to $21 \mu \mathrm{mol} / \mathrm{m}^{2} / \mathrm{s}$ $(0.78 \mu \mathrm{m} / \mathrm{h})$ with addition of $0.5 \mathrm{~g} / \mathrm{L}$ ferricyanide as $\mathrm{Fe}^{3+}$. With the variation of leaching parameters, the process was proved to be mass transfer controlled while the Arrhenius activation energy was calculated to be $6.7 \mathrm{~kJ} / \mathrm{mol}$. The final silver extraction rose with the increase of cyanide and ferricyanide concentration. Furthermore, the ferricyanide/cyanide ratio was found to play an important role in determining the silver extraction rate. 
The effect of several typical non-silver sulfide minerals on the leaching kinetics of silver sulfide in ferricyanide-cyanide system was also investigated. With the comparison of the final silver extraction, Xie (2006) concluded that the presence of chalcopyrite and pyrrhotite did the most serious harm to the silver sulfide leaching while a small amount of pyrite, galena and sphalerite slightly decreased silver extraction. The solution potential record also revealed that, with the addition of other sulfide minerals, the potential dropped faster than pure acanthite leaching, indicating that the non-silver metal sulfide minerals also consumed ferricyanide.

According to Xie's conclusions, ferricyanide was an effective oxidant for the cyanidation of gold/silver minerals. It is economically applicable to high silver content gold ores and slow leaching minerals such as acanthite. A potential flowsheet for the cyanidation process with ferricyanide is shown in Figure 2-6.

The only concern regarding the application of ferricyanide in industry is the excessive consumption of ferricyanide by other reducing minerals in the ore (Xie, 2006). Therefore the economic balance of ferricyanide assisted cyanidation should be thoroughly assessed before practice. However, as shown in the flowsheet, the regeneration of ferricyanide from the final leaching solution may solve this problem. The conversion from ferrocyanide to ferricyanide via chemical or electrochemical methods may be further investigated to improve the ferricyanide leaching process. 


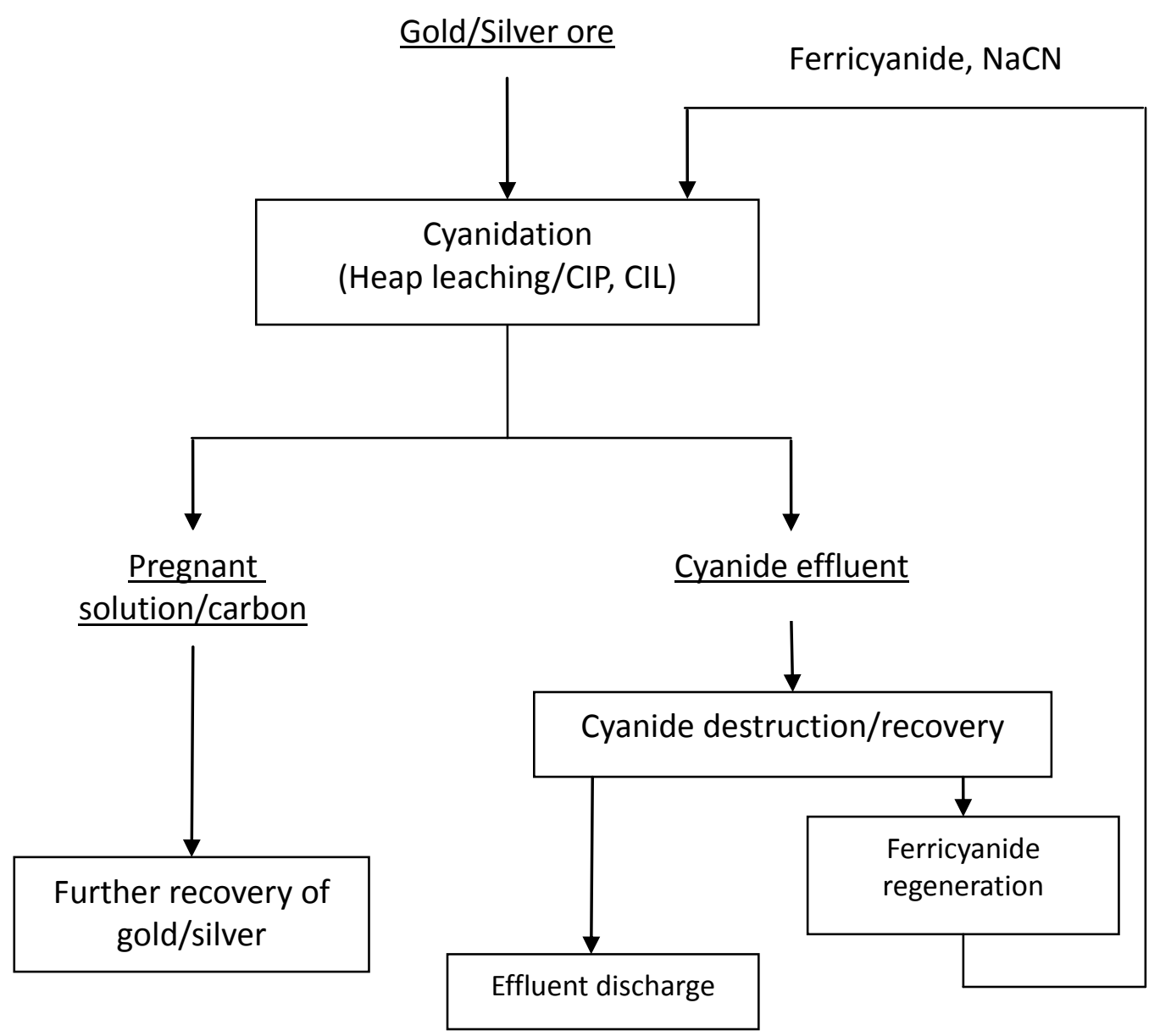

Figure 2-6 Simplified flowsheet for the application of ferricyanide in gold/silver cyanidation (Xie et al., 2007)

\subsubsection{Hydrogen Peroxide}

As a typical oxidizing agent, $\mathrm{H}_{2} \mathrm{O}_{2}$ could act as an oxidant in cyanidation of gold/silver ores (Arslan et al., 2003; Sun et al., 1993). Acting as an auxiliary oxidant, one of its advantages is that it can act as an oxidant itself to accelerate the reaction (Reaction 2-31, 2-32). Furthermore, its decomposition produces only oxygen and water (Reaction 2-33), increasing the oxygen in the alkaline solution without introducing new impurities (Zhang, 1995). In addition, the solubility in the cyanide solution is not a problem for $\mathrm{H}_{2} \mathrm{O}_{2}$.

$$
\mathrm{H}_{2} \mathrm{O}_{2}+2 \mathrm{e}=2 \mathrm{OH}^{-} \quad \mathrm{E}^{0}=1.01 \mathrm{~V}(\mathrm{SHE}) \quad \text { Reaction 2-31 }
$$




$$
\begin{array}{cr}
2 \mathrm{Au}+4 \mathrm{NaCN}+\mathrm{H}_{2} \mathrm{O}_{2}=2 \mathrm{NaAu}(\mathrm{CN})_{2}+2 \mathrm{NaOH} & \text { Reaction 2-32 } \\
\mathrm{H}_{2} \mathrm{O}_{2}=\mathrm{H}_{2} \mathrm{O}+1 / 2 \mathrm{O}_{2} & \text { Reaction 2-33 }
\end{array}
$$

Some practical operations with the addition of $\mathrm{H}_{2} \mathrm{O}_{2}$ to gold cyanidation process reflected that low concentration of $\mathrm{H}_{2} \mathrm{O}_{2}$ did not increase gold dissolution while too much addition caused the oxidation of cyanide to cyanate, inhibiting the complexing of cyanide with gold (Knorre et al., 1993; Knorre et al., 1994). However, there are still successful cases for the application of appropriate concentration $\mathrm{H}_{2} \mathrm{O}_{2}$ in gold ore cyanide leaching in both lab scale and real industry.

Guzman et al. (1999) investigated the chemical and electrochemical process during gold cyanidation in the presence of $\mathrm{H}_{2} \mathrm{O}_{2}$. With open circuit potential measurements, voltammetry and gold concentration detections, they tested different variables to study the electrochemical nature of the process. It was proved that at concentrations lower than $0.01 \mathrm{M}, \mathrm{H}_{2} \mathrm{O}_{2}$ did not oxidize free cyanide. Based on the electrochemical data, it was suggested that less than $0.0025 \mathrm{M} \mathrm{H}_{2} \mathrm{O}_{2}$ raised the mixed potential of gold cyanidation reaction to the region where gold passivation (formation of $\mathrm{AuCN}$ ) can take place, thus decreasing the gold cyanidation rate. However, with the increase of the $\mathrm{H}_{2} \mathrm{O}_{2}$ concentration, the potential moved to a higher value (more anodic). This potential was determined to be the transpassivation potential resulting in higher cyanidation velocity.

Several researches indicated that in the $\mathrm{H}_{2} \mathrm{O}_{2}$ assisted cyanidation process the main oxidant was $\mathrm{H}_{2} \mathrm{O}_{2}$. The generated $\mathrm{O}_{2}$ by $\mathrm{H}_{2} \mathrm{O}_{2}$ decomposition was likely not active since the oxidative potential was increaseed by $\mathrm{H}_{2} \mathrm{O}_{2}$ to a high extent (Knorre et al., 1993; Knorre et al., 1994). This was also proved by the findings of Guzman et al. (1999) that the performance of $\mathrm{H}_{2} \mathrm{O}_{2}$-cyanidation system was sensitive to $\mathrm{pH}$.

Enhanced cyanidation process with $\mathrm{H}_{2} \mathrm{O}_{2}$ addition has been performed for several years (Yang et al., 2003). Invented in 1987 by a Germany company Degussa, the Peroxide 
Assistant Leaching (PAL) process was applied by more than 20 plants all around the world. This process has the following advantages:

1. Accelerate cyanide leaching;

2. Be able to extract all the precious metals to improve their recovery;

3. Shorten the leaching time and reduce the capital cost.

However, too much $\mathrm{H}_{2} \mathrm{O}_{2}$ will oxidize free cyanide in the solution and thus retard leaching. Based on this, there was a method for the detoxification of waste cyanide solution with high concentration $\mathrm{H}_{2} \mathrm{O}_{2}$ before disposal (Marsden and House, 2006; Sarla et al., 2004).

\subsubsection{Calcium Peroxide}

$\mathrm{CaO}_{2}$, another common peroxide reagent, is also considered as an auxiliary oxidant for gold and silver cyanidation. The application of $\mathrm{CaO}_{2}$ as the replacement of $\mathrm{H}_{2} \mathrm{O}_{2}$ was first announced by a company named Interon in 1989 (Yang et al., 2003). The introduction of $\mathrm{CaO}_{2}$ into conventional cyanidation can not only enhance gold extraction, but can also reduce cyanide consumption. Compared to $\mathrm{H}_{2} \mathrm{O}_{2}$ assisted gold leaching, application of $\mathrm{CaO}_{2}$ is much cheaper and more convenient (Sun et al., 1993). The mechanism is claimed to be similar to the use of $\mathrm{H}_{2} \mathrm{O}_{2}$ cyanidation process. The only difference is that $\mathrm{CaO}_{2}$ can react with alkaline solution first and generate $\mathrm{H}_{2} \mathrm{O}_{2}$ (Reaction 2-34). The following reactions involving $\mathrm{H}_{2} \mathrm{O}_{2}$ are the same in the two systems. Another explanation is that since lime is usually used in the conventional cyanidation process to maintain the pulp $\mathrm{pH}$, the added $\mathrm{H}_{2} \mathrm{O}_{2}$ in PAL process will react with $\mathrm{Ca}(\mathrm{OH})_{2}$ and form $\mathrm{CaO}_{2}$. Therefore, the addition of $\mathrm{CaO}_{2}$ as auxiliary oxidant is just another form of PAL (Sun et al., 1993).

$$
\mathrm{CaO}_{2}+2 \mathrm{H}_{2} \mathrm{O}=\mathrm{Ca}(\mathrm{OH})_{2}+\mathrm{H}_{2} \mathrm{O}_{2} \quad \text { Reaction 2-34 }
$$

Another application of $\mathrm{CaO}_{2}$ to gold/silver ore cyanide leaching was reported by $\mathrm{Li}$ et al. 
(2001). With the addition of $0.75 \sim 1.5 \mathrm{~kg} / \mathrm{t} \mathrm{CaO}$, silver extraction was 5\% 30\% higher. Liu (2010) described the process to produce $\mathrm{CaO}_{2}$ in industry and did a series of comparative experiments about $\mathrm{CaO}_{2}$ assisted cyanidation of gold concentrate to better illustrate the effect of $\mathrm{CaO}_{2}$. The results are listed in Table 2-4.

Table 2-4 Leaching results with different auxiliary oxidants

\begin{tabular}{ccccc}
\hline Auxiliary oxidant & $\begin{array}{c}\text { Leaching time/ } \\
\text { hour }\end{array}$ & $\begin{array}{c}\text { Addition of } \\
\text { assisting oxidant/ } \\
\mathbf{k g / t}\end{array}$ & $\begin{array}{c}\text { Consumption } \\
\text { of NaCN/ }\end{array}$ & $\begin{array}{c}\text { Final gold } \\
\text { extraction/ }\end{array}$ \\
\hline Compressed air & 32 & 0 & 3 & $\%$ \\
$\mathbf{H}_{2} \mathbf{O}_{2}$ & 24 & 1.5 & 2 & 95.01 \\
$\mathbf{C a O}_{2}$ & 24 & 1.0 & 1 & 95.02 \\
\hline
\end{tabular}

Liu et al. (1998) did some comparisons between the ability of different peroxidants to increase oxygen content in cyanide solution and improve gold extraction. He noticed that dissolved oxygen content increased at the addition of oxidants including $\mathrm{H}_{2} \mathrm{O}_{2}$ and $\mathrm{CaO}_{2}$, which can be contributed to their decomposition reactions. He also observed that in the $\mathrm{CaO}_{2}$-cyanide systems, the oxygen content maintained at a stable level after $4 \mathrm{~h}$, while the $\mathrm{H}_{2} \mathrm{O}_{2}$-cyanide system displayed a higher initial oxygen content but a lower level after $4 \mathrm{~h}$ compared to that of $\mathrm{CaO}_{2}$-cyanide system. Therefore, $\mathrm{CaO}_{2}$ has the advantage of maintaining a stable oxygen level in solution.

Therefore, the main differences between $\mathrm{CaO}_{2}$ and $\mathrm{H}_{2} \mathrm{O}_{2}$ are summarized as the following:

1. Calcium peroxide is more stable in high $\mathrm{pH}$ solution;

2. Calcium peroxide has the advantage of maintaining a stable oxygen level in solution;

3. Calcium peroxide is a $\mathrm{pH}$ adjusting reagent itself, producing $\mathrm{Ca}(\mathrm{OH})_{2}$ and avoiding sharp drop of the pulp $\mathrm{pH}$; 
4. Calcium peroxide is stored and transported as solid, which is more convenient than the liquid $\mathrm{H}_{2} \mathrm{O}_{2}$.

However, there is a concern about $\mathrm{CaO}_{2}$. It has been reported that in $\mathrm{CaO}_{2}$ assisted cyanidation system gold recovery increased with the addition of $\mathrm{CaO}_{2}$ when $\mathrm{CaO}_{2}$ was lower than $0.4 \%$. If the $\mathrm{CaO}_{2}$ concentration continued to increase, gold extraction decreased (Liu et al., 1998).

\subsubsection{Lead Nitrate}

$\mathrm{Pb}\left(\mathrm{NO}_{3}\right)_{2}$ is commonly used as a promoter in gold cyanidation and its working mechanism has been investigated by numerous researchers. Different from the peroxides, $\mathrm{Pb}\left(\mathrm{NO}_{3}\right)_{2}$ is not treated as an oxidant and its main effect is believed to come from the function of lead ion in promoting leaching (Marsden and House, 2006).

Beyers was the first one who studied the effect of lead on gold leaching in 1936 (Jeffrey and Ritchie, 2000). Later researchers' work verified the conclusion that lead ion in the solution could enhance the cyanidation of gold. Fink and Putnam claimed that $6 \mathrm{ppm}$ of lead in the solution could increase the gold extraction by 4 times (Fink and Putnam, 1950). These findings attracted great interest in the working mechanism of lead in gold cyanidation.

It was proved that the formation of insoluble AuCN film on the surface of gold particles is one of the key limitations to gold extraction. Jeffrey and Ritchie (2000) pointed out that the main function of lead in the solution was to modify the surface by cementation to prevent passivation (Reaction 2-35).

$$
\mathrm{Pb}^{2+}+2 \mathrm{Au}+4 \mathrm{CN}^{-}=\mathrm{Pb}+2 \mathrm{Au}(\mathrm{CN})_{2}^{-} \quad \text { Reaction 2-35 }
$$

A more detailed explanation elucidating its function was provided by Sandenbergh and 
Miller (2001). They claimed that lead ion inhibited the formation of the passive layer by occupying sites on the surface, which prevented the cyanide from acting as a bidentate ligand which was necessary for the formation of the ...-Au-CN-Au-CN-... polymer.

In addition, there are some other explanations for the function of lead in the gold cyanidation process. Some researchers deduced that lead ion in the solution was reduced and formed an alloy with metallic gold. A galvanic cell circle was formed as shown in Figure 2-7, which accelerated the dissolution of gold (Wu et al., 2002).

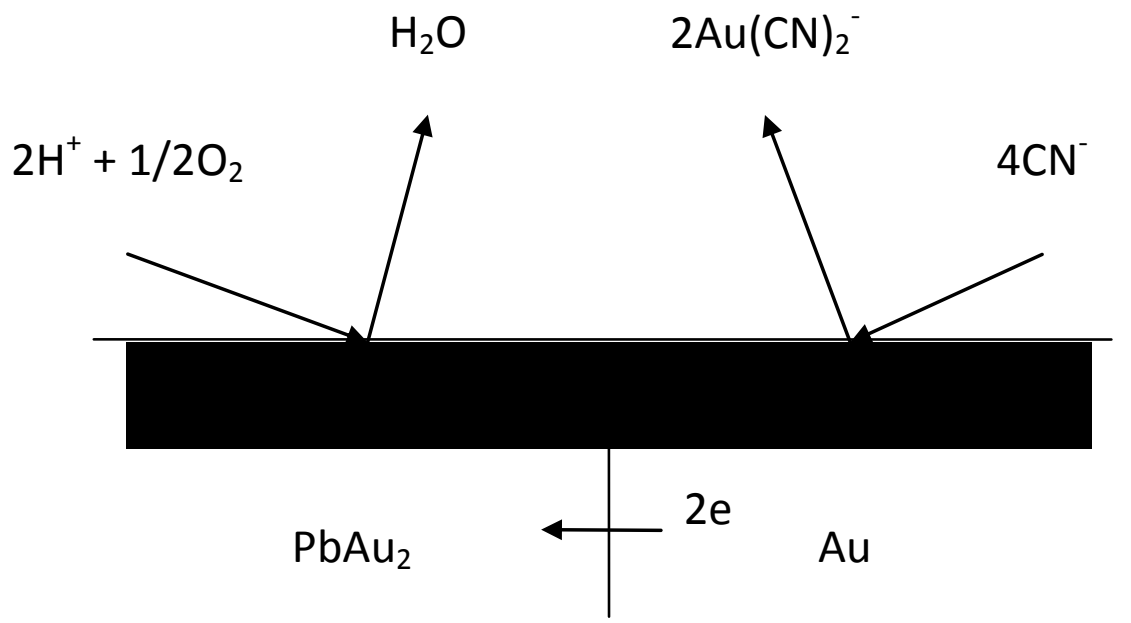

Figure 2-7 Schematic diagram of primary cell reaction

According to Jeffrey and Ritchie's (2000) electrochemical analysis, once lead was present in the solution the over-potential required for the oxidation of gold was reduced and the reduction of oxygen was also enhanced. This was reasonable since with lead cemented on the particle surface, a bimetallic corrosion cell could be established. Thus, oxygen could reduce preferentially at the active lead sites. Dai and Breuer (2013) reported that both anodic and cathodic reactions were enhanced by the under-potential deposition of lead onto the solid surface in saturated cyanide solution. More specifically, potentiostatic polarization experiments performed by Tshilombo et al. (2001) indicated that the effect of the lead came from the interaction of a soluble lead species with the passive layer, not the 
reduction of lead ion to metallic lead. Moreover, it was claimed that the improvement by addition of lead was only obvious in high cyanide/oxygen ratio systems (Tshilombo et al., 2001).

In another study, it was found that if there was sulfide ion in the solution, the enhancement on the leaching process was based on a different mechanism. When leaching sulfide minerals with cyanide, sulfide oxidation by oxygen was catalyzed with the presence of lead ion. The role of lead was to promote the precipitation of $\mathrm{PbS}$ and enhance the anodic oxidation of gold via a gold-lead alloy film. The addition of galena to the cyanide solution containing chalcocite was proved to impact the process in the same way as the addition of lead nitrate (Dai and Jeffrey, 2006).

Breuer et al. (2008) found that in cyanide solution containing sulfide ion, the oxidation of sulfide ion was quite slow while in the presence of lead ion, sulfide concentration decreased rapidly with the formation of thiocyanate. It was suspected that the precipitated lead sulfide provided a surface for electron transfer in the oxidation of sulfide ion (Reaction 2-36).

$$
\mathrm{PbS}+\mathrm{CN}^{-}+1 / 2 \mathrm{O}_{2}+\mathrm{H}_{2} \mathrm{O}=\mathrm{Pb}^{2+}+\mathrm{SCN}^{-}+2 \mathrm{OH}^{-} \quad \text { Reaction 2-36 }
$$

With the analysis of sulfur species in the cyanide solution, polysulfides were found as intermediate oxidation products of sulfide oxidation. They were further oxidized to thiosulfate and sulfite (Reaction 2-37 2-41).

$$
\begin{array}{cr}
2 \mathrm{~S}^{2-}+1 / 2 \mathrm{O}_{2}+\mathrm{H}_{2} \mathrm{O}=\mathrm{S}_{2}{ }^{2-}+2 \mathrm{OH}^{-} & \text {Reaction 2-37 } \\
\mathrm{S}_{\mathrm{x}-1}{ }^{2-}+\mathrm{S}^{2-}+1 / 2 \mathrm{O}_{2}+\mathrm{H}_{2} \mathrm{O}=\mathrm{S}_{\mathrm{x}}{ }^{2-}+2 \mathrm{OH}^{-} & \text {Reaction 2-38 } \\
\mathrm{S}_{\mathrm{x}}{ }^{2-}+\mathrm{CN}^{-}=\mathrm{SCN}^{-}+\mathrm{S}_{\mathrm{x}-1}{ }^{2-} & \text { Reaction 2-39 } \\
\mathrm{S}_{\mathrm{x}}{ }^{2-}+\mathrm{O}_{2}+2 \mathrm{OH}^{-}=\mathrm{S}_{2} \mathrm{O}_{3}{ }^{2-}+\mathrm{S}_{\mathrm{x}-2}{ }^{2-}+\mathrm{H}_{2} \mathrm{O} & \text { Reaction 2-40 } \\
\mathrm{S}_{\mathrm{x}}{ }^{2-}+\mathrm{O}_{2}+2 \mathrm{OH}^{-}=\mathrm{SO}_{3}{ }^{2-}+\mathrm{S}_{\mathrm{x}-1}{ }^{2-}+\mathrm{H}_{2} \mathrm{O} & \text { Reaction 2-41 }
\end{array}
$$

Regarding cyanidation of silver sulfide, direct leaching of acanthite, stephanite and 
pyrargyrite yielded low silver recovery. However, with the addition of lead nitrate, the final silver extraction was greatly improved (Deschenes et al., 2011). Deschenes and his colleagues found that in silver sulfide cyanidation polysulfides were formed on the surface of minerals, limiting the dissolution of silver. They added a pretreatment step with lead nitrate addition prior to the conventional acanthite cyanidation. Silver recovery was raised to $86 \%$. Direct addition of lead nitrate to the cyanide leaching process dissolved $98 \%$ of stephanite. In sulfur species analysis, no polysulfide was found with the lead nitrate addition. They also tried $500 \mathrm{ppm} \mathrm{NaCN}$ and $250 \mathrm{~g} / \mathrm{t}$ lead nitrate on high grade Kupol concentrate. The improvement of silver extraction by lead nitrate addition was congruent with the former tests on high grade acanthite, stephanite and pyrargyrite.

\subsubsection{LeachWELL LM $^{\text {TM }}$}

Nowadays there is a new gold assay method in several analytical labs, called LeachWELL ${ }^{\mathrm{TM}}$ Technique. It is a process consisting of intense cyanide leaching with the addition of a chemical named LeachWELL ${ }^{\mathrm{TM}}$ (Elder, 2000).

LeachWELL ${ }^{\mathrm{TM}}$ is a registered trademark product that provides accelerated extraction of gold, silver and other cyanide leachable metals. It was initially developed by David Menne and marketed by an Australian company named Mineral Process Control. It is described as a mild oxidant and simply provides the oxygen for the leaching (MPC PTY LTD website, 2013). According to the information provided by its supplier, LeachWELL $^{\mathrm{TM}}$ comes as small granules, about $4-6 \mathrm{~mm}$ in diameter, and it is reasonably soluble in cyanide solution. It consists of approximately 2 percent of lead nitrate and 98 percent of a mild organic oxidant (Copper, 2012).

Some studies on the application of LeachWELL ${ }^{\mathrm{TM}}$ have proved its efficiency on gold cyanidation. LeachWELL ${ }^{\mathrm{TM}}$ has critical effects on controlling the leaching of natural ores (Gray et al., 1999). In Gray's report, it was clear that the use of LeachWELL ${ }^{\mathrm{TM}}$ led to a 
suppression of copper leaching and an acceleration of gold leaching. The cyanide consumption was also reduced by a factor.

However, no report about the application of LeachWELL ${ }^{\mathrm{TM}}$ to silver mineral cyanidation process could be found. The effect of LeachWELL ${ }^{\mathrm{TM}}$ on cyanidation of acanthite is worth investigating.

\subsubsection{Alternative Methods and Additives}

Bubbling air/oxygen in tank leaching is another common method to improve cyanide leaching (Marsden and House, 2006). Air or pure oxygen can be introduced into cyanide solution purely for aeration or sparged into tanks as the primary method of agitation. In each system the main goal is to guarantee sufficient oxygen with satisfactory bubble dispersion. It is reported that the dissolved oxygen concentrations can be maintained at calculated saturation levels with air sparging (i.e., $8.2 \mathrm{mg} / \mathrm{L} \mathrm{O}_{2}$ at sea level at $25^{\circ} \mathrm{C}$ ). Furthermore, the optimum sparging system depends on the geometry of the leach tanks. In a few cases that deal with the oxygen-consuming minerals, pure oxygen can be used (Marsden and House, 2006).

Also, the exploration for a new oxidant to replace oxygen in cyanidation never stops. There is another idea that uses potassium permanganate as an oxidant in the cyanide leaching system. Permanganate is not as oxidizing as $\mathrm{H}_{2} \mathrm{O}_{2}$, but it possesses a higher reduction potential than dissolved $\mathrm{O}_{2}$ (Reaction 2-42). Its function in assisting gold cyanidation can be expressed as Reaction 2-43.

$$
\begin{array}{ccc}
\mathrm{MnO}_{4}{ }^{-}+2 \mathrm{H}_{2} \mathrm{O}+3 \mathrm{e}=\mathrm{MnO}_{2}+4 \mathrm{OH}^{-} & \mathrm{E}^{0}=0.56 \mathrm{~V}(\mathrm{SHE}) & \text { Reaction 2-42 } \\
3 \mathrm{Au}+6 \mathrm{CN}^{-}+\mathrm{MnO}_{4}{ }^{-}+2 \mathrm{H}_{2} \mathrm{O}=3 \mathrm{Au}(\mathrm{CN})_{2}{ }^{-}+4 \mathrm{OH}^{-}+\mathrm{MnO}_{2} & \text { Reaction 2-43 }
\end{array}
$$

Permanganate can eliminate the obstacle of the oxygen diffusion from air to solution and alleviate oxidation of free cyanide by a strong oxidant such as $\mathrm{H}_{2} \mathrm{O}_{2}$. Zhang et al. (1997) 
studied cyanide leaching of a gold concentrate with the assistance of $\mathrm{CaO}_{2}$ and potassium permanganate mixed in weight proportion 4:1. The gold recovery was improved by $10.28 \%$. Leaching time and cyanide consumption were reduced by $40 \%$ and $50 \%$, respectively. The improvement was attributed to the increase of hydroxyl radical in the system.

There are still other options to increase gold/silver extraction and reduce leaching time. However, none of these methods are universally suitable for all of the minerals. The application of additives and assistant operations should take mineralogy and mineral composition into consideration for better recovery of the valuable metals and less leaching time. Furthermore, the evaluation of the capital and operating financing availability is necessary in industry practice. 


\section{Chapter 3 Cyanidation of Synthetic Silver}

\section{Sulfide with Auxiliary Oxidants}

\subsection{Introduction}

As indicated, oxygen is not an effective oxidant for silver sulfide cyanidation (Luna-Sanchez and Lapidus, 2000). Therefore, the objective of this project is to find suitable auxiliary additives to improve cyanide leaching of silver sulfide. Hydrogen peroxide $\left(\mathrm{H}_{2} \mathrm{O}_{2}\right)$, calcium peroxide $\left(\mathrm{Ca}_{2} \mathrm{O}\right)$ and LeachWELL ${ }^{\mathrm{TM}}$ (a commercial silver extraction enhancement product) are the objects of testing.

The performances of the candidates of auxiliary oxidants on silver extraction from $\mathrm{Ag}_{2} \mathrm{~S}$ were assessed in batch leaching tests. In addition to silver extraction, the assessment on reagent consumption of the complexing agent $(\mathrm{NaCN})$ and alkali $(\mathrm{NaOH})$, for $\mathrm{pH}$ adjustment, were also conducted to further evaluate their potential applicability in economical production.

In this chapter, leaching of synthetic $\mathrm{Ag}_{2} \mathrm{~S}$ in aerated solution (section 3.3.1) was performed and was used as a baseline to compare with leaching with addition of $\mathrm{H}_{2} \mathrm{O}_{2}$, $\mathrm{CaO}_{2}$ and LeachWELL ${ }^{\mathrm{TM}}$ (section 3.3.2). Through comparison between these three auxiliary oxidants, LeachWELL ${ }^{\mathrm{TM}}$ was proved the most appropriate choice. Therefore, variation tests on LeachWELL ${ }^{\mathrm{TM}}$ assisted leaching were conducted as well as a blank test which evaluated the consumption of $\mathrm{NaCN}$ and $\mathrm{NaOH}$ in LeachWELL ${ }^{\mathrm{TM}}$-cyanide system (Chapter 3.3.3). In addition, as a known component of LeachWELL ${ }^{\mathrm{TM}}$, lead nitrate was also added into the system separately to justify its effect on silver extraction (Chapter 3.3.4). 


\subsection{Experimental Set-up}

\subsubsection{Samples and Reagents}

(a) Synthetic $\mathrm{Ag}_{2} \mathrm{~S}$ Minerals

Tests were conducted on synthetic acanthite minerals. The synthetic acanthite was $99.998 \%$ Silver sulfide, Premion ${ }^{\circledR}$, from Alfa Aesar. To ensure the consistency of particle size, synthetic $\mathrm{Ag}_{2} \mathrm{~S}$ was ground and sieves were used to sieve out particles larger than $45 \mu \mathrm{m}$. The result of P80 particle distribution analysis showed (Figure 3-1) that the P80 of the synthetic $\mathrm{Ag}_{2} \mathrm{~S}$ samples was $~ 37 \mu \mathrm{m}$.

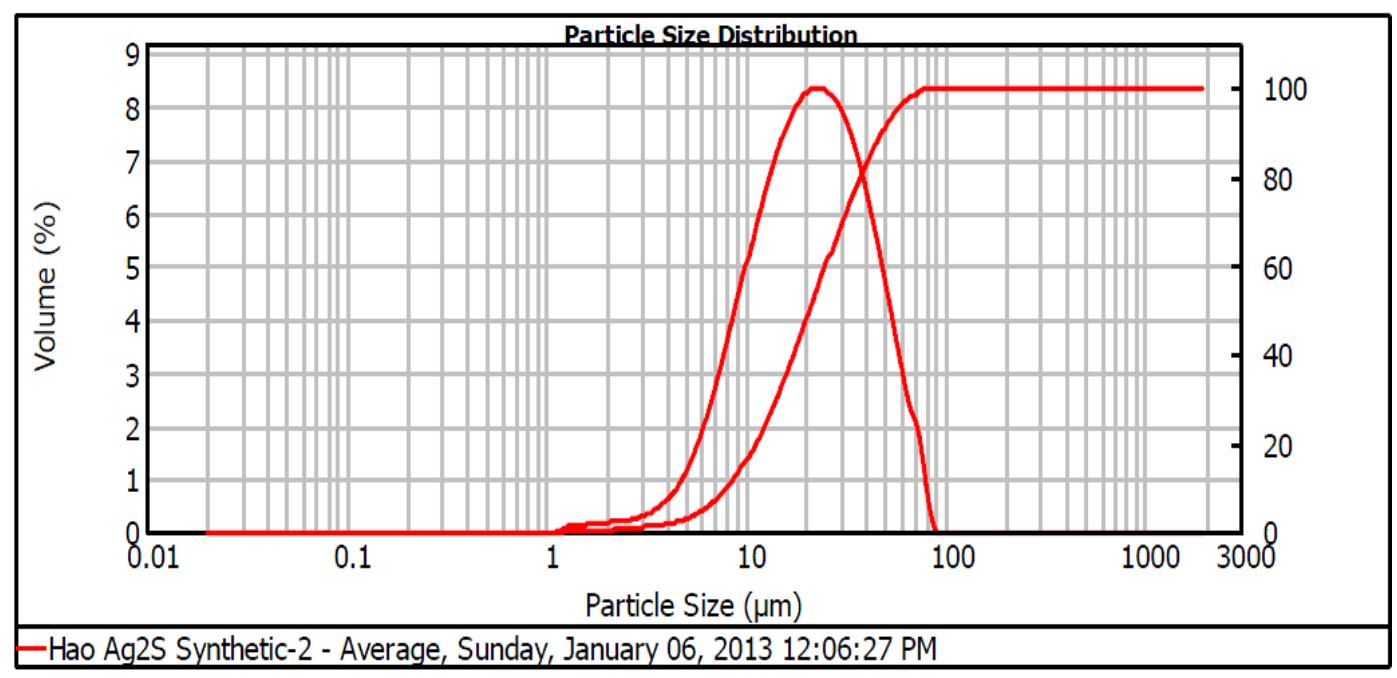

Figure 3-1 Particle size distribution curve of synthetic $\mathrm{Ag}_{2} \mathrm{~S}$ solid

(b) Reagents

Lead nitrate ( $>99.99 \%$ trace metals basis) and $75 \%$ calcium peroxide $\mathrm{CaO}_{2}$ (with the other $25 \%$ as calcium oxide) were purchased from Sigma Aldrich. The source of free cyanide was $\mathrm{NaCN}$ (Granular/Certified ACS). Both $\mathrm{NaCN}$ and $\mathrm{H}_{2} \mathrm{O}_{2}$ (certificated ACS $30 \%$ ) used came from Fisher Chemical. LeachWELL ${ }^{\mathrm{TM}}$ was provided by Mineral Process Control (MPC) Pty Ltd. 
The solution used in each test was made from de-ionized water and all of the other chemicals used in this study were certified analytical grade chemicals.

\subsubsection{Leaching Conditions}

The silver grade in common silver sulfide concentrates is normally in the range of $\sim 200 \mathrm{~g}$ silver per tonne and the pulp density in the industrial tank leaching is between $30 \% \sim 50 \%$. Assuming that all of the silver was present as silver sulfide, the concentration of silver in the pulp was:

$$
\begin{aligned}
& 200 \mathrm{~g} \mathrm{Ag} / \text { tonne ore } \times \text { 40tonne ore/100tonne pulp } \\
= & 8000 \mathrm{~g} \mathrm{Ag} / 100 \text { tonne pulp } \\
= & 0.08 \mathrm{~g} \mathrm{Ag} / 1 \mathrm{~kg} \text { pulp }
\end{aligned}
$$

Since the density of weak cyanide solution is $\sim 1 \mathrm{~kg} / \mathrm{L}$, the silver content as silver sulfide was calculated as:

$0.08 \mathrm{~g} \mathrm{Ag} / \mathrm{kg}$ pulp $\times 1 \mathrm{~kg}$ pulp $=0.08 \mathrm{~g} \mathrm{Ag}$

This value can be converted from a silver basis to a pure silver sulfide basis:

$$
0.08 \mathrm{~g} \mathrm{Ag} \times 248 \mathrm{~g} \mathrm{Ag}_{2} \mathrm{~S} / 216 \mathrm{~g} \mathrm{Ag}=0.092 \mathrm{~g} \mathrm{Ag}_{2} \mathrm{~S}
$$

Based on the above calculations the synthetic silver sulfide content in the studied system was set as $0.1 \mathrm{~g}$.

\section{a) Synthetic silver sulfide leaching in aerated solution}

Leaching of synthetic silver sulfide in aerated solution (Section 3.3.1) was performed in duplicate to justify the repeatability of the applied apparatus and procedure. The leaching conditions were described in Table 3-1. 
Table 3-1 Leaching conditions of baseline experiment

\begin{tabular}{|c|c|}
\hline Volume of solution & $1 \mathrm{~L}$ \\
\hline Solid & $0.1 \mathrm{~g}$ synthetic $\mathrm{Ag}_{2} \mathrm{~S}$ \\
\hline Solution pH & 12 \\
\hline Temperature & Room temperature, $17^{\circ} \mathrm{C}\left( \pm 3^{\circ} \mathrm{C}\right)$ \\
\hline Atmosphere & Air \\
\hline Rotation speed & $500 \mathrm{rpm}$ \\
\hline Leaching Time & $60 \mathrm{hr}$ \\
\hline NaCN & $0.5 \mathrm{~g} / \mathrm{L}$ \\
\hline
\end{tabular}

\section{b) Synthetic silver sulfide cyanidation with auxiliary oxidants}

Cyanide leaching experiments of synthetic silver sulfide were conducted with different additions of $\mathrm{H}_{2} \mathrm{O}_{2}, \mathrm{CaO}_{2}$ and LeachWELL ${ }^{\mathrm{TM}}$ (Section 3.3.2). The tested contents of these three oxidants were summarized as following:

- $\mathrm{H}_{2} \mathrm{O}_{2}: 0.01 \mathrm{~mol} / \mathrm{L}, 0.05 \mathrm{~mol} / \mathrm{L}, 0.1 \mathrm{~mol} / \mathrm{L}$

- $\mathrm{CaO}_{2}: 0.001 \mathrm{~mol} / \mathrm{L}, 0.005 \mathrm{~mol} / \mathrm{L}, 0.01 \mathrm{~mol} / \mathrm{L}, 0.05 \mathrm{~mol} / \mathrm{L}, 0.1 \mathrm{~mol} / \mathrm{L}, 0.15 \mathrm{~mol} / \mathrm{L}$

- LeachWELL ${ }^{\mathrm{TM}}: 0.2 \mathrm{~g} / \mathrm{L}, 0.5 \mathrm{~g} / \mathrm{L}, 0.8 \mathrm{~g} / \mathrm{L}$

Except for the presence of auxiliary oxidants, these leaching tests were conducted under conditions shown in Table 3-1.

\section{c) Variables on LeachWELL ${ }^{\mathrm{TM}}$ leaching}

LeachWELL ${ }^{\mathrm{TM}}$, s performance was further evaluated by additional tests with variations in pulp $\mathrm{pH}$, temperature and cyanide concentration. The concentration of LeachWELL ${ }^{\mathrm{TM}}$ was held constant at $0.2 \mathrm{~g} / \mathrm{L}$ in each leaching test and the variables are summarized as following: 
Table 3-2 Leaching conditions of variation tests of LeachWELL ${ }^{\text {TM }}$

\begin{tabular}{|c|c|}
\hline Volume of solution & $1 \mathrm{~L}$ \\
\hline Solid & $0.1 \mathrm{~g}$ synthetic $\mathrm{Ag}_{2} \mathrm{~S}$ \\
\hline Solution pH & $10.5,11,11.5,12$ \\
\hline Temperature & $17^{\circ} \mathrm{C}\left( \pm 3^{\circ} \mathrm{C}\right), 30^{\circ} \mathrm{C}, 40^{\circ} \mathrm{C}$ \\
\hline Atmosphere & Air \\
\hline Rotation speed & $500 \mathrm{rpm}$ \\
\hline Leaching Time & $60 \mathrm{hr}$ \\
\hline NaCN & $0.25 \mathrm{~g} / \mathrm{L}, 0.5 \mathrm{~g} / \mathrm{L}, 0.75 \mathrm{~g} / \mathrm{L}, 1.0 \mathrm{~g} / \mathrm{L}, 1.5 \mathrm{~g} / \mathrm{L}, 2.0 \mathrm{~g} / \mathrm{L}$, \\
& $3.0 \mathrm{~g} / \mathrm{L}$ \\
\hline
\end{tabular}

\section{d) Investigation on LeachWELL ${ }^{\mathrm{TM}}$-cyanide system}

Two blank tests were designed for the evaluation of blank $\mathrm{NaCN}$ and $\mathrm{NaOH}$ consumption in LeachWELL ${ }^{\mathrm{TM}}$-cyanide system.

$\mathrm{Pb}\left(\mathrm{NO}_{3}\right)_{2}$ assisted leaching were conducted under the same conditions described in Table 3-1 except the pulp pH was controlled at 11 . The tested $\mathrm{Pb}\left(\mathrm{NO}_{3}\right)_{2}$ concentrations were $0.004 \mathrm{~g} / \mathrm{L}$ and $0.01 \mathrm{~g} / \mathrm{L}$.

\subsubsection{Experimental Procedure}

The leaching tests were conducted in 2L PYREX glass beakers with rubber stoppers. There were several openings not only for exposure to air, but also for the overhead agitator, reagent injection, sampling tubes and $\mathrm{Eh} / \mathrm{pH}$ probes. An automatic motor connected with stainless impellers agitated the solution, providing essential mixing for the leaching system. A picture of the experimental setup is shown as Figure 3-2. 


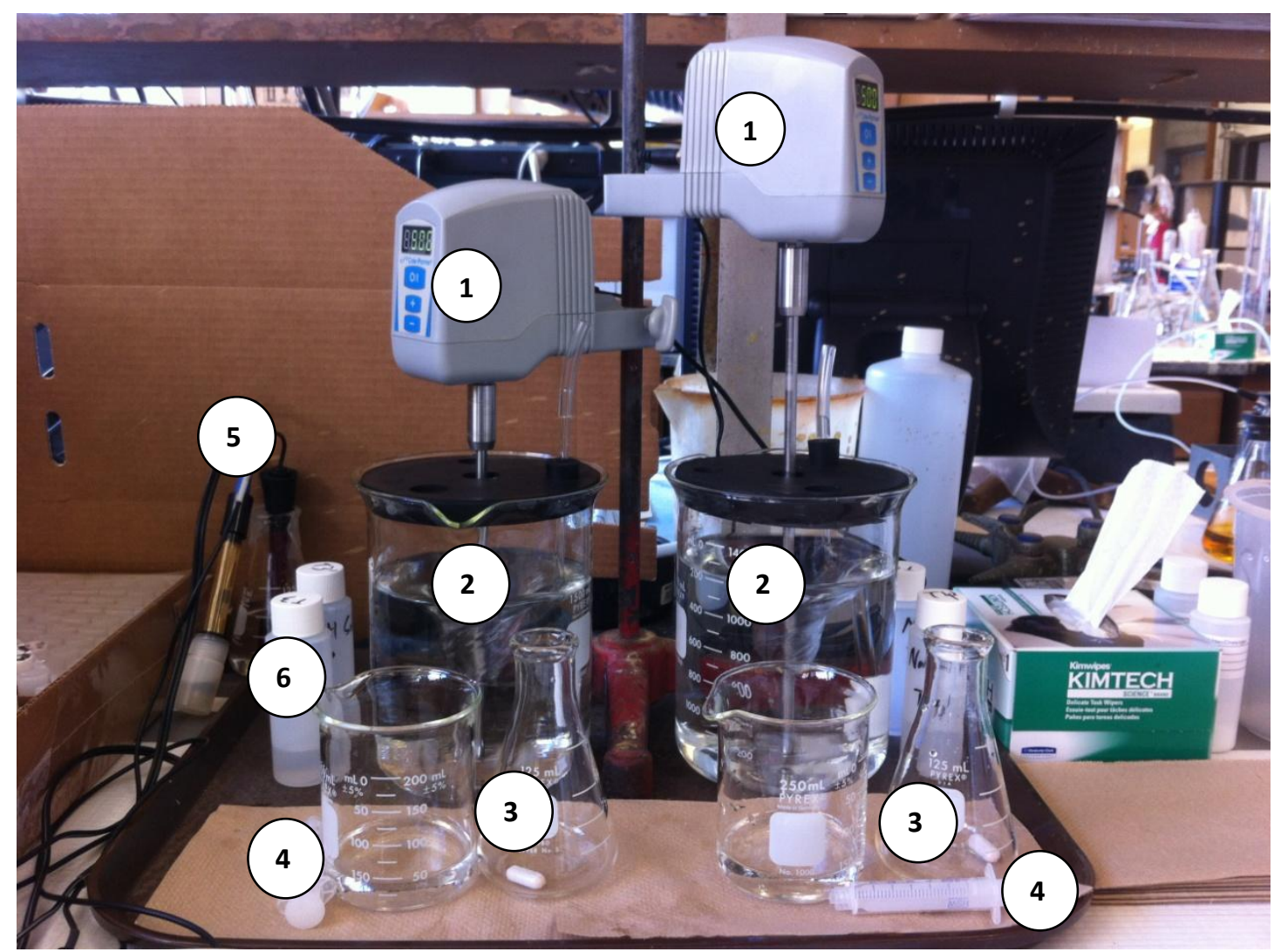

Figure 3-2 Experimental apparatus for leaching tests

(1-Amotic motor; 2-Reactor beaker; 3-conical flask; 4-Syringe; 5-pH and Eh probe; 6-Supplimentary $\mathrm{NaOH}$ solution)

The calculated amount of chemicals such as $\mathrm{NaCN}$, oxidants and well prepared synthetic $\mathrm{Ag}_{2} \mathrm{~S}$ were added into the agitated sodium hydroxide solution at the beginning of each test. Each test lasted 60 hours and sampling time was set at 0.5 hr, 1 hr, 2 hr, 4 hr, 8 hr, 12 $\mathrm{hr}, 24 \mathrm{hr}, 36 \mathrm{hr}, 48 \mathrm{hr}$ and $60 \mathrm{hr}$. Each 5ml sample was drawn with syringe and 20- $\mu \mathrm{m}$ polyethylene in-solution filter. An equivalent volume of fresh solution with the same composition of the initial leaching solution was added after each sampling.

At each sampling time, the oxidation-reduction potential (ORP) of the solution was measured with a standardized $\mathrm{Ag} / \mathrm{AgCl}$ probe. The $\mathrm{pH}$ was also measured via a standard $\mathrm{pH}$ probe with an OAKTON pH 11 meter calibrated with standard $\mathrm{pH}$ buffer solution. Because of cyanide loss and introduction of $\mathrm{CO}_{2}$ into the solution, the pulp $\mathrm{pH}$ decreased during the leaching process. Stringent control over $\mathrm{pH}$ was achieved by addition of $2 \mathrm{M}$ 
sodium hydroxide solution to maintain the $\mathrm{pH}$ at target value. The amount of the sodium hydroxide solution addition was recorded and used to calculate the $\mathrm{NaOH}$ consumption.

The consumption of $\mathrm{NaCN}$ was also a key parameter when choosing the appropriate oxidant. Each sample was titrated by standardized silver nitrate as soon as it was taken out in order to detect the concentration of free cyanide that remained in the solution. After titration, the amount of free cyanide in the solution was calculated and supplementary $\mathrm{NaCN}$ solid was added into the leach solution. The amount of supplementary $\mathrm{NaCN}$ was recorded as the consumption of $\mathrm{NaCN}$.

At the end of each test, the volume of the final leaching solution was measured for calculation of final silver extraction. In addition, the solution samples were analyzed (where required) with Atomic Absorption Spectrophotometer (AAS) for silver concentration.

\subsubsection{Analysis}

The Atomic Absorption Spectrophotometer (AAS) instrument was used to measure the concentrations of silver in samples taken from the leaching tests. The free cyanide contents in solution were analyzed by titration method summarized in Appendix B.

\subsection{Results and Discussion}

\subsubsection{Synthetic Silver Sulfide Leaching in Aerated Cyanide}

\section{Solution}

Leaching of synthetic pure silver sulfide in aerated cyanide solution was performed twice as baseline experiments. In these tests, the only oxidant in the system was dissolved oxygen. The result was treated as a baseline to compare with the following enhanced 
leaching system. Furthermore, these baseline tests could prove the reliability of the experimental apparatus and procedure.

The silver extraction from synthetic $\mathrm{Ag}_{2} \mathrm{~S}$ over a 60 hour period is shown in Figure 3-3.

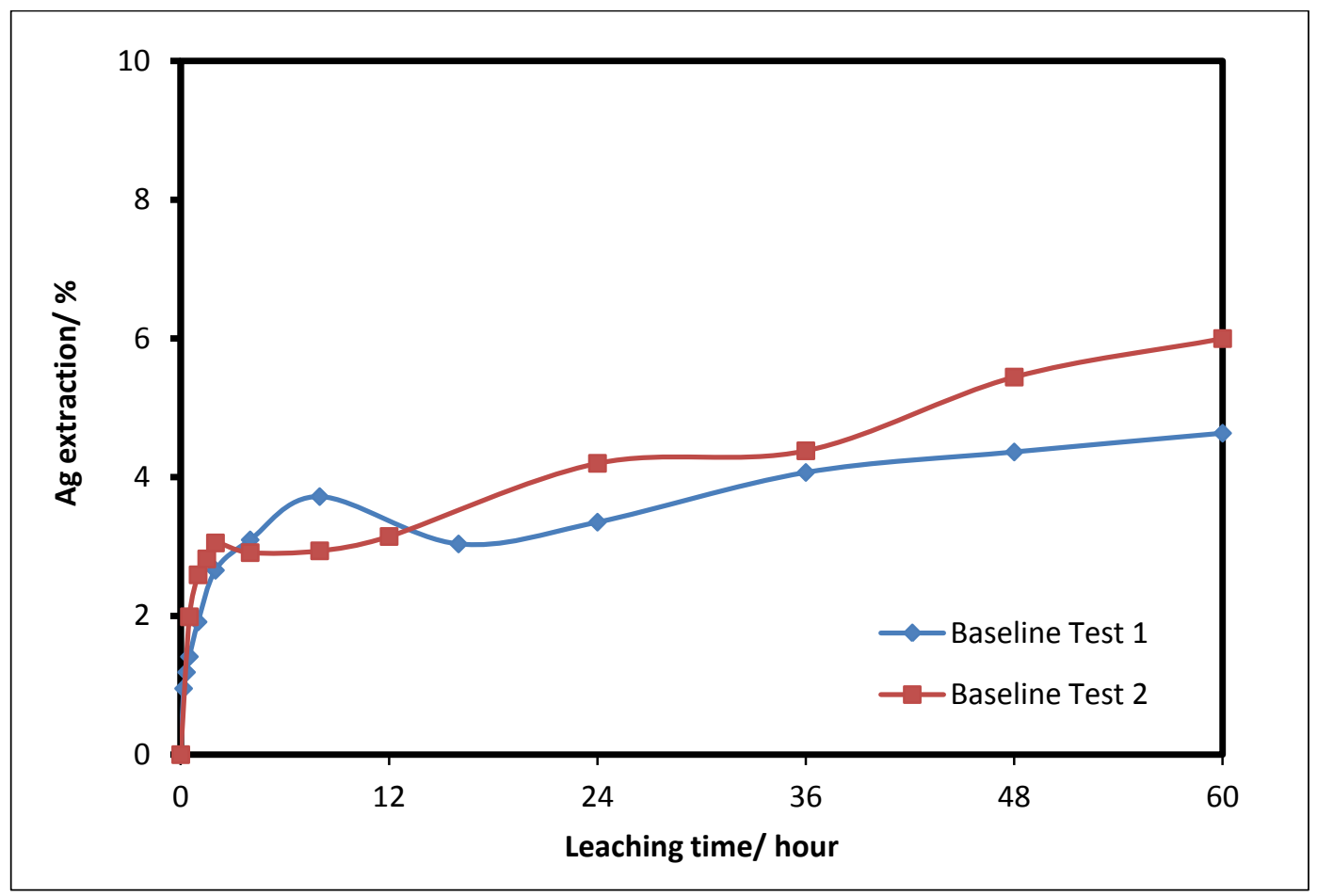

Figure 3-3 Ag extraction vs leaching time in baseline experiments

$(0.5 \mathrm{~g} / \mathrm{L} \mathrm{NaCN}, \mathrm{pH}=12$, room temperature, $500 \mathrm{rpm})$

Considering the low pulp density of the system and the accuracy of the AAS it can be concluded that the baseline experiments had a good reproducibility.

In these two tests, dissolved $\mathrm{O}_{2}$ was the only oxidant. Figure 3-3 showed that final extraction of silver was only $\sim 5 \%$ after 60 hours. This result confirmed that it was difficult to extract silver from silver sulfide by the conventional cyanidation processes. As mentioned before, low Ag extraction could be caused by the low solubility of silver sulfide in cyanide solution and the slow kinetics of oxygen reduction in this system.

These two experiments also provided the baseline for the consumption of $\mathrm{NaCN}$ and 
$\mathrm{NaOH}$ in synthetic silver sulfide leaching process (Table 3-3). The potential of the solution after 60 hour leaching was also recorded (Figure 3-4).

Table 3-3 Auxiliary parameters of baseline experiments

\begin{tabular}{lccc}
\hline & Baseline test 1 & Baseline test 2 & Average \\
\hline $\mathrm{NaCN}$ Consumption/g & 0 & 0 & 0 \\
$\mathrm{NaOH}$ Consumption/g & 1.4681 & 2.2816 & 1.88 \\
\hline
\end{tabular}

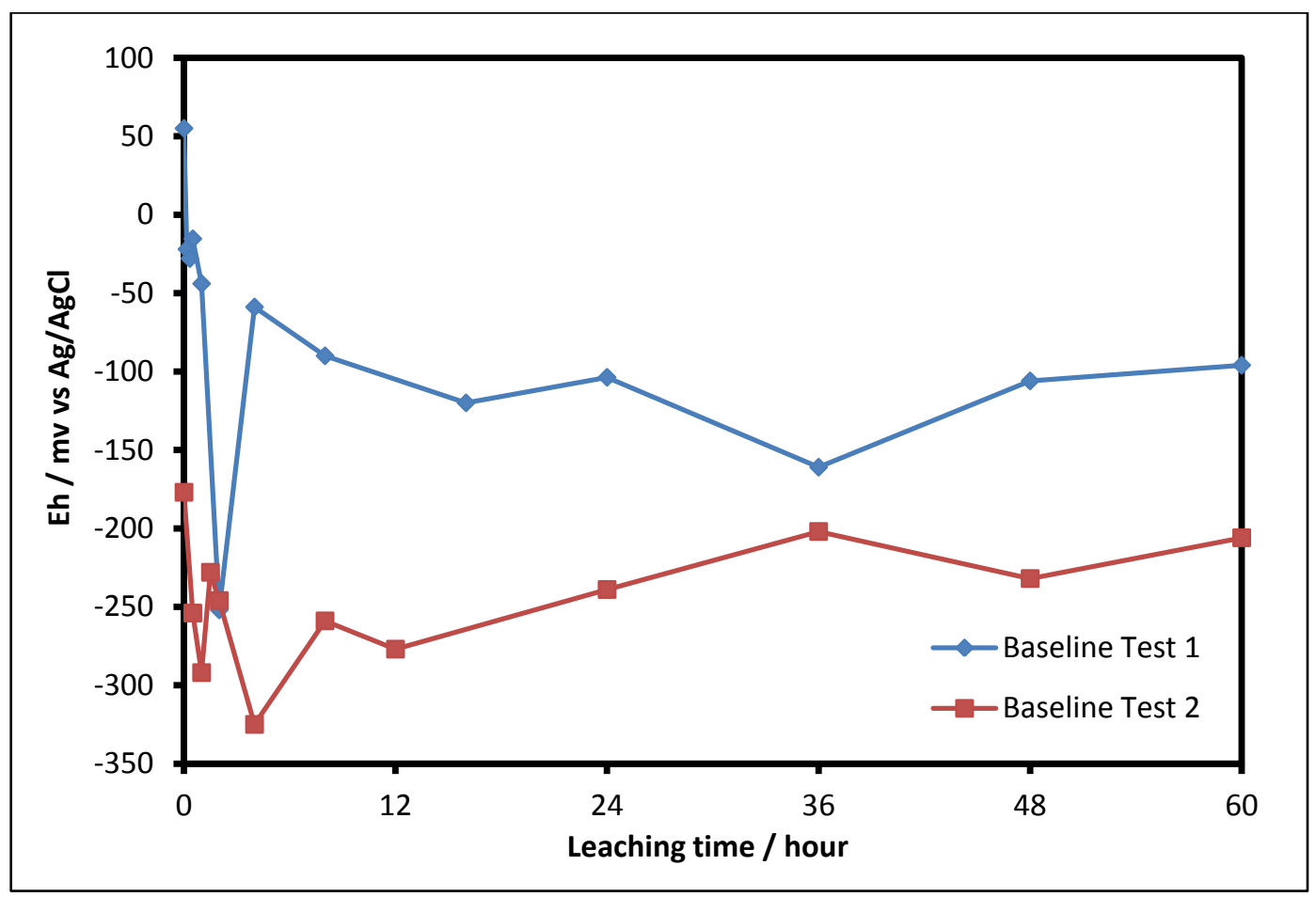

Figure 3-4 Pulp potential vs leaching time in baseline experiments (0.5 $\mathrm{g} / \mathrm{L} \mathrm{NaCN}, \mathrm{pH}=12$, room temperature, $500 \mathrm{rpm})$

It was shown by Table 3-3 that in baseline tests, with reasonable titration accuracy, no supplementary $\mathrm{NaCN}$ was needed. Combined with the fact that the dissolved silver was rather low and pulp $\mathrm{pH}$ was maintained at a high level, the loss of $\mathrm{CN}^{-}$by $\mathrm{HCN}$ volatilization and combination with dissolver silver under these conditions were negligible. In these baseline experiments the mean value of the consumption of solid $\mathrm{NaOH}$ was $1.88 \mathrm{~g}$, which was higher than the expected value. This was mainly because the $\mathrm{pH}$ was maintained at 12 , which was higher than that used in industrial practice. In 
the following comparison the average values of the $\mathrm{NaCN}$ and $\mathrm{NaOH}$ baseline consumption were applied.

The low solubility of oxygen in high $\mathrm{pH}$ pulp and the existence of a reducing sulfide mineral in the system could explain the low pulp potential shown in Figure 3-4. The low pulp density in these leaching systems could result to less accuracy of the potential measurement, causing the variation of these two curves.

From the results of the baseline experiments, it was obvious that finding auxiliary oxidants to enhance the dissolution of $\mathrm{Ag}_{2} \mathrm{~S}$ in cyanide solution was necessary. Therefore evaluation of several oxidants is shown in the following section.

\subsubsection{Silver Sulfide Cyanidation with Auxiliary Oxidants}

\subsubsection{Hydrogen Peroxide}

Small amounts of $\mathrm{H}_{2} \mathrm{O}_{2}$ are often used as a strong acidic liquid oxidant. Referring to the gold cyanidation process using $\mathrm{H}_{2} \mathrm{O}_{2}$ (Guzman et al., 1999), the concentrations of $\mathrm{H}_{2} \mathrm{O}_{2}$ in the following tests were $0.34 \mathrm{~g} / \mathrm{L}(0.01 \mathrm{~mol} / \mathrm{L}), 1.7 \mathrm{~g} / \mathrm{L}(0.05 \mathrm{~mol} / \mathrm{L})$ and $3.4 \mathrm{~g} / \mathrm{L}(0.1$ mol/L). Figure 3-5 shows the silver extractions versus time with different $\mathrm{H}_{2} \mathrm{O}_{2}$ concentrations. 


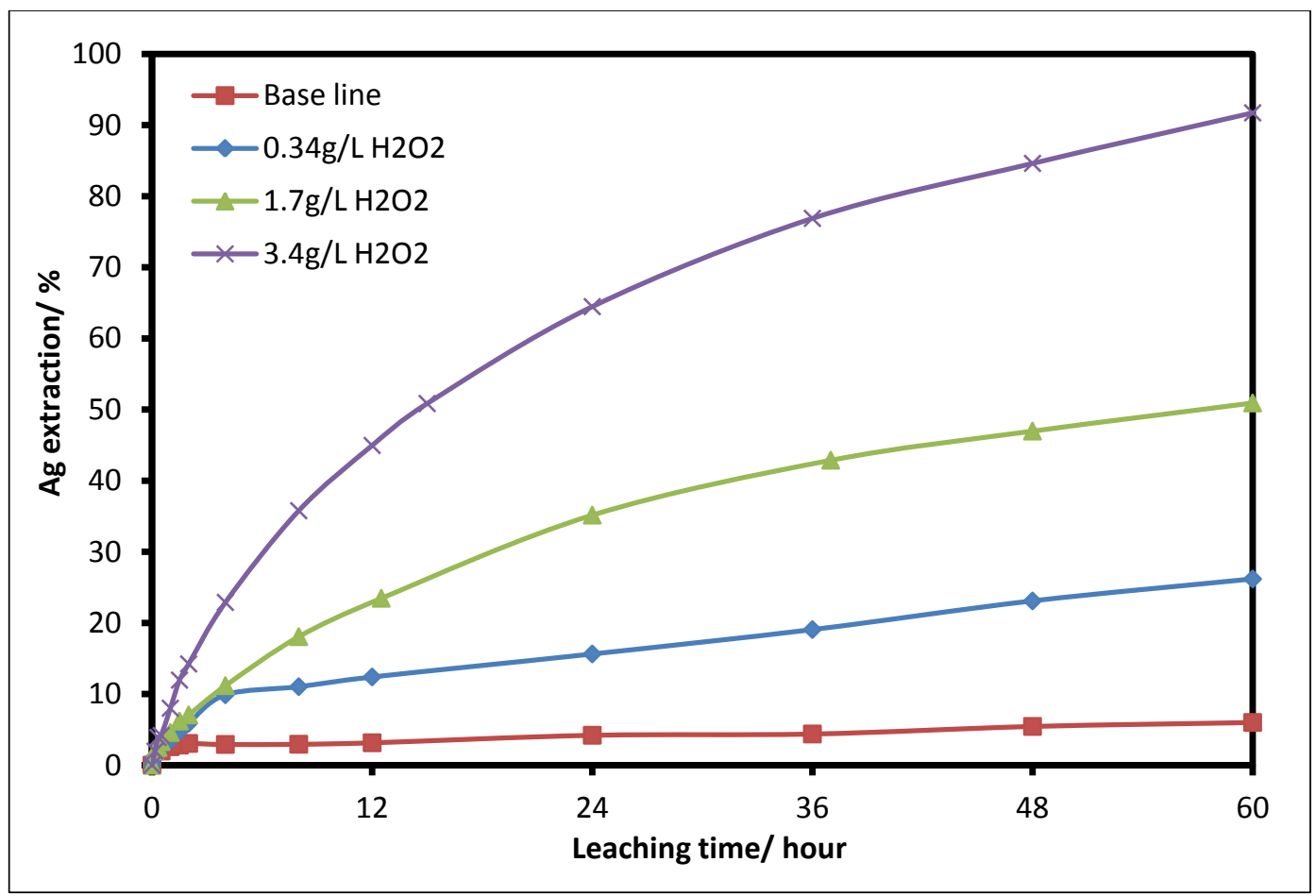

Figure 3-5 Ag extraction vs leaching time with different $\mathrm{H}_{2} \mathrm{O}_{2}$ concentrations $(0.5 \mathrm{~g} / \mathrm{L} \mathrm{NaCN}, \mathrm{pH}=12$, room temperature, $500 \mathrm{rpm})$

As suggested by Figure 3-5, leaching was continuous during the 60 hour process. The addition of $\mathrm{H}_{2} \mathrm{O}_{2}$ did improve the recovery of silver compared with the baseline experiment. In general, extraction of silver increased with the concentration of $\mathrm{H}_{2} \mathrm{O}_{2}$. This result indicated that the oxidation of silver sulfide by hydrogen peroxide was faster than the rate of oxidation with dissolved oxygen. In this series tests, with $3.4 \mathrm{~g} / \mathrm{L} \mathrm{H}_{2} \mathrm{O}_{2}$ addition, $91.7 \%$ of total silver was extracted from the solid mineral after 60 hours enhanced cyanide leaching. In addition, the final extraction at $0.34 \mathrm{~g} / \mathrm{L}$ and $1.7 \mathrm{~g} / \mathrm{L} \mathrm{H}_{2} \mathrm{O}_{2}$ were $26.2 \%$ and $50.9 \%$, respectively.

The consumption of $\mathrm{NaCN}$ and $\mathrm{NaOH}$ also increased with $\mathrm{H}_{2} \mathrm{O}_{2}$ concentration, as shown in Figure 3-6 and Figure 3-7. 


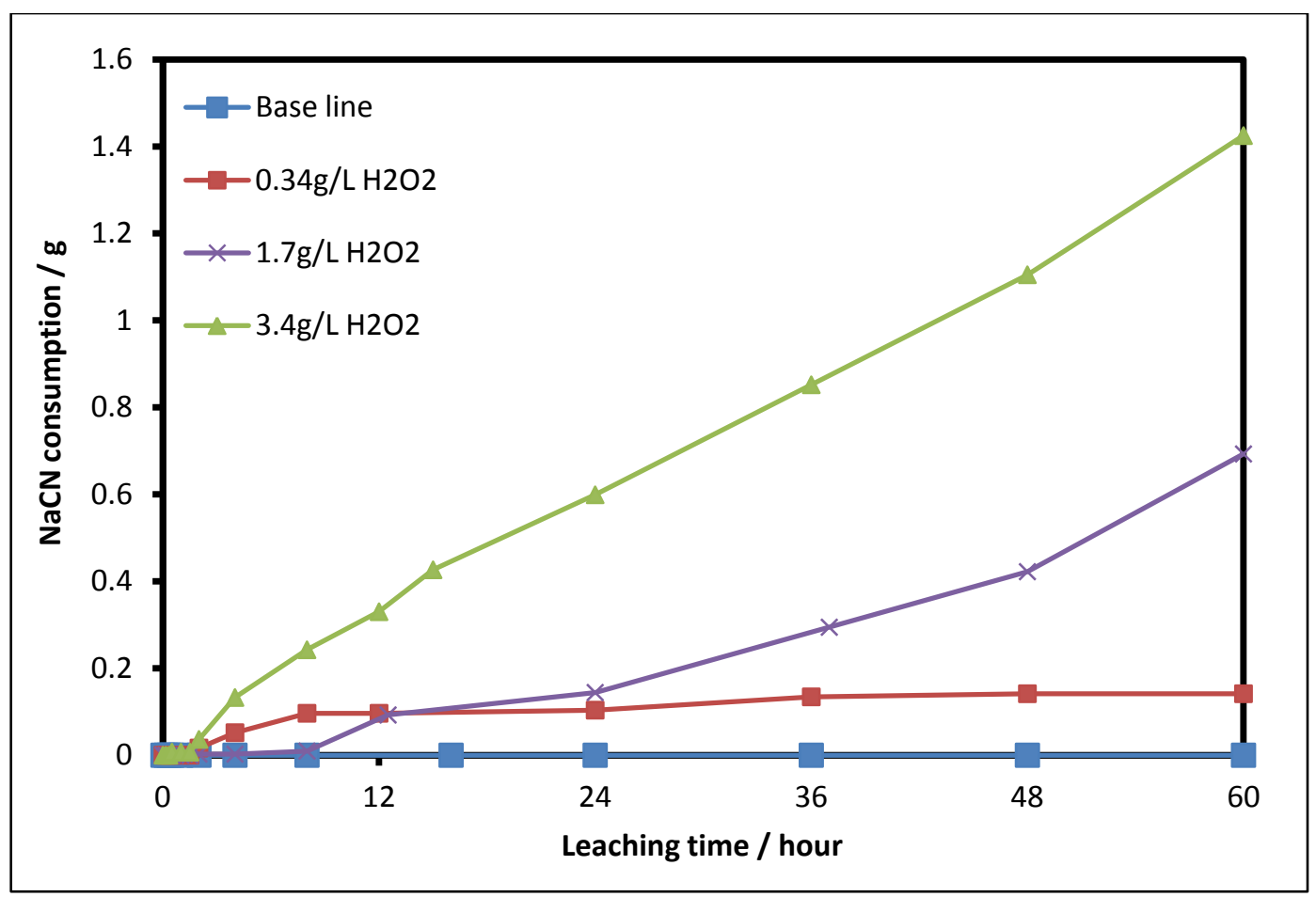

Figure 3-6 $\mathrm{NaCN}$ consumption vs leaching time with different $\mathrm{H}_{2} \mathrm{O}_{2}$ concentrations $(0.5 \mathrm{~g} / \mathrm{L} \mathrm{NaCN}, \mathrm{pH}=12$, room temperature, $500 \mathrm{rpm})$

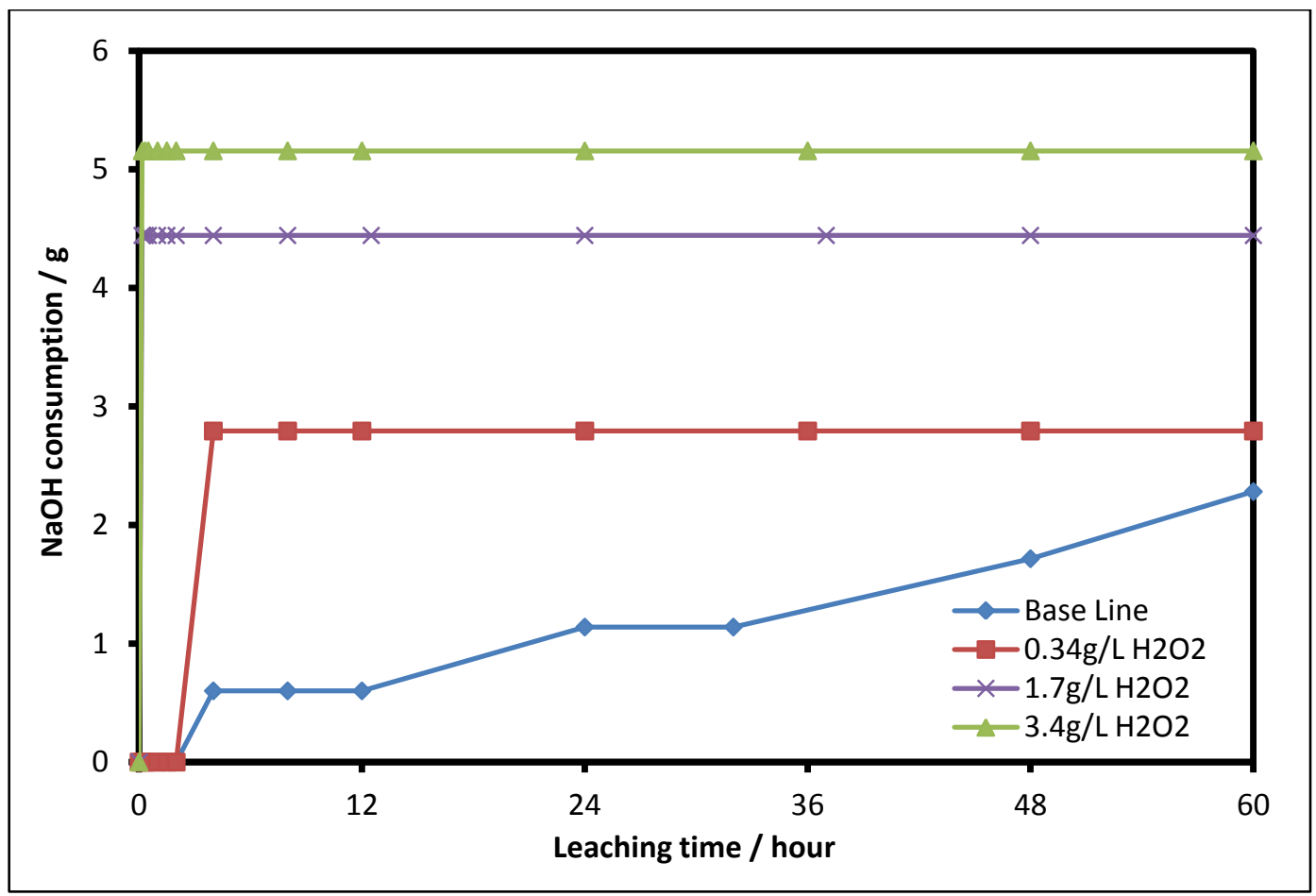

Figure 3-7 NaOH consumption vs leaching time with different $\mathrm{H}_{2} \mathrm{O}_{2}$ concentrations $(0.5 \mathrm{~g} / \mathrm{L} \mathrm{NaCN}, \mathrm{pH}=12$, room temperature, $500 \mathrm{rpm})$ 
For clear comparison, a new indicator was set named $\mathrm{NaCN}$ utilization efficiency. The calculation formula of $\mathrm{NaCN}$ utilization efficiency is:

$\mathrm{NaCN}$ utilization efficiency $=$ moles of theoretical $\mathrm{NaCN}$ complexing with extracted silver/ moles of measured $\mathrm{NaCN}$ consumption $\times 100 \%$

$\mathrm{NaCN}$ utilization efficiency in $3.4 \mathrm{~g} / \mathrm{L} \mathrm{H}_{2} \mathrm{O}_{2}$ assisted leaching was calculated as following:

Step 1. The extraction of silver:

$0.1 \mathrm{Ag}_{2} \mathrm{~S} \times 216 \mathrm{~g} \mathrm{Ag} / 249 \mathrm{~g} \mathrm{Ag} 2 \mathrm{~S} \times 91.7 \% / 106 \mathrm{~g} \mathrm{Ag} / \mathrm{mol} \mathrm{Ag}=7.5 \times 10^{-4} \mathrm{~mol} \mathrm{Ag}$

Step 2. The theoretical demand of $\mathrm{NaCN}$ complexing with extracted silver as $\operatorname{Ag}(\mathrm{CN})_{2}^{-}:$

$7.5 \times 10^{-4} \mathrm{~mole} \mathrm{Ag} \times 2 \mathrm{~mol} \mathrm{NaCN} / \mathrm{mol} \mathrm{Ag}=1.5 \times 10^{-3} \mathrm{~mol} \mathrm{NaCN}$

Step 3. The measured consumption of $\mathrm{NaCN}$ :

$1.4249 \mathrm{~g} \mathrm{NaCN} / 49 \mathrm{~g} \mathrm{NaCN} / \mathrm{mol} \mathrm{NaCN}=2.5 \times 10^{-2} \mathrm{~mol} \mathrm{NaCN}$

Step 4. The NaCN utilization efficiency:

$$
1.5 \times 10^{-3} / 2.5 \times 10^{-2} \times 100 \%=5.9 \%
$$

Based on the above calculations, it could be seen that most of the supplementary $\mathrm{NaCN}$ in $\mathrm{H}_{2} \mathrm{O}_{2}$ assisted leaching was lost, resulting in high reagent consumption and cost. Compared with the baseline, the consumption of $\mathrm{NaCN}$ and $\mathrm{NaOH}$ in leaching tests with $\mathrm{H}_{2} \mathrm{O}_{2}$ as an auxiliary oxidant were much higher. This result could be explained by the nature of the $\mathrm{H}_{2} \mathrm{O}_{2}$. As a weak acid, when $\mathrm{H}_{2} \mathrm{O}_{2}$ was added into the cyanide solution, alkalis were consumed for counteraction and hydroxide ion concentration decreased. Therefore, increased $\mathrm{H}_{2} \mathrm{O}_{2}$ addition led to higher $\mathrm{NaOH}$ demand for maintaing the $\mathrm{pH}$ at 12. The strong oxidizing power of $\mathrm{H}_{2} \mathrm{O}_{2}$ explained the observed high $\mathrm{NaCN}$ consumption. Hydrogen peroxide would oxidize cyanide as shown in Reaction 3-1.

$$
\mathrm{CN}^{-}+\mathrm{H}_{2} \mathrm{O}_{2}=\mathrm{CNO}^{-}+\mathrm{H}_{2} \mathrm{O} \quad \text { Reaction 3-1 }
$$

Cyanate would further be oxidized to ammonium and carbonate ions in concentrated 
$\mathrm{H}_{2} \mathrm{O}_{2}$ solution (Sarla et al., 2004). Therefore, $\mathrm{H}_{2} \mathrm{O}_{2}$ addition resulted in more oxidation of free cyanide, leading to the decreasing of free cyanide left in the solution. In order to ensure a sufficient supply of free cyanide, more supplementary $\mathrm{NaCN}$ was needed.

The decrease of pulp potential during the process could be attributed to the consumption of $\mathrm{H}_{2} \mathrm{O}_{2}$ by direct oxidization of sulfide. Leaching lasted for 60 hours while the potential dropped in the first few hours and then became stable. This indicates that oxidation of sulfide was not the only source that consumed $\mathrm{H}_{2} \mathrm{O}_{2}$. Another possible explanation for the drop of pulp potential was that high concentration of $\mathrm{H}_{2} \mathrm{O}_{2}$ may decompose in the first few hours of leaching (Reaction 2-33). This process is thermodynamically favorable and occurs more rapidly in alkaline solution. In $\mathrm{H}_{2} \mathrm{O}_{2}$-cyanide systems, part of the $\mathrm{H}_{2} \mathrm{O}_{2}$ reacted quickly in the first few hours, accompanied by the oxidation of sulfide and possibly the oxidation of cyanide as well, lowering the pulp potential rapidly. As the reactions proceeded, the $\mathrm{H}_{2} \mathrm{O}_{2}$ concentration reduced to a certain level that $\mathrm{H}_{2} \mathrm{O}_{2}$ could no longer self-decompose, but the oxidation of sulfide was still feasible. Thus silver dissolution continued.

\subsubsection{Calcium Peroxide}

The effect of $\mathrm{CaO}_{2}$ concentration on the dissolution of silver sulfide was examined in the range from $0.001 \mathrm{~mol} / \mathrm{L}(0.72 \mathrm{~g} / \mathrm{L})$ to $0.15 \mathrm{~mol} / \mathrm{L}(10.8 \mathrm{~g} / \mathrm{L})$. The silver extraction curves in $\mathrm{CaO}_{2}$-cyanide solution during 60 hour leaching were shown in Figure 3-8. 


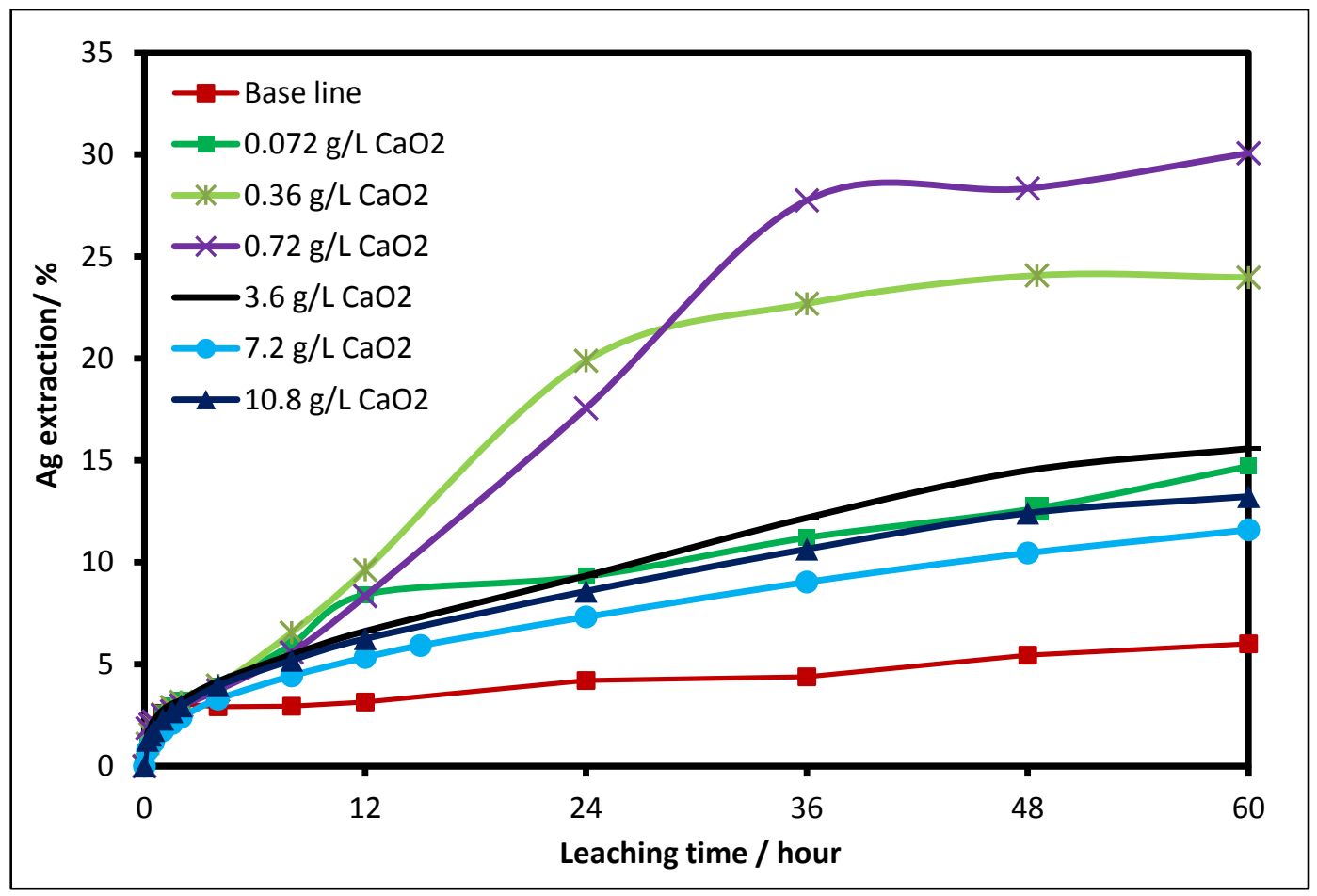

Figure 3-8 Ag extraction vs leaching time with different $\mathrm{CaO}_{2}$ concentrations $(0.5 \mathrm{~g} / \mathrm{L} \mathrm{NaCN}, \mathrm{pH}=12$, room temperature, $500 \mathrm{rpm})$

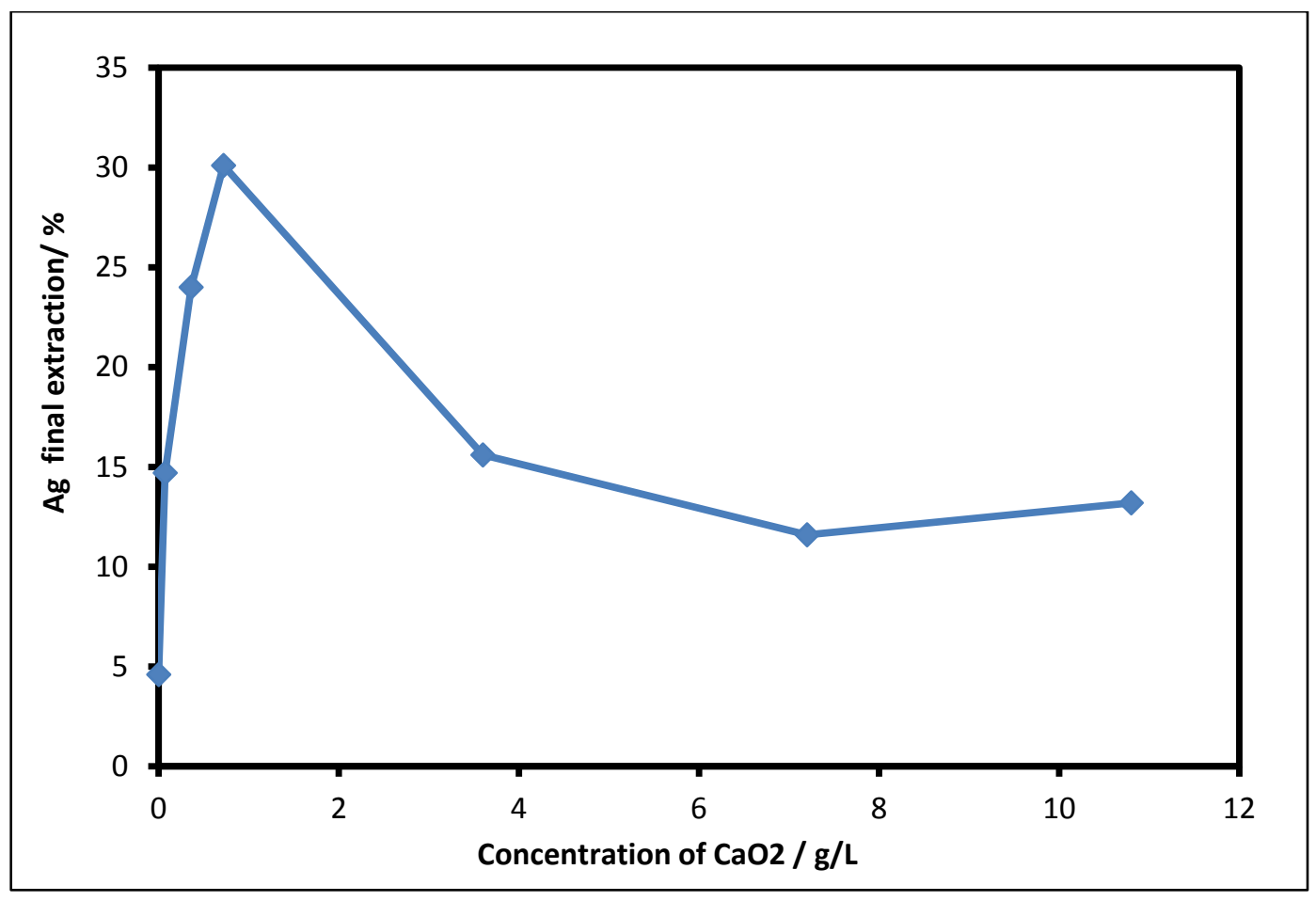

Figure 3-9 Final silver extraction vs $\mathrm{CaO}_{2}$ contents

$(0.5 \mathrm{~g} / \mathrm{L} \mathrm{NaCN}, \mathrm{pH}=12$, room temperature, $500 \mathrm{rpm})$ 
As can be observed from Figure 3-8, silver extraction changed with the addition of $\mathrm{CaO}_{2}$ as auxiliary oxidant was different from $\mathrm{H}_{2} \mathrm{O}_{2}$ assisted leaching. There was a peak at about $0.72 \mathrm{~g} / \mathrm{L} \mathrm{CaO}_{2}$ where the final extraction reached $30 \%$. Raising and lowering the addition of $\mathrm{CaO}_{2}$ could not yield a higher silver extraction (Figure 3-9).

It was suspected that with high content of $\mathrm{CaO}_{2}$ an insoluble layer was formed on the surface of the silver sulfide which blocked its contact with solution and thus hindered leaching.

One possible explanation was based on the solubility of $\mathrm{Ca}(\mathrm{OH})_{2}$ in alkaline solution. The hydrolysis reaction of $\mathrm{CaO}_{2}$ produced $\mathrm{Ca}(\mathrm{OH})_{2}$ and $\mathrm{O}_{2}$, which increased the concentration of oxygen in the solution thus benefiting the cyanidation process (Reaction $3-2)$.

$$
\mathrm{CaO}_{2}+\mathrm{H}_{2} \mathrm{O}=\mathrm{Ca}(\mathrm{OH})_{2}+1 / 2 \mathrm{O}_{2} \quad \text { Reaction 3-2 }
$$

The solubility of $\mathrm{Ca}(\mathrm{OH})_{2}$ in alkaline solution was very low $\left(1.85 \mathrm{~g} / \mathrm{L} \mathrm{H}_{2} \mathrm{O}\right)$. Its low solubility could resulte in the deposition of solid $\mathrm{Ca}(\mathrm{OH})_{2}$ on the silver sulfide particle surface at the addition of $\mathrm{CaO}_{2}$. This assumption can explain the trend of $\mathrm{Ag}$ extraction in Figure 3-9. When the concentration of $\mathrm{CaO}_{2}$ was below a certain level, silver extraction increased with $\mathrm{CaO}_{2}$ content since all of the added $\mathrm{CaO}_{2}$ was dissolved. When the addition of $\mathrm{CaO}_{2}$ was above the critical level, the excess $\mathrm{Ca}(\mathrm{OH})_{2}$ could not dissolve and it interfered with silver leaching by forming a layer over the particle surface. Therefore there was an optimum $\mathrm{CaO}_{2}$ concentration for silver extraction.

Similar to the trend of silver extraction, $\mathrm{NaCN}$ consumption also increased initially and then decreased when $\mathrm{CaO}_{2}$ concentration reached a critical value. This similarity indicated a direct correlation between silver extraction and $\mathrm{NaCN}$ consumption. It also showed that $\mathrm{CaO}_{2}$ did not react with $\mathrm{NaCN}$ extensively, since $\mathrm{NaCN}$ did not increase all the way with the increase of $\mathrm{CaO}_{2}$. The low interference of $\mathrm{CaO}_{2}$ with $\mathrm{NaCN}$ could also be observed by comparing the $\mathrm{NaCN}$ utilization efficiency between $\mathrm{CaO}_{2}$ tests and $\mathrm{H}_{2} \mathrm{O}_{2}$ tests: with $0.72 \mathrm{~g} / \mathrm{L} \mathrm{CaO}_{2}, 0.026 \mathrm{~g} \mathrm{Ag}$ was extracted. If all of the dissolved silver 
complexed with cyanide as $\mathrm{Ag}(\mathrm{CN})_{2}{ }^{-}, \mathrm{NaCN}$ consumption would be $0.024 \mathrm{~g}$. Since the measured addition of $\mathrm{NaCN}$ was $0.12 \mathrm{~g}$, the $\mathrm{NaCN}$ utilization efficiency in this test was $20 \%$, which was higher than $\mathrm{H}_{2} \mathrm{O}_{2}$ assisted leaching.

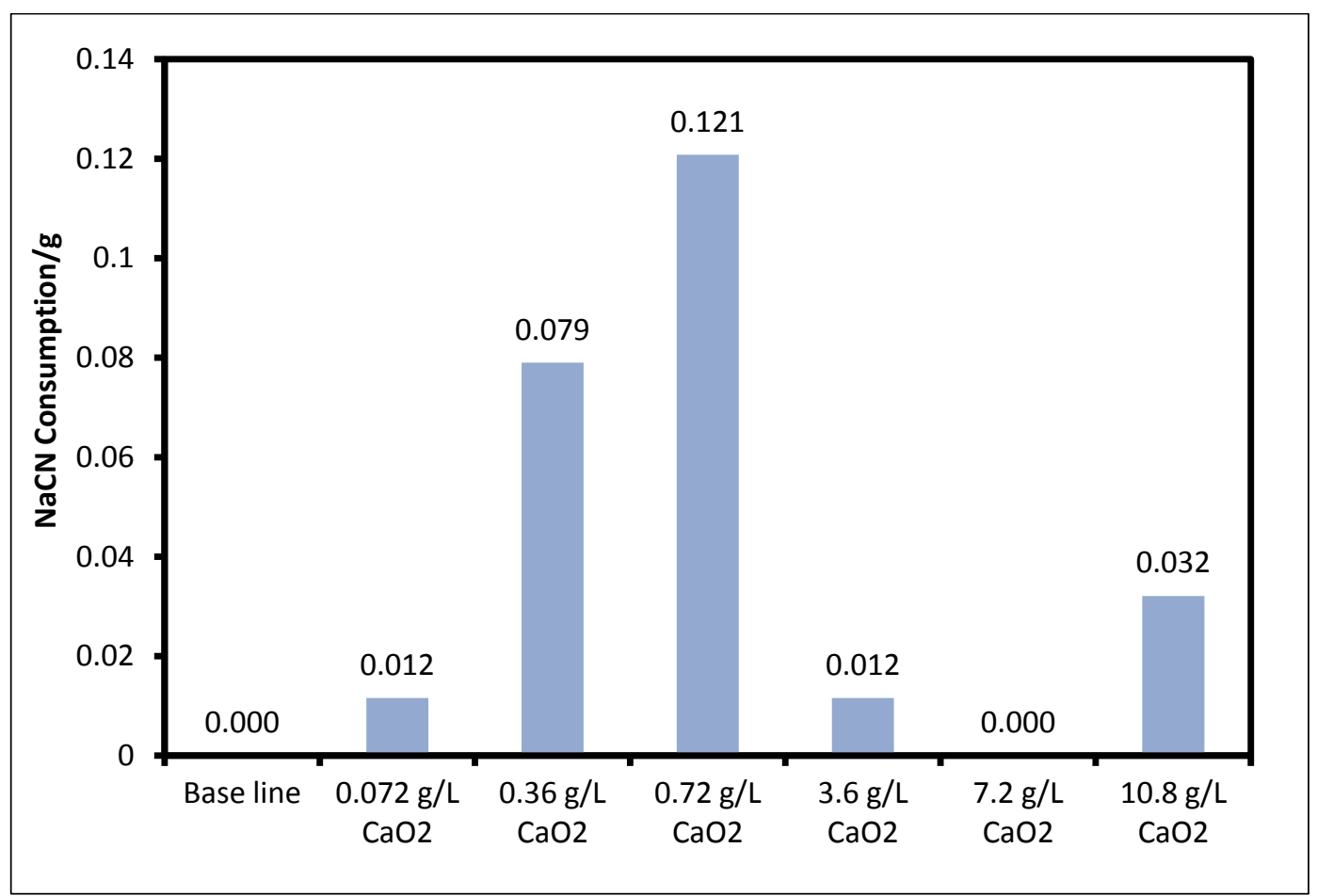

Figure 3-10 $\mathrm{NaCN}$ consumption vs leaching time with different $\mathrm{CaO}_{2}$ concentrations $(0.5 \mathrm{~g} / \mathrm{L} \mathrm{NaCN}, \mathrm{pH}=12$, room temperature, $500 \mathrm{rpm})$

The consumption of $\mathrm{NaOH}$ is shown in Figure 3-11. It is clear that the consumption of $\mathrm{NaOH}$ dropped as the concentration of $\mathrm{CaO}_{2}$ increased, likely due to the fact that $\mathrm{CaO}_{2}$ was alkali itself and it reacted with water to form $\mathrm{Ca}(\mathrm{OH})_{2}$ which can also increase the $\mathrm{pH}$. 


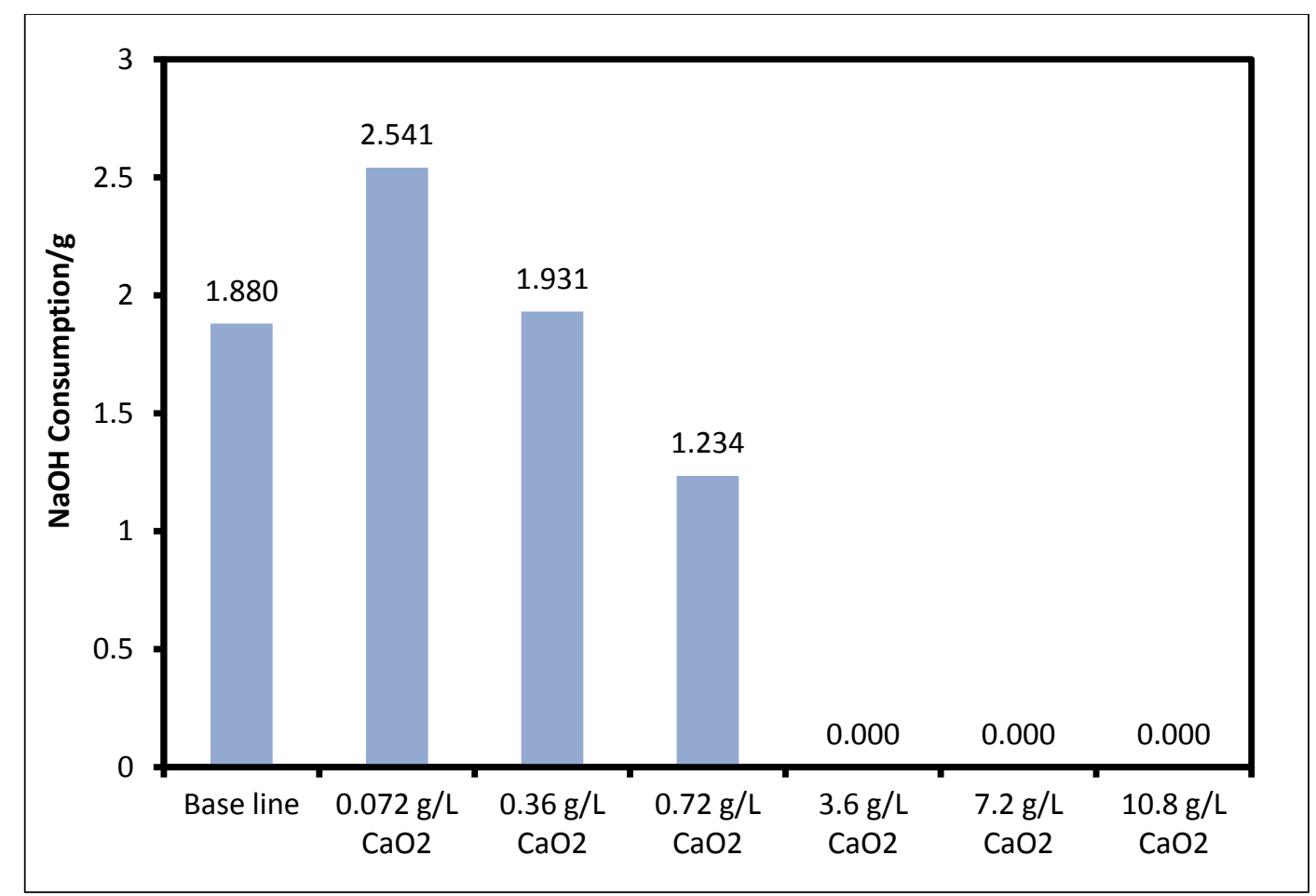

Figure 3-11 $\mathrm{NaOH}$ consumption vs leaching time with different $\mathrm{CaO}_{2}$ concentrations $(0.5 \mathrm{~g} / \mathrm{L} \mathrm{NaCN}, \mathrm{pH}=12$, room temperature, $500 \mathrm{rpm})$

Based on the analysis above, even though $\mathrm{CaO}_{2}$ reduced the consumption of sodium hydroxide, it was not an appropriate auxiliary oxidant because of its inability to significantly increase the final silver extraction.

\subsubsection{LeachWELLTM}

As a registered trademark product used in analytical labs to accelerate the extraction of gold, LeachWELL ${ }^{\mathrm{TM}}$ is another option as auxiliary oxidant for silver sulfide cyanidation. The provider described it as a cyanide leach accelerant which provides oxygen for the dissolution of gold. The available information about it indicates that it is soluble in cyanide solution and it contains $2 \%$ lead nitrate and $98 \%$ mild organic oxidant. Further details about composition and working mechanism are unavailable.

In this series of experiments, the concentration of LeachWELL ${ }^{\mathrm{TM}}$ varied in the range from $0.2 \mathrm{~g} / \mathrm{L}$ to $0.8 \mathrm{~g} / \mathrm{L}$. The final $\mathrm{Ag}$ extraction, $\mathrm{NaCN}$ consumption and $\mathrm{NaOH}$ 
consumption were shown in Figure 3-12, Figure 3-13 and Figure 3-14 below. In order to make a clear comparison, the results of $\mathrm{H}_{2} \mathrm{O}_{2}(3.4 \mathrm{~g} / \mathrm{L})$ and $\mathrm{CaO}_{2}(0.72 \mathrm{~g} / \mathrm{L})$ leaching from the previous chapters were also included.

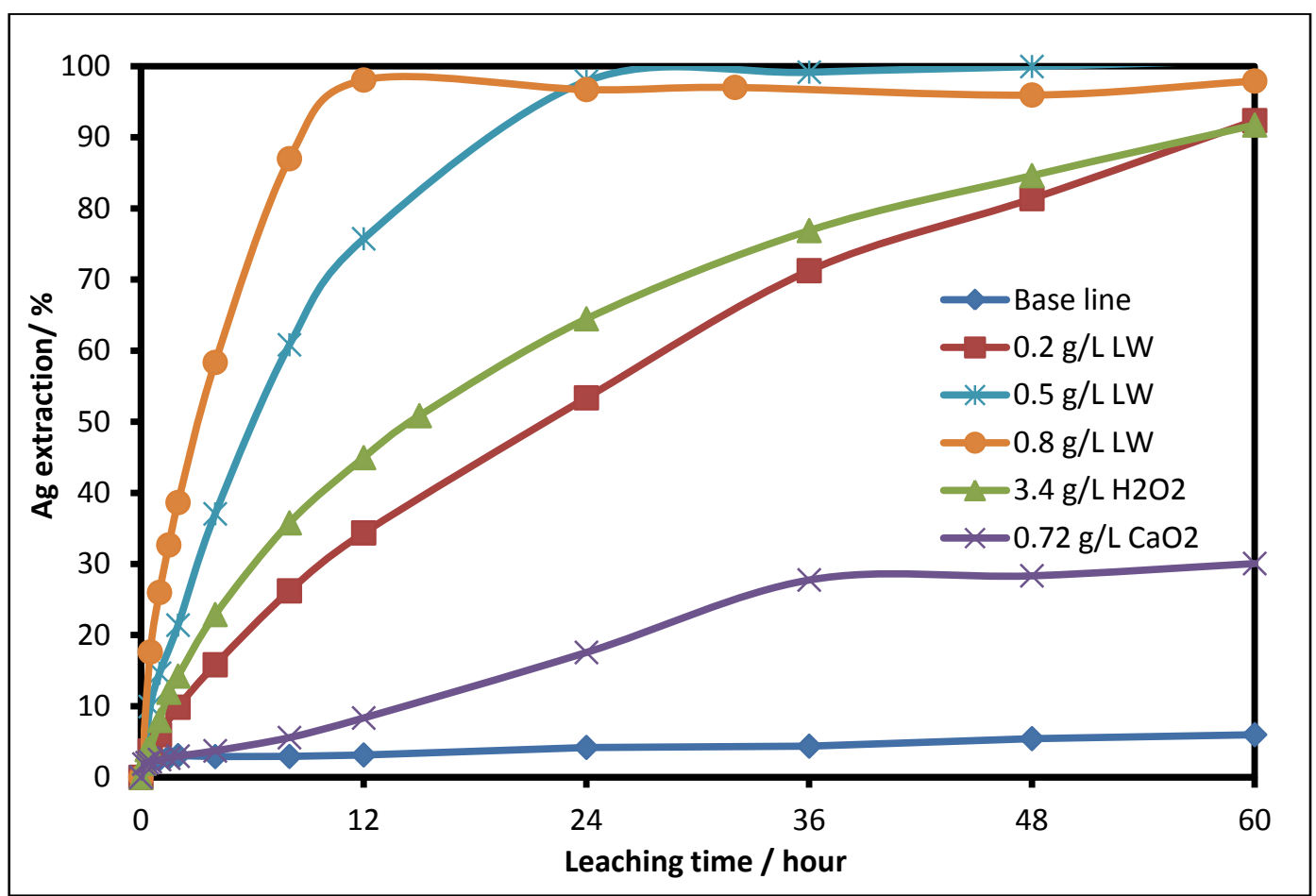

Figure 3-12 Ag extraction vs leaching time with different LechWELL ${ }^{\mathrm{TM}}$ concentrations $\left(0.5 \mathrm{~g} / \mathrm{L} \mathrm{NaCN}, \mathrm{pH}=12\right.$, room temperature, $500 \mathrm{rpm}, \mathrm{LW}=$ LeachWELL $\left.{ }^{T M}\right)$

The performance of LeachWELL ${ }^{\mathrm{TM}}$ on improving silver extraction was obviously significant when compared with the baseline results. With the addition of $0.2 \mathrm{~g} / \mathrm{L}$ LeachWELL $^{\mathrm{TM}}, 92.3 \%$ silver was extracted after 60 hour leaching. Dissolution of silver sulfide was accelerated with the increase of LeachWELL ${ }^{\mathrm{TM}}$ concentration. Complete extraction was achieved within 48 hours and 12 hours with $0.5 \mathrm{~g} / \mathrm{L}$ and $0.8 \mathrm{~g} / \mathrm{L}$ LeachWELL ${ }^{\mathrm{TM}}$ respectively.

Comparing $\mathrm{H}_{2} \mathrm{O}_{2}, \mathrm{CaO}_{2}$ and LeachWELL ${ }^{\mathrm{TM}}$, it was observed that LeachWELL ${ }^{\mathrm{TM}}$ had the advantage of improving silver extraction at a lower concentration than $\mathrm{H}_{2} \mathrm{O}_{2}$ and $\mathrm{CaO}_{2}$. The silver extraction using $0.2 \mathrm{~g} / \mathrm{L}$ LeachWELL ${ }^{\mathrm{TM}}$ was as much as that achieved with $3.4 \mathrm{~g} / \mathrm{L} \mathrm{H}_{2} \mathrm{O}_{2}$ and was far more than that observed with $0.72 \mathrm{~g} / \mathrm{L} \mathrm{CaO}_{2}$. Another advantage 
of LeachWELL ${ }^{\mathrm{TM}}$ was that the cyanide utilization efficiency in the cyanidation process was high, which could be proved by Figure 3-13. Figure 3-13 indicates that the accumulated $\mathrm{NaCN}$ consumption after 60 hours in the LeachWELL ${ }^{\mathrm{TM}}$ system was the lowest compared to $\mathrm{H}_{2} \mathrm{O}_{2}$ and $\mathrm{CaO}_{2}$. In other words, it could enhance the extraction not only with the lowest addition of auxiliary oxidant, but also with the highest efficiency of cyanide.

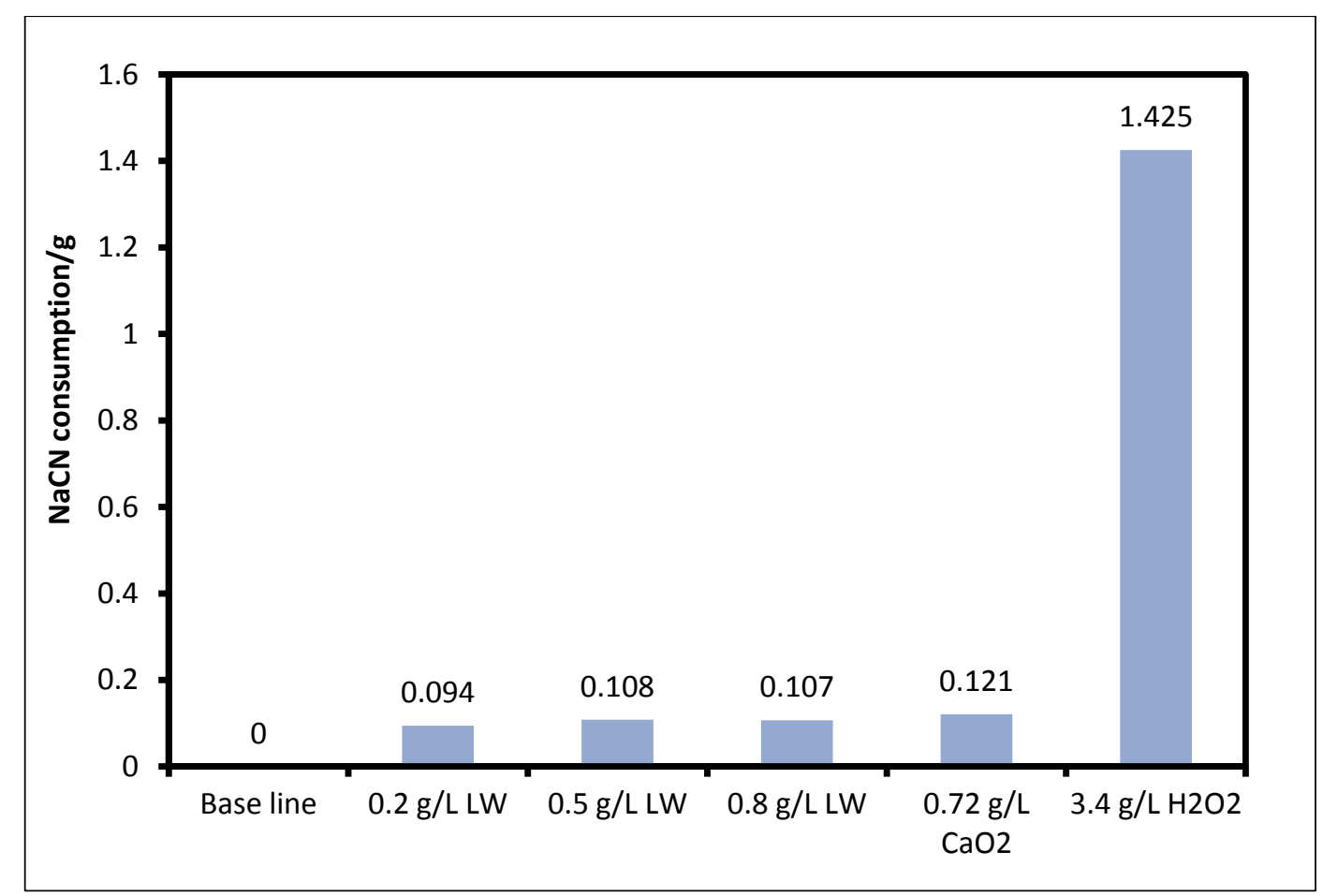

Figure 3-13 Accumulated $\mathrm{NaCN}$ consumption in 60 hours with different oxidants $\left(0.5 \mathrm{~g} / \mathrm{L} \mathrm{NaCN}, \mathrm{pH}=12\right.$, room temperature, $500 \mathrm{rpm}, \mathrm{LW}=$ Leach $\left.W E L L^{T M}\right)$

With $0.2 \mathrm{~g} / \mathrm{L}$ LeachWELL ${ }^{\mathrm{TM}}$ addition, $7.55 \times 10^{-4} \mathrm{~mol}$ silver was extracted. The demand of $\mathrm{NaCN}$ complexing with dissolved silver as $\mathrm{Ag}(\mathrm{CN})_{2}{ }^{-}$was $1.51 \times 10^{-3} \mathrm{~mol}(0.074 \mathrm{~g})$ and the measured $\mathrm{NaCN}$ consumption was $0.094 \mathrm{~g}$. The difference between these two numbers was likely to be attributed to the oxidation of cyanide by LeachWELL $^{\mathrm{TM}}$ and other inevitable loss of free cyanide (HCN volatilization). This assumption can be supported by the fact that higher concentration of LeachWELL ${ }^{\mathrm{TM}}$ resulted in higher consumption of $\mathrm{NaCN}$ during the 60 hour leach period. This result indicated that the oxidation of cyanide by LeachWELL ${ }^{\mathrm{TM}}$ was mild compared to $\mathrm{H}_{2} \mathrm{O}_{2}$, resulting in an acceptable cyanide 
utilization efficiency.

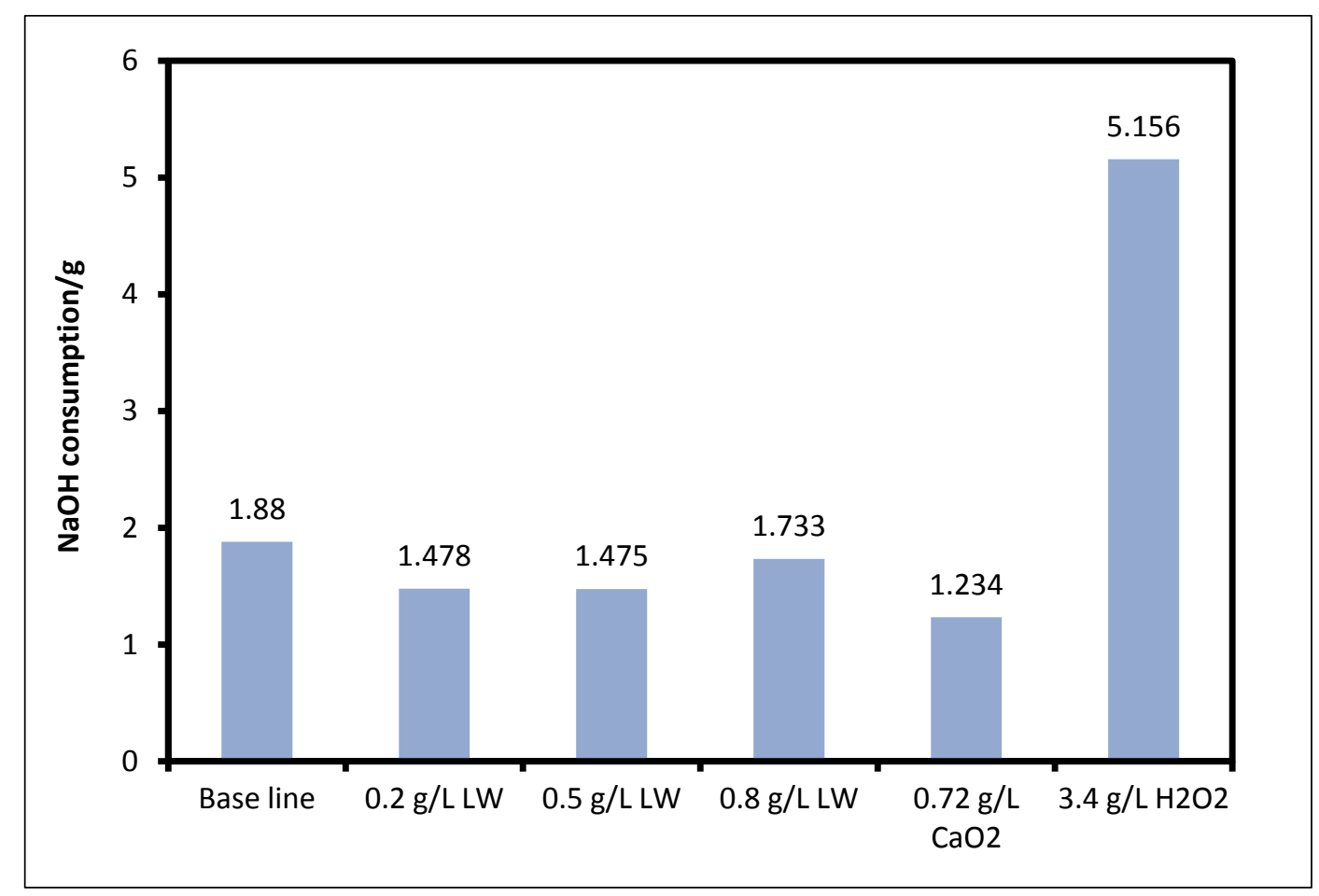

Figure 3-14 Accumulated $\mathrm{NaOH}$ consumption in 60 hours with different oxidants $\left(0.5 \mathrm{~g} / \mathrm{L} \mathrm{NaCN}, \mathrm{pH}=12\right.$, room temperature, $500 \mathrm{rpm}, \mathrm{LW}=$ Leach $\left.W E L L^{T M}\right)$

Figure 3-14 shows that within an acceptable error range, the consumption of $\mathrm{NaOH}$ was constant at the variation of the LeachWELL ${ }^{\mathrm{TM}}$ concentration. The $\mathrm{NaOH}$ consumption in LeachWELL ${ }^{\mathrm{TM}}$-cyanide systems was in the same level with that in the baseline experiment. It indicated that LeachWELL ${ }^{\mathrm{TM}}$ did not consume $\mathrm{OH}^{-}$in the solution.

\subsubsection{Variables on LeachWELL ${ }^{\mathrm{TM}}$ Leaching}

Based on a comprehensive consideration, LeachWELL ${ }^{\mathrm{TM}}$ is the best choice among the three auxiliary oxidants. It dissolved silver sulfide more rapidly and completely with less $\mathrm{NaCN}$ and $\mathrm{NaOH}$ consumption. As a result, further investigation on LeachWELL ${ }^{\mathrm{TM}}$ was conducted to examine its performance in different conditions. The variation conditions include temperature, $\mathrm{pH}$ and $\mathrm{NaCN}$ concentration. Since $0.2 \mathrm{~g} / \mathrm{L}$ LeachWELL ${ }^{\mathrm{TM}}$ extracted more than $90 \%$ silver in 60 hours, which was acceptable for final silver 
recovery, the concentration of LeachWELL ${ }^{\mathrm{TM}}$ in the following investigation was kept at $0.2 \mathrm{~g} / \mathrm{L}$. In several tests $0.5 \mathrm{~g} / \mathrm{L}_{\text {LeachWELL }}{ }^{\mathrm{TM}}$ was added.

\subsubsection{Effect of Temperature}

Considering that industrial cyanide leaching may be performed in the open air and the plant location may vary from warm to cold climates, tests at three different temperatures were conducted in order to better understand the applicability of LeachWELL ${ }^{\mathrm{TM}}$ in cyanidation process. The studied leaching temperatures were $17{ }^{\circ} \mathrm{C}$ (room temperature in the lab), $30^{\circ} \mathrm{C}$ and $40^{\circ} \mathrm{C}$. Silver extraction and $\mathrm{NaCN}$ consumption are shown below.

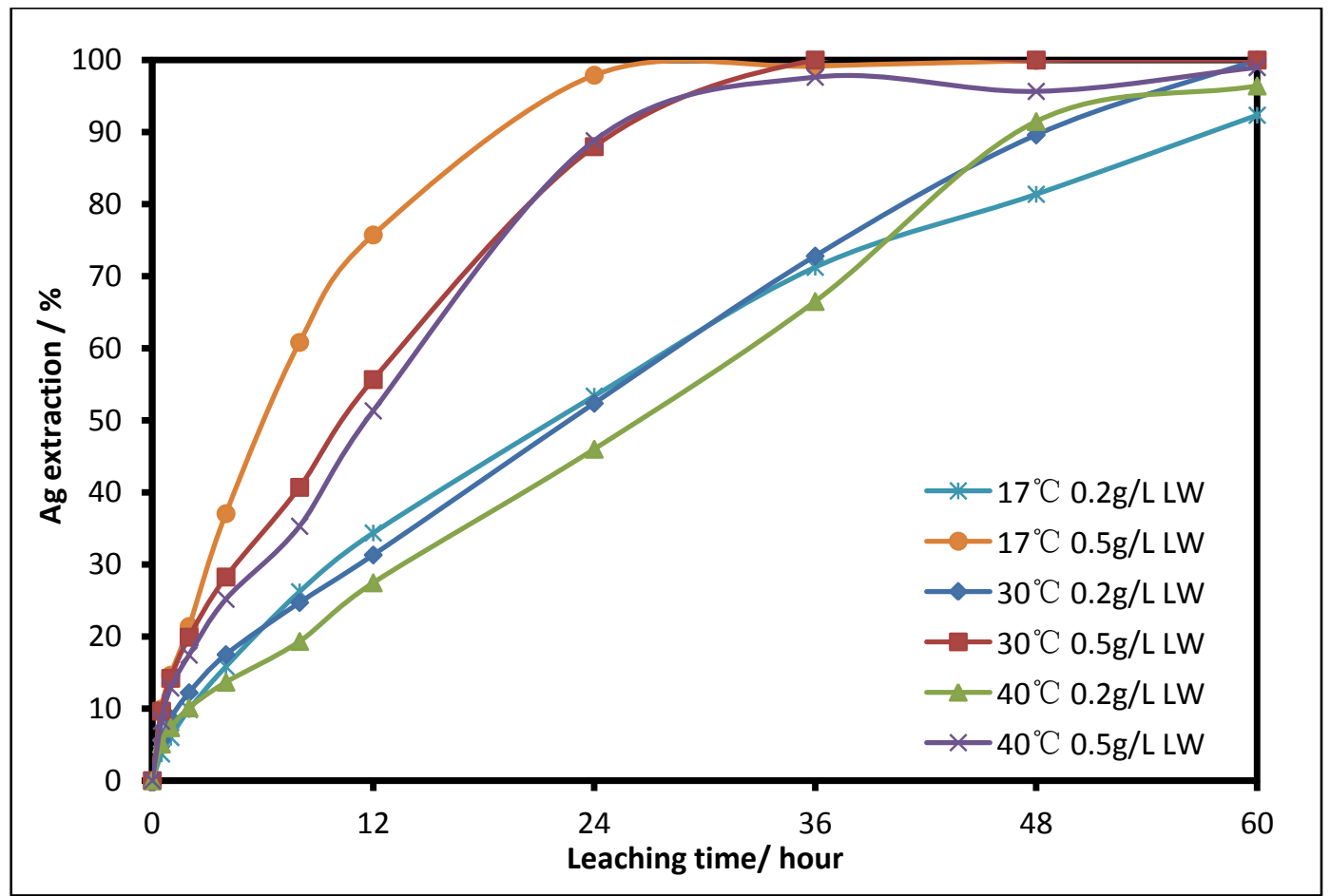

Figure 3-15 Ag extraction vs leaching time at different temperatures in LeachWELL $^{\mathrm{TM}}$-cyanide system $\left(0.5 \mathrm{~g} / \mathrm{L} \mathrm{NaCN}, \mathrm{pH}=12,500 \mathrm{rpm}, \mathrm{LW}=\operatorname{LeachWELL^{TM}}\right)$

As could be seen from Figure 3-15, the leaching rate was a bit slower during the leaching process. Volatilization of the organic composition in LeachWELL ${ }^{\mathrm{TM}}$ with higher temperature might result to this decrease. These phenomena could also be explained by 
the fact that for organic compounds, their side reactions may increase with the temperature rises, which damage its original function.

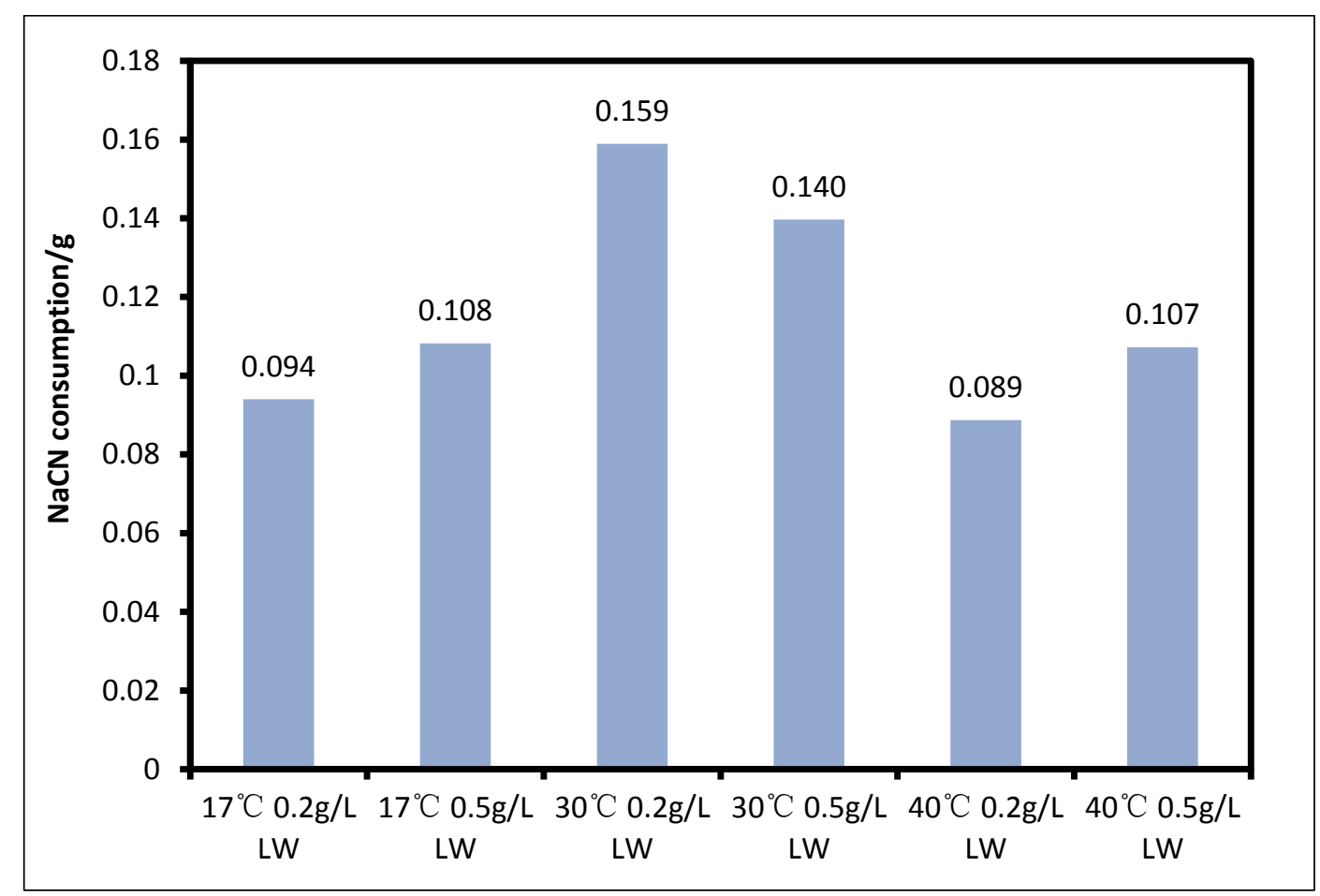

Figure 3-16 Accumulated NaCN consumption in 60 hours at different temperatures in LeachWELL ${ }^{\mathrm{TM}}$-cyanide system $\left(0.5 \mathrm{~g} / \mathrm{L} \mathrm{NaCN}, \mathrm{pH}=12,500 \mathrm{rpm}, \mathrm{LW}=\right.$ Leach WELL $\left.^{T M}\right)$

The consumption of $\mathrm{NaCN}$ remained at a low level at different temperatures with reasonable deviation (Figure 3-16). However, maintaining pulp $\mathrm{pH}$ at 12 required different base addition at different temperatures. The consumption of $\mathrm{NaOH}$ at room temperature was about $1.48 \mathrm{~g}$, while the number was much higher at high temperatures $\left(30^{\circ} \mathrm{C}\right.$ and $40^{\circ} \mathrm{C}$ ) (averaged $8.5 \mathrm{~g} \mathrm{NaOH}$ solid). The possible explanation was that the $\mathrm{pKa}$ of reactions involving $\mathrm{NaOH}$ changed with temperature, which in turn resulted in change of $\mathrm{NaOH}$ demand.

\subsubsection{Effect of pH}

The LeachWELL ${ }^{\mathrm{TM}}$ assisted cyanidation was examined in the $\mathrm{pH}$ range from 10.5 to 12 
at which the conventional cyanidation processes were usually performed. The silver extraction curves at different $\mathrm{pH}$ were shown in Figure 3-17. During the process, the $\mathrm{pH}$ was maintained at initial level with addition of $2 \mathrm{M} \mathrm{NaOH}$ solution. It could be observed that in this series of tests, the silver sulfide dissolution rate did not change with $\mathrm{pH}$. The effect of LeachWELL ${ }^{\mathrm{TM}}$ was believed to be independent of the concentration of $\mathrm{OH}^{-}$ concentration in the system. These four tests also demonstrated the excellent reproducibility of the leaching and analytical technique.

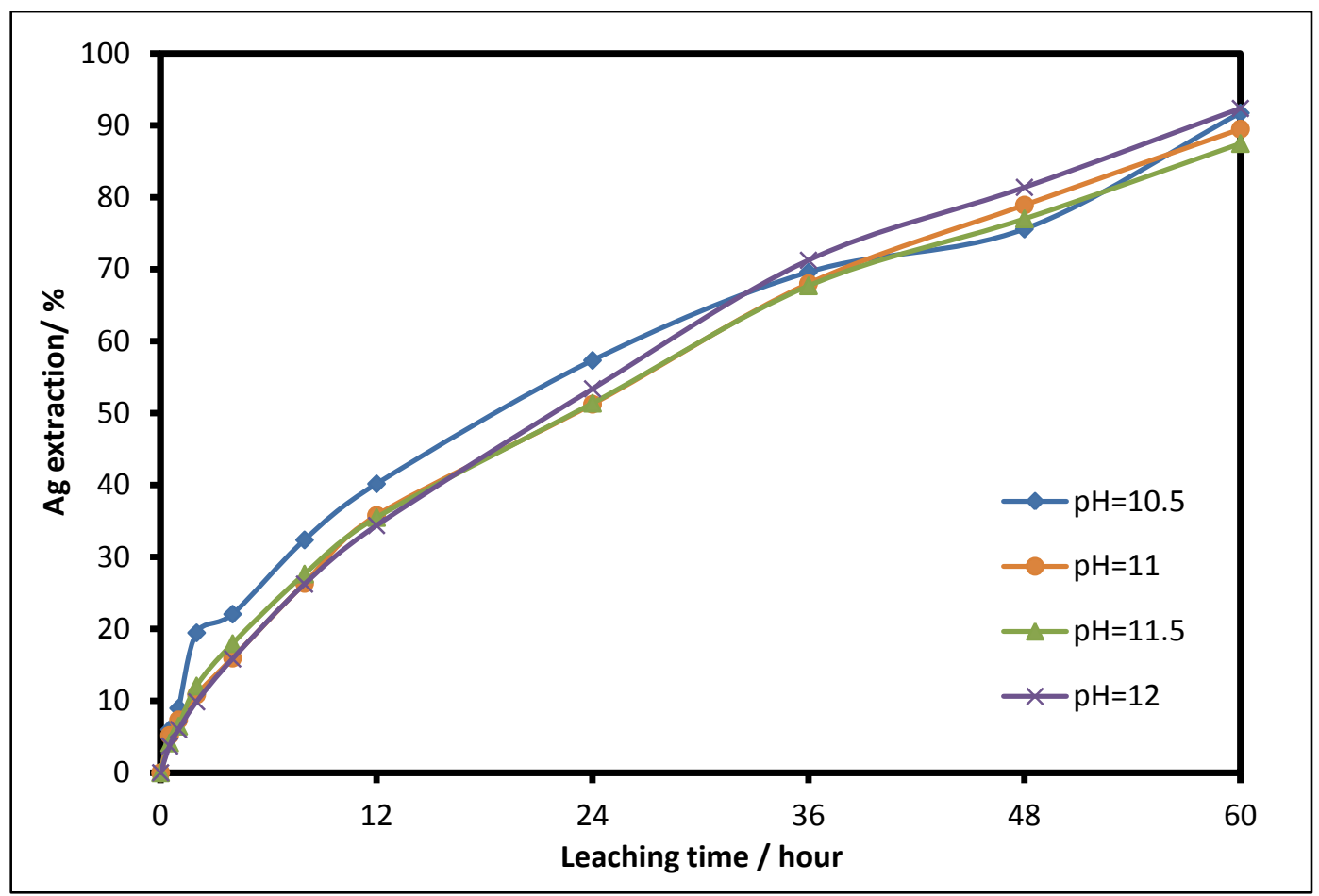

Figure 3-17 Ag extraction vs leaching time at different pH in LeachWELL ${ }^{\mathrm{TM}}$-cyanide system $\left(0.2 \mathrm{~g} / \mathrm{L}\right.$ LeachWELL $L^{T M}, 0.5 \mathrm{~g} / \mathrm{L} \mathrm{NaCN}$, room temperature, $\left.500 \mathrm{rpm}\right)$

As mentioned above, the hydrolysis of cyanide and volatilization of hydrogen cyanide decreased with the increase of $\mathrm{pH}$. This trend was obvious in Figure 3-18. High $\mathrm{pH}$ solution consumed less supplementary $\mathrm{NaCN}$. Calculated cyanide utilization efficiency was ranked in the following order;

$$
\text { pH } 12>\text { pH } 11.5>\text { pH } 11>\text { pH } 10.5
$$

However, it was noted that increasing $\mathrm{pH}$ raised the amount of $\mathrm{NaOH}$ added into the systems (Figure 3-19). 


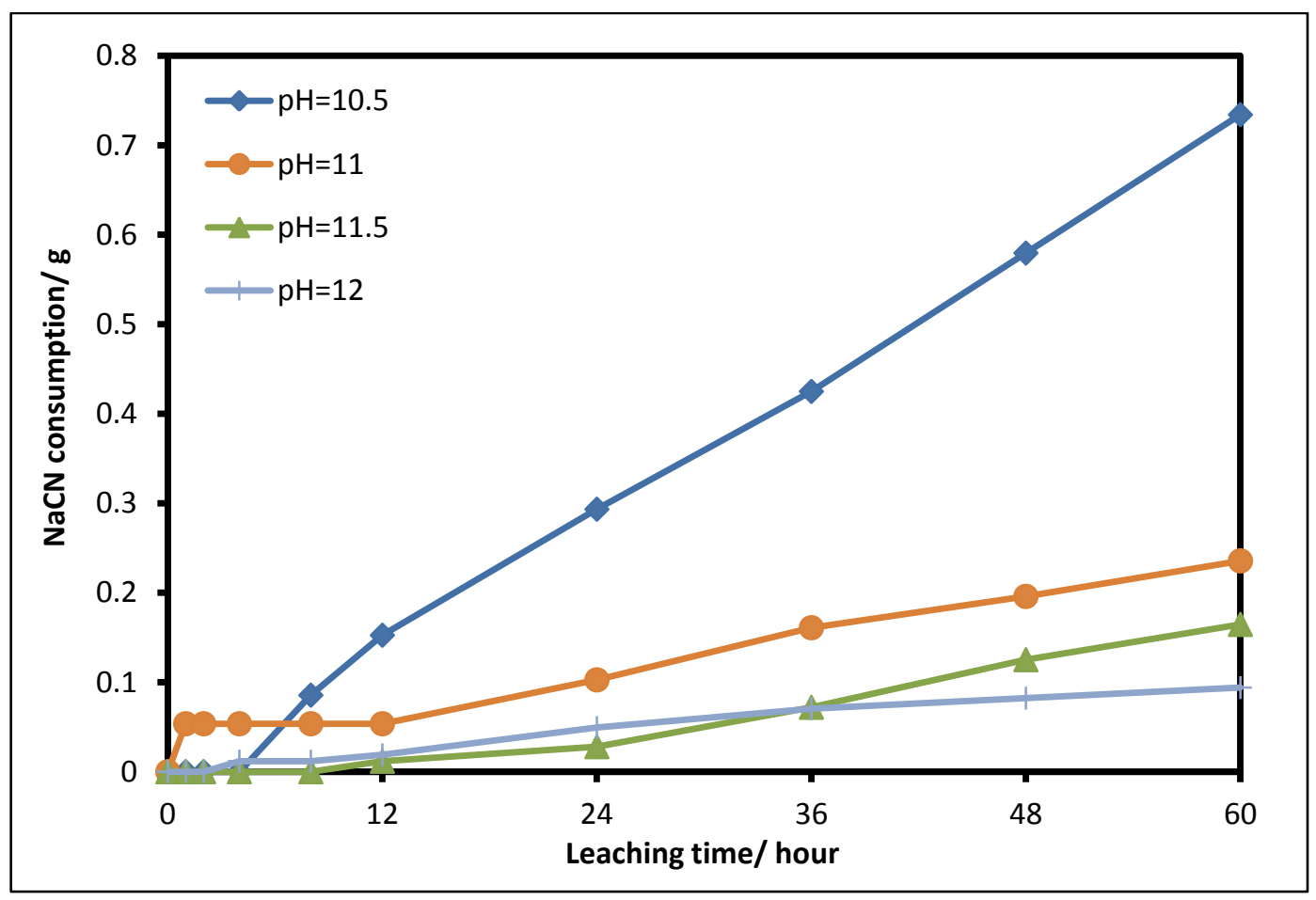

Figure 3-18 NaCN consumption vs leaching time at different pH in LeachWELL ${ }^{\mathrm{TM}}$-cyanide system $\left(0.2 \mathrm{~g} / \mathrm{L}\right.$ LeachWELL ${ }^{T M}, 0.5 \mathrm{~g} / \mathrm{L} \mathrm{NaCN}$, room temperature, $\left.500 \mathrm{rpm}\right)$

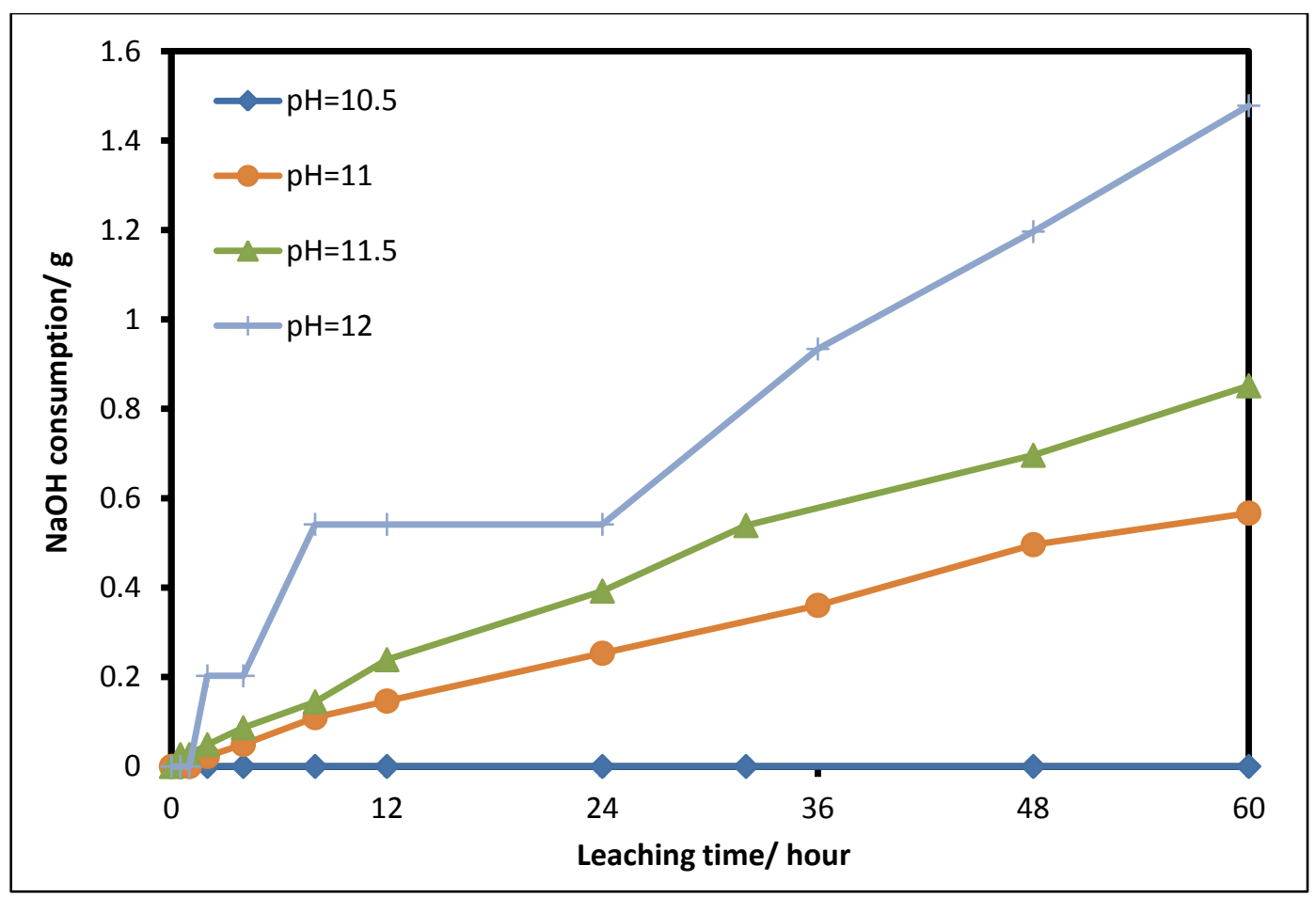

Figure 3-19 $\mathrm{NaOH}$ consumption vs leaching time at different $\mathrm{pH}$ in LeachWELL ${ }^{\mathrm{TM}}$-cyanide system $\left(0.2 \mathrm{~g} / \mathrm{L}\right.$ LeachWELL ${ }^{T M}, 0.5 \mathrm{~g} / \mathrm{L} \mathrm{NaCN}$, room temperature, $\left.500 \mathrm{rpm}\right)$ 
It could be concluded that the pulp $\mathrm{pH}$ did not affect silver extraction. In practical production, usually the $\mathrm{pH}$ was maintained between 11 and 11.5. Therefore in the following tests, the $\mathrm{pH}$ of the systems was controlled at 11 .

\subsubsection{Effect of NaCN Concentration}

The effect of $\mathrm{NaCN}$ concentration on the LeachWELL ${ }^{\mathrm{TM}}$ assisted leaching system was determined in the range from $0.25 \mathrm{~g} / \mathrm{L} \mathrm{NaCN}$ to $3 \mathrm{~g} / \mathrm{L} \mathrm{NaCN}$. Figure 3-20 shows silver extraction curves with different cyanide concentration. It can be found that the $\mathrm{Ag}$ extraction increased smoothly with an increase in $\mathrm{NaCN}$ concentration.

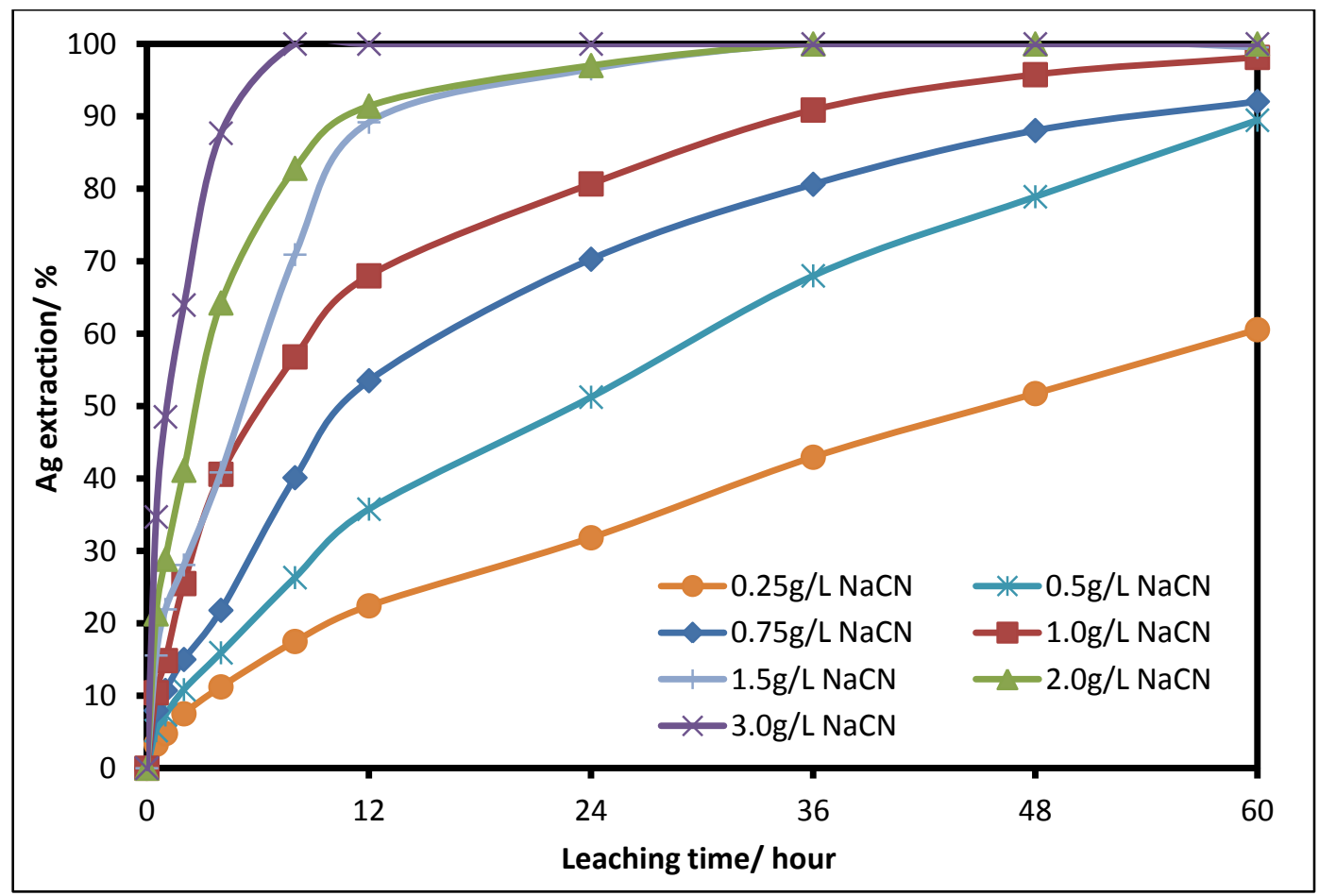

Figure 3-20 Ag extraction vs leaching time at different $\mathrm{NaCN}$ concentration in LeachWELL $^{\text {TM }}$-cyanide system

$\left(0.2 \mathrm{~g} / \mathrm{L}\right.$ LeachWELL $L^{T M}, p H=11$, room temperature, $\left.500 \mathrm{rpm}\right)$

This was different from the effect of cyanide concentration on dissolution of native gold or silver in aerated cyanide solution. Metallic silver dissolution increased proportionally 
with cyanide concentration at low cyanide content and reached its limit when $\mathrm{NaCN}$ concentration exceeded a critical value. Xie (2006) pointed out that, in the dissolution of native silver, the function of cyanide was to complex the oxidized $\mathrm{Ag}^{+}$. When the cyanide concentration was too low to complex and stabilize the dissolved $\mathrm{Ag}^{+}$, the increase of $\mathrm{NaCN}$ content could improve silver dissolution. However, if the cyanide concentration in the solution was high enough to complex the dissolved $\mathrm{Ag}^{+}$, increasing $\mathrm{CN}^{-}$further would not improve the silver extraction.

However, the presence of sulfide ion in the cyanide solution in the present case made it different from metallic silver cyanidation system. In the silver sulfide leaching system, LeachWELL $^{\mathrm{TM}}$ acted as an oxidant to improve the dissolution of not only silver but also sulfur species. More liberated sulfur species could react with cyanide as Reaction 2-38 2-41. Therefore, dissolution of silver sulfide could be improved by increasing cyanide concentration.

The recovery of silver as well as the supplementary $\mathrm{NaCN}$ consumption rose with the increase of cyanide concentration (Figure 3-21). The only exception was that the $0.25 \mathrm{~g} / \mathrm{L}$ $\mathrm{NaCN}$ system consumed more supplementary cyanide than the $0.5 \mathrm{~g} / \mathrm{L} \mathrm{NaCN}$ system, which was probably due to the low accuracy of silver nitrate titration in detecting such a low cyanide concentration. The increase in supplementary $\mathrm{NaCN}$ consumption can be attributed to the reason that, according to Henry's law, high cyanide concentration causes high volatilization of hydrogen cyanide. On the contrary, since $\mathrm{NaCN}$ is an alkali, pulp $\mathrm{pH}$ increased with the addition of $\mathrm{NaCN}$. Therefore, $\mathrm{NaOH}$ consumption during the 60 hour leaching period reduced to zero when the $\mathrm{NaCN}$ concentration increased to $1 \mathrm{~g} / \mathrm{L}$. Higher concentration of $\mathrm{NaCN}$ maintained the $\mathrm{pH}$ around 11.3 and did not require supplementary $\mathrm{NaOH}$ addition at all. 


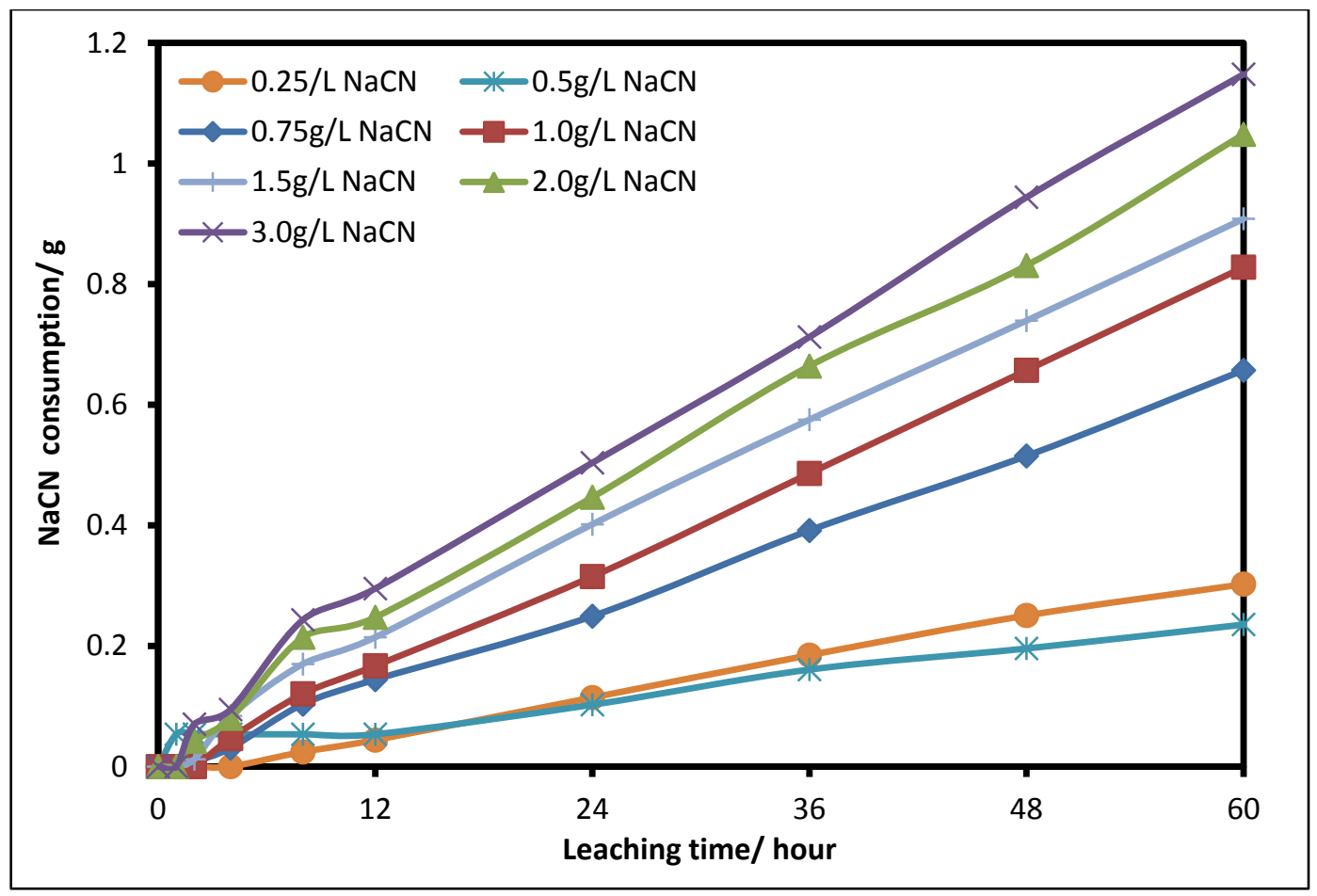

Figure 3-21 NaCN consumption vs leaching time at different $\mathrm{NaCN}$ concentration in LeachWELL $^{\mathrm{TM}}$-cyanide system

$\left(0.2 \mathrm{~g} / \mathrm{L}\right.$ LeachWELL $L^{T M}, p H=11$, room temperature, $\left.500 \mathrm{rpm}\right)$

Table 3-4 Cyanide utilization efficiency in LeachWELL ${ }^{\mathrm{TM}}$ leaching

\begin{tabular}{|c|c|c|c|c|}
\hline $\begin{array}{c}\mathrm{NaCN} \\
\text { concentration/g/L }\end{array}$ & $\begin{array}{c}\text { Leaching time/ } \\
\text { hour }\end{array}$ & $\underset{\text { extraction/ }}{\mathrm{Ag}}$ & $\begin{array}{c}\mathrm{NaCN} \\
\text { addition/g }\end{array}$ & $\begin{array}{c}\text { Cyanide Utilization } \\
\text { efficiency/ \% }\end{array}$ \\
\hline 0.25 & 60 & 60.55 & 0.3026 & 15.81 \\
\hline 0.5 & 60 & 89.50 & 0.2356 & 30.02 \\
\hline 0.75 & 60 & 92.05 & 0.6571 & 11.07 \\
\hline 1 & 48 & 98.15 & 0.8281 & 9.37 \\
\hline 1.5 & 24 & 100 & 0.9083 & 8.7 \\
\hline 2 & 24 & 100 & 1.0483 & 7.54 \\
\hline 3 & 8 & 100 & 1.148 & 6.88 \\
\hline
\end{tabular}


The cyanide utilization efficiency in this series of tests was calculated and shown in Table 3-4. It was clear that when the cyanide concentration was higher than $0.5 \mathrm{~g} / \mathrm{L}$, with the increase of cyanide concentration, the cyanide utilization efficiency went down.

\subsubsection{Investigation of the LeachWELL ${ }^{\mathrm{TM}}$-Cyanide System}

\subsubsection{Consumption of $\mathrm{NaCN}$ and $\mathrm{NaOH}$ by LeachWELL ${ }^{\mathrm{TM}}$}

For the LeachWELL ${ }^{\mathrm{TM}}$-cyanide system, another two blank experiments were conducted. One was for blank $\mathrm{NaCN}$ volatilization loss and the other one was for $\mathrm{NaCN}$ loss caused by LeachWELL ${ }^{\mathrm{TM}}$. Both tests were conducted in a $1 \mathrm{~L} \mathrm{NaOH}$ solution $(\mathrm{pH}=11)$ with the addition of $0.5 \mathrm{~g} / \mathrm{L} \mathrm{NaCN}$ for 60 hours without silver sulfide mineral. But $0.2 \mathrm{~g} / \mathrm{L}$ LeachWELL ${ }^{\mathrm{TM}}$ was only introduced in the latter test with the purpose of investigating the influence of LeachWELL ${ }^{\mathrm{TM}}$ on $\mathrm{NaCN}$ and $\mathrm{NaCN}$ loss. The accumulated $\mathrm{NaOH}$ and $\mathrm{NaCN}$ consumption in these two tests were also recorded in the same manner as in the other silver sulfide leaching tests.

From the first $\mathrm{NaCN}$ volatilization test the amount of $\mathrm{NaCN}$ and $\mathrm{NaOH}$ consumption without oxidants and cyanidation were obtained. The second test provided data that indicated the consumption of $\mathrm{NaCN}$ and $\mathrm{NaOH}$ caused by $0.2 \mathrm{~g} / \mathrm{L} \mathrm{LeachWELL}^{\mathrm{TM}}$. 


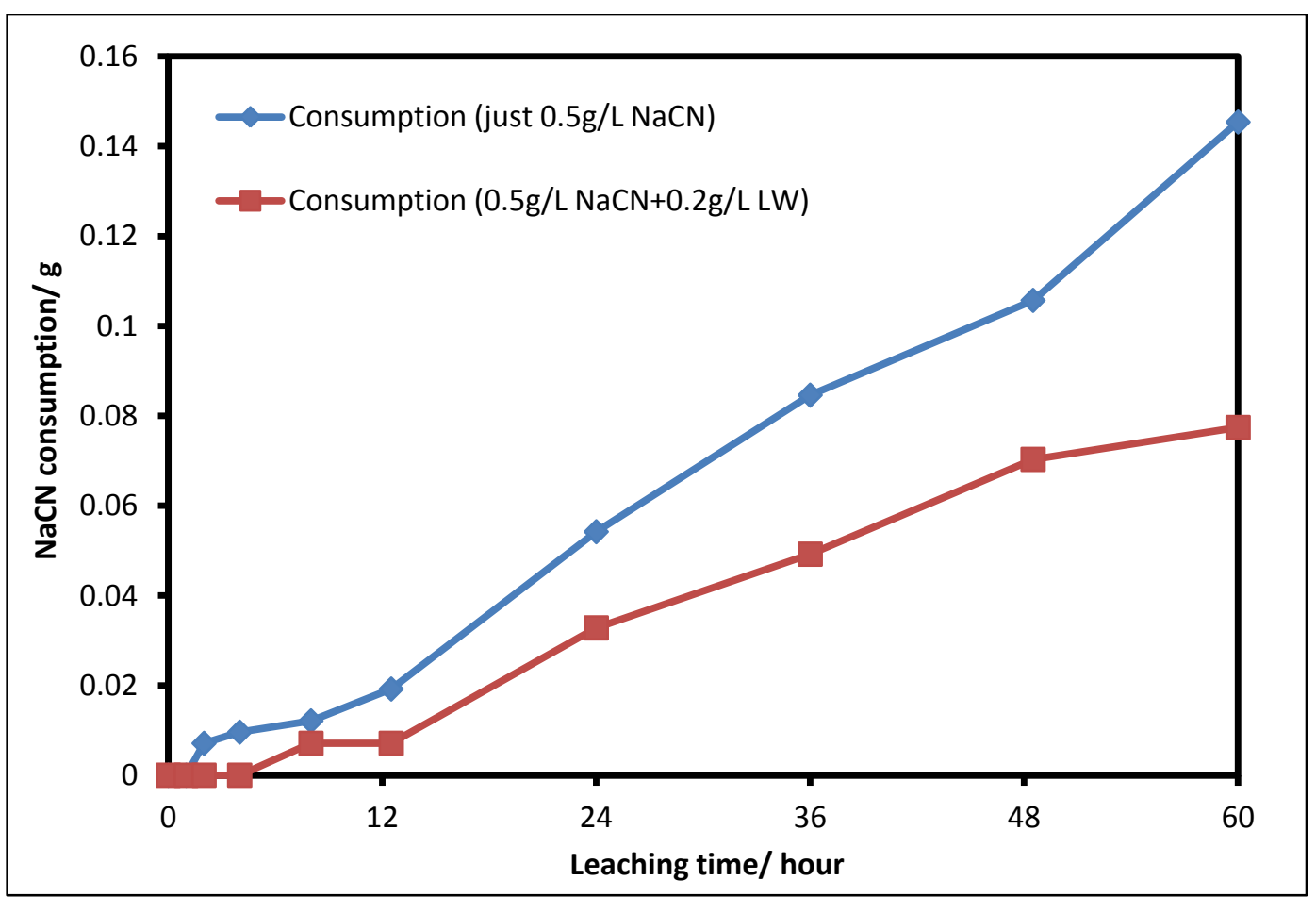

Figure 3-22 NaCN consumption vs leaching time without $\mathrm{Ag}_{2} \mathrm{~S}$ in LeachWELL ${ }^{\mathrm{TM}}$-cyanide system $\left(0.5 \mathrm{~g} / \mathrm{L} \mathrm{NaCN}, p H=11\right.$, room temperature, $500 \mathrm{rpm}, L W=$ LeachWELL $\left.^{T M}\right)$

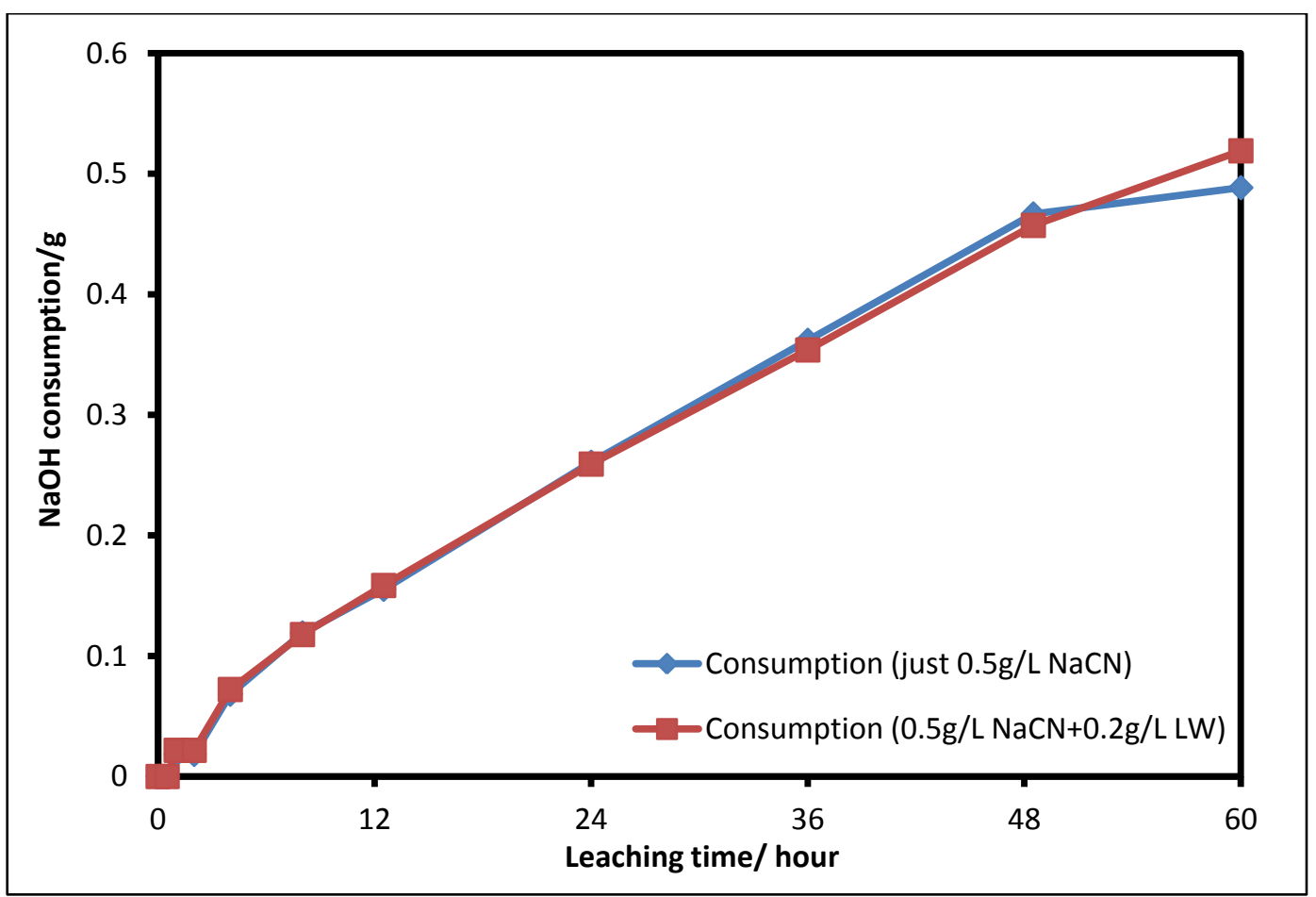

Figure 3-23 $\mathrm{NaOH}$ consumption vs leaching time without $\mathrm{Ag}_{2} \mathrm{~S}$ in LeachWELL ${ }^{\mathrm{TM}}$-cyanide system $\left(0.5 \mathrm{~g} / \mathrm{L} \mathrm{NaCN}, \mathrm{pH}=11\right.$, room temperature, $500 \mathrm{rpm}, \mathrm{LW}=$ Leach $\left.W E L L^{T M}\right)$ 
Figure 3-22 and Figure 3-23 indicated that in these two tests, the consumption of $\mathrm{NaOH}$ were almost the same, indicating that $0.2 \mathrm{~g} / \mathrm{L} \mathrm{LeachWELL}^{\mathrm{TM}}$ did not consume too much $\mathrm{OH}^{-}$. NaCN consumption was expected to increase with the addition of $0.2 \mathrm{~g} / \mathrm{L}$ LeachWELL $^{\mathrm{TM}}$ because of the oxidation of free cyanide by LeachWELL ${ }^{\mathrm{TM}}$. However, the measured $\mathrm{NaCN}$ consumption decreased slightly with the addition of $0.2 \mathrm{~g} / \mathrm{L}$ LeachWELL $^{\mathrm{TM}}$.

Cyanide was consumed in three ways: complexing with silver/sulfur species, hydrolysis and volatilization of $\mathrm{HCN}$, and oxidation by oxidants. In these two tests, the factor of complexing with silver/sulfur was eliminated. Hydrolysis and volatilization of HCN were considered to be equal since the $\mathrm{pH}$ and $\mathrm{NaOH}$ consumption were the same in these two tests. Therefore it could be concluded that the loss of free cyanide by reacting with LeachWELL ${ }^{\mathrm{TM}}$ was insignificant in this system.

\subsubsection{Synthetic Silver Sulfide Leaching with Lead Nitrate}

Since LeachWELL ${ }^{\mathrm{TM}}$ was effective in silver sulfide cyanidation, further research was necessary to study its working mechanism. It is known as a mixture of $2 \%$ of lead nitrate and $98 \%$ of mild organic oxidant. Therefore, the same amount of $\mathrm{Pb}\left(\mathrm{NO}_{3}\right)_{2}$, as was in the LeachWELL $^{\mathrm{TM}}$ additions, were tested separately for comparison with LeachWELL ${ }^{\mathrm{TM}}$. With a total of $0.004 \mathrm{~g} / \mathrm{L}$ and $0.01 \mathrm{~g} / \mathrm{L} \mathrm{Pb}\left(\mathrm{NO}_{3}\right)_{2}$ addition, which were equivalent to the content in $0.2 \mathrm{~g} / \mathrm{L}$ and $0.5 \mathrm{~g} / \mathrm{L} \mathrm{LeachWELL}^{\mathrm{TM}}$, the leaching results are listed below. 


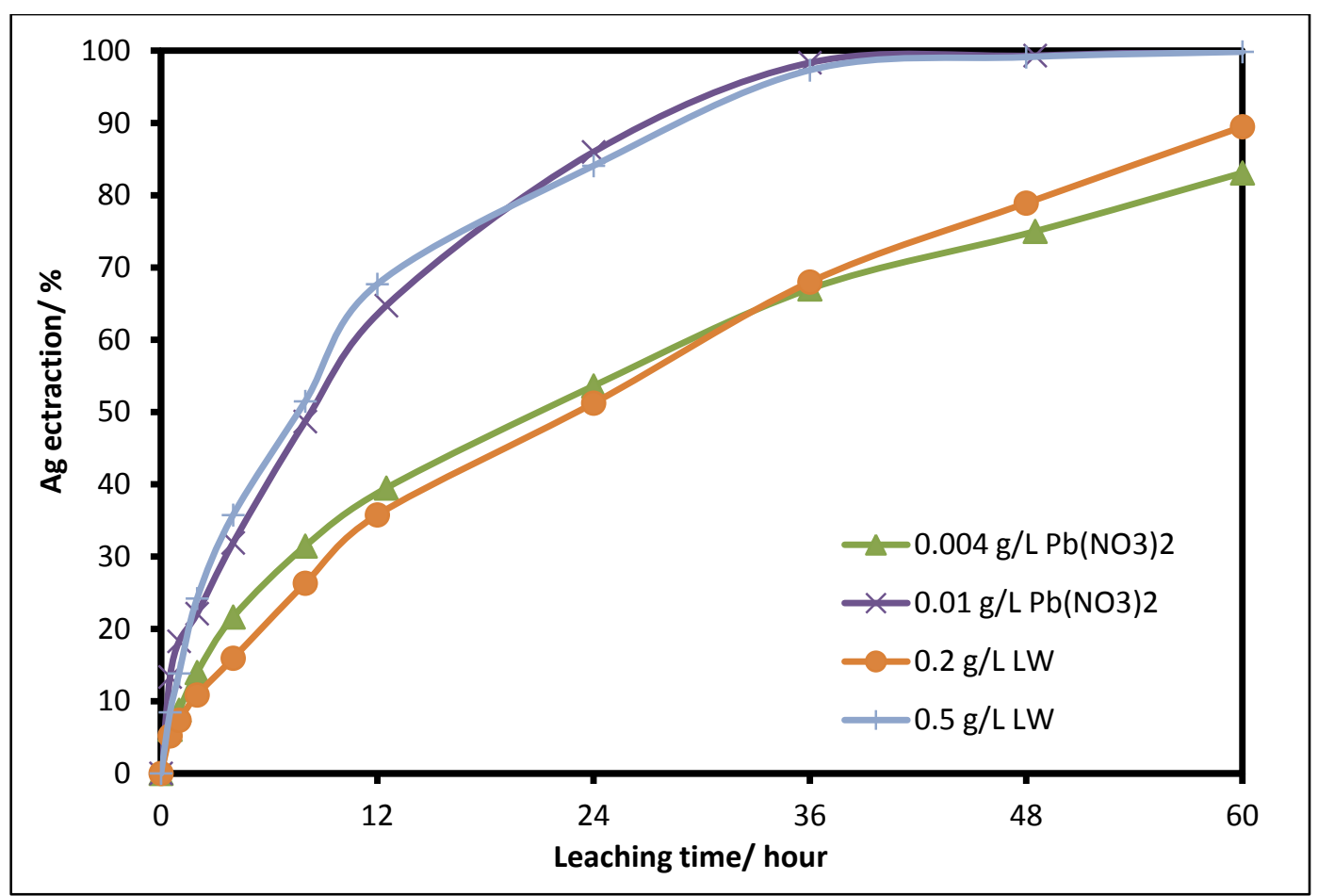

Figure 3-24 Ag extraction vs leaching time with LeachWELL ${ }^{\mathrm{TM}} / \mathrm{Pb}\left(\mathrm{NO}_{3}\right)_{2}$ $\left(0.5 \mathrm{~g} / \mathrm{L} \mathrm{NaCN}, p H=11\right.$, room temperature, $500 \mathrm{rpm}, L W=$ LeachWELL $\left.^{T M}\right)$

Figure 3-24 shows a direct comparison between LeachWELL ${ }^{\mathrm{TM}}$ and $\mathrm{Pb}\left(\mathrm{NO}_{3}\right)_{2}$ on silver extraction. The extraction curves are almost the same, which means that lead nitrate played an important role in enhancing cyanidation in both LeachWELL ${ }^{\mathrm{TM}}$ and $\mathrm{Pb}\left(\mathrm{NO}_{3}\right)_{2}$ assisted leaching.

In the above test a similar result to that of Luna et al. (2003) was observed. In silver sulfide cyanidation, according to the investigation by Luna et al. (2003), evaluation of the Evans diagrams of systems, with or without lead addition, illustrated that the presence of lead ion favors the sulfide oxidation velocity. They also leached a low grade acanthite mineral with the addition of lead ion. It was believed that the positive effect of lead ion on silver sulfide leaching could be explained by the action of lead as a sequestering agent that trapped sulfide and/or hydroxyl ions at the interface as soon as they were formed, slowly allowing the release of the silver ions (Luna et al., 2003). It was reported that the formation of redox couples, such as $\mathrm{PbO}$ and $\mathrm{Pb}(\mathrm{OH})_{2}$, could improve the continuous oxidation of silver sulfide minerals and accelerate the oxidation of sulfide ion (Breuer et 
al., 2008; Deschenes et al., 2011). Therefore, in synthetic silver sulfide cyanide leaching tests with LeachWELL ${ }^{\mathrm{TM}}$ and lead nitrate, the enhancement of the silver dissolution could be attributed to the presence of lead ion.

From the $\mathrm{NaOH}$ consumption results (Figure 3-26) it could be observed that LeachWELL ${ }^{\mathrm{TM}}$ and $\mathrm{Pb}\left(\mathrm{NO}_{3}\right)_{2}$ showed no difference in affecting the pulp alkalinity. In addition, the constant $\mathrm{NaOH}$ consumption with different LeachWELL ${ }^{\mathrm{TM}} / \mathrm{Pb}\left(\mathrm{NO}_{3}\right)_{2}$ addition indicate that the complexing of $\mathrm{Ag}^{+}$and $\mathrm{CN}^{-}$did not influence the pulp pH too much, probably because of the low pulp density in these leaching system.

The consumption of $\mathrm{NaCN}$ in both the $\mathrm{Pb}\left(\mathrm{NO}_{3}\right)_{2}$ and LeachWELL ${ }^{\mathrm{TM}}$ systems were similar but different from the blank tests without $\mathrm{Ag}_{2} \mathrm{~S}$ (Figure 3-25). The difference (about $0.1 \mathrm{~g} \mathrm{NaCN}$ ) could be attributed to the combination of cyanide with dissolved silver. Taking $0.2 \mathrm{~g} / \mathrm{L}$ LeachWELL $^{\mathrm{TM}}$ assisted leaching system as an example we can calculate the cyanide consumption.

- Dissolved silver $=90 \% \times 0.1 \mathrm{~g} \mathrm{Ag}_{2} \mathrm{~S} / 248 \mathrm{~g} \mathrm{Ag}_{2} \mathrm{~S} / \mathrm{mol} \mathrm{Ag}_{2} \mathrm{~S} \times 2 \mathrm{~mol} \mathrm{Ag} / \mathrm{mol} \mathrm{Ag}_{2} \mathrm{~S}=7.3 \times 10^{-4} \mathrm{~mol} \mathrm{Ag}$

- The amount of $\mathrm{NaCN}$ for complexing $=2 \mathrm{~mol} \mathrm{NaCN} / \mathrm{mol} \mathrm{Ag} \times 7.3 \times 10^{-4} \mathrm{~mol} \mathrm{Ag} \times 49 \mathrm{~g} \mathrm{NaCN} / \mathrm{mol} \mathrm{NaCN}=0.071 \mathrm{~g} \mathrm{NaCN}$

- The difference value between $0.2 \mathrm{~g} / \mathrm{L}$ LeachWELL ${ }^{\mathrm{TM}}$-cyanide systems with and without mineral

$$
=0.2082 \mathrm{~g} \mathrm{NaCN}-0.0774 \mathrm{~g} \mathrm{NaCN}=0.1308 \mathrm{~g} \mathrm{NaCN}
$$

The calculation proved that the amount of $\mathrm{NaCN}$ complexed with dissolved silver $(0.071 \mathrm{~g} \mathrm{NaCN})$ accounted for a large proportion of the difference $(0.1308 \mathrm{~g} \mathrm{NaCN})$. 


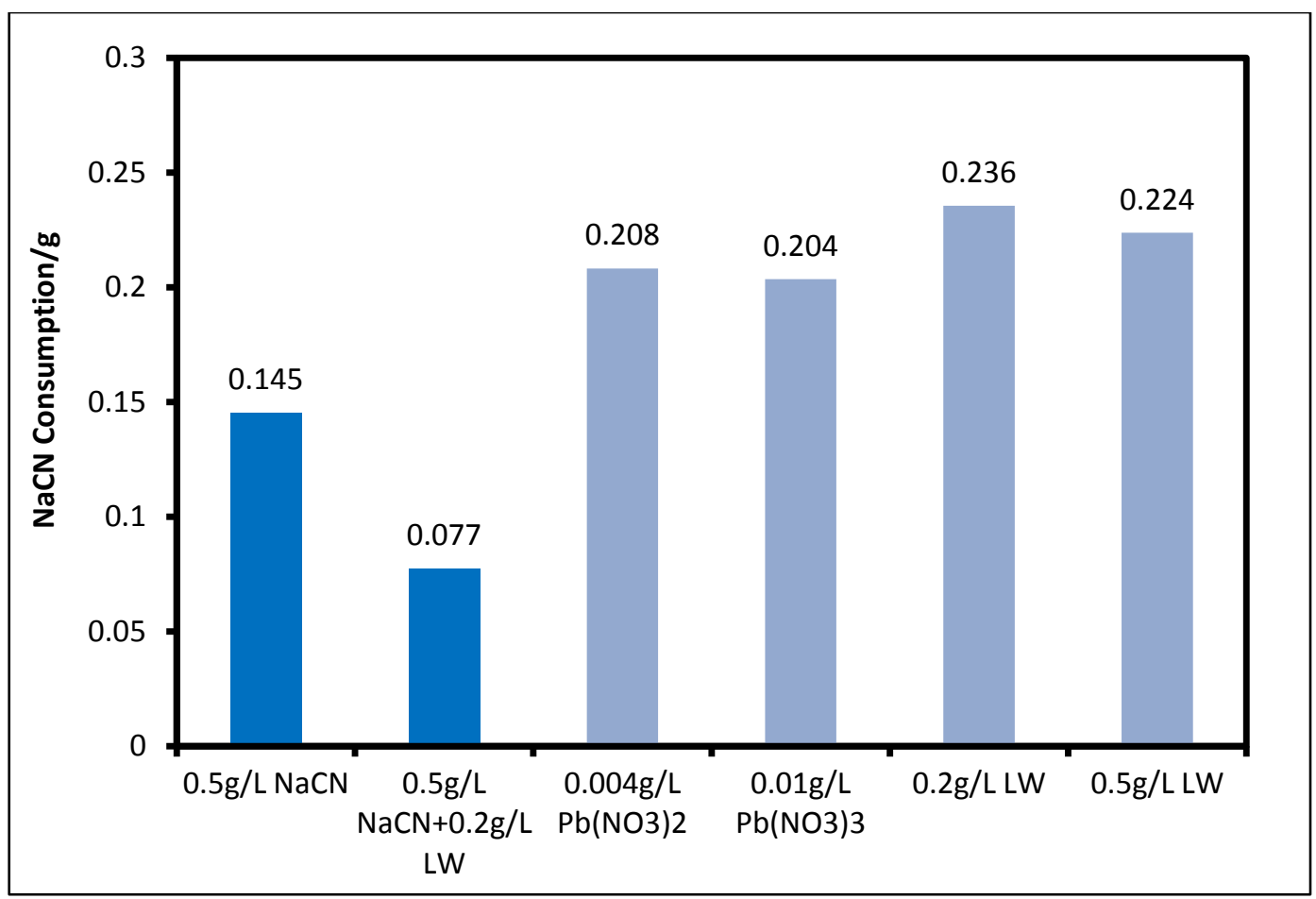

Figure 3-25 Accumulated $\mathrm{NaCN}$ consumption in 60 hours with LeachWELL $\mathrm{LM}^{\mathrm{TM}} / \mathrm{Pb}\left(\mathrm{NO}_{3}\right)_{2}$ $\left(0.5 \mathrm{~g} / \mathrm{L} \mathrm{NaCN}, p H=11\right.$, room temperature, $500 \mathrm{rpm}, L W=$ LeachWELL $\left.^{T M}\right)$

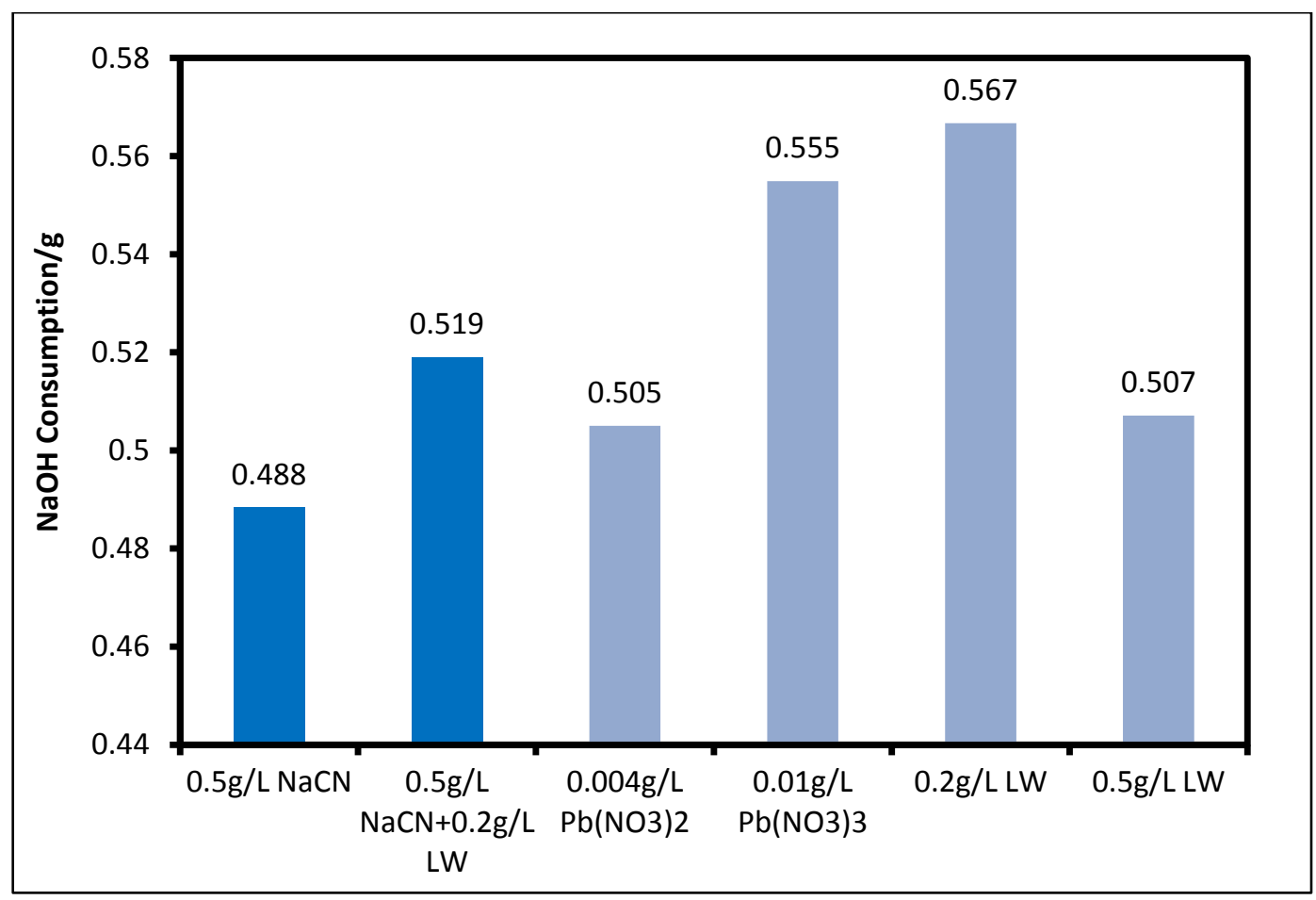

Figure 3-26 Accumulated $\mathrm{NaOH}$ consumption in 60 hours with LeachWELL ${ }^{\mathrm{TM}} / \mathrm{Pb}\left(\mathrm{NO}_{3}\right)_{2}$ $\left(0.5 \mathrm{~g} / \mathrm{L} \mathrm{NaCN}, p H=11\right.$, room temperature, $500 \mathrm{rpm}, L W=$ LeachWELL $\left.^{T M}\right)$ 


\subsection{Summary}

The effect of three auxiliary oxidants $\left(\mathrm{H}_{2} \mathrm{O}_{2}, \mathrm{CaO}_{2}\right.$ and LeachWELL $\left.{ }^{\mathrm{TM}}\right)$ on enhancing synthetic silver sulfide cyanidation was studied. The leaching results were analyzed in terms of final silver extraction, $\mathrm{NaCN}$ consumption and $\mathrm{NaOH}$ consumption.

Without any of these auxiliary oxidants, only $5 \%$ of a synthetic silver sulfide sample was extracted in an aerated cyanide solution.

The addition of $\mathrm{H}_{2} \mathrm{O}_{2}$ increased silver recovery to as much as $90 \%$, but also raised the consumption of $\mathrm{NaOH}$ and $\mathrm{NaCN}$. Hence the application of $\mathrm{H}_{2} \mathrm{O}_{2}$ in the cyanidation process is challenged by high reagent consumption and cost.

$\mathrm{CaO}_{2}$ assisted leaching only yielded as high as $30 \%$ silver extraction. Thus it did not improve silver recovery to a satisfactory level. In addition, final silver extraction even dropped with the increase of $\mathrm{CaO}_{2}$ addition when the $\mathrm{CaO}_{2}$ concentration was above a critical value. Based on these results, $\mathrm{CaO}_{2}$ was deemed not an appropriate auxiliary oxidant. The $\mathrm{NaCN}$ and $\mathrm{NaOH}$ demand was low but this is not significant as the silver extraction was uneconomical.

Compared to the previous two oxidants, LeachWELL ${ }^{\mathrm{TM}}$ dissolved silver sulfide more quickly and completely with less $\mathrm{NaCN}$ and $\mathrm{NaOH}$ consumption, making it the best oxidant among the three auxiliary oxidants studied. Therefore effects of temperature, $\mathrm{pH}$ and cyanide concentration on LeachWELL ${ }^{\mathrm{TM}}$ assisted systems were conducted. $\mathrm{pH}$ did not influence silver recovery with LeachWELL ${ }^{\mathrm{TM}}$, but impacted the $\mathrm{NaCN}$ and $\mathrm{NaOH}$ consumption. Rised temperature slightly decreased the silver sulfide leaching rate in enhanced cyanidation. Increasing $\mathrm{NaCN}$ concentration accelerated the reaction kinetics of silver leaching.

Tests with $\mathrm{Pb}\left(\mathrm{NO}_{3}\right)_{2}$ showed that $\mathrm{Pb}\left(\mathrm{NO}_{3}\right)_{2}$ enhanced the leaching of silver sulfide to the same extent as LeachWELL ${ }^{\mathrm{TM}}$ did. Furthermore, the comparison to blank leaching 
indicated that the oxidation of free cyanide by LeachWELL ${ }^{\mathrm{TM}}$ was insignificant. 


\section{Chapter 4 Cyanidation of Mixed Minerals and}

\section{Natural Acanthite}

\subsection{Introduction}

In this chapter, leaching of mixtures of sulfide minerals (including natural acanthite) was investigated. The tests on mixed minerals had a focus of comparing the interference of non-silver metal sulfide minerals on the LeachWELL ${ }^{\mathrm{TM}}$ assisted cyanidation of $\mathrm{Ag}_{2} \mathrm{~S}$. The objective of natural acanthite sample leaching was to test the performance of LeachWELL ${ }^{\mathrm{TM}}$ as well as $\mathrm{H}_{2} \mathrm{O}_{2}$ and $\mathrm{CaO}_{2}$ in natural silver sulfide leaching and thus their applicability to industrial leaching.

\subsection{Experimental Set-up}

\subsubsection{Samples and Reagents}

(a) Non-silver sulfide minerals

Seven non-silver sulfide minerals (source unspecified) studied were pyrite $\left(\mathrm{FeS}_{2}\right)$, pyrrhotite $\left(\mathrm{Fe}_{7} \mathrm{~S}_{8}\right)$, chalcopyrite $\left(\mathrm{CuFeS}_{2}\right)$, covellite $(\mathrm{CuS})$, chalcocite $\left(\mathrm{Cu}_{2} \mathrm{~S}\right)$, sphalerite $(\mathrm{ZnS})$ and galena $(\mathrm{PbS})$. The XRD (X-ray Diffraction) analysis of these mineral samples indicated that, except for sphalerite $(\mathrm{ZnS})$ and galena $(\mathrm{PbS})$, the other five minerals had very high purity and could be treated as pure sulfides. In the sphalerite sample, except for $\mathrm{ZnS}$, the main impurity was silica $\left(\mathrm{SiO}_{2}\right)$. For the galena sample, its composition analysis indicated that it contained $\sim 60 \% \mathrm{PbS}, \sim 20 \% \mathrm{Fe} / \mathrm{ZnS}$ and $\sim 7 \% \mathrm{FeS}_{2}$. This is a qualitative analysis of the impact of the non-silver metal sulfide minerals on synthetic silver sulfide 
cyanidation, thus no further elemental analysis of theses minerals were conducted. In addition, the size of the non-silver sulfide mineral particles were controlled between $45 \mu \mathrm{m} \sim 75 \mu \mathrm{m}$ by grinding and sieving.

(b) Natural acanthite

Through comparison, the natural acanthite mineral with highest degree of silver sulfide was applied. This natural acanthite sample was provided by Mineralogical Research Company with high $\mathrm{Ag}_{2} \mathrm{~S}$ content ( $\left.38 \%\right)$. According to the result of the ICP (Inductive Coupled Plasma) analysis, the main components of the rest of the concentrate were $18.1 \%$ $\mathrm{Fe}, 11.38 \% \mathrm{~Pb}$, and $26.15 \% \mathrm{~S}\left(24.64 \% \mathrm{~S}^{2-}\right)$.

The chemical composition of the natural acanthite concentrate is shown in Table 4-1. It shows that the mineral sample contained $33.20 \%$ silver with iron and lead present as the main non-silver metals. There were also small amounts of copper and zinc present. Most of the metals were present as sulfide minerals since $\mathrm{S}^{2-}$ accounted for almost all the rest of the total composition. Cyanidation results of this natural acanthite concentrate are shown in the following diagrams.

Table 4-1 Fire Assay and ICP analysis results of natural acanthite sample

\begin{tabular}{cccccccc}
\hline Element & Ag \% & Total S \% & $\mathbf{S}^{2-} \%$ & Fe \% & Pb \% & Cu \% & Zn \% \\
\hline & 33.20 & 26.15 & 24.635 & 18.095 & 11.375 & 0.164 & 0.033 \\
\hline
\end{tabular}

For comparison with synthetic silver sulfide leaching, the particle size of the natural acanthite sample was controlled under $45 \mu \mathrm{m}$, at the same level with synthetic silver sulfide. The pulp density was maintained at $0.1 \mathrm{~g} / \mathrm{L}$.

\subsubsection{Leaching Conditions}

For each kind of sulfide mineral, different concentrations of mineral addition were tested in order to better understand its effect on LeachWELL ${ }^{\mathrm{TM}}$ assisted silver sulfide leaching. The addition of each non-silver metal sulfide mineral were $0.1 \mathrm{~g} / \mathrm{L}, 0.5 \mathrm{~g} / \mathrm{L}, 1 \mathrm{~g} / \mathrm{L}$ and $2 \mathrm{~g} / \mathrm{L}$. The optimum (for high extraction of silver) conditions for LeachWELL ${ }^{\mathrm{TM}}$ cyanidation 
obtained from the previous series experiments were applied.

Table 4-2 Leaching conditions of sulfide minerals mixtures cyanidation

\begin{tabular}{|c|c|}
\hline Volume of solution & $1 \mathrm{~L}$ \\
\hline Solid & $0.1 \mathrm{~g}$ synthetic $\mathrm{Ag}_{2} \mathrm{~S}$ \\
& $+0.1 / 0.5 / 1 / 2 \mathrm{~g} / \mathrm{L}$ non-silver sulfide mineral \\
\hline Solution pH & 11 \\
\hline Temperature & Room temperature $17^{\circ} \mathrm{C}\left( \pm 3^{\circ} \mathrm{C}\right)$ \\
\hline Atmosphere & Air \\
\hline Rotation speed & $500 \mathrm{rpm}$ \\
\hline Leaching Time & $60 \mathrm{hr}$ \\
\hline NaCN & $0.5 \mathrm{~g} / \mathrm{L}$ \\
\hline LeachWELL & $0.2 \mathrm{~g} / \mathrm{L}$ \\
\hline
\end{tabular}

To further study the feasibility of the three oxidants on natural acanthite cyanidation process, natural acanthite provided by Mineralogical Research Company was leached under similar conditions as synthetic silver sulfide leaching tests. The leaching conditions are summarized as Table 4-3.

Table 4-3 Leaching conditions of natural acanthite cyanidation

\begin{tabular}{|c|c|}
\hline Volume of solution & $1 \mathrm{~L}$ \\
\hline Solid & $0.1 \mathrm{~g}$ natural acanthite \\
\hline Solution pH & 11 \\
\hline Temperature & Room temperature, $17^{\circ} \mathrm{C}\left( \pm 3^{\circ} \mathrm{C}\right)$ \\
\hline Atmosphere & Air \\
\hline Rotation speed & $600 \mathrm{rpm}$ \\
\hline Leaching Time & $0.5 \mathrm{gr} / \mathrm{L}$ \\
\hline NaCN & $0.2 \mathrm{~g} / \mathrm{L}, 0.5 \mathrm{~g} / \mathrm{L}, 0.8 \mathrm{~g} / \mathrm{L}$ \\
\hline LeachWELL & $3.4 \mathrm{~g} / \mathrm{L}$ \\
\hline $\mathbf{H}_{\mathbf{2}} \mathbf{O}_{2}$ & $0.72 \mathrm{~g} / \mathrm{L}$ \\
\hline $\mathbf{C a O}_{\mathbf{2}}$ & \\
\hline
\end{tabular}




\subsubsection{Experimental Procedure}

The experimental operations in these tests were the same as the synthetic silver sulfide leaching tests. Filtration of the final leaching solution was an additional operation in leaching of mixtures of sulfide minerals.

\subsubsection{Analysis}

The ore samples were analyzed using Inductively Coupled Plasma (ICP), X-ray Diffraction (XRD) and Fire Assay. XRD analyses were performed using a Multiflex 2KW Copper Long-Find Focus diffractometer. ICP analysis was conducted by Inspectorate, a certificate assayer in Richmond, BC. The Fire Assay for the degree of silver and the sulfur species detection in ores were also performed by Inspectorate.

The solution analysis was conducted in the same manner as in the previous chapter. Silver concentration in the solution was measured with an Atomic Absorption Spectrophotometer (AAS) instrument. Free cyanide content in solution was analyzed by titration of standardized silver nitrate. The only difference was the detection of dissolved non-silver metal $(\mathrm{Fe}, \mathrm{Cu}, \mathrm{Zn}$ and $\mathrm{Pb})$ concentrations in the solution with AAS to determine the dissolution of the added minerals.

\subsection{Results and Discussion}

\subsubsection{Cyanidation of Mixed Minerals}

\section{a) Pyrite and silver sulfide}

The decomposition of iron sulfide minerals adversely affected the leaching rate of gold. The dissolved iron will form $\mathrm{Fe}(\mathrm{CN})_{6}{ }^{4-}$ and various aqueous sulfur species. The order of decomposition rate of the most important iron sulfide minerals in cyanide solution was 
considered to be (Marsden and House, 2006):

Pyrrhotite $>>>$ marcasite $>$ arsenopyrite > pyrite

Figure 4-1 shows the effect of different concentrations of pyrite on silver extraction.

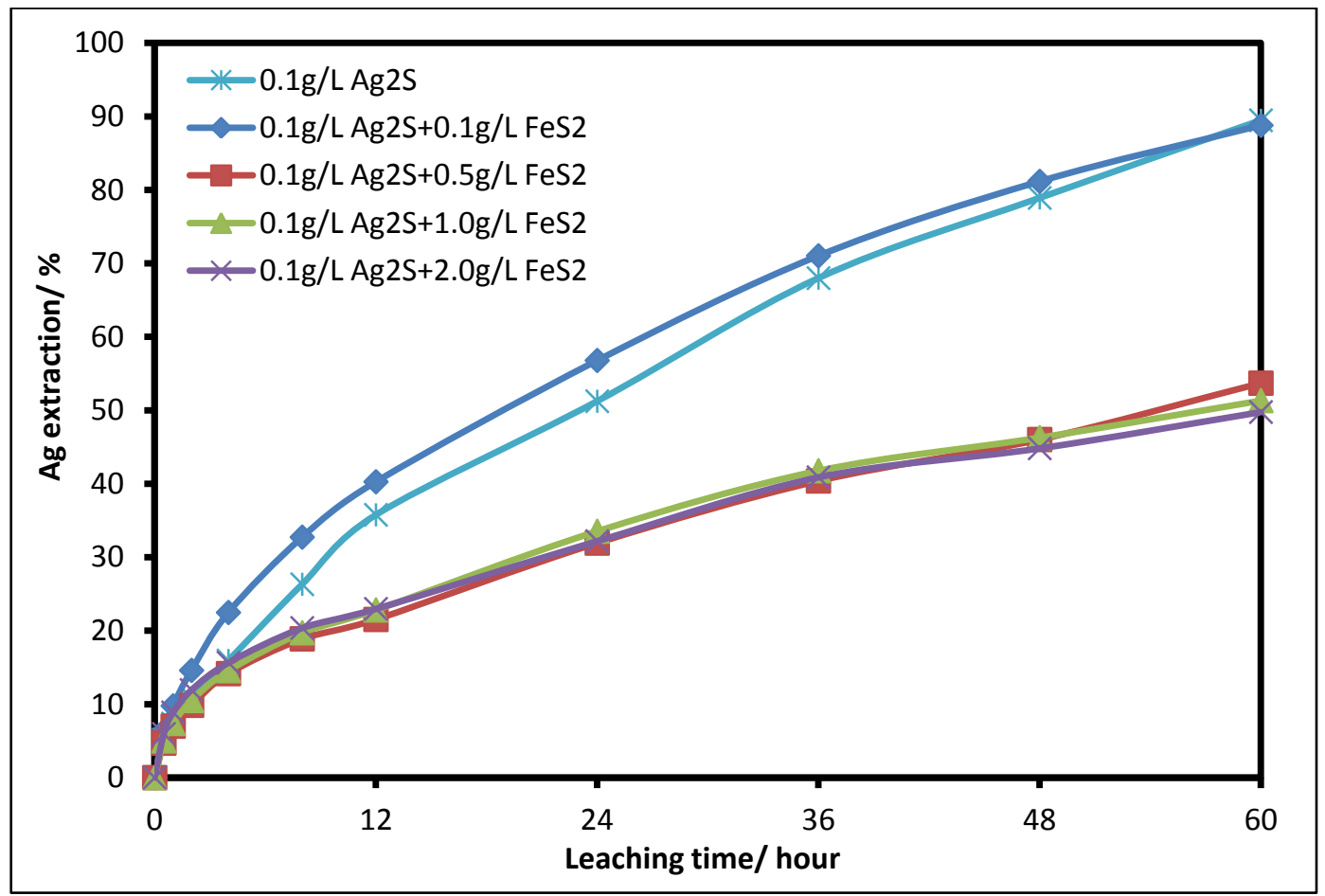

Figure 4-1 Ag extraction vs leaching time with different pyrite addition in LeachWELL ${ }^{\mathrm{TM}}$-cyanide system

$\left(0.2 \mathrm{~g} / \mathrm{L}\right.$ LeachWELL $\mathrm{L}^{\mathrm{TM}}, 0.5 \mathrm{~g} / \mathrm{L} \mathrm{NaCN}, \mathrm{pH}=11$, room temperature, $\left.500 \mathrm{rpm}\right)$

It can be observed that when the pyrite concentration was the same as that of silver sulfide, silver recovery was not affected. However, when pyrite level increased to $0.5 \mathrm{~g} / \mathrm{L}$ and higher, only $50 \%$ of silver sulfide could be dissolved. One possible explanation for this decrease was the competition of LeachWELL ${ }^{\mathrm{TM}}$ as oxidant between silver sulfide and pyrite. 


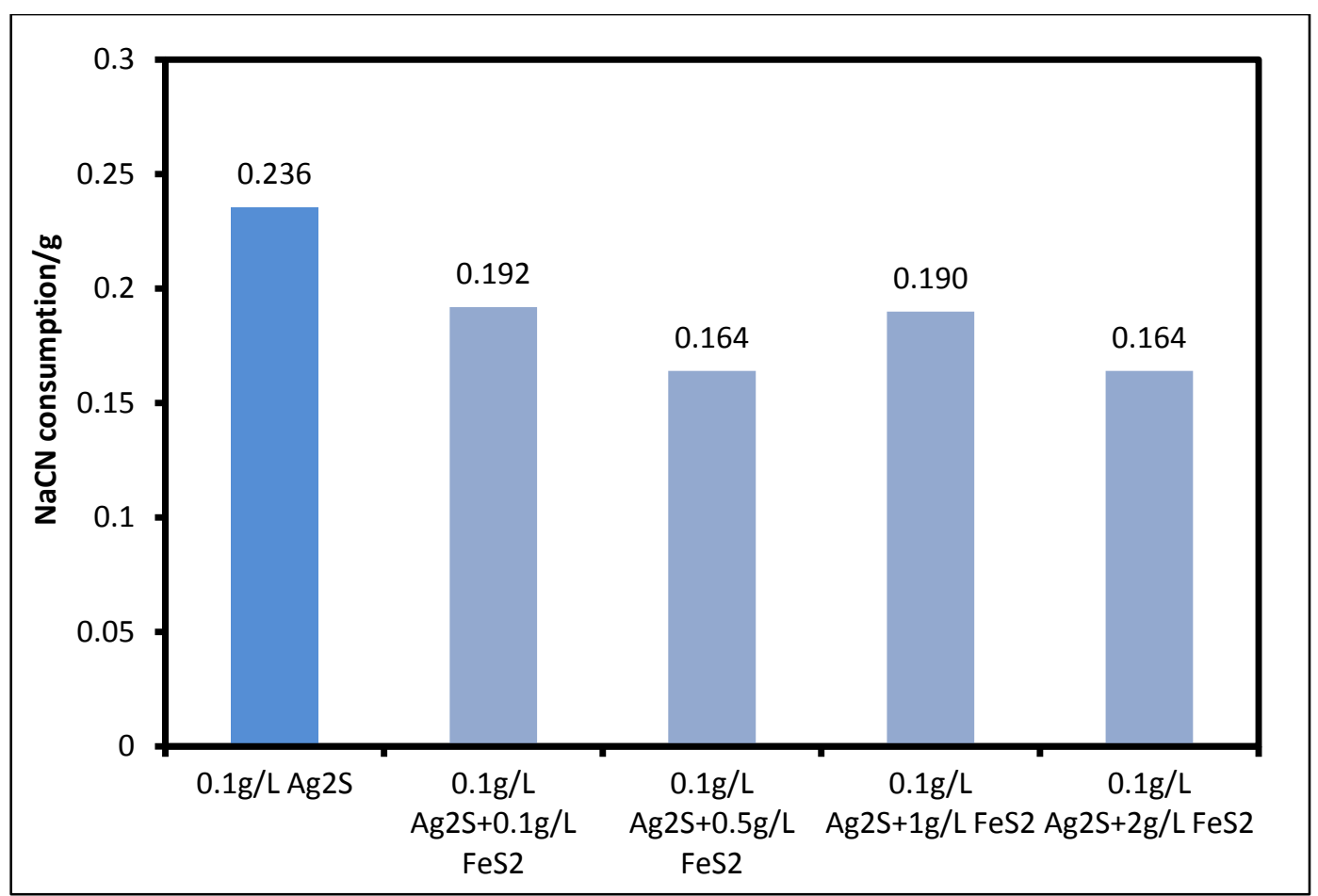

Figure 4-2 Accumulated NaCN consumption in 60 hours with different pyrite addition in LeachWELL $^{\mathrm{TM}}$-cyanide system

$\left(0.2 \mathrm{~g} / \mathrm{L}\right.$ LeachWELL $L^{T M}, 0.5 \mathrm{~g} / \mathrm{L} \mathrm{NaCN}, \mathrm{pH}=11$, room temperature, $\left.500 \mathrm{rpm}\right)$

As shown in Figure 4-2, the consumption of cyanide did not change with the increase of pyrite content. Even though iron concentration in the solution samples rose with the increase of pyrite addition, iron concentration was still quite low. The highest iron concentration detected in leaching solution was $9 \mathrm{mg} / \mathrm{L}$, indicating that no more that 2 percent of pyrite was dissolved. This result showed that the combination of cyanide with iron was not the main consumption of $\mathrm{NaCN}$.

\section{b) Pyrrhotite and silver sulfide}

Pyrrhotite is the most reactive iron sulfide in alkaline cyanide solution. The dissolution reaction can be divided into two steps (Marsden and House, 2006):

$$
\begin{array}{cl}
\mathrm{Fe}_{7} \mathrm{~S}_{8}+\mathrm{CN}^{-}=7 \mathrm{FeS}+\mathrm{CNS}^{-} & \text {Reaction 4-1 } \\
2 \mathrm{FeS}+12 \mathrm{CN}^{-}+5 \mathrm{O}_{2}+2 \mathrm{H}_{2} \mathrm{O}=2 \mathrm{Fe}(\mathrm{CN})_{6}{ }^{4-}+2 \mathrm{SO}_{4}{ }^{2-}+4 \mathrm{OH}^{-} & \text {Reaction 4-2 }
\end{array}
$$

As can be seen from Figure 4-3, silver extraction decreased with addition of pyrrhotite. In $0.1 \mathrm{~g} / \mathrm{L}$ silver sulfide cyanidation process, equivalent concentration of pyrrhotite reduced 
the silver extraction to $50 \%$, so did five and ten times pyrrhotite addition. With $2 \mathrm{~g} / \mathrm{L}$ pyrrhotite in the pulp, the extraction of silver was reduced to less than $40 \%$. It was suspected that pyrrhotite consumed LeachWELL ${ }^{\mathrm{TM}}$, thus less oxidant was available for acanthite dissolution.

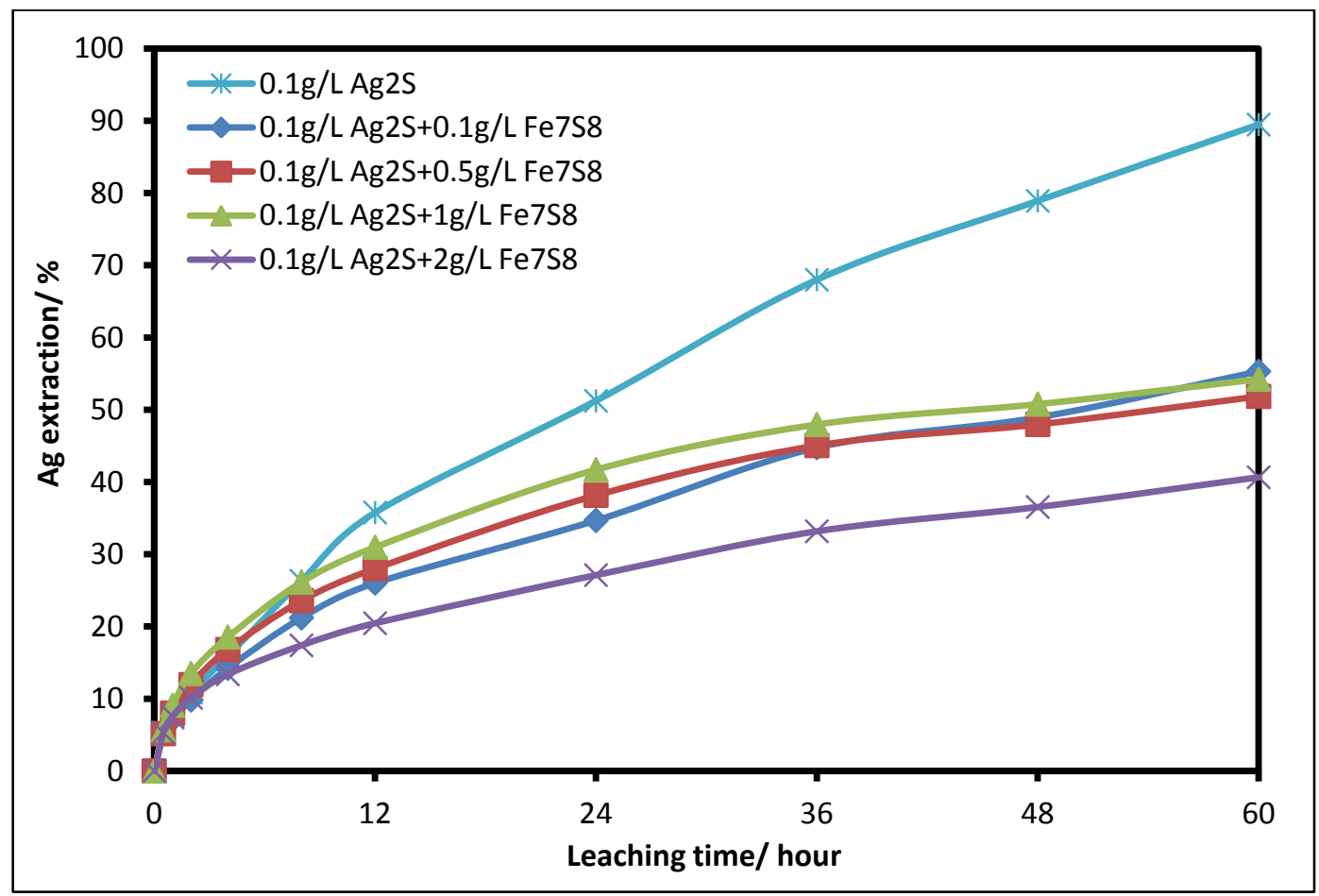

Figure 4-3 Ag extraction vs leaching time with different pyrrhotite addition in LeachWELL $^{\mathrm{TM}}$-cyanide system

$\left(0.2 \mathrm{~g} / \mathrm{L}\right.$ LeachWELL ${ }^{T M}, 0.5 \mathrm{~g} / \mathrm{L} \mathrm{NaCN}, \mathrm{pH}=11$, room temperature, $\left.500 \mathrm{rpm}\right)$

The consumption of $\mathrm{NaCN}$ did not increase with the increasing addition of pyrrhotite (Figure 4-4). Combined with the fact that dissolved iron concentration in the leaching solution is lower than $10 \mathrm{mg} / \mathrm{L}$, this turned out to be reasonable. Consumption of cyanide through combination with iron was insignificant. With the same consideration as in pyrite addition leaching, since less silver sulfide dissolved, the amount of cyanide that complexed with dissolved silver reduced, resulting in the decrease of total $\mathrm{NaCN}$ consumption. 


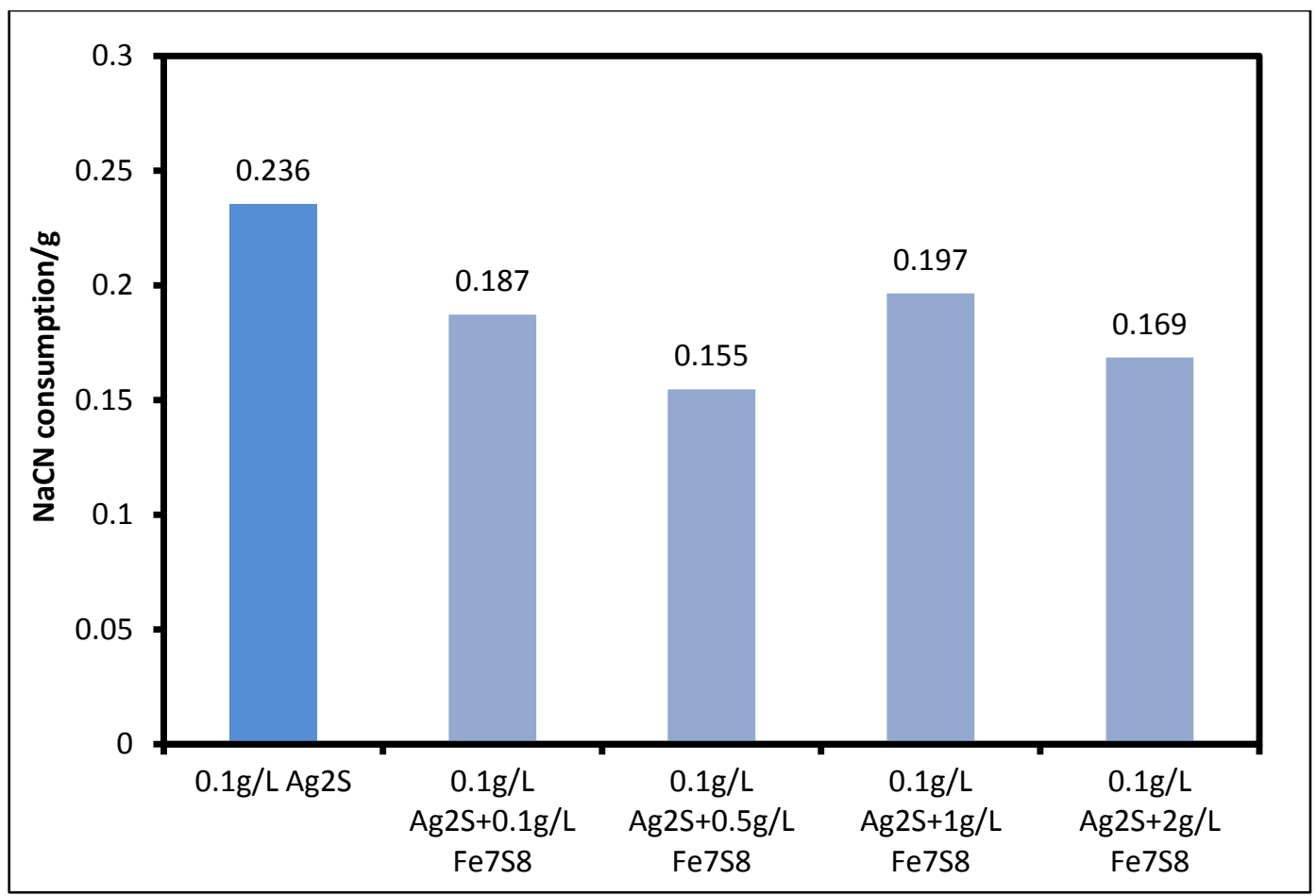

Figure 4-4 Accumulated NaCN consumption in 60 hours with different pyrrhotite addition in LeachWELL $^{\mathrm{TM}}$-cyanide system

$\left(0.2 \mathrm{~g} / \mathrm{L}\right.$ LeachWELL ${ }^{T M}, 0.5 \mathrm{~g} / \mathrm{L} \mathrm{NaCN}, \mathrm{pH}=11$, room temperature, $\left.500 \mathrm{rpm}\right)$

\section{c) Chalcopyrite and silver sulfide}

In gold cyanidation, copper minerals dissolve to varying degrees. Copper minerals dissolve to form a variety of $\mathrm{Cu}(\mathrm{I})$ cyanide complexes, $\mathrm{Cu}(\mathrm{CN})_{2}{ }^{-}, \mathrm{Cu}(\mathrm{CN})_{3}{ }^{2-}, \mathrm{Cu}(\mathrm{CN})_{4}{ }^{3-}$ and their stability constant are at the same level with silver cyanide complexes (Marsden and House, 2006).

Chalcopyrite is the least soluble copper mineral and it is capable of removing gold from solution by reduction at the mineral surface (Marsden and House, 2006). The impact of different amounts of chalcopyrite on $0.1 \mathrm{~g} / \mathrm{L}$ silver sulfide cyanidation process was investigated. Figure 4-5 indicates that with the addition of chalcopyrite, the final silver extraction decreased to $\sim 50 \%$. The influence of chalcopyrite on silver recovery did not change with the content of chalcopyrite in the pulp.

It was reported that the existence of silver ion in the solution can greatly improve the 
leaching of chalcopyrite by absorption into chalcopyrite minerals. Therefore, in this series test, the dissolved silver could be reabsorbed into $\mathrm{CuFeS}_{2}$ and the concentrations of silver ion remaining in the solution were in the same level.

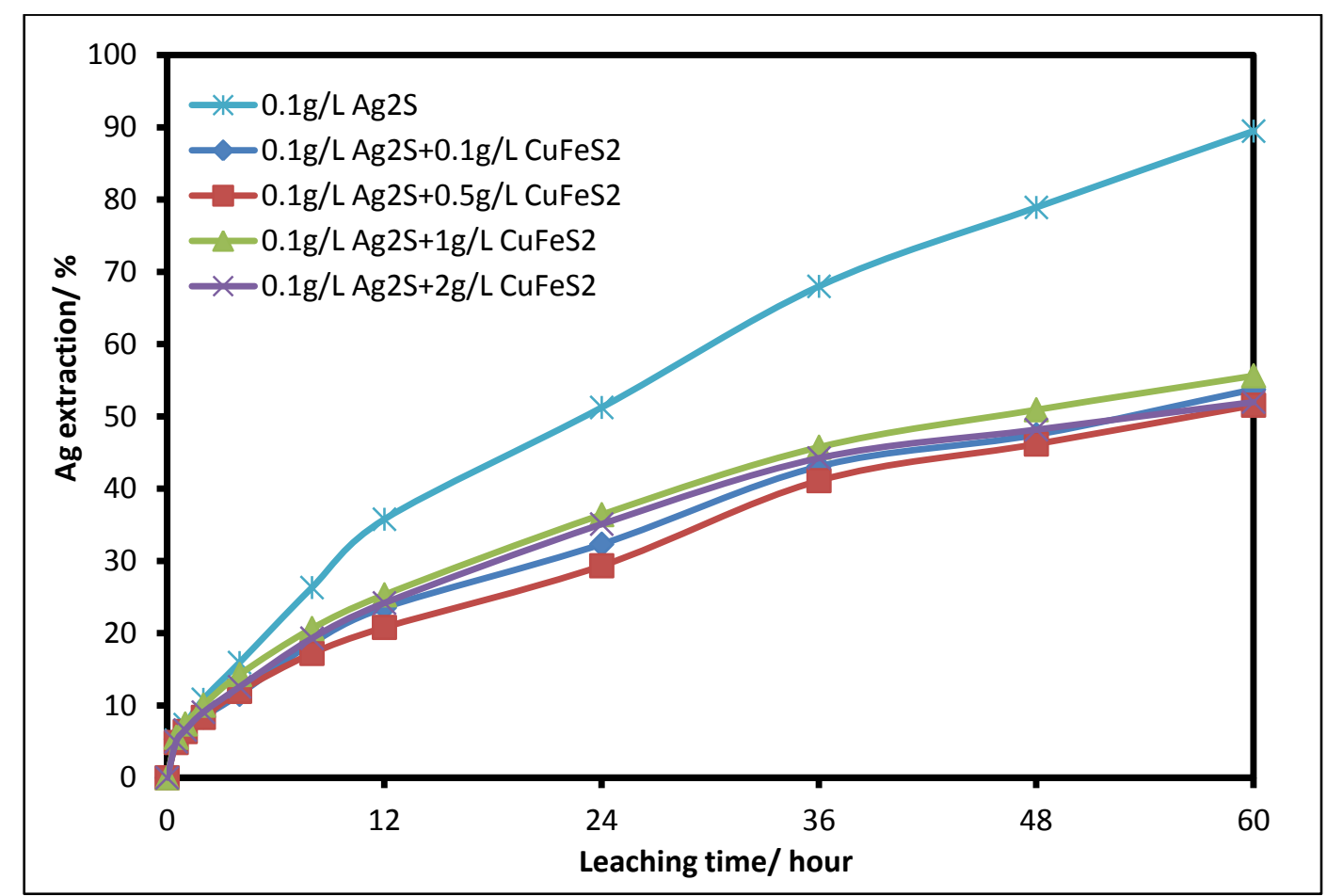

Figure 4-5 Ag extraction vs leaching time with different chalcopyrite addition in LeachWELL ${ }^{\mathrm{TM}}$-cyanide system $\left(0.2 \mathrm{~g} / \mathrm{L}\right.$ LeachWELL $L^{T M}, 0.5 \mathrm{~g} / \mathrm{L} \mathrm{NaCN}, \mathrm{pH}=11$, room temperature, $\left.500 \mathrm{rpm}\right)$

The copper and iron concentration in the solution samples were also analyzed and the results are shown in Figure 4-6 and Figure 4-7. In the first 12 hours of the leaching process, the concentration of copper and iron in the leaching solution increased sharply and then tended to increase smoothly, which indicates that most of the dissolution of chalcopyrite occurred in the first 12 (or less) hours. 


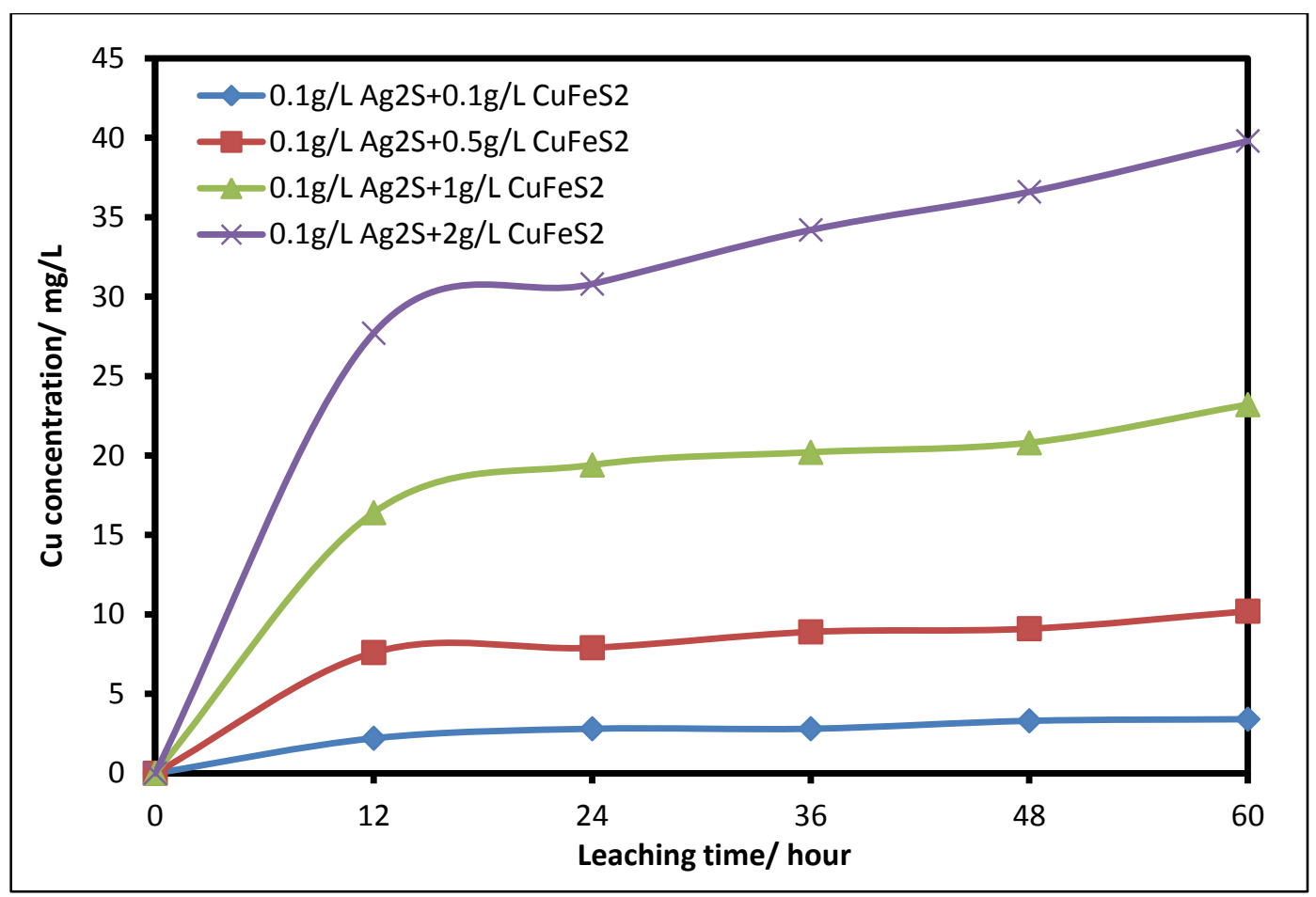

Figure 4-6 $\mathrm{Cu}$ concentration vs leaching time with different chalcopyrite addition in LeachWELL $^{\text {TM }}$-cyanide system

$\left(0.2 \mathrm{~g} / \mathrm{L}\right.$ LeachWELL ${ }^{T M}, 0.5 \mathrm{~g} / \mathrm{L} \mathrm{NaCN}, \mathrm{pH}=11$, room temperature, $\left.500 \mathrm{rpm}\right)$

Comparing Figure 4-6 and Figure 4-7, it can be observed that the dissolved copper concentration in leachate was much higher than iron concentration. With equal moles of copper and iron in chalcopyrite, this result indicates selective leaching of chalcopyrite. A thermodynamic explanation to this is the different complexing ability of copper and iron with cyanide. The complex stability constants of $\mathrm{Cu}(\mathrm{CN})_{4}{ }^{3-}$ and $\mathrm{Fe}(\mathrm{CN})_{6}{ }^{2-}$ are about $2 \times 10^{27}$ and $1 \times 10^{24}$ (Speight, 2005). The combination of copper and cyanide was more favorable than iron and cyanide, thus more copper was dissolved than iron. 


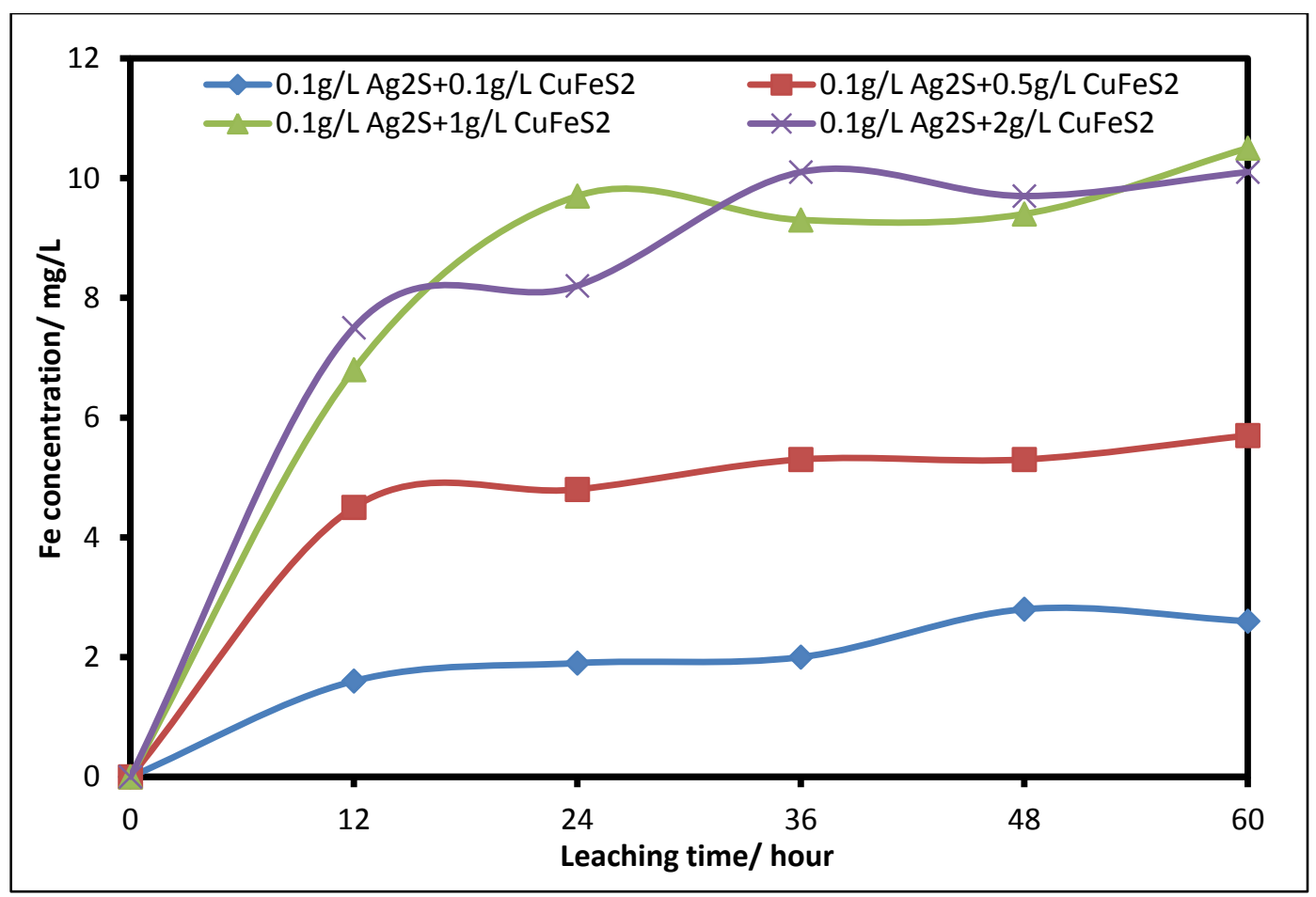

Figure 4-7 Fe concentration vs leaching time with different chalcopyrite addition in LeachWELL ${ }^{\text {TM }}$-cyanide system

$\left(0.2 \mathrm{~g} / \mathrm{L}\right.$ LeachWELL ${ }^{T M}, 0.5 \mathrm{~g} / \mathrm{L} \mathrm{NaCN}, \mathrm{pH}=11$, room temperature, $\left.500 \mathrm{rpm}\right)$

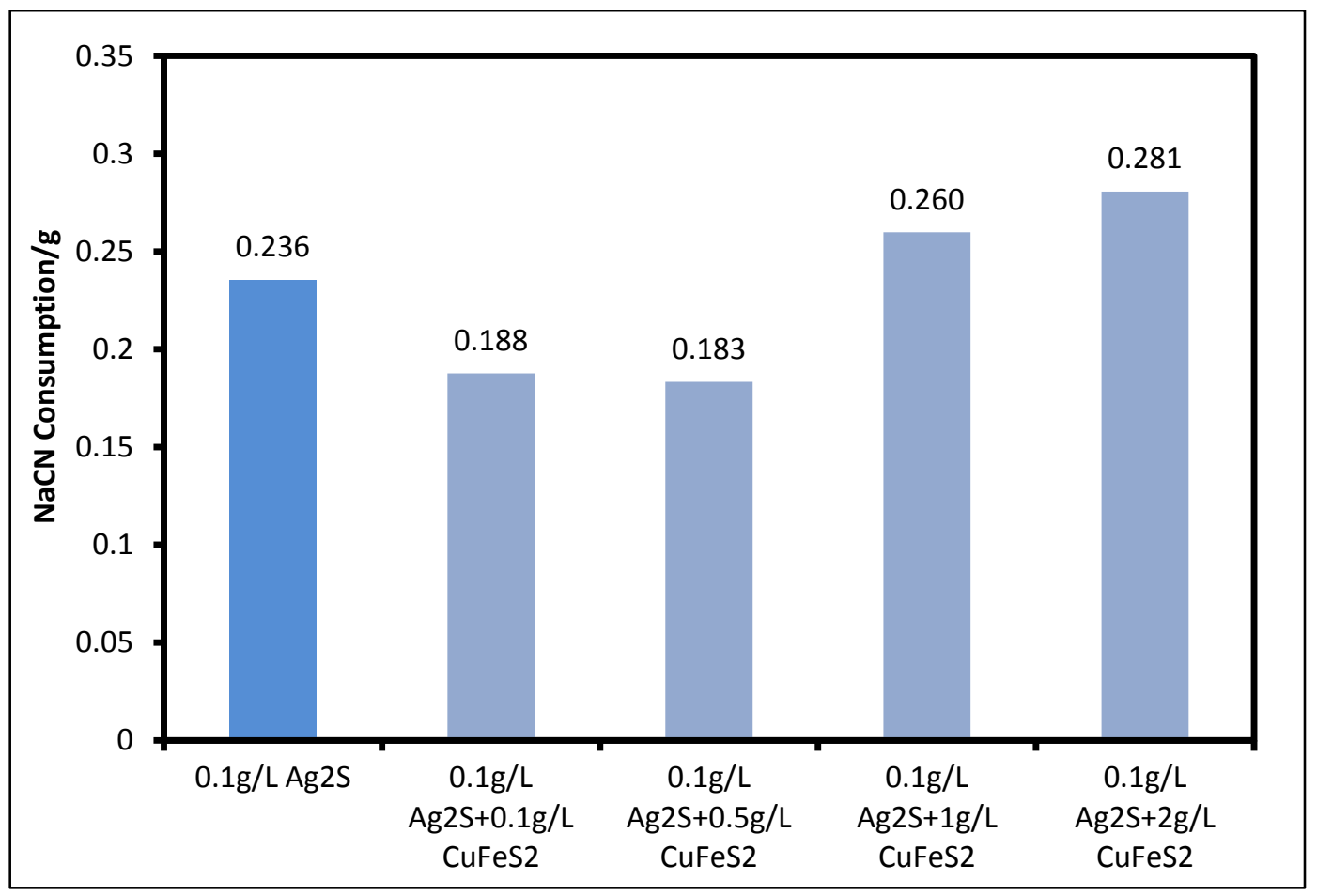

Figure 4-8 Accumulated NaCN consumption in 60 hours with different chalcopyrite addition in LeachWELL ${ }^{\mathrm{TM}}$-cyanide system

$\left(0.2 \mathrm{~g} / \mathrm{L}\right.$ LeachWELL $L^{T M}, 0.5 \mathrm{~g} / \mathrm{L} \mathrm{NaCN}, \mathrm{pH}=11$, room temperature, $\left.500 \mathrm{rpm}\right)$ 
Generally speaking, the amount of supplementary $\mathrm{NaCN}$ increased with the addition of chalcopyrite. However, when the dissolved copper and iron were low with $0.1 \mathrm{~g} / \mathrm{L}$ and $0.5 \mathrm{~g} / \mathrm{L}$ chalcopyrite addition, the $\mathrm{NaCN}$ consumption was lower than that in the pure $0.1 \mathrm{~g} / \mathrm{L} \mathrm{Ag}_{2} \mathrm{~S}$ leaching. When the content of chalcopyrite in the solution was high enough, such as $1 \mathrm{~g} / \mathrm{L}$ and $2 \mathrm{~g} / \mathrm{L}$, the decrease of $\mathrm{NaCN}$ consumption caused by the decrease of silver extraction was more than compensated by the improvement of copper and iron complexing with cyanide, thus increasing total cyanide consumption.

\section{d) Covellite and silver sulfide}

Covellite and chalcocite are highly soluble in cyanide solution and dissolution of these minerals can severely affect gold leaching (Marsden and House, 2006). The results of leaching with addition of covellite are shown in the following figures. Combining Figure 4-9 and Figure 4-10, it can be summarized that the extraction of silver decreased with the increase of copper dissolution. Dissolved copper concentration in the leaching solution was analyzed and calculations confirmed that $70 \%$ of original copper in covellite was extracted.

As can be observed from Figure 4-11, the consumption of $\mathrm{NaCN}$ increased dramatically with the increasing addition of covellite. One possible reason was that more cyanide was necessary to complex with large amounts of dissolved copper, thus increase the supplementary $\mathrm{NaCN}$ addition. 


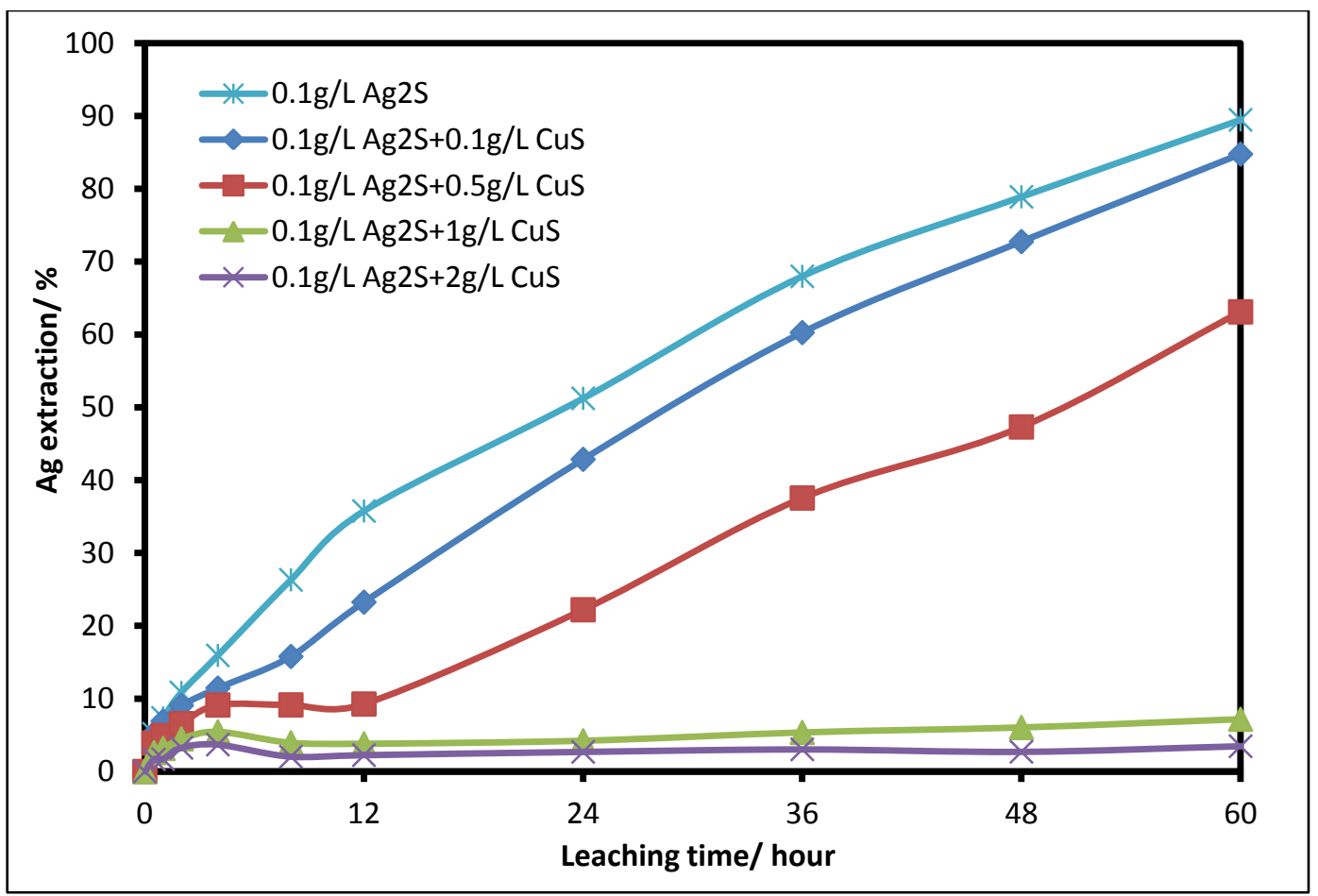

Figure 4-9 Ag extraction vs leaching time with different covellite addition in LeachWELL $^{\mathrm{TM}}$-cyanide system

$\left(0.2 \mathrm{~g} / \mathrm{L}\right.$ LeachWELL ${ }^{T M}, 0.5 \mathrm{~g} / \mathrm{L} \mathrm{NaCN}, \mathrm{pH}=11$, room temperature, $\left.500 \mathrm{rpm}\right)$

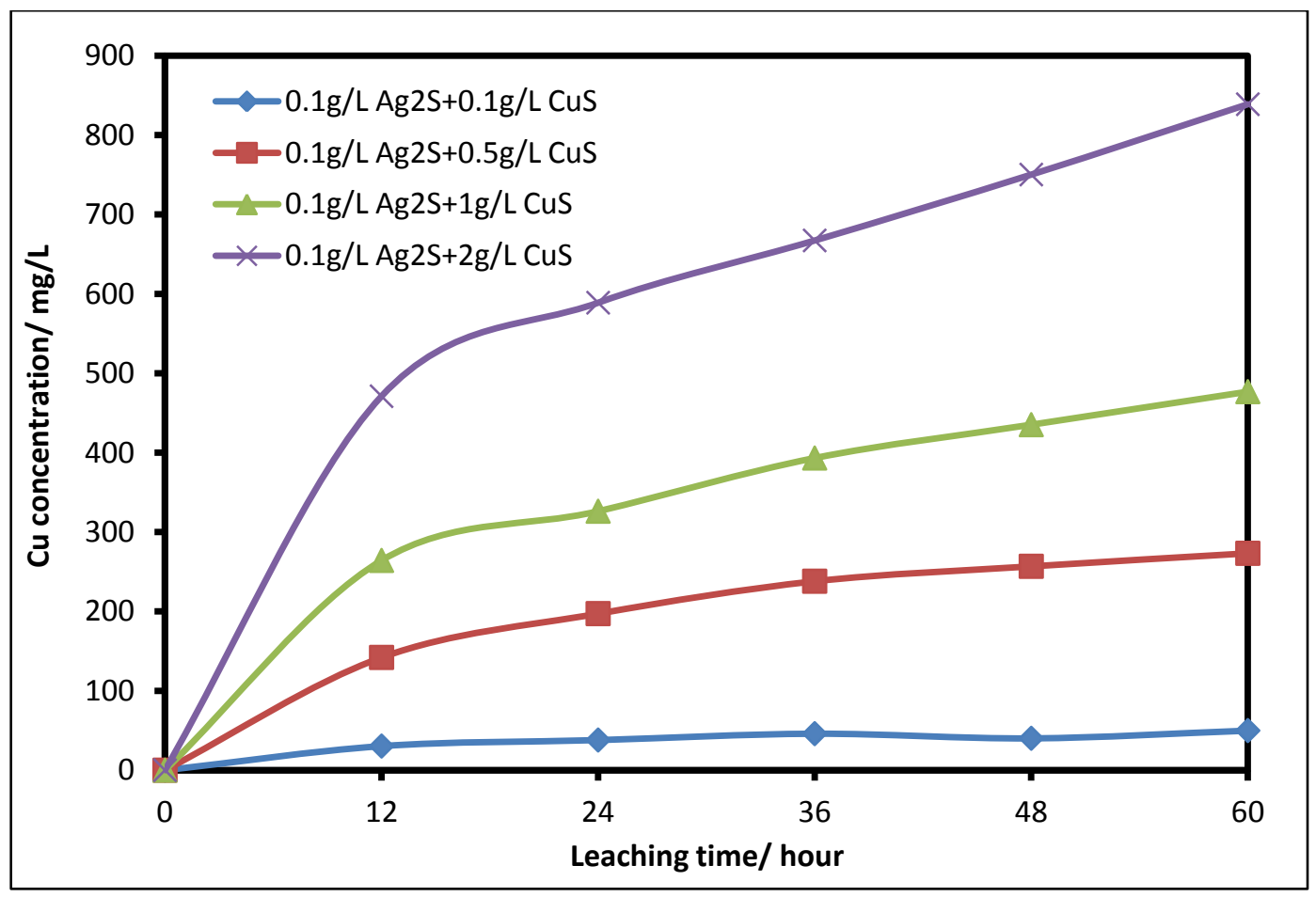

Figure 4-10 Cu concentration vs leaching time with different covellite addition in LeachWELL $^{\mathrm{TM}}$-cyanide system

$\left(0.2 \mathrm{~g} / \mathrm{L}\right.$ LeachWELL $L^{T M}, 0.5 \mathrm{~g} / \mathrm{L} \mathrm{NaCN}, \mathrm{pH}=11$, room temperature, $\left.500 \mathrm{rpm}\right)$ 


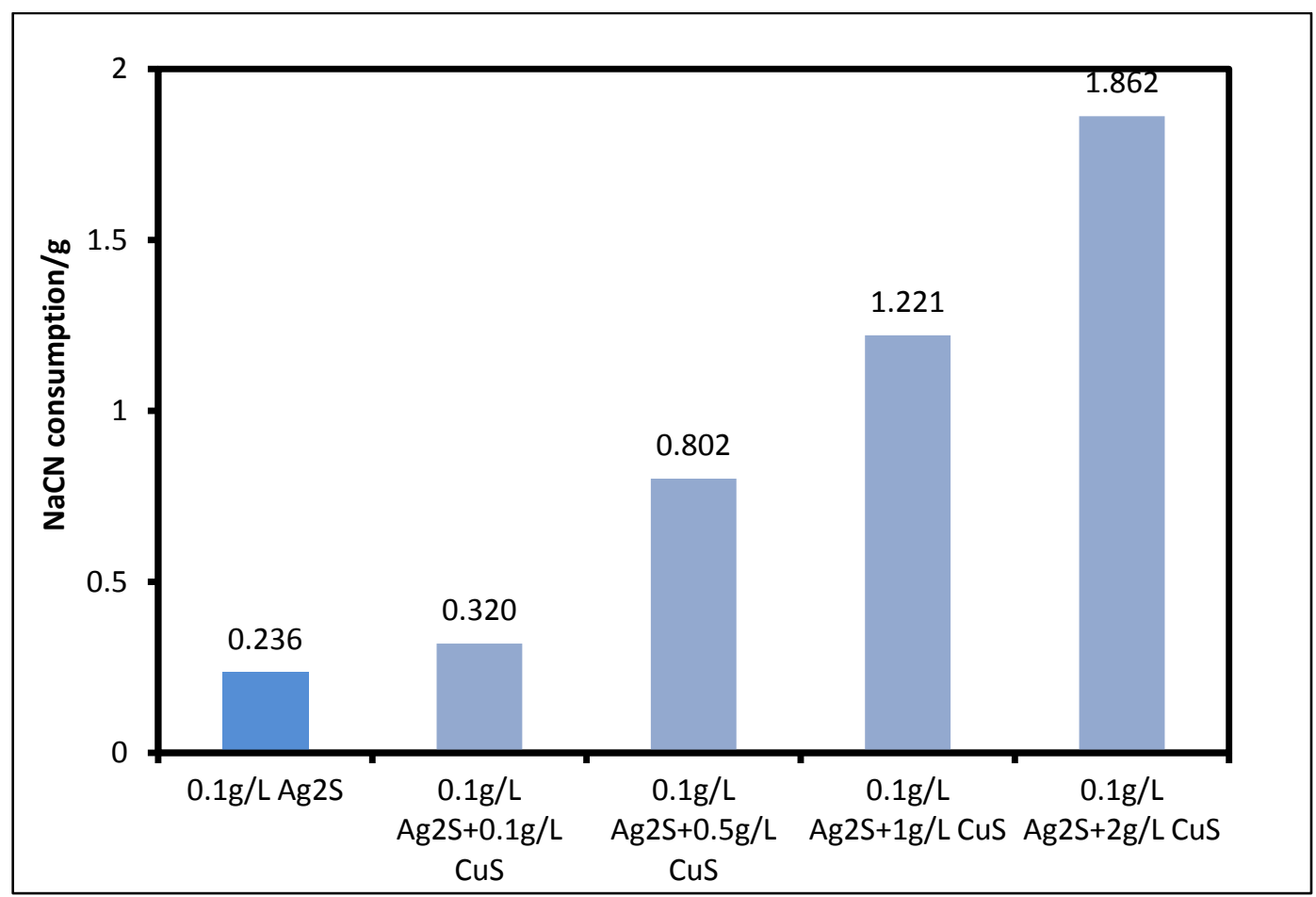

Figure 4-11 Accumulated NaCN consumption in 60 hours with different covellite addition in LeachWELL ${ }^{\mathrm{TM}}$-cyanide system $\left(0.2 \mathrm{~g} / \mathrm{L}\right.$ LeachWELL ${ }^{T M}, 0.5 \mathrm{~g} / \mathrm{L} \mathrm{NaCN}, \mathrm{pH}=11$, room temperature, $\left.500 \mathrm{rpm}\right)$

\section{e) Chalcocite and silver sulfide}

The situation in silver sulfide leaching with the presence of chalcocite was almost the same as that of covellite. The only difference was that dissolved copper as well as the $\mathrm{NaCN}$ consumption were higher than covellite leaching. This was expected due to the higher copper content in chalcocite than in covellite.

Compared Figure 4-9, Figure 4-12 with Figure 4-5, 0.1g/L addition of $\mathrm{CuFeS}_{2}$ had more significant impact on decreasing the silver recovery than same addition of $\mathrm{CuS}$ and $\mathrm{Cu}_{2} \mathrm{~S}$. It could be explained that the dissolution of chalcopyrite could be enhanced by the existence of silver ion in the solution by displacement precipitation of copper and iron. Therefore the dissolved silver could be re-precipitated on the chalcopyrite mineral, lowering the final silver ion concentration in the leachate. However, with the increasing addition of copper sulfide minerals, $\mathrm{CuS}$ and $\mathrm{Cu}_{2} \mathrm{~S}$ had more negative impact on the 
silver recovery since the dissolution of them extensively consumed cyanide and oxidant in the system.

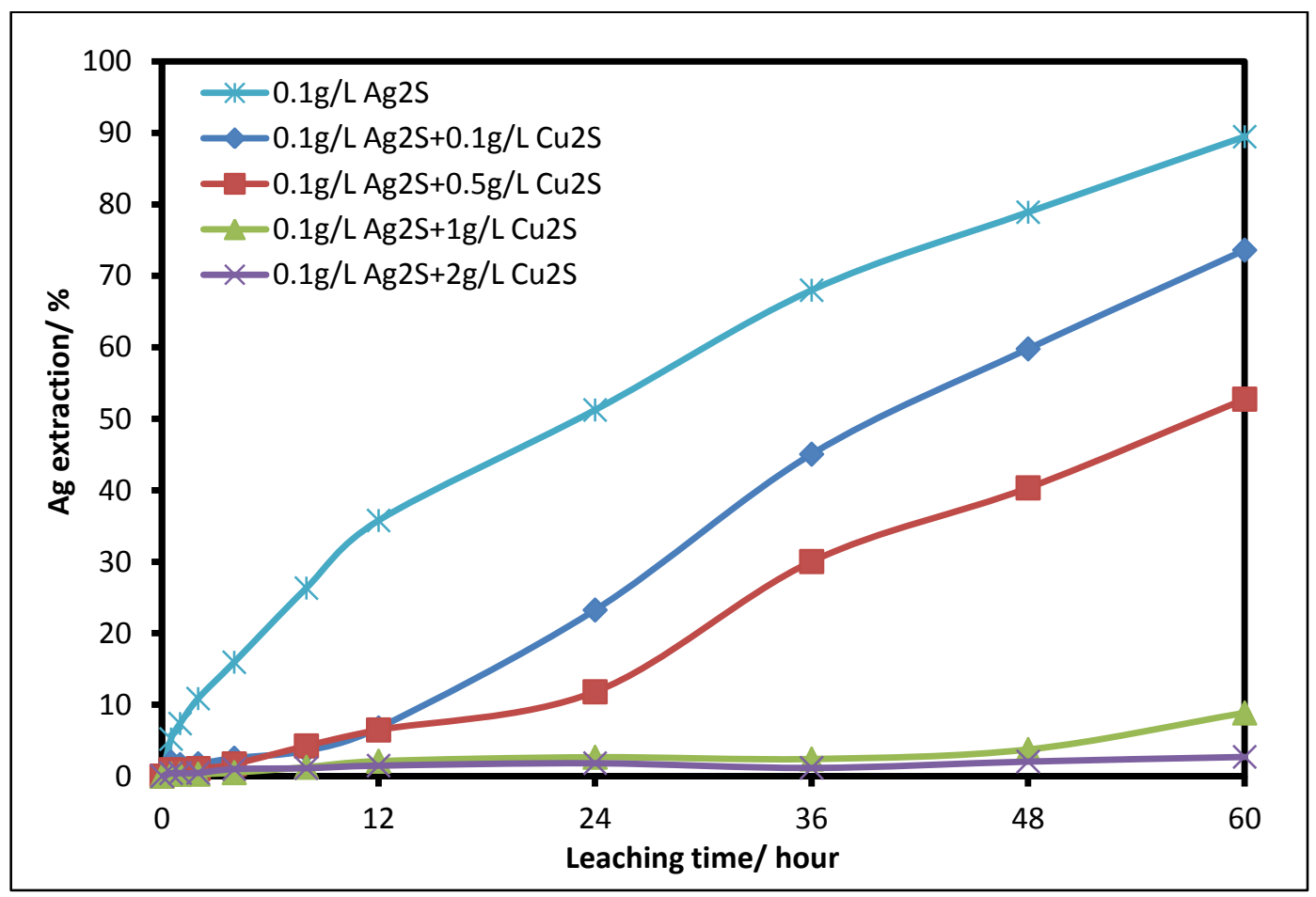

Figure 4-12 Ag extraction vs leaching time with different chalcocite addition in LeachWELL ${ }^{\text {TM }}$-cyanide system

$\left(0.2 \mathrm{~g} / \mathrm{L}\right.$ LeachWELL ${ }^{T M}, 0.5 \mathrm{~g} / \mathrm{L} \mathrm{NaCN}, \mathrm{pH}=11$, room temperature, $\left.500 \mathrm{rpm}\right)$ 


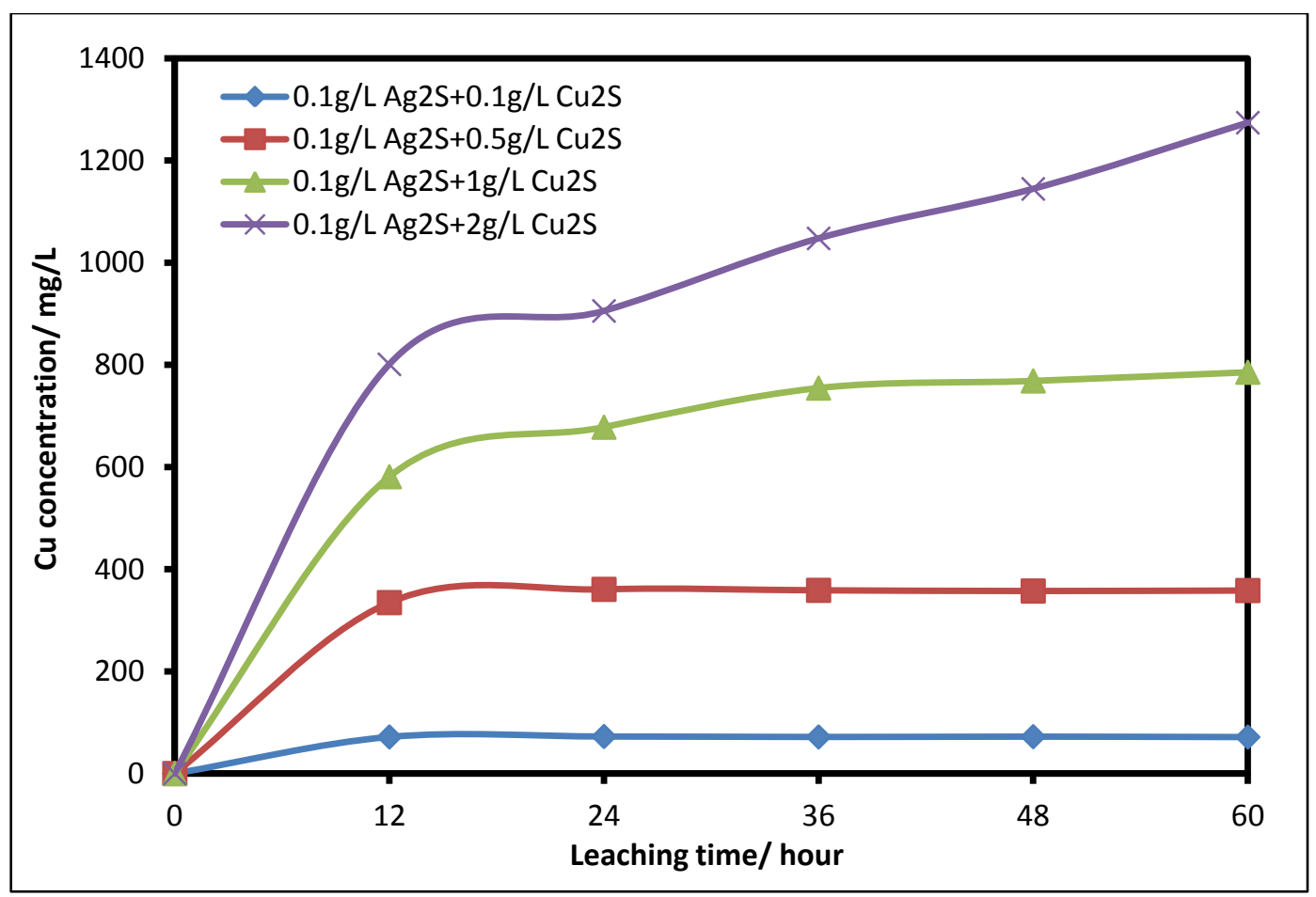

Figure 4-13 Cu concentration vs leaching time with different chalcocite addition in LeachWELL $^{\mathrm{TM}}$-cyanide system

$\left(0.2 \mathrm{~g} / \mathrm{L}\right.$ LeachWELL ${ }^{T M}, 0.5 \mathrm{~g} / \mathrm{L} \mathrm{NaCN}, \mathrm{pH}=11$, room temperature, $\left.500 \mathrm{rpm}\right)$

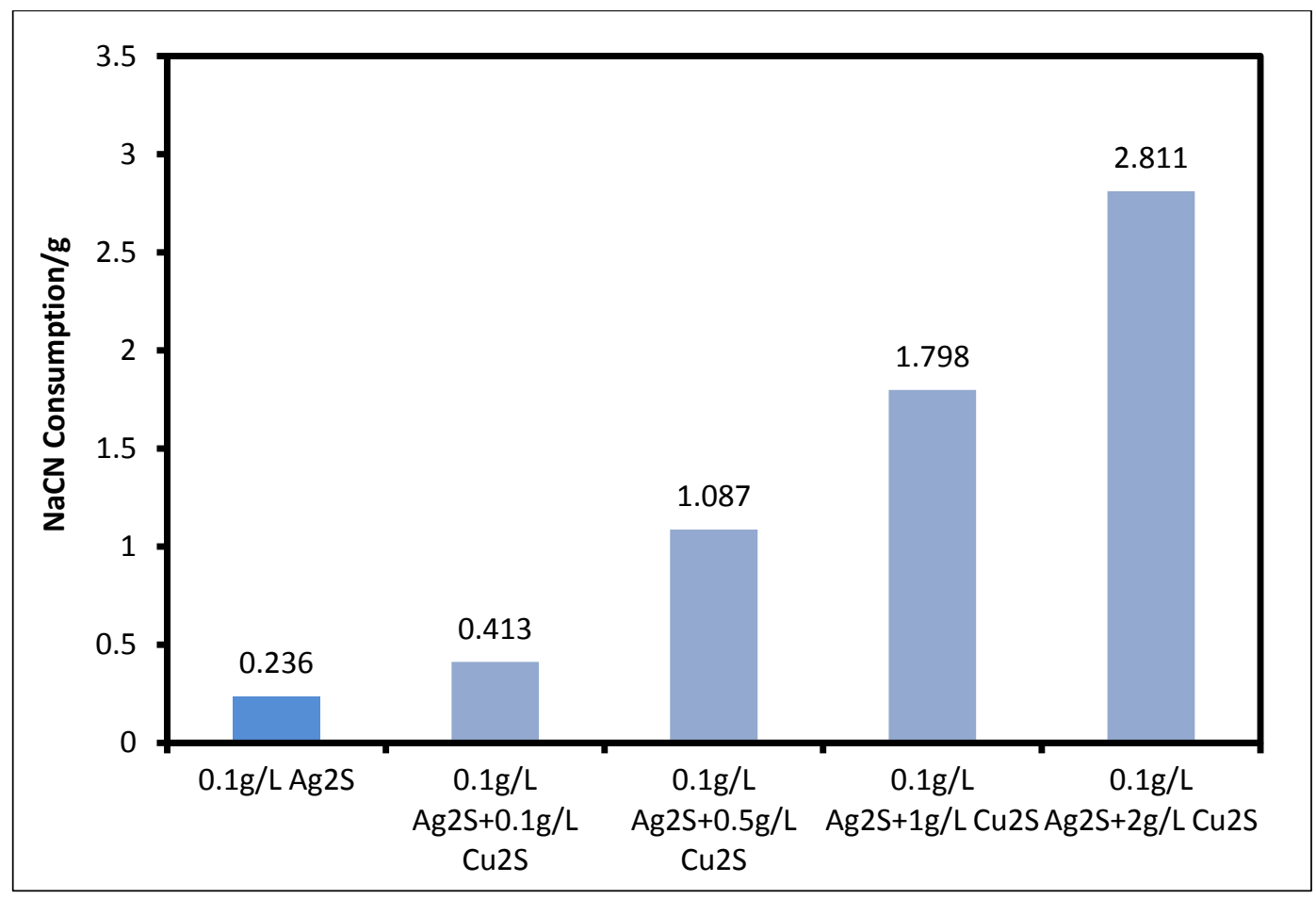

Figure 4-14 Accumulated NaCN consumption in 60 hours with different chalcocite addition in LeachWELL ${ }^{\mathrm{TM}}$-cyanide system

$\left(0.2 \mathrm{~g} / \mathrm{L}\right.$ LeachWELL ${ }^{T M}, 0.5 \mathrm{~g} / \mathrm{L} \mathrm{NaCN}, \mathrm{pH}=11$, room temperature, $\left.500 \mathrm{rpm}\right)$ 
The above sulfide minerals all disturb silver extraction. In industrial cyanidation, several pretreatment methods should be adopted if the dissolution of unwanted sulfide minerals was significant. Pre-aeration, pressure oxidation, roasting and biological oxidation may be considered when ores contain significant amounts of sulfide that can reduce leaching efficiency (Marsden and House, 2006).

\section{f) Sphalerite and silver sulfide}

Even though the sphalerite mineral used contained both $\mathrm{ZnS}$ and $\mathrm{SiO}_{2}$, the results of the sphalerite mineral addition leaching still qualitatively reflected the effect of $\mathrm{ZnS}$ on silver sulfide cyanidation.

Compared to the pure synthetic silver sulfide leaching, almost no difference can be observed from the silver extraction curves (Figure 4-15). It seemed $\mathrm{ZnS}$ had a negligible impact on silver recovery from silver sulfide.

Figure 4-16 further supports the conclusion that $\mathrm{ZnS}$ did not affect the cyanidation of silver sulfide. The concentration of zinc in the leaching solution was very low and no more than $2 \%$ of the mineral was dissolved. The consumption of $\mathrm{NaCN}$ and $\mathrm{NaOH}$ in the tests with addition of sphalerite minerals were similar to those of pure silver sulfide leaching, which was additional evidence proving that silver sulfide cyanidation was not affected by the presence of the sphalerite mineral. 


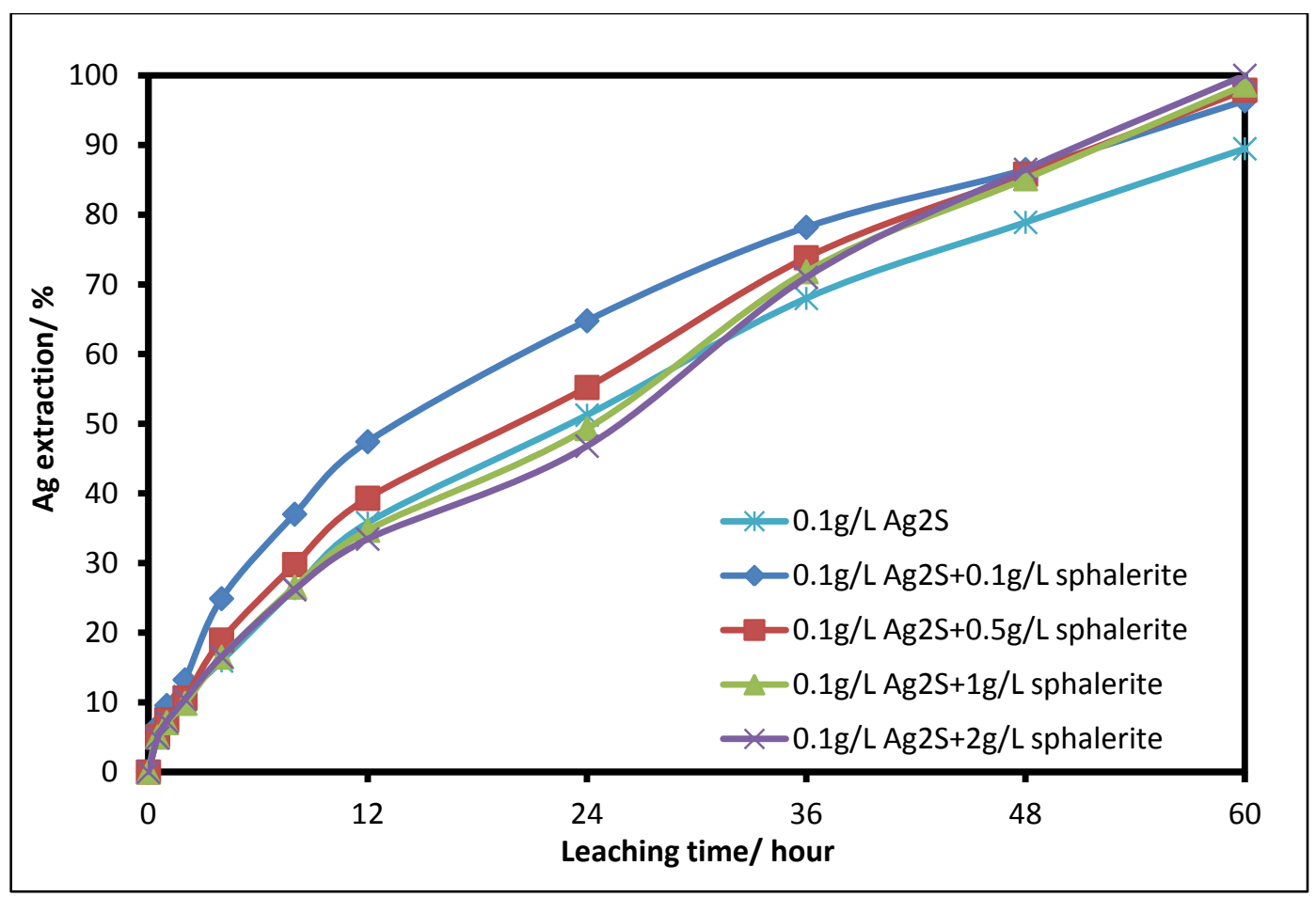

Figure 4-15 Ag extraction vs leaching time with different sphalerite mineral addition in LeachWELL $^{\mathrm{TM}}$-cyanide system

$\left(0.2 \mathrm{~g} / \mathrm{L}\right.$ LeachWELL ${ }^{T M}, 0.5 \mathrm{~g} / \mathrm{L} \mathrm{NaCN}, \mathrm{pH}=11$, room temperature, $\left.500 \mathrm{rpm}\right)$

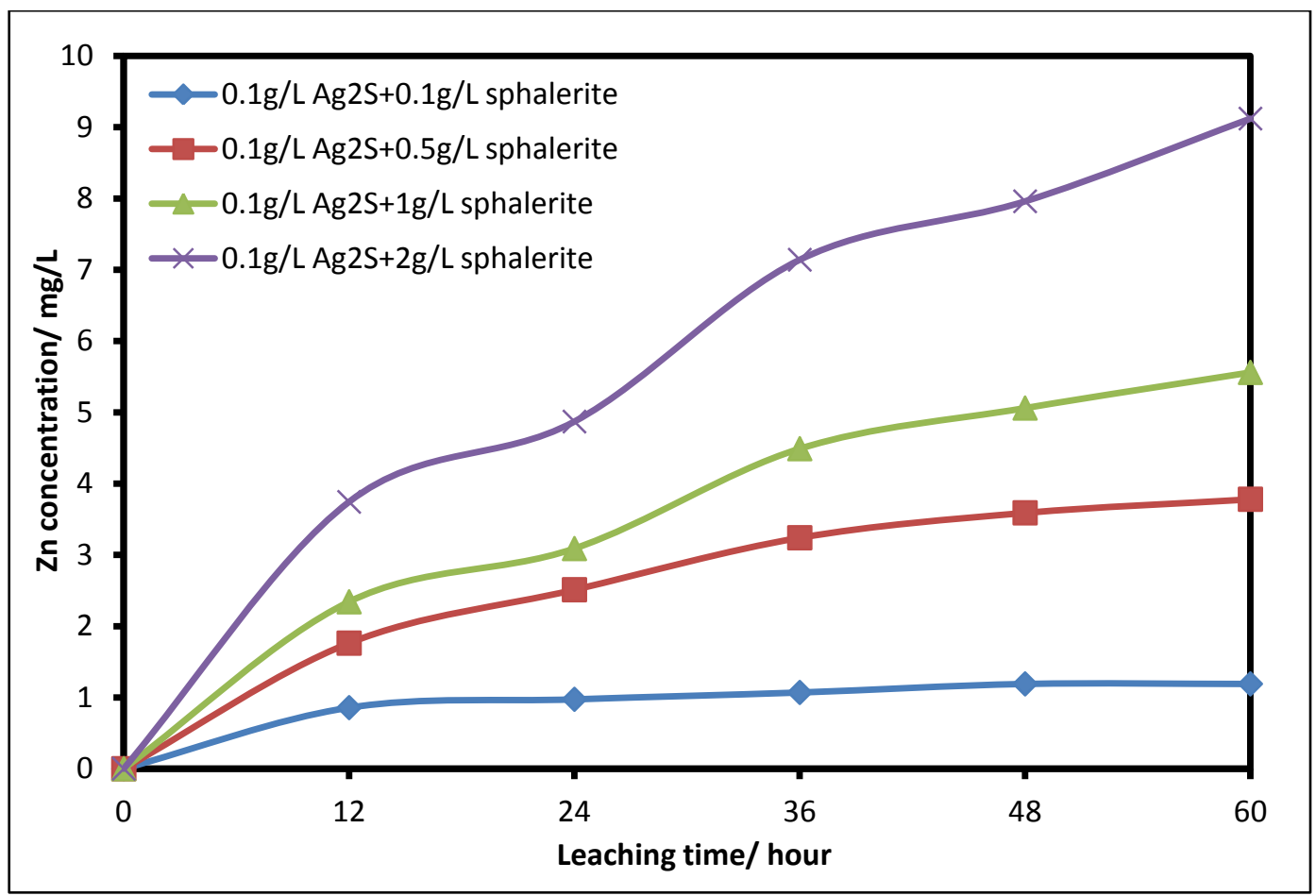

Figure 4-16 Zn concentration vs leaching time with different sphalerite mineral addition in LeachWELL $^{\mathrm{TM}}$-cyanide system

$\left(0.2 \mathrm{~g} / \mathrm{L}\right.$ LeachWELL $L^{T M}, 0.5 \mathrm{~g} / \mathrm{L} \mathrm{NaCN}, \mathrm{pH}=11$, room temperature, $\left.500 \mathrm{rpm}\right)$ 


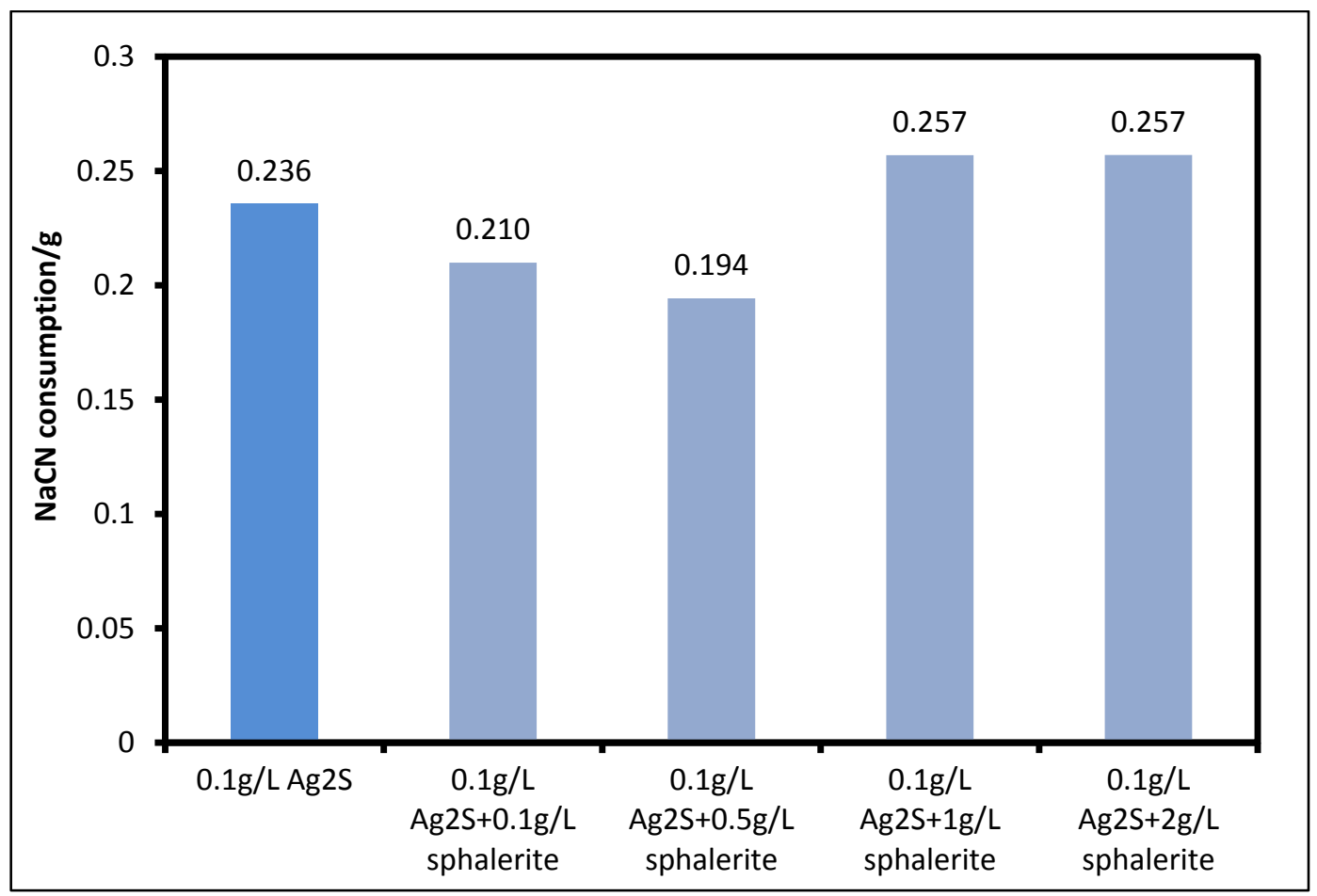

Figure 4-17 Accumulated $\mathrm{NaCN}$ consumption in 60 hours with different sphalerite mineral addition in LeachWELL ${ }^{\mathrm{TM}}$-cyanide system

$\left(0.2 \mathrm{~g} / \mathrm{L}\right.$ LeachWELL ${ }^{T M}, 0.5 \mathrm{~g} / \mathrm{L} \mathrm{NaCN}, \mathrm{pH}=11$, room temperature, $\left.500 \mathrm{rpm}\right)$

\section{g) Galena and silver sulfide}

Different additions of galena mineral improved the leaching of silver sulfide to different extents. As can be seen from Figure 4-18, silver extraction was accelerated with the addition of galena mineral. Higher content of galena mineral resulted in more obvious acceleration.

The dissolution of galena was measured through analysis of the lead concentration in the solution. The highest concentration of lead ion in the solution was about $10 \mathrm{mg} / \mathrm{L}$, which indicated that the dissolution of $\mathrm{PbS}$ was not favorable. However, combined with the results from previous tests with $\mathrm{Pb}\left(\mathrm{NO}_{3}\right)_{2}$ [3.3.4.2 Synthetic Silver Sulfide Leaching with Lead Nitrate], it could be concluded that a small amount of lead ion in the system can improve the silver sulfide cyanidation. 
Dai and Jeffrey (2006) found that lead ion could catalyze the oxidation of sulfide by oxygen when leaching sulfide minerals. Breuer et al. (2008) noticed that in cyanide leaching system containing sulfide ion, the oxidation of sulfide ion was quite slow. However, sulfide concentration decreased rapidly with the presence of lead ion.

Deschenes et al. (2011) did a similar experiment and they found that during cyanidation of silver sulfide polysulfides were formed on the surface of minerals, limiting the extraction of silver. Their XPS spectra data indicated that with the addition of lead nitrate, $\mathrm{PbO}$ species and minor amounts of $\mathrm{Pb}(\mathrm{OH})_{2}$ were found on the solid surface while no $\mathrm{PbS}$ nor other polysulfide was detected. Based on the analysis, it could be suggested that $\mathrm{PbO}$ or $\mathrm{Pb}(\mathrm{OH})_{2}$, the precipitation of lead ion, acted as redox couples and favored the continuous oxidation of silver sulfide.

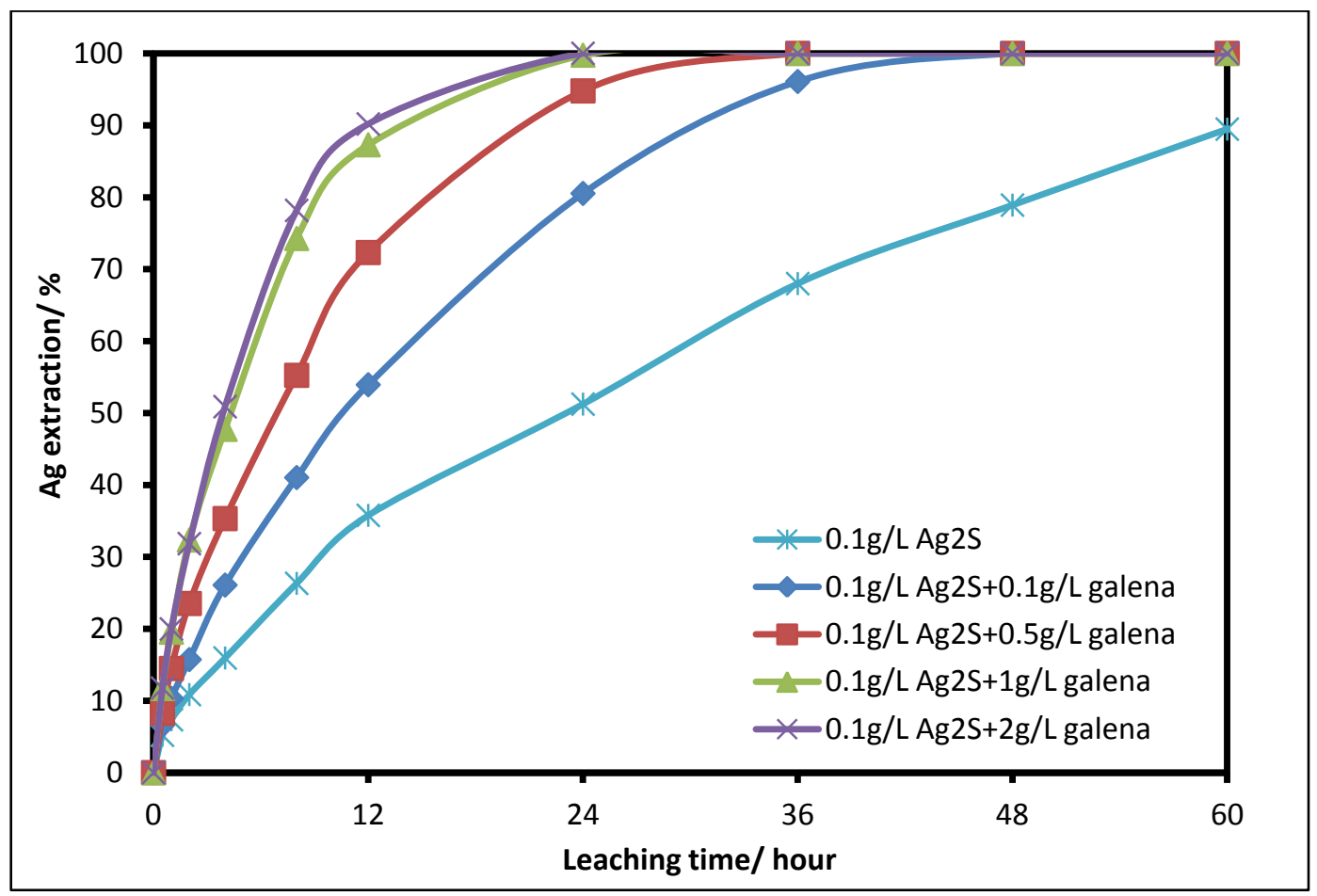

Figure 4-18 Ag extraction vs leaching time with different galena mineral addition in LeachWELL $^{\mathrm{TM}}$-cyanide system

$\left(0.2 \mathrm{~g} / \mathrm{L}\right.$ LeachWELL ${ }^{T M}, 0.5 \mathrm{~g} / \mathrm{L} \mathrm{NaCN}, \mathrm{pH}=11$, room temperature, $\left.500 \mathrm{rpm}\right)$

Considering the consumption of $\mathrm{NaCN}$ and $\mathrm{NaOH}$ in these tests, no clear differences from pure silver sulfide leaching could be found. The other components in the natural 
galena mineral did not consume extra cyanide or sodium hydroxide.

\subsubsection{Cyanidation of Natural Acanthite}

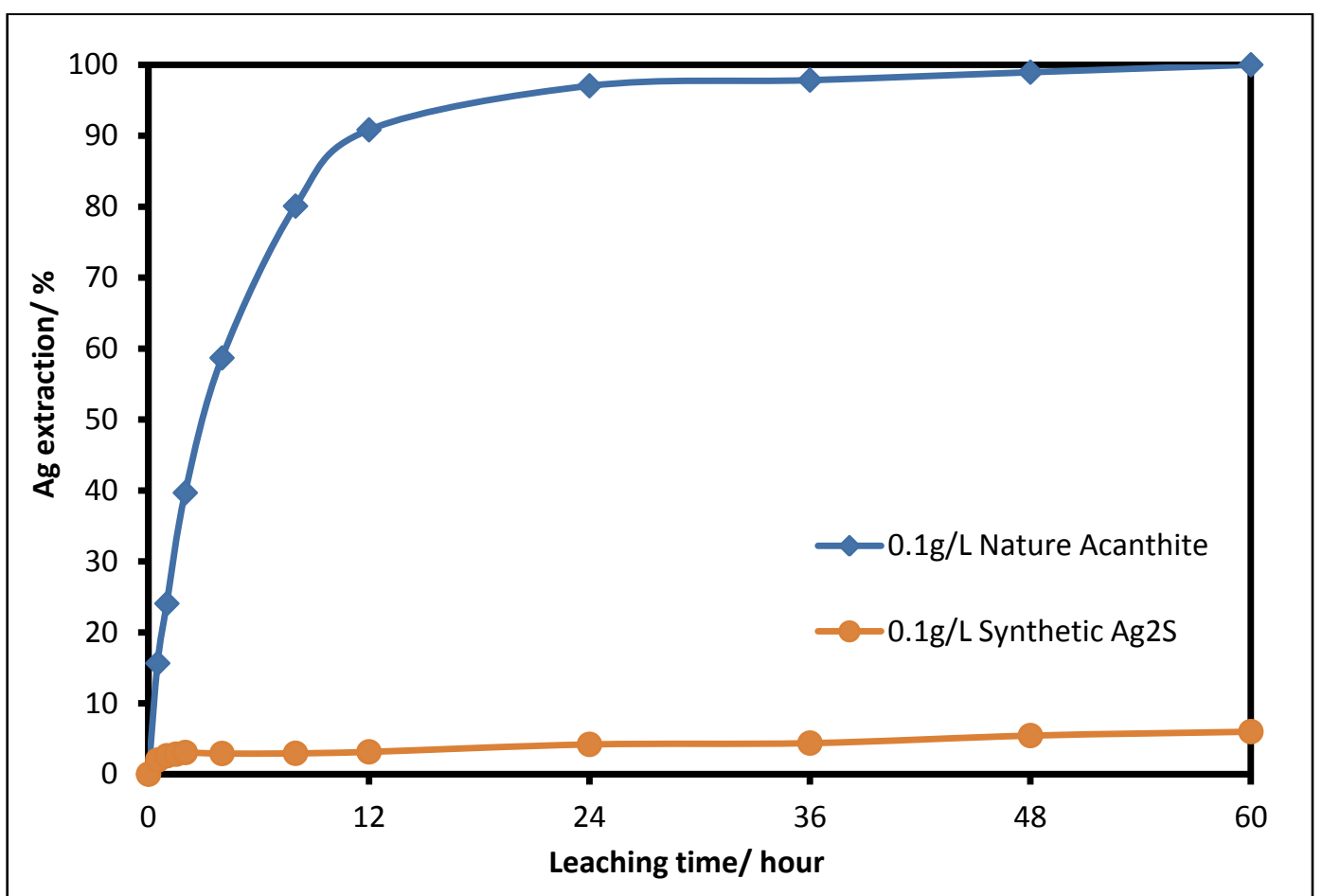

Figure 4-19 Ag extraction from different minerals vs leaching time $(0.5 \mathrm{~g} / \mathrm{L} \mathrm{NaCN}$, room temperature, $500 \mathrm{rpm})$

Figure 4-19 indicates that the leaching of this natural acanthite sample with just $0.5 \mathrm{~g} / \mathrm{L}$ $\mathrm{NaCN}$ in aerated solution achieved $100 \%$ silver extraction within 24 hours, which was totally different from the baseline leaching of synthetic silver sulfide. The presence of lead in the sample may have provided enough dissolved lead ion which was beneficial to silver sulfide oxidation. 


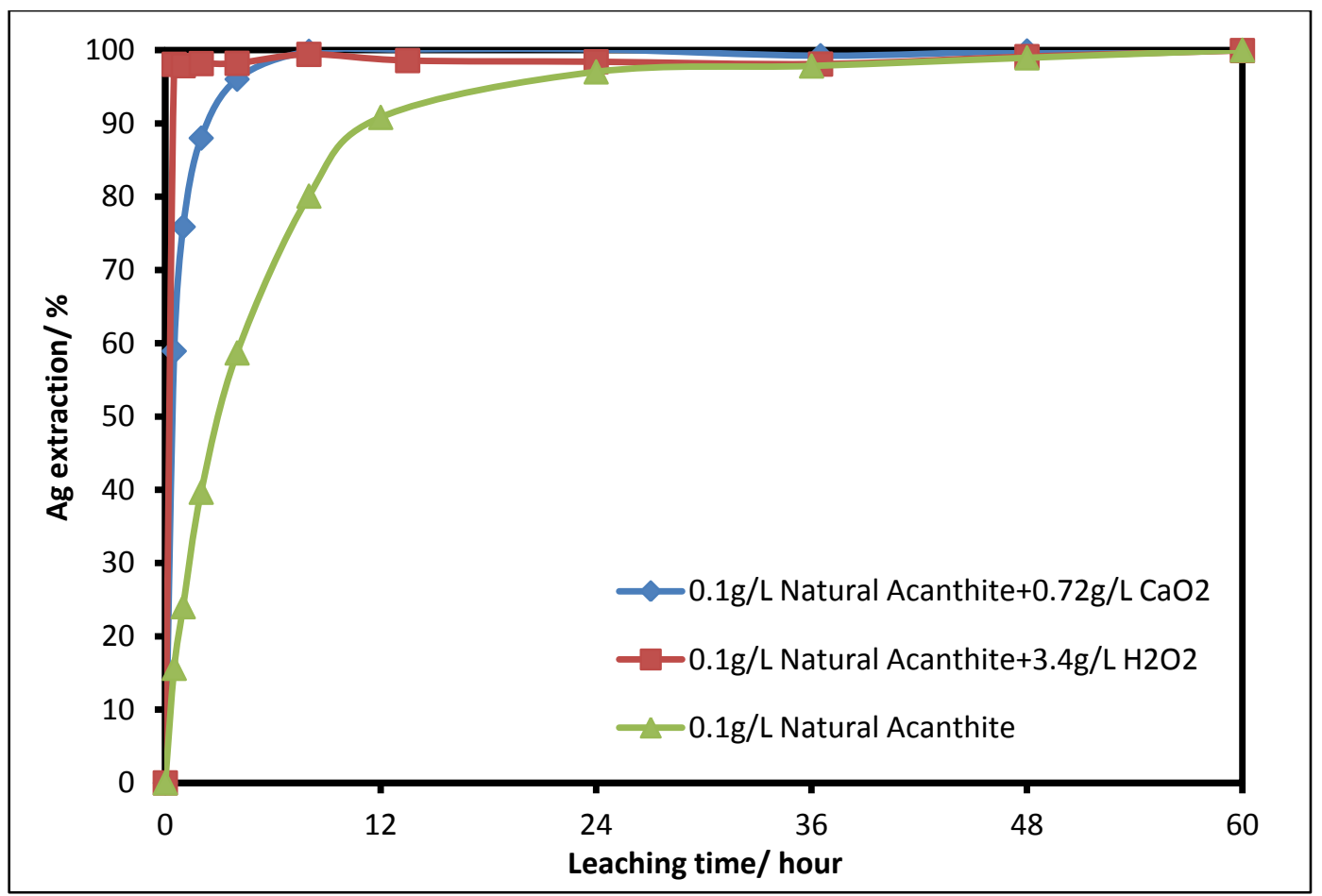

Figure 4-20 Ag extraction from natural acanthite sample vs leaching time with different oxidants $(0.5 \mathrm{~g} / \mathrm{L} \mathrm{NaCN}, \mathrm{pH}=11$, room temperature, $500 \mathrm{rpm})$

3.4g/ $\mathrm{L} \mathrm{H}_{2} \mathrm{O}_{2}$ and $0.72 \mathrm{~g} / \mathrm{L} \mathrm{CaO}$ were tested on natural acanthite sample. Figure 4-20 reveals their performance on improving silver extraction. As can be observed, without auxiliary oxidants $100 \%$ extraction could be achieved, but $\mathrm{H}_{2} \mathrm{O}_{2}$ and $\mathrm{CaO}_{2}$ still accelerated the process. With the addition of $\mathrm{H}_{2} \mathrm{O}_{2}$, most of the silver sulfide was dissolved almost immediately in the first 0.5 hour. $\mathrm{CaO}_{2}$ also shortened the leaching time into 8 hours. It can be concluded that oxidants did improve the dissolution of the tested acanthite. 


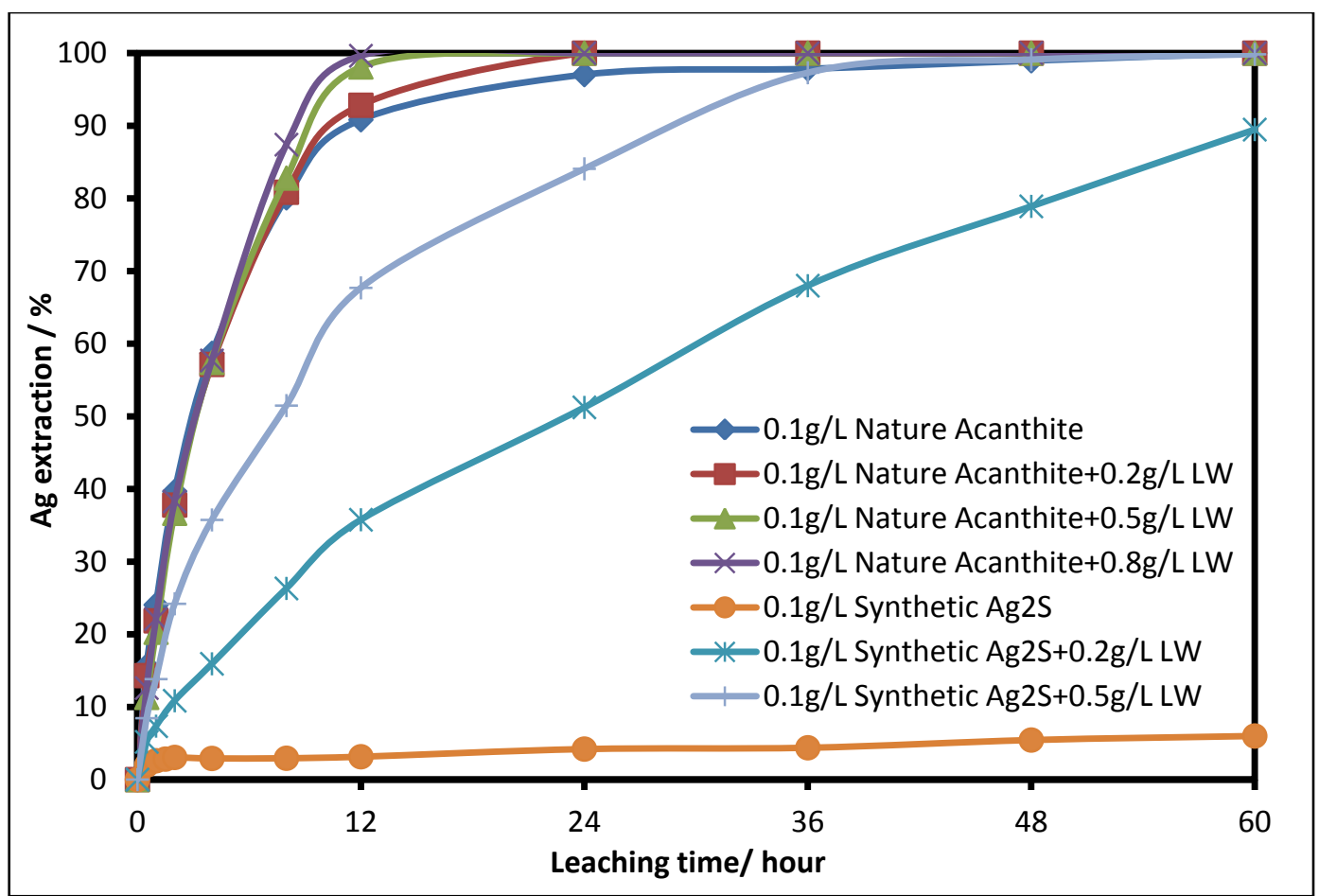

Figure 4-21 Ag extraction from different minerals vs leaching time with different LeachWELL ${ }^{\text {TM }}$ concentration

(0.5g/L NaCN, $p H=11$, room temperature, $500 \mathrm{rpm})$

Figure 4-21 shows the performance of LeachWELL ${ }^{\mathrm{TM}}$ on natural acanthite mineral leaching. It can be observed that the effect of LeachWELL ${ }^{\mathrm{TM}}$ on this sample was not as obvious as on synthetic silver sulfide leaching. With $0.5 \mathrm{~g} / \mathrm{L}$ and $0.8 \mathrm{~g} / \mathrm{L}$ LeachWELL $^{\mathrm{TM}}$ addition, the extraction time was shorten to 12 hours while the addition of $0.2 \mathrm{~g} / \mathrm{L}$ LeachWELL $^{\mathrm{TM}}$ made no obvious improvement. The result may be explained by the fact that the main effective ingredient of LeachWELL ${ }^{\mathrm{TM}}$ in this system was lead. In lead-bearing acanthite leaching system, lead could be supplied by the natural acanthite mineral itself, thus the $\mathrm{Pb}\left(\mathrm{NO}_{3}\right)_{2}$ from LeachWELL ${ }^{\mathrm{TM}}$ showed less obvious effect on improving silver leaching than in systems without lead. On the other hand, the mild oxidant in LeachWELL ${ }^{\mathrm{TM}}$ was not as oxidative as $\mathrm{H}_{2} \mathrm{O}_{2}$ and $\mathrm{CaO}_{2}$. It could not further accelerate the process. 
Table 4-4 Accumulated $\mathrm{NaCN}$ and $\mathrm{NaOH}$ consumption in 60hours in different leaching systems

\begin{tabular}{ccc}
\hline Leaching test & $\begin{array}{c}\text { NaCN } \\
\text { consumption/g }\end{array}$ & $\begin{array}{c}\text { NaOH } \\
\text { consumption/ g }\end{array}$ \\
\hline No auxiliary oxidant & 0.18 & 0.5959 \\
$\mathbf{0 . 7 2 g} / \mathbf{L ~ C a O}_{2}$ & 0.1035 & 0 \\
${\mathbf{3 . 4 g} / \mathbf{L ~ H}_{\mathbf{2}} \mathbf{O}_{2}}^{\mathbf{0 . 2 g} / \text { LeachWELL }^{\text {TM }}}$ & 0.1732 & 1.2406 \\
$\mathbf{0 . 5 g} /$ LeachWELL $^{\text {TM }}$ & 0.1453 & 0.5876 \\
$\mathbf{0 . 8 g} /$ LeachWELL $^{\text {TM }}$ & 0.185 & 0.5655 \\
\hline
\end{tabular}

Considering the consumption of $\mathrm{NaCN}$ and $\mathrm{NaOH}$, the presence of LeachWELL ${ }^{\mathrm{TM}}$ did not result in much improvement compared with the other auxiliary oxidants.

\subsection{Summary}

The effect of some typical non-silver sulfide minerals on the cyanide leaching of synthetic silver sulfide in LeachWELL ${ }^{\mathrm{TM}}$ assisted system has been investigated. Each kind of non-silver metal sulfide mineral influenced the effect of LeachWELL ${ }^{\mathrm{TM}}$ on synthetic silver sulfide cyanidation to different extents. This was likely due to their mineralogy difference and different complexing ability of dissolved metals with cyanide. The influence of non-silver sulfides was indicated by the differences in final silver extraction as well as $\mathrm{NaCN}$ consumption and was summarized as following:

1. High content non-silver metal sulfide minerals retard silver extraction are: covellite > chalcocite > chalcopyrite > pyrrhotite > pyrite. Sphalerite, on the other hand, did not affect silver sulfide cyanidation. Moreover, galena enhanced silver extraction via the function of $\mathrm{Pb}^{2+}$ in the system. For each kind of non-silver metal sulfide mineral, the influence on silver extraction increased with the increasing mineral addition.

2. The consumption of $\mathrm{NaCN}$ increased with the addition of cyanide leachable minerals such as chalcocite and covellite. For the other minerals, $\mathrm{NaCN}$ consumption 
kept constant or even became lower than pure silver sulfide leaching because of low dissolution of non-silver metals.

3. In all these sulfide minerals mixtures leaching, the demand for $\mathrm{NaOH}$ to maintain pulp $\mathrm{pH}$ did not vary too much, which was probably due to the low pulp density of the leaching system.

The cyanidation of natural acanthite concentrate sample with different oxidants was conducted. Through the results of natural acanthite cyanidation tests, it was clear that with the co-existence of non-silver sulfide minerals such as galena in the ore, the dissolution of silver sulfide was fast and complete. Sufficient auxiliary oxidant, like $\mathrm{H}_{2} \mathrm{O}_{2}$ and $\mathrm{CaO}_{2}$, accelerated silver extraction. However, LeachWELL ${ }^{\mathrm{TM}}$ had few effects on the high lead content acanthite cyanidation. 


\section{Chapter 5 Conclusions and Recommendations}

\subsection{Conclusions}

The performance of four selected auxiliary oxidants/additives $\left(\mathrm{H}_{2} \mathrm{O}_{2}, \mathrm{CaO}_{2}\right.$, LeachWELL ${ }^{\mathrm{TM}}$ and $\mathrm{Pb}\left(\mathrm{NO}_{3}\right)_{2}$ ) in silver sulfide cyanidation were evaluated in stirred reactor leaching tests under the typical cyanide leaching conditions.

The conventional cyanide leaching of synthetic acanthite was proved to be inefficient (aerated solution, $0.1 \mathrm{~g} / \mathrm{L}$ synthetic silver sulfide, $0.5 \mathrm{~g} / \mathrm{L} \mathrm{NaCN}, \mathrm{pH}=12$, room temperature). The leach experiment showed that only $5 \%$ of silver sulfide could be dissolved after 60 hours.

The addition of $\mathrm{H}_{2} \mathrm{O}_{2}$ increased silver recovery from pure synthetic silver sulfide. With 3.4g/ $\mathrm{L} \mathrm{H}_{2} \mathrm{O}_{2}$ addition, the highest recovery of silver could be achieved (90\%). However, the consumption of $\mathrm{NaCN}$ and $\mathrm{NaOH}$ also increased with increasing $\mathrm{H}_{2} \mathrm{O}_{2}$ addition.

$0.72 \mathrm{~g} / \mathrm{L} \mathrm{CaO} 2$ could improve silver extraction to $30 \%$. When the $\mathrm{CaO}_{2}$ concentration was under $0.72 \mathrm{~g} / \mathrm{L}$, silver recovery increased with $\mathrm{CaO}_{2}$ addition. However, higher than $0.72 \mathrm{~g} / \mathrm{L} \mathrm{CaO} 2$ could not further improve the dissolution of pure acanthite, which was most likely due to low solubility of calcium hydroxide in cyanide solution. The relationship between supplementary cyanide consumption and $\mathrm{CaO}_{2}$ addition followed the trend of silver recovery. The demand for base addition declined with increasing $\mathrm{CaO}_{2}$ addition.

LeachWELL $^{\mathrm{TM}}$ performed better than the peroxides in improving silver extraction from pure acanthite as well as reducing $\mathrm{NaCN}$ and $\mathrm{NaOH}$ consumption. In the presence of $0.2 \mathrm{~g} / \mathrm{L}_{\text {LeachWELL }}{ }^{\mathrm{TM}}, 90 \%$ of silver in the solid was dissolved. High concentration of 
LeachWELL ${ }^{\mathrm{TM}}$ and cyanide significantly enhanced the kinetics of the leaching process. Increasing temperature caused a slight decrease in leaching velocity. Recovery of silver was not influenced by $\mathrm{pH}$.

Lead nitrate was an important ingredient of LeachWELL ${ }^{\mathrm{TM}}$ and could be used as an additive in acanthite cyanide leaching. Similar results in LeachWELL ${ }^{\mathrm{TM}}$ assisted cyanidation could be obtained with an equivalent amount of lead nitrate. Therefore, it was speculated that the main working ingredient of LeachWELL ${ }^{\mathrm{TM}}$ in this system was lead nitrate.

Leaching of sulfide minerals mixture (containing silver sulfide) in LeachWELL ${ }^{\mathrm{TM}}$-cyanide system has been investigated. The tests showed that different sulfide minerals influenced cyanidation of acanthite to different extents. High addition of covellite and chalcocite were the most detrimental sulfide minerals to acanthite cyanidation. Different additions of chalcopyrite decreased the silver recovery to the same level. The presence of pyrrhotite and pyrite also retarded silver extraction. Sphalerite shows no impact on silver sulfide cyanidation while galena greatly improved silver sulfide dissolution. It was therefore concluded that lead in the system acted as a promoter to silver extraction.

The applicability of the $\mathrm{H}_{2} \mathrm{O}_{2}, \mathrm{CaO}_{2}$ and LeachWELL ${ }^{\mathrm{TM}}$ to natural acanthite concentrate cyanidation has been investigated by leaching the lead-bearing acanthite sample. Cyanide leaching without any auxiliary oxidants extracted all of the silver, which was different from pure synthetic silver sulfide leaching. Cyanide leaching of this lead-bearing acanthite was accelerated by $\mathrm{H}_{2} \mathrm{O}_{2}$ and $\mathrm{CaO}_{2}$. However, the effect of LeachWELL ${ }^{\mathrm{TM}}$ on enhancing cyanidation of this sample was insignificant. By analyzing the pulp potential and mineral composition of the natural sample, it is believed that the co-existence of acanthite with galena in the acanthite sample result in the enhanced cyanidation. Additionally, with enough lead in the system improving silver extraction, sufficient oxidant would further accelerate the leaching process. 


\subsection{Recommendations}

The behavior of the oxidants/additives in cyanide leaching of silver sulfide has been explored for relative short time periods. This is useful in evaluating the performance of different oxidants/additives in acanthite cyanidation, but more work would be necessary to further study the working mechanism.

Current understanding of LeachWELL ${ }^{\mathrm{TM}}$ is limited. Considering that LeachWELL $^{\mathrm{TM}}$ is effective in accelerate silver sulfide cyanidation without increasing $\mathrm{NaCN}$ and $\mathrm{NaOH}$ consumption, more research on its working mechanism is necessary to gain a fundamental understanding of LeachWELL ${ }^{\mathrm{TM}}$ assisted cyanide leaching processes.

The presence of lead nitrate, galena or other lead-bearing minerals in the system is beneficial to silver extraction from acanthite. Further work to comprehensive study the effect and working mechanism of lead ion on silver sulfide leaching should be undertaken to determine if it would be a common addition to the acanthite ore leaching operation.

The behavior of different associated minerals in acanthite cyanide leaching has not been well examined. A study on the dissolution of silver sulfide in a well designed system with the presence of different possible associated minerals would further reveal the process of mixed mineral cyanide leaching.

The performance of oxidants/additives in acanthite cyanidation has been tested in low pulp density systems with only $0.1 \mathrm{~g} / \mathrm{L}$ pure synthetic silver sulfide or natural acanthite concentrate. In future study of the applicability of theses oxidants/additives, high pulp density leaching would provide more detailed information about the improvement by the oxidants/additives. Furthermore, real ore column leaching with appropriate oxidant/additive is necessary to simulate the real industrial operation. 


\section{References}

Almeida, M.F. and Amarante, M.A., Leaching of a silver bearing sulfide by-product with cyanide, thiourea, and chloride solutions, Minerals Engineering, v.8, No.3, 1995, 257-271

Anthony, J.W., Bideaux, R.A., Bladh, K.W. and Nichols, M.C., Handbook of Mineralogy. Mineralogical Society of America, Chantilly, VA, USA, 1994-2010

Arslan, F., Ozdamar, D.Y. and Muduroglu, M., Cyanidation of Turkish gold-silver ore and the use of hydrogen peroxide, The European Journal of Mineral Processing and Environmental Protection, v.3, 2003, 309-315

Ayata, S. and Yildiran, H., A novel technique for silver extraction from silver sulphide ore, Turkish Journal of Chemistry, 25(2), 2001, 187-191

Aylmore, M.G. and Muir, D.M., Thiosulfate leaching of gold-A review, Minerals Engineering, v.14, No.2, 2011, 135-174

Balaz, P., Ficeriova, J., Sepelak, V. and Kammel, R., Thiourea leaching of silver from mechanically activated tetrahedrite, Hydrometallurgy, v.43, 1996, 367-377

Benari, M.D. and Hefter, G.T., The corrosion of silver and silver sulphide in halide solutions in water and dimethylsulphoxide, Hydrometallurgy, v.28, 1992, 191-203

Boyle, R.W., The geometry of silver and its deposits, Geological survey of Canadian Bulletin, No.160, 1968

Breuer, P.L., Jeffrey, M.I. and Hewittet D. M., Mechanisms of sulfide ion oxidation during cyanidation, Part I: The effect of lead ions, Minerals Engineering, v.21, 2008, $579-586$

Breuer, P.L., Sutcliffe, C.A. and Meakin, R.L., Cyanide measurement by silver nitrate titration: Comparison of rhodanine and potentiometric end-points, Hydrometallurgy, v.106, 2011, 135-140

Briones, R. and Lapidus, G.T., The leaching of silver sulfide with the thiosulfate-ammonia-cupric ion system, Hydrometallurgy, v.50, 1998, 243-260

Chase, C.K., Treatment of manganiferous silver ores for recovery of silver, in view of changed precious metal economics. Chicago: AIME, 1981 
Cooper, J., Personal communication, 2012

Cui, Y., Tong, X. and Alejandro Lopez-Valdivieso, Silver sulfide leaching with a copper-thiosulfate solution in the absence of ammonia, Rare Metals, v.30, No. 2, 2011, 105-109

Dai, X. and Breuer, P.L., Leaching and electrochemistry of gold, Gilver and Gold-Silver Alloys in Cyanide Solutions: Effect of Oxidant and Lead Ions, Hydrometallurgy, v.133, 2013, 139-148

Dai, X. and Jeffrey, M.I., The effect of sulfide minerals on the leaching of gold in aerated cyanide solutions, Hydrometallurgy, v.82, 2006, 118-125

Davis, R. E., Displacement reactions at the sulfur atom, The reaction of cyanide with thiosulfate, J. Phys. Chem.,v. 66, 1962, 956-957

Deschenes, G., Rajala, J., Pratt, A.R., Guo, H., et al, Advances in the cyanidation of silver, Minerals and Metallurgical Processing, v.28, 2011, 37-43

Deutsch, J.L., Dreisinger, D.B., Silver sulfide leaching with thiosulfate in the presence of additives Part I: Copper-ammonia leaching, Hydrometallurgy, 2013, v. 137, 156-164

Deutsch, J.L., Dreisinger, D.B., Silver sulfide leaching with thiosulfate in the presence of additives Part II: Ferric complexes and the application to silver sulfide ore, Hydrometallurgy, 2013, v. 137, 165-172

Deutsch, J.L., Master Thesis, Fundamental Aspects of thiosulfate leaching of silver sulfide in the presence of additives, The University of British Columbia, 2012

Dutrizac, J.E., The leaching of silver sulfides in ferric ion media, Hydrometallurgy, v.35, 1994, 275-292

Elder, D.J., Leachwell Versus Fire assay: Comments from assay quality assurance at Tarmoola Gold mine, $4^{\text {th }}$ International Mining Geology Conference, 2000, 14-17

Feng, D. and Denver, J., Effect of hematite on thiosulphate leaching of gold, International Journal of Mineral Processing, v.82, 2007, 138-147

Ficeriová, J., Baláz, P. and Boldizárová, E., Combined mechanochemical and thiosulphate leaching of silver from a complex sulphide concentrate, International Journal of Mineral Processing, v.76, 2005, 260-265

Fink, C.G. and Putnam, G.L., The Action of Sulphide Ion and of Metal Salts on the Dissolution of Gold in Cyanide Solutions, Mining Engineering, v187, 1950

Fleming, C.A., The leaching and recovery of gold from ores and concentrates section 1: 
Cyanidation of gold and silver, Lakefield Research Ltd., 2007a

Fleming, C.A., The Leaching and Recovery of Gold from Ores and Concentrates Section 3: Gold and silver recovery, Lakefield Research Ltd., 2007c

Gasparrini, C., The mineralogy of silver and its significance in metal extraction, CIM Bulletin, June 1984, 99-110

Gasparrini, C. and Lowell, G. R., The silver bearing inclusions in "argentiferous" galena from the Southeastern Missouri, The Canadian Mineralogist, 1983

Gray, S., Katsikaros, N. and Fallon, P., Gold Recovery from Copper Gold Gravity Concentrates using the InLine Leach Reactor and Weak Base Resin, Oretest Copper Gold Symposium ,1999

Greenwood, N. N. and Earnshaw, A., Chemistry of the Elements, Second Edition, 1997

Guzman, L. et al, Electrochemistry of conventional gold cyanidation, Electrochimica Acta, v.44, 1999, 2625-2632

Hiskey, J.B. and Atluri, V.P., Dissolution of gold and silver in different lixiviants, Mineral Processing and Extractive Metallurgy Review, v.4, 1988, 95-134

Hiskey, J.B. and Sanchez, V.M., Mechanistic and kinetic aspects of silver dissolution in cyanide solutions, Journal of Applied Electrochemistry, v.20, 1990, 479-487

Holloway, P.C., Merriam, K.P. and Etsell, T.H., Nitric acid leaching of silver sulfide precipitates, Hydrometallurgy, v.74, 2004, 213-220

Jeffrey, M.I., Kinetics of gold and silver leaching in ammonia-thiosulfate solutions, Hydrometallurgy, v.60, 2001, 7-16

Jeffrey, M.I. and Ritchie Ian M., The leaching of gold in cyanide solutions in the presence of impurities I: The effect of lead, Journal of The Electrochemical Society, v.147, 2000, 3257-3262

Kappes, D.W., Heap leaching of gold and silver ores, Developments in Mineral Processing, v.15, 2005, 456-478

Knorre, H., Griffiths, A., Loroesch, J., Fischer, J., Process for the leaching of gold and silver cyanide leaching solution and controlled addition of hydrogen peroxide, US Patent No. 5,275,791, 1994

Knorre, H., Loroesch, J., Gos, S., Stoll, M., Ziegler, A., Process for leaching precious metals with hydrogen peroxide and cyanide leaching solution, U.S. Patent No. 5,250,272, 1993 
Li, J. and Wadsworth, M.E., Electrochemical study of silver dissolution in cyanide solutions, J. Electrochem. Soc. v.140, 1993, 1921-1927

Li, W., et al., Discussion on the cause of low silver leaching rate taken place in gold and silver cyanide leaching and ways to increase it, Gold, v. 22, 2001, 35-38

Liu, B., et al., Study on Oxidant in The Cyanide Leaching of Gold, Gold, v.19, 1998, 33-36

Liu, Y., Industrial preparation for calcium peroxide and its application to gold cyanidation, Inorganic Chemicals Industry, v. 42, 2010, 41-43

Luna-Sanchez, R.M. and Lapidus, G.T., Cyanidation kinetics of silver sulfide, Hydrometallurgy, v.56, 2000, 171-188

Luna-Sanchez, R.M. et al, A comparative study of silver sulfide oxidation in cyanide media, Journal of the Electrochemical Society, 150(8), 2003, D155-D161

Luthy R. G. and Bruce, S .G., Kinetics of reaction of cyanide and reduced sulfur species in aqueous solution, Environ. Sci. Technol., v.13, 1979, 1481-1487

Marsden, J. O. and House, C.L., The Chemistry of Gold Extraction, Second edition, Society for Mining, Metallurgy, and Exploration, Inc., 2006

MPC PTY LTD website, Mineral Process Control Proprietary Limited Website, 2013 ( http://www.mineralprocesscontrol.com.au/ )

Patterson, C.C., Silver Stocks and Losses in Ancient and Medieval Times, Economic History Review, 25(2), 1972, 205-235.

Pesic, B. and Seal, T., A rotating disk study of silver dissolution with thiourea in the presence of ferric sulfate, Metallurgical and Materials Transactions B, v.21, 1990, 419427

Pietsch, H.B., Bings, H. and Lehmann, R., Application of the tube digester in hydrometallurgy. Paper presented at the 14th Annual CIM Hydromet Meeting, Timmins, ON, Oct 1984

Ramsdell, L.S., The crystallography of acanthite, $\mathrm{Ag}_{2} \mathrm{~S}$. American Mineralogist, 1943, 28(7-8), 401-425

Sandenbergh, R.F. and Miller, J.D., Catalysis of the Leaching of Gold in Cyanide Solutions by Lead, Bismuth and Thallium, Minerals Engineering, v.14, 2001, 1379-1386

Sarla, M., Pandit, M., Tyagi, D.K. and Kapoor, J.C., Oxidation of cyanide in aqueous 
solution by chemical and photochemical process, Journal of Hazardous Materials, B116, 2004, 49-56

Scheiner, B.J., et al, Extraction of silver from refractory ores, Bureau of Mines, P. A., Reports of Investigation 7736, Feb. 171976

Senanayake, G., The cyanidation of silver metal: Review of kinetics and reaction mechanism, v.81, 2006, 75-85

Speight, J.G., Lang's handbook of chemistry, Sixteenth edition, 2005

Sun, X., et al., Cyanide leaching of gold reinforced by peroxide assistant leaching, Gold, v. 14, 1993, 41-43

Sun, X., Guan, Y.C., and Han, K.N., Electrochemical behavior of the dissolution of goldsilver alloys in cyanide solutions, Metallurgical and Materials Transactions B, v.27, 1996, 355-360

Tshilombo A.F., et al, An electrochemical study of the effect of lead and sulphide ions on the dissolution rate of gold in alkaline cyanide solutions, Hydrometallurgy, v.60, 2001, $55-67$

Woods, J.L., and Pittman, T.A., Process for recovering gold and silver. US Patent No.3,826,723, 1974

World Silver Survey 2012, GFMS limited/ The Silver Institute, 2012, (http://www.silverinstitute.org/site/)

Wu, G., et al, Research Status of Mechanisms and Applications about Lead Salts in Cyanide Leaching of Gold, Hydrometallurgy of China, v.21, 2002, 113-116

Wyslouzil, D.M. and Salter, R.S., Silver leaching fundamentals, Lead-Zinc'90, edited by Mackey, T. S. and Prengaman, R. D., The Minerals, Metals \& Materials Society, 1990, 87-107

Xie, F., Master Thesis, Catalytic leaching of Silver with Ferricyanide-cyanide solution, The University of British Columbia, 2006

Xie, F., Dreisinger, D.B., and Lu,J., The novel application of ferricyanide as an oxidant in the cyanidation of gold and silver, Minerals Engineering, v.21, 2008, 1109-1114

Xie, F., and Dreisinger, D.B., Leaching of silver sulfide with ferricyanide-cyanide solution, Hydrometallurgy, v.88, 2007, 98-108

Xue, T. and Osseo-Asare, K., Heterogeneous Equilibria in the Au-CN-H Ag-CN-H2O system, Metallurgical Transactions B, v.16B, Sept 1985, 455-463 
Yang, S., LI, Z., Zhou, Y. and Yang, F., The assistant leaching process of peroxide in cyanide leaching Au , Hydrometallurgy of China, v.22, 2003, 133-135

Zeng, N., et al, Silver mineral and paragenesis in the Kangjianwan $\mathrm{Pb}-\mathrm{Zn}-\mathrm{Ag}$-Au deposits of the Shuikoushan Mineral District, Hunan province, China, The Canadian Mineralogists, v.38, 2000, 11-22

Zhang, P., et al., Study on liquid oxidant-assisted gold leaching and investigation on its mechanism, Metal Mine Design and Construction, v.29, 1997, 25-27

Zhang, X, Novel application of peroxides in gold extraction process, Foreign mineral processing, 1995, 1-7

Zhang, Y., Fang, Z. and Muhammed, M., On the solution chemistry of cyanidation of gold and silver bearing sulphide ores, A critical evaluation of thermodynamics calculation, Hydrometallurgy, v.46, 1997, 251-269

Zipperian, D., Raghavan, S. and Wilson, J.P., Gold and Silver Extraction by Ammoniacal Thiosulfate Leaching from a Rhyolite Ore, Hydrometallurgy, v.19, 1988, 361-375 


\section{Appendices}

\section{Appendix A Sample Calculations}

\section{Head}

Head of $\mathrm{Ag}=$ mass of $\mathrm{Ag}$ in the ore sample $/$ mass of the ore sample $\times 10^{6} \mathrm{~g} / \mathrm{t}$

For example, for natural acanthite sample,

Head Ag in the sample $=\mathrm{m}_{\mathrm{Ag}} / \mathrm{m}_{\text {ore }} \times 10^{6} \mathrm{~g} / \mathrm{t}=33.20 \% \times 10^{6} \mathrm{~g} / \mathrm{t}=3.32 \times 10^{5} \mathrm{~g} / \mathrm{t}$

\section{Silver extraction}

Extraction $=$ mass of $\mathrm{Ag}$ dissolved $/$ mass of $\mathrm{Ag}$ in the ore sample $\times 100 \%$

Mass of metal in the ore sample $=$ Head of metal $\times$ mass of ore sample

$\mathrm{Ag}$ dissolved at the time when sample $\mathrm{j}$ was taken is a function of the initial solution volume $\mathrm{V}_{\text {initial}}$, the sample $\mathrm{Ag}$ assays $\mathrm{C}_{\mathrm{i}}$ for $\mathrm{i}=1,2, \ldots, \mathrm{j}$ and the sample solution volumes $\mathrm{V}_{\mathrm{i}}$ for $\mathrm{i}=1,2, \ldots, \mathrm{j}-1$ (where the current sample is sample $\mathrm{j}$ ):

$$
\mathrm{Ag}_{\mathrm{dis}}(\mathrm{j})=\sum_{\mathrm{i}=1}^{\mathrm{j}-1} \mathrm{~V}_{\mathrm{i}} \mathrm{C}_{\mathrm{i}}+\mathrm{V}_{\text {initial }} \mathrm{C}_{\mathrm{j}}
$$

The Ag dissolved was calculated for all samples $i=1,2, \ldots, n$. The total Ag dissolved for the leaching period equal to the total Ag dissolved when the last sample was taken.

\section{Cyanide consumption}

Cyanide consumption

$=$ mass of cyanide consumed 
$=$ total mass of cyanide added - mass of free cyanide left in final leaching solution

\section{Sodium hydroxide consumption}

Sodium hydroxide consumption

$=$ mass of sodium added during the leaching process 


\section{Appendix B Analysis Methods}

\section{Free cyanide analysis}

\section{Principle}

Both uncomplexed cyanide ion $\left(\mathrm{CN}^{-}\right)$, and molecular hydrogen cyanide $(\mathrm{HCN})$ are defined as free cyanide in the solution. Silver nitrate titration with p-dimethylaminobenzylidene rhodanine indicator has been adopted in many operations as one of the trusted free cyanide determination methods. In the titration process, cyanide complexes with silver ion from silver nitrate first, forming silver cyanide complex which is more stable than the silver rhodanine complex (Reaction A-1). Once all of the free cyanide has been complexed by silver, excess silver complexes with rhodanine (Reaction A-2) and the solution color change occurs, which is recognized as the end point.

$$
\begin{array}{cr}
\mathrm{Ag}^{+}+2 \mathrm{CN}^{-}=\mathrm{Ag}(\mathrm{CN})_{2}{ }^{-} & \text {Reaction A-1 } \\
\mathrm{Rh}(\text { yellow })+\mathrm{Ag}^{+}=\mathrm{Rh}-\mathrm{Ag} \text { (pink) } & \text { Reaction A-2 }
\end{array}
$$

Before the use of silver nitrate solution in titration, it is necessary to standardize it with the standardized $\mathrm{NaCl}$ solution with a potentiometric end-point. Based on Reaction A-1, the calculation of the cyanide concentration is:

$$
\left[\mathrm{CN}^{-}\right]=\frac{\left[\mathrm{AgNO}_{3}\right] \times \mathrm{V}_{\mathrm{t}} \times 2 \times \mathrm{DF}}{\mathrm{V}_{\mathrm{s}}}
$$

$\left[\mathrm{CN}^{-}\right]=$free cyanide concentration, mol/L (multiply by 26 for $\mathrm{CN}$ in $\mathrm{g} / \mathrm{L}$ )

$\left[\mathrm{AgNO}_{3}\right]=$ silver nitrate concentration, $\mathrm{mol} / \mathrm{L}$

$\mathrm{V}_{\mathrm{t}}=$ titration volume, $\mathrm{ml}$

$\mathrm{DF}=$ dilution factor

$\mathrm{V}_{\mathrm{s}}=$ sample volume, $\mathrm{ml}$

\section{Apparatus and reagents}

- 50ml burette

- $125 \mathrm{ml}$ conical flask 
- Magnetic stirring plate and Teflon coated magnetic stir bar

- Deionized water

- $0.01 \mathrm{~mol} / \mathrm{L} \mathrm{NaOH}(0.4 \mathrm{~g} / \mathrm{L})$

- Standard $\mathrm{NaCl}$ solution, $0.01 \mathrm{~mol} / \mathrm{L}$

- $0.612 \mathrm{~g} / \mathrm{L} \mathrm{AgNO}_{3}$ solution, prepare weekly and store in a brown glass vessel in the dark

- p-dimethylaminobenzal rhodamine indicator $(0.2 \mathrm{~g} / \mathrm{L}$ in acetone $)$

\section{Procedure}

1. Add $20 \sim 30 \mathrm{ml} 0.01 \mathrm{~mol} / \mathrm{L} \mathrm{NaOH}$ into a $125 \mathrm{ml}$ Erlenmeyer flask;

2. Take $1.5 \mathrm{ml}$ leaching solution sample and put it into the flask;

3. Add 6 8 drops of p-dimethylaminobenzal rhodamine indicator;

4. Put the flask on the magnetic stirring plate and start stirring under the burett;

5. Titrate with $0.0036 \mathrm{~mol} / \mathrm{L} \mathrm{AgNO}_{3}$ solution;

6. Record the end-point when the cooler turns from yellow to pink and calculate the free cyanide concentration in the sample.

\section{Comments}

There are several interferences, such as copper ion in the system, to the determination of the end-point and thus accuracy of the titration. It is recommended that the automated controlled process in industry adopt the potentiometric end-point method (Breuer et al., 2011). 


\section{Appendix C XRD/QXRD Photos of Mineral Samples}

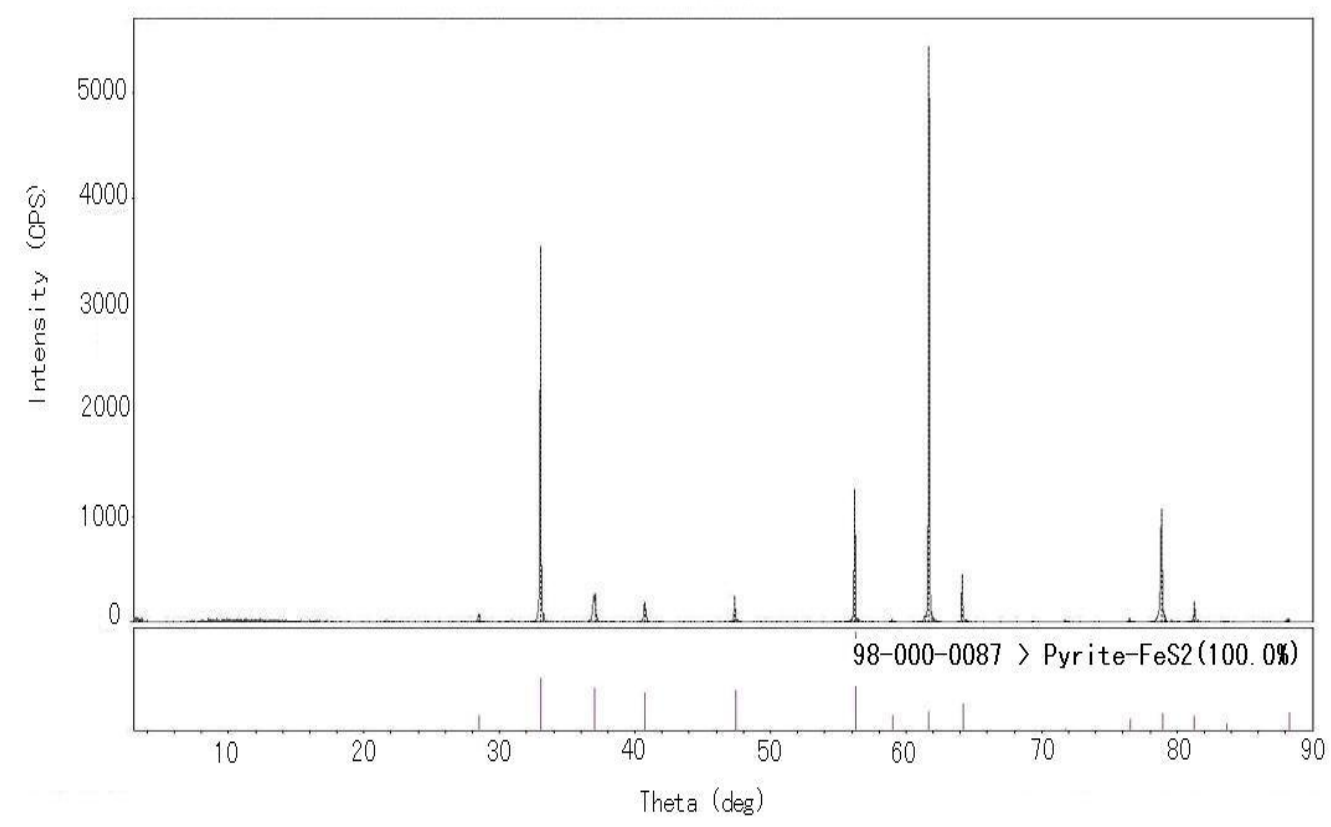

Figure C-1 XRD pattern of pyrite powders

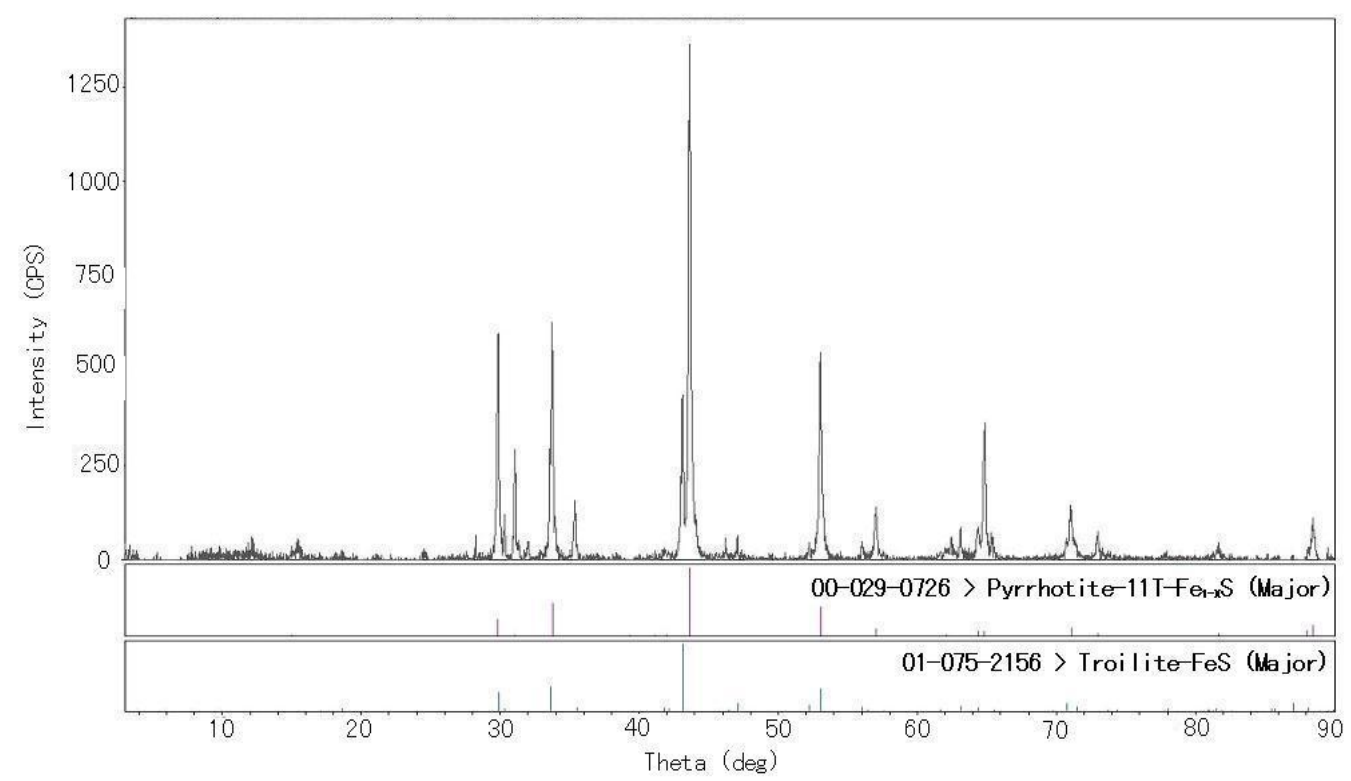

Figure C-2 XRD pattern of pyrrhotite powders 


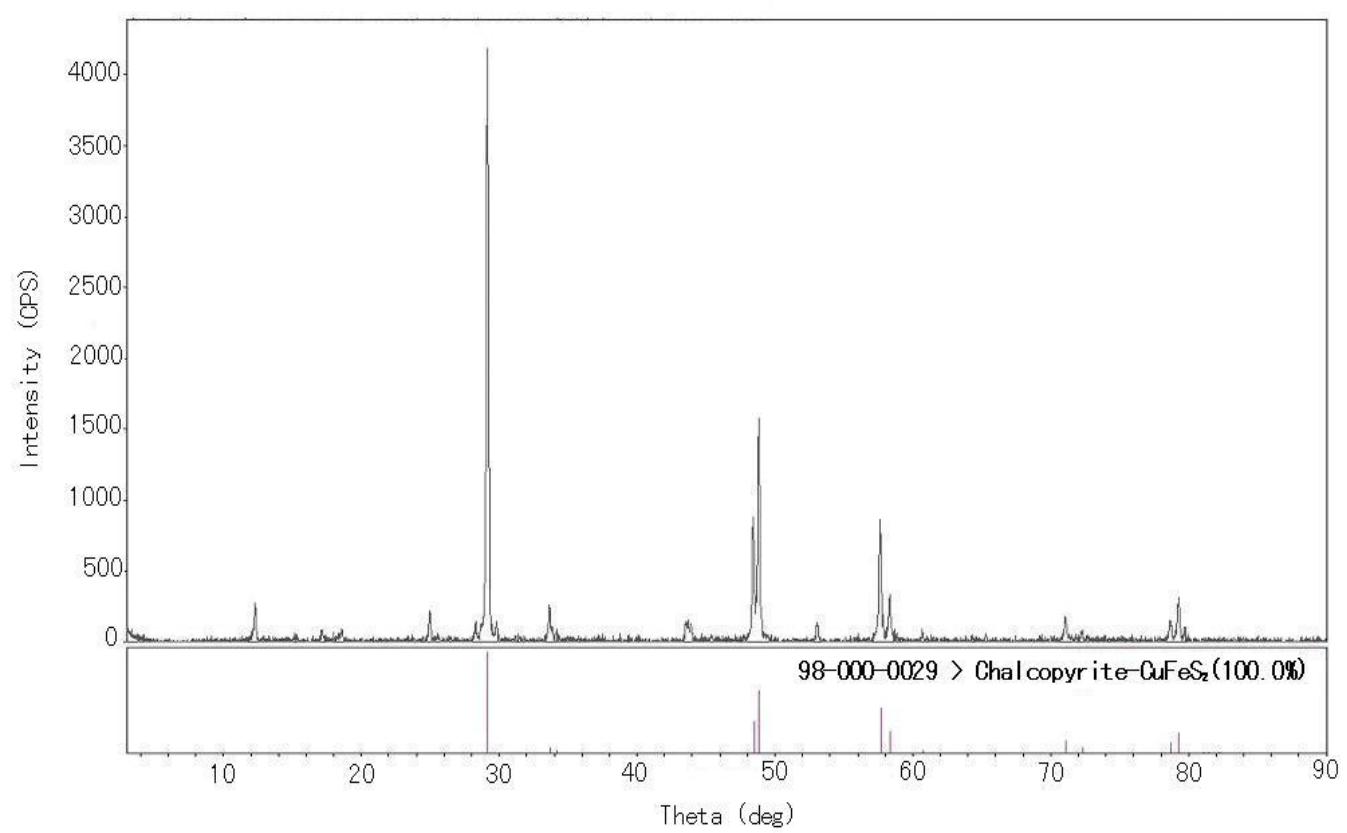

Figure C-3 XRD pattern of chalcopyrite powders

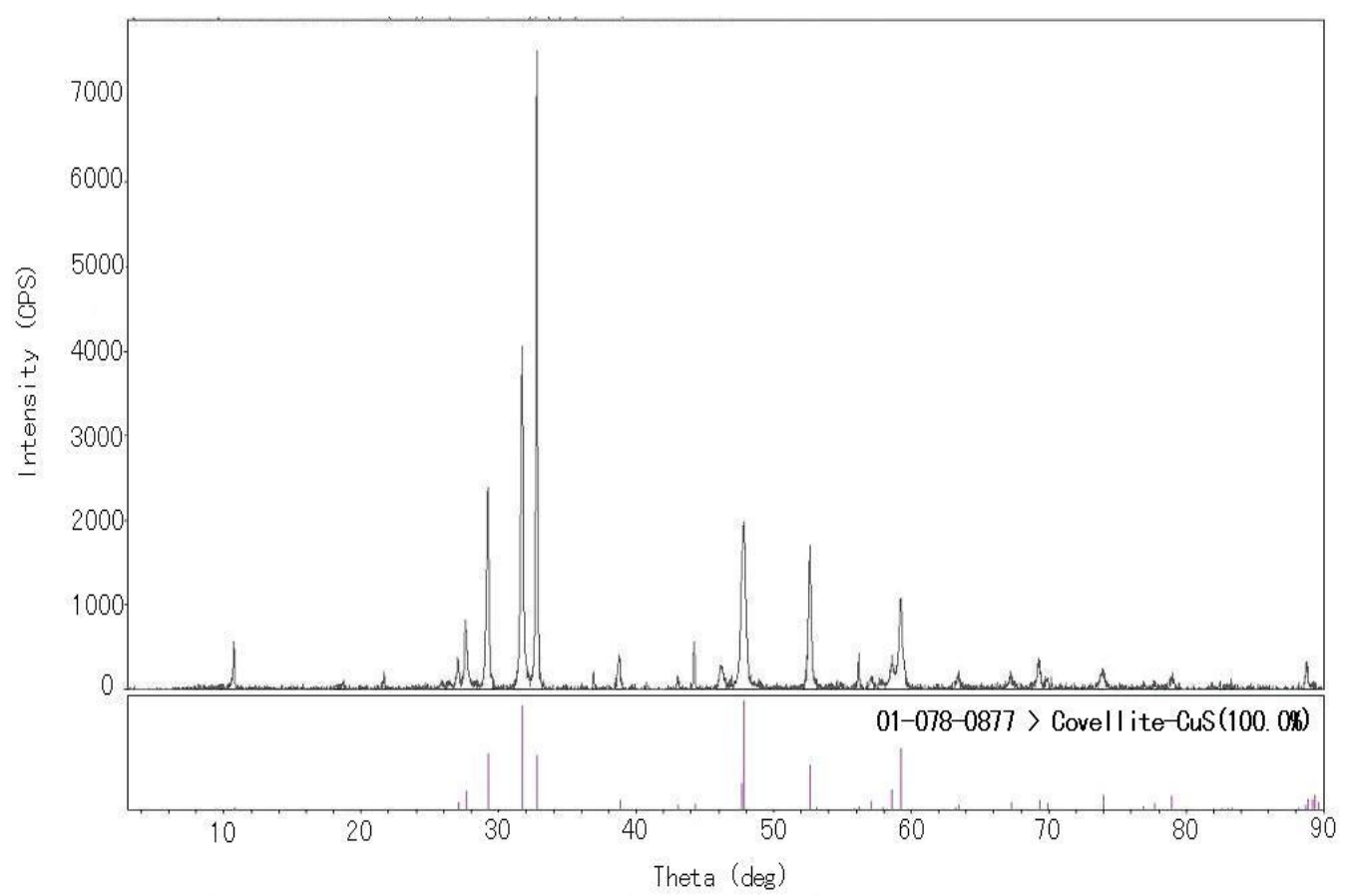

Figure C-4 XRD pattern of covellite powders 


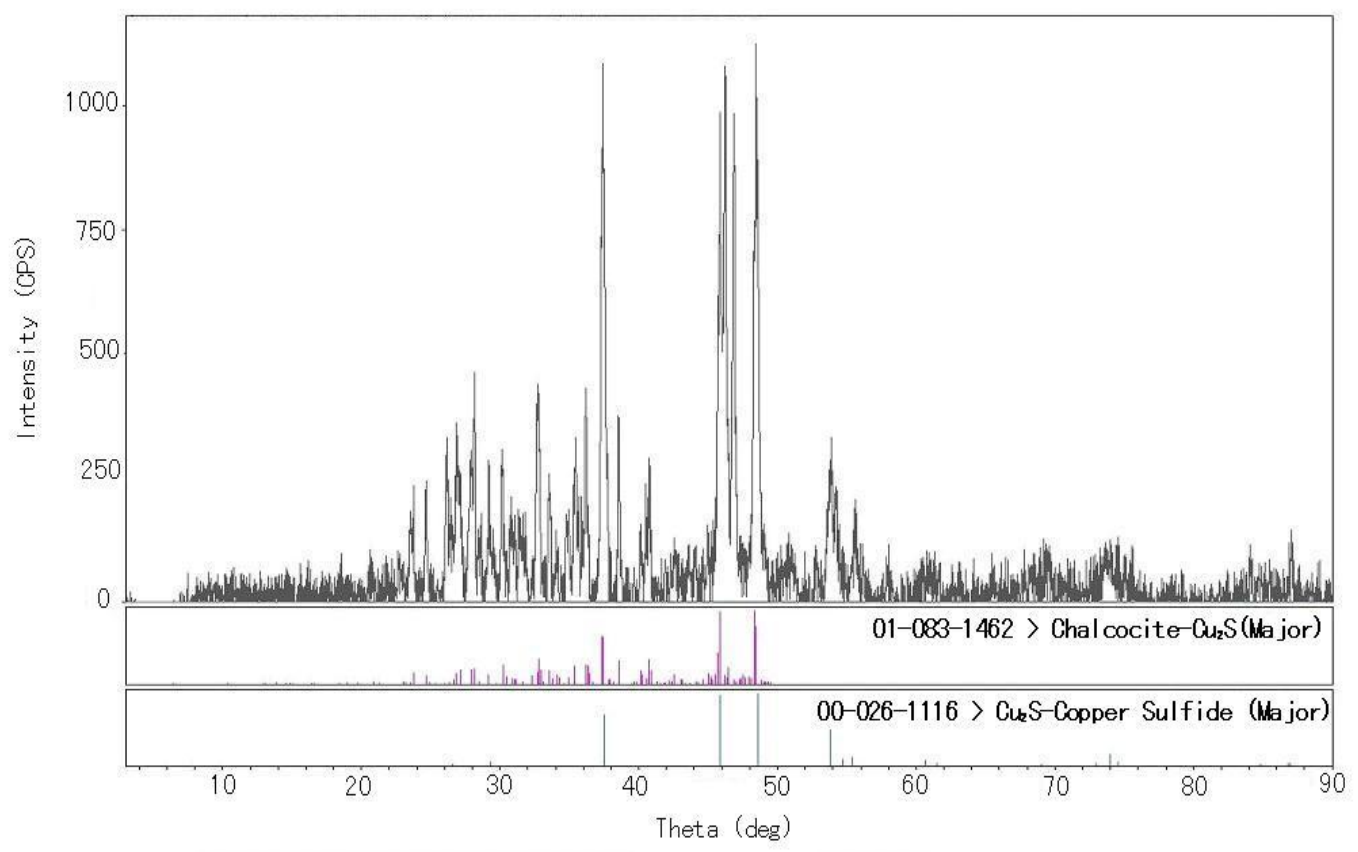

Figure C-5 XRD pattern of chalcocite powders

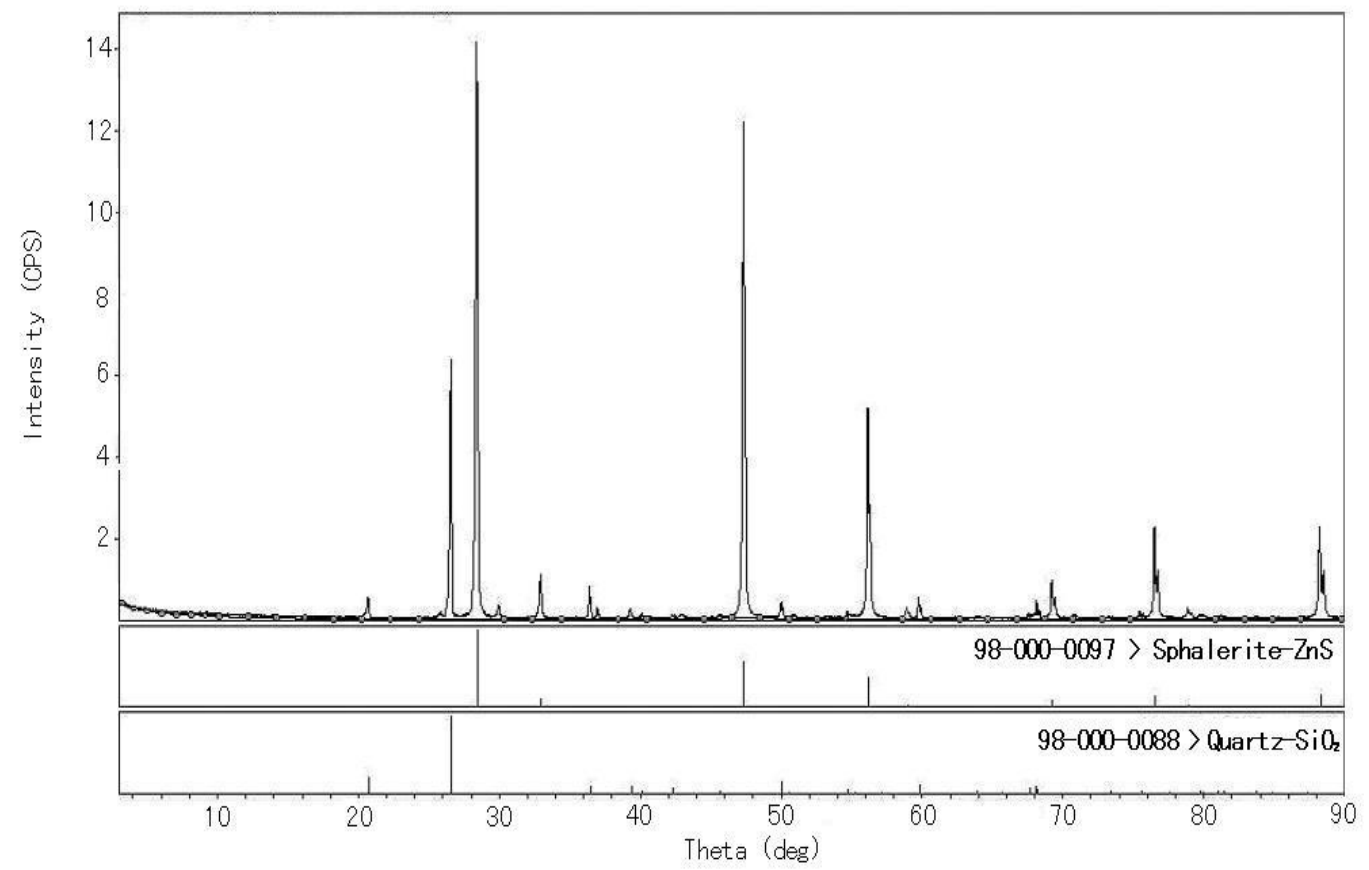

Figure C-6 XRD pattern of sphalerite powders 


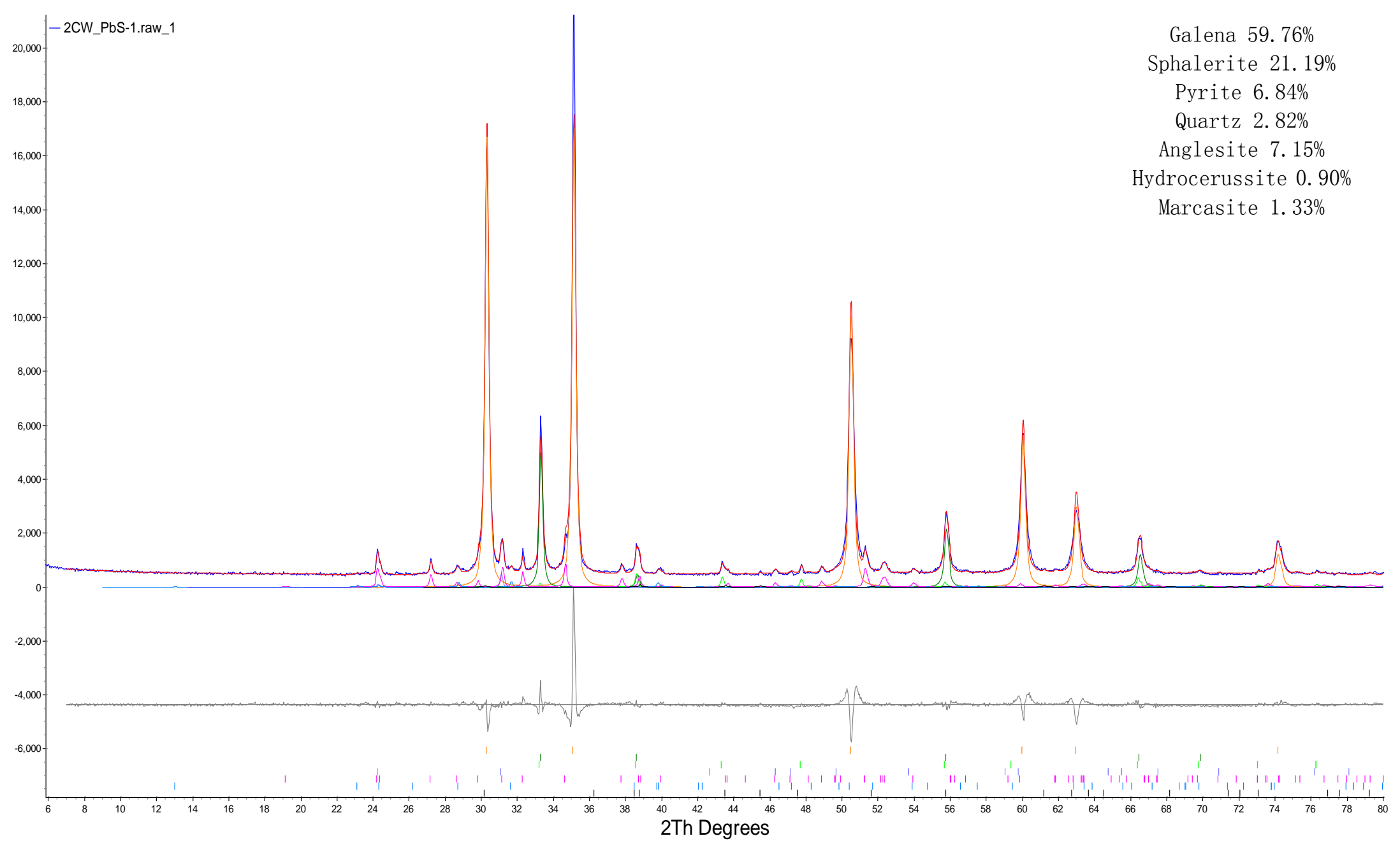

Figure C-7 Quantitative-XRD pattern of sphalerite powders 